Pacific Northwest

National Laboratory

Operated by Battelle for the

U.S. Department of Energy

\title{
ImSET: Impact of Sector Energy Technologies
}

\author{
J. M. Roop \\ M. J. Scott \\ R. W. Schultz
}

July 2005

Prepared for the U.S. Department of Energy under Contract DE-AC05-76RL01830

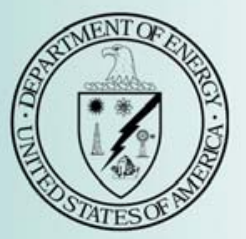


PNNL-15273

\section{ImSET: Impact of Sector Energy Technologies}

J. M. Roop

M. J. Scott

R. W. Schultz

July 2005

Prepared for the U.S. Department of Energy under Contract DE-AC05-76RL01830 


\section{DISCLAIMER}

This report was prepared as an account of work sponsored by an agency of the United States Government. Neither the United States Government nor any agency thereof, nor Battelle Memorial Institute, nor any of their employees, makes any warranty, express or implied, or assumes any legal liability or responsibility for the accuracy, completeness, or usefulness of any information, apparatus, product, or process disclosed, or represents that its use would not infringe privately owned rights. Reference herein to any specific commercial product, process, or service by trade name, trademark, manufacturer, or otherwise does not necessarily constitute or imply its endorsement, recommendation, or favoring by the United States Government or any agency thereof, or Battelle Memorial Institute. The views and opinions of authors expressed herein do not necessarily state or reflect those of the United States Government or any agency thereof.

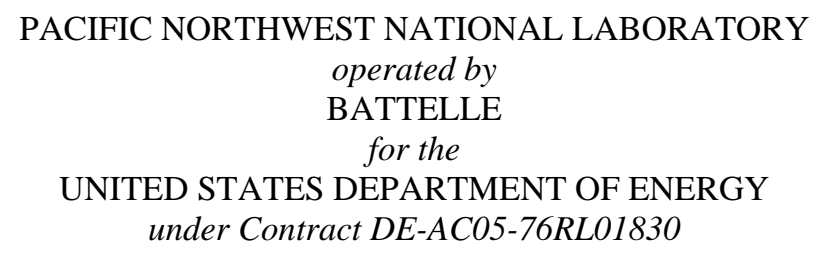

Printed in the United States of America

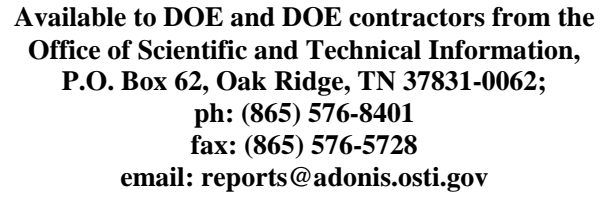

Available to the public from the National Technical Information Service, U.S. Department of Commerce, 5285 Port Royal Rd., Springfield, VA 22161 ph: (800) 553-6847 fax: (703) 605-6900 email: orders@ntis.fedworld.gov online ordering: http://www.ntis.gov/ordering.htm 
PNNL-15273

\title{
ImSET: Impact of Sector Energy Technologies
}

\author{
J. M. Roop \\ M. J. Scott \\ R. W. Schultz
}

July 2005

Prepared for

the U.S. Department of Energy under Contract DE-AC05-76RL01830

Pacific Northwest National Laboratory Richland, Washington 99352 


\section{Summary}

This version of the Impact of Sector Energy Technologies (ImSET) model represents the next generation of the previously developed Visual Basic model (ImBUILD 2.0) that was developed in 2003 to estimate the macroeconomic impacts of energy-efficient technology in buildings. More specifically, a special-purpose version of the Benchmark National Input-Output (I-O) model was designed specifically to estimate the national employment and income effects of the deployment of Office of Energy Efficiency and Renewable Energy (EERE)-developed energy-saving technologies. In comparison with the previous versions of the model, this version allows for more complete and automated analysis of the essential features of energy efficiency investments in buildings, industry, transportation, and the electric power sectors. ImSET is also easier to use than extant macroeconomic simulation models and incorporates information developed by each of the EERE offices as part of the requirements of the Government Performance and Results Act. While it does not include the ability to model certain dynamic features of markets for labor and other factors of production featured in the more complex models, for most purposes these excluded features are not critical. The analysis is credible as long as the assumption is made that relative prices in the economy would not be substantially affected by energy efficiency investments. In most cases, the expected scale of these investments is small enough that neither labor markets nor production cost relationships should seriously affect national prices as the investments are made. The exact timing of impacts on gross product, employment, and national wage income from energy efficiency investments is not well-enough understood that much special insight can be gained from the additional dynamic sophistication of a macroeconomic simulation model. Thus, we believe that this version of ImSET is a cost-effective solution to estimating the economic impacts of the development of energyefficient technologies. 


\section{Contents}

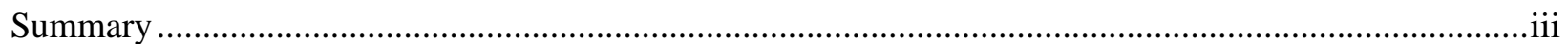

1.0 Introduction: A Method for Assessing Economic Impacts of Energy-Efficient Technologies......1-1

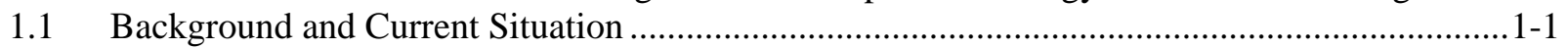

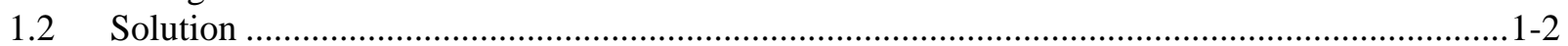

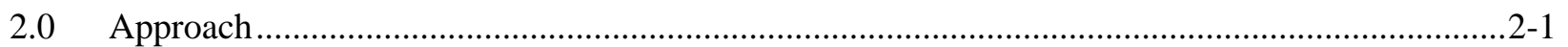

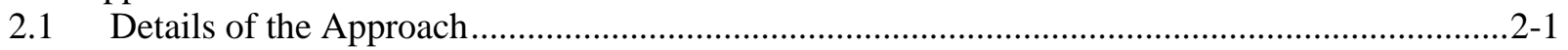

2.2 Components of Impacts: A Once-Only Investment ........................................................2-5

3.0 ImSET Model Results for Example EERE Programs ...............................................................

3.1 Comparison of Capital and Operating Cost Scenarios for Sample Technologies .......................3-1

3.2 Heat Pump Water Heater ...............................................................................................

3.3 EPACT (Commercial Air Conditioning) Efficiency Standards .............................................3-10

3.4 Glass Manufacturing Technologies ................................................................................

4.0 Comparison with Other Studies: An Update............................................................................

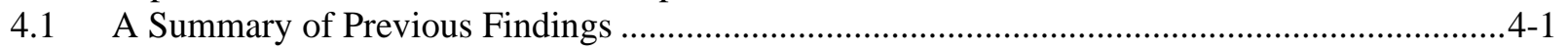

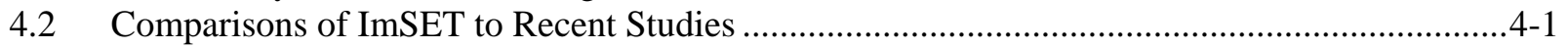

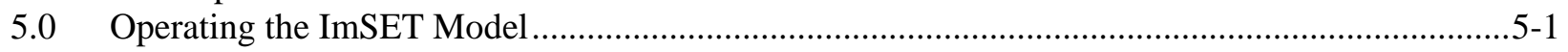

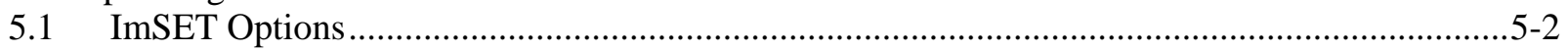

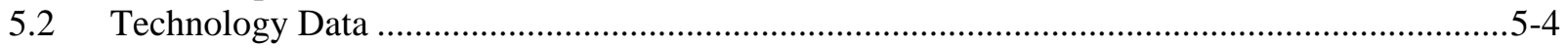

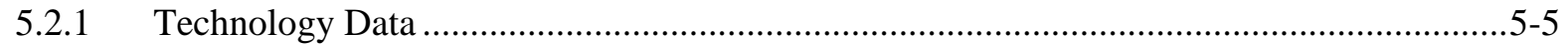

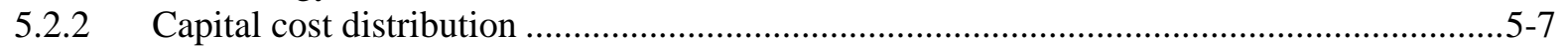

5.2.3 Energy and Water Cost Savings Distribution .................................................................. $5-7$

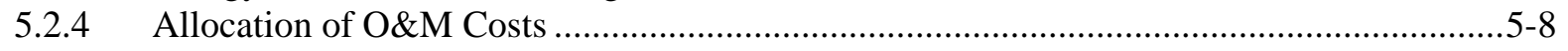

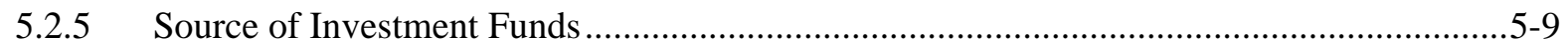

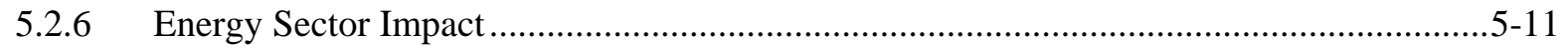

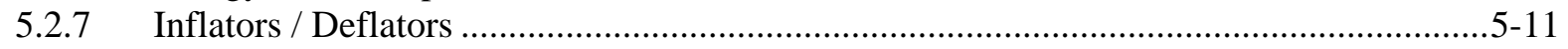

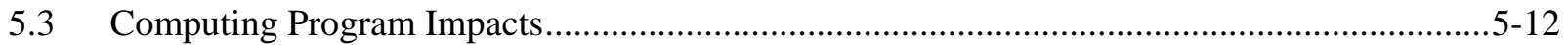

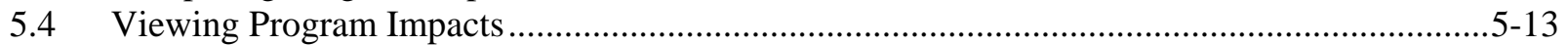

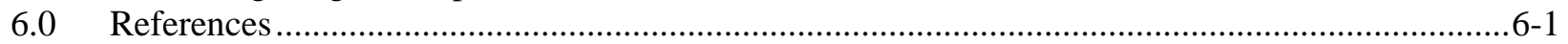

Appendix A. Base Cases for Energy Efficiency Technologies................................................................... 1

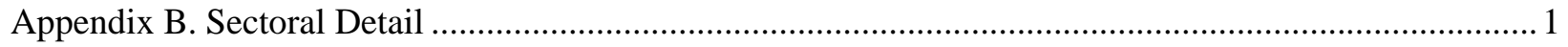

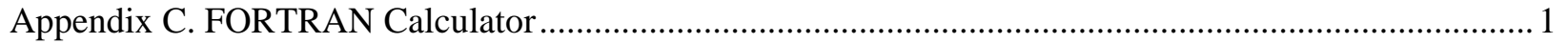

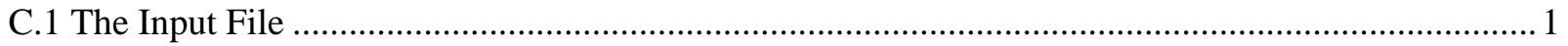

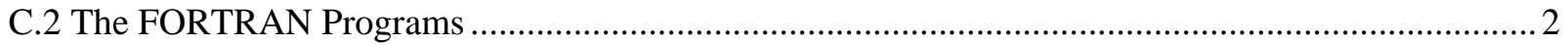

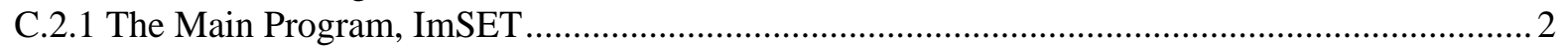

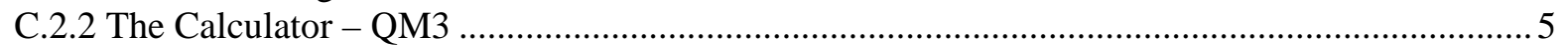

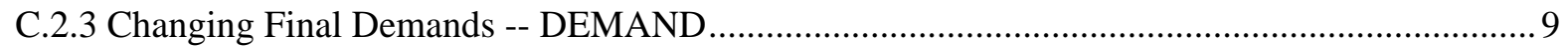

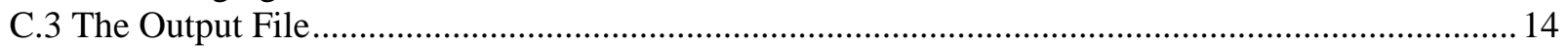




\section{Figures}

Figure 2-1. Process for Analyzing Economic Impact of Energy Efficiency Programs ............................2-2

Figure 2-2. Detailed Calculations of the ImSET Model .................................................................2-4

Figure 2-3. Impact on National Employment of a Hypothetical Once-Only Investment in Appliance

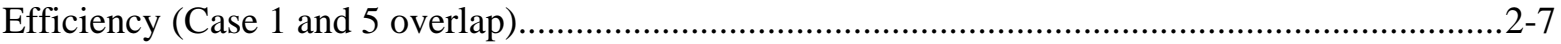

Figure 3-1. Incremental Capital Costs by Year for GPRA Metrics Market Scenarios of Heat Pump Water

Heater, EPACT Efficiency Standards, and Glass Manufacturing Technologies ..............................3-2

Figure 3-2. Value of Energy Savings by Year Relative to Baseline for GPRA Metrics Market Scenarios.35

Figure 3-3. Employment Impacts of Investment in Heat Pump Water Heaters .......................................3-5

Figure 3-4. Effect of HPWH Financing on Employment …..............................................................

Figure 3-5. Impact of HPWH Investment on National Wage Income (\$2003) ......................................3-8

Figure 3-6. Sensitivity of Impacts on National Wage Income to HPWH Investments (\$2003) ................3-9

Figure 3-7. Impact on National Employment of EPACT Standards ...................................................3-10

Figure 3-8. Impact of EPACT Standards Energy Savings on National Wage Income (\$2003) ..............3-11

Figure 3-9. Impact of Glass Manufacturing Sector Savings on National Employment..........................3-12

Figure 3-10. Impact of Glass Manufacturing Sector Savings on National Wage Income (\$2003) ..........3-12

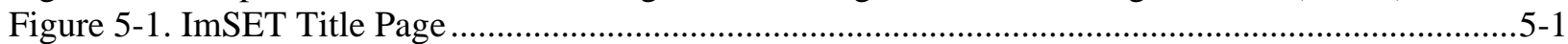

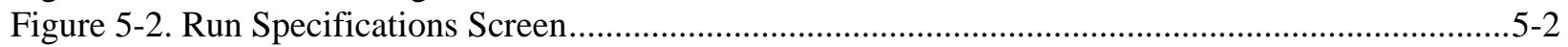

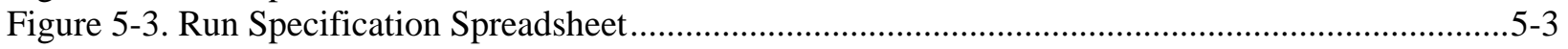

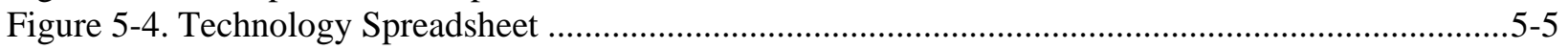

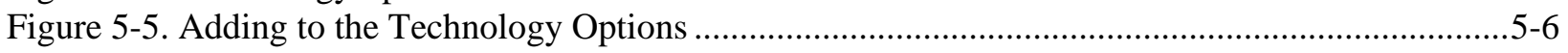

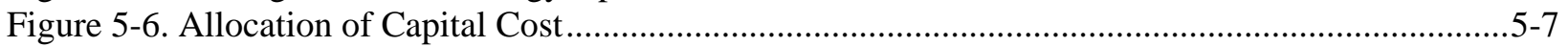

Figure 5-7. Energy/Water Cost Savings Distribution Across Sectors ..................................................5-8

Figure 5-8. O\&M Cost Savings Distribution for Commercial Sector......................................................5-9

Figure 5-9. Opportunity Cost of Invested Funds ................................................................................5-10

Figure 5-10. Impact of Energy Savings on Energy Sector Investments ...............................................5-11

Figure 5-11. Assigning Inflators and Deflators...................................................................................12

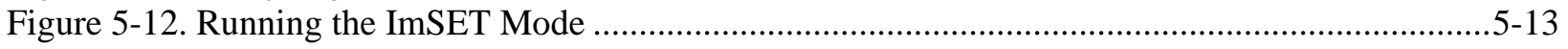

Figure 5-13. Report Manager Screens for Output (Graphical Display) .................................................5-14

Figure 5-14 Report Manager Screens for Output (Table Display)........................................................5-15

\section{Table}

Table 3-1. Efficiency Standards and Energy Savings for Commercial Air Conditioning Equipment 3-3

Table 4.1. Employment Multipliers, Nayak, and Selected ImSET Industries ........................................ 4-3 


\subsection{Introduction: A Method for Assessing Economic Impacts of Energy-Efficient Technologies}

\subsection{Background and Current Situation}

As part of measuring the impact of government programs in improving the energy efficiency of the nation's infrastructure, the U.S. Department of Energy's Office of Energy Efficiency and Renewable Energy (EERE) is interested in assessing the economic impacts of these programs, specifically on national employment and wage income. As a consequence, EERE funded Pacific Northwest National Laboratory (PNNL) to develop a simple-to-use method for in-house estimation of economic impacts of individual programs. After surveying three fundamental methods available to estimate employment and wage income impacts for selected energy efficiency improvements in the U.S. economy (multipliers input-output [I-O] models, and macroeconomic simulation models), the I-O approach was selected for the original version of Impact of Sector Energy Technologies (ImSET) model, known as ImBuild, because of its focus on technologies for residential and commercial buildings (for an overview of each of these approaches, see the original documentation in Scott et al. 1998). The current (third) version of the model also deals with impacts of technologies designed to reduce energy use in industrial processes, transportation, and electric power generation.

This version of ImSET uses essentially the same methodology as the previous version (see Scott, Roop, and Schultz, 2002), but greatly expands the scope of the model to include more sectors of the economy and thus covers a wider array of technologies. By covering more sectors, the model lends itself to assessing the impacts of evaluating technologies developed outside the original model's scope, including power, industrial, and transportation technologies. The major features of ImSET are:

- The Input-Output structure is based on the 1997 Benchmark U.S. table (Lawson, et al. 2002), specially aggregated for this project to 188 sectors (ImBuild II featured 98 sectors).

- Associated FORTRAN programs have been extensively revised.

- The treatment of Operating and Maintenance (O\&M) costs has been substantially revised.

- The time scale of the model has been extended to 50 years.

The model is a static input-output model, which allows a great deal of flexibility concerning the types of energy efficiency effects that can be accommodated. For example, certain economic effects of energy efficiency improvements require an assessment of inter-industry purchases. Some energy efficiency investments will not only reduce the costs of energy but the costs of labor and other goods and services as well. In the language of economics, this represents an investment-specific increase in productivity and value-added $^{1}$ and a change to the input-output structure, differing from a case in which a constant I-O structure is applied to a change in investment. Yet, this effect is at the heart of many investment decisions.

\footnotetext{
${ }^{1}$ Value-added is the difference between the value of the output of a sector and the costs of the purchased goods and services that go into the sector. It is mainly composed of labor and proprietor income, retained earnings of corporations, rents, and taxes.
} 
Savings in the energy, labor, materials, and services from improved productivity are the source of subsequent rounds of investment and economic growth.

I-O models such as ImSET can be used to estimate the impact of changes in overall efficiency and productivity in the economic sectors that make energy-efficiency investments. As an example, ImSET could apply to an investment by a paper mill in more energy-efficient equipment, the investment by an electric utility in more efficient plant, or improvements in transportation infrastructure. An I-O model also can keep track of the potential increases in value-added that result from the improvement in efficiency and can, with appropriate assumptions, calculate the macroeconomic effects associated with spending of this increased income.

While ImSET is greatly expanded in its capabilities, it has a user-friendly shell that makes it easy to use, with the advantage that it provides more theoretically plausible and comprehensive results than alternative models.

The chief drawbacks of this, or any I-O model, are that 1) they do not provide information on the timing of impacts (for example, they do not say how long an investment in efficiency will take to work its way through the economy), and 2) because no prices or explicit behavioral adjustment mechanisms are found in I-O models, no internal market features are present, such as increasing prices for sector output or for factors of production that automatically limit the size of impacts. In an I-O model, it is assumed that inputs needed for production in each sector are available without limit in constant proportions at constant unit cost. Thus, when analyzed in an I-O model, even very large scale investments that increase the scale of an industry many times over would not encounter either labor or material shortages that might cause prices to rise in the real world and dampen the economic response.

While we acknowledge these drawbacks, the scale of most energy-efficiency improvements, relative to the overall economy, are small enough to make this an inconsequential effect. To analyze larger scale efficiency improvements or investments, a macroeconomic simulation model would be more appropriate, as it would account for changes in relative prices that could be expected from very large investment cases.

\subsection{Solution}

The programmatic needs of EERE suggest that a simple, flexible, user-friendly method is needed to derive national employment income and output impacts of EERE programs. This special-purpose version of the national 1997 I-O table was designed specifically to estimate the employment, income, and output effects of building and other EE-sponsored energy efficiency technologies. In comparison with alternative models, ImSET allows for more complete and automated analysis of the essential features of energy efficiency investments. ImSET is also easier to use than extant macroeconomic simulation models. It does not include the ability to model certain dynamic features of markets for labor and other factors of production featured in the more complex models, but for most purposes these excluded features are not critical. Analysis using ImSET should be credible as long as the assumption is made that relative prices in the economy would not be substantially affected by energy efficiency investments. In most cases, the expected scale of these investments is small enough that neither labor markets nor production cost relationships should seriously affect national prices as the investments are made. The exact timing of impacts on gross product, employment, and national wage income from energy efficiency investments is 
not well-enough understood that much special insight can be gained from the additional dynamic sophistication of a macroeconomic simulation model. Thus, we believe that ImSET is a cost-effective solution to the problem at hand. 


\subsection{Approach}

The macroeconomic impacts of EERE programs can be analyzed using the following four-step process, illustrated in Figure 2.1. The first three steps are conducted as part of the normal analysis of costs and energy savings associated in the Government Performance and Results Act (GPRA) Metrics process; however, the fourth step (calculating the economic impacts) has been automated in ImSET. The goal of the model-building process was to create a computerized tool that required only a knowledge of ImSET technologies to run. The national I-O model is a $188 \times 188$-sector version of the $495-\times 495$-sector benchmark U. S. Input-Output table for 1997. The 188 sectors are those deemed most important for analyzing economic impacts of EERE technologies; it is comprehensive enough to cover all energyefficient technologies produced within EERE.

\subsection{Details of the Approach}

\section{Step 1. Identify Program Economic Characteristics}

To analyze existing EERE R\&D programs, a set of assumptions must be developed concerning the effects in the marketplace when more efficient technologies are developed or adopted as a result of the programs. The relevant program information includes size of the incremental investment in the technology over time compared with the conventional technology it replaces, corresponding extra energy savings by fuel type in physical and monetary terms (may include additional use of some fuels when one type of fuel replaces another), and non-energy operations savings (if any) in comparison with current (conventional) technology. Sufficient information of this type currently exists on many of the EERE technology development and deployment projects as a result of the GPRA Metrics process. Three technologies are used as examples in this report. They were chosen to demonstrate different types of programs, as well as some related macroeconomic issues.

- Residential Heat Pump Water Heater. The purpose of the DOE program in this area is to develop and commercialize highly efficient water heaters. The technology is expected to displace the next generation of already highly-efficient conventional water heaters. ${ }^{2}$

- Energy Policy Act of 1992 (EPACT) Commercial Building Standards-Air Conditioning. The DOE program is continuing the development of efficiency standards for commercial air conditioning that will improve the comfort and reduce the cost of air conditioning commercial retail and office space.

- Glass Manufacture: The final example is a group of three technologies focused on the glass manufacturing process. These technologies are oxygen enrichment for the glass furnace, cullet preheating for glass, and a new type of glass temperature sensor.

\footnotetext{
${ }^{2}$ Heat Pump Water Heaters are no longer an active DOE research and development effort, but they serve as a good application of the tool.
} 


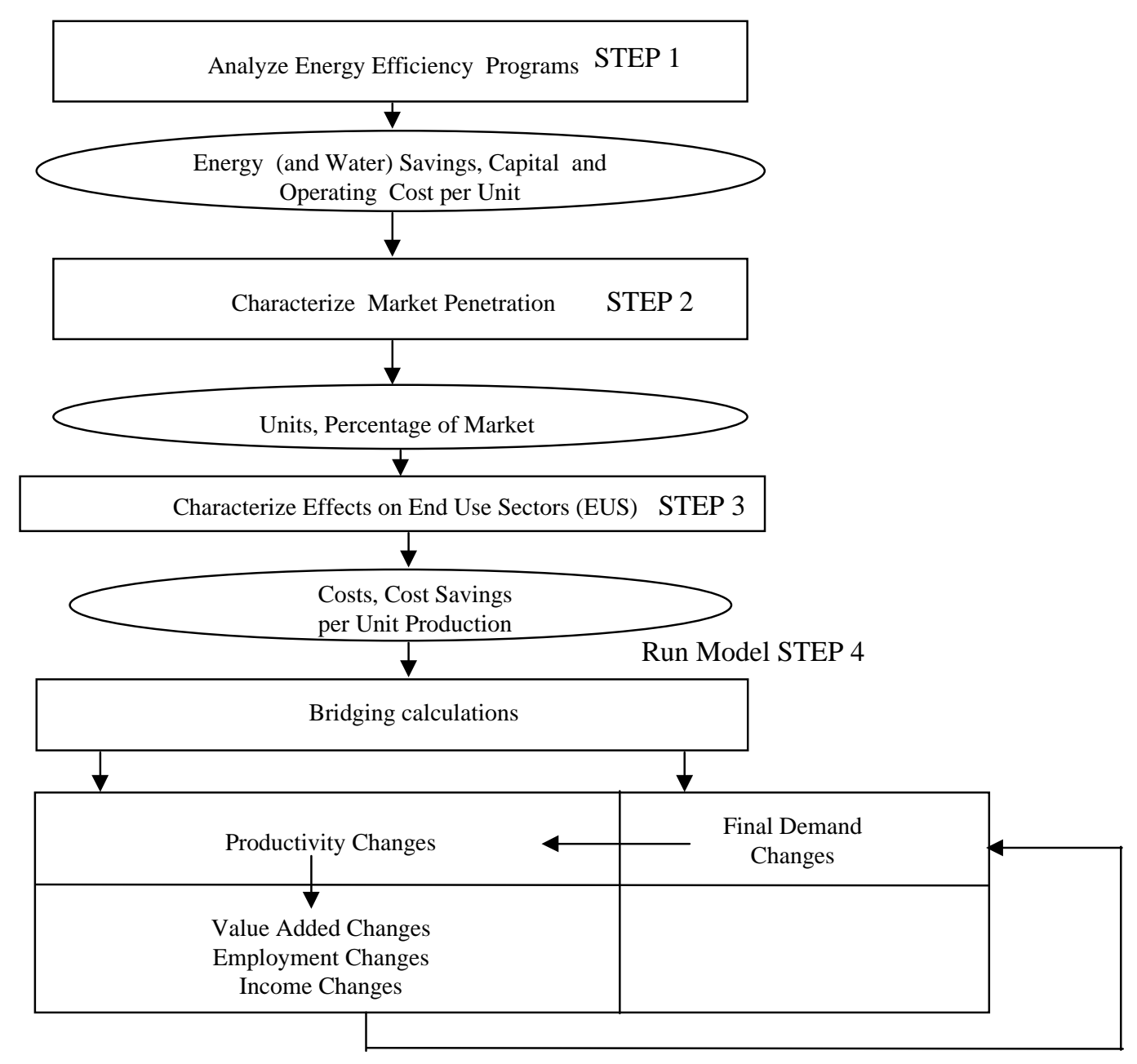

Figure 2-1. Process for Analyzing Economic Impact of Energy Efficiency Programs

Together, these examples demonstrate the impact of programs aimed at residential technology development, programs aimed at commercial technology development, and programs aimed at industrial process energy efficiency knowledge and products.

\section{Step 2. Characterize Market Penetration of the New Technologies}

Existing research on the size and characteristics of the market niche(s) being addressed by the EERE technologies or programs is used to estimate market penetration of the new technologies or programs (see Elliott et al. 2004). The GPRA Metrics effort produces this type of information.

\section{Step 3. Characterize Effects of the EERE Programs on End Use Sectors (Residential, and Commercial Buildings, Industrial, Transportation and Power Production Sectors)}

Effects of the program on the end-use sectors, using the technology or results of the program, must be characterized. This step combines analysis from Steps 1 and 2. A bridging matrix is used to match buildings and equipment investments in end-use sectors (for example, classes of commercial buildings) to the economic sectors that construct, operate or occupy these buildings. This process is necessary because, 
although the EERE programs are organized around the principal energy-consuming sectors of the economy and their end uses, I-O models use economic sectors organized according to North American Industry Classification System (NAICS) codes (these have supplanted the standard industrial classification [SIC] system since 1997). For purposes of the empirical analysis in this report, economic sectors occupying commercial buildings are assumed to experience savings in proportion to their baseline expenditures on energy and building maintenance goods and services.

\section{Step 4. Calculate Economic Impacts}

Given the data developed in Steps 1-3, the ImSET model then calculates the impacts of energy efficiency programs on employment in the following three sub-steps.

\section{Initial Investment Impacts}

First, the model calculates the gross output, income, and employment effects of initial spending on energy efficiency investments. (These impacts include the initial spending on plant and equipment by businesses and households that adopt the new energy-efficient equipment and practices. The impact of spending by the EERE programs on services provided in government, universities, and other contractors is not computed.) In an I-O model, this impact is estimated by changing expenditure levels in the government, household consumption, and business investment columns of final demand and in the productivity changes box of Figure 2.1. The left-hand side of Figure 2.2 illustrates the necessary calculations in more detail. The residential and commercial buildings investments are estimated, based on Step 2, and then allocated to business sectors through the bridging calculations. This calculation is done directly in the business sector for industrial processes, transportation, and power production.

An important finding of this project is that the size and algebraic sign of the employment impacts of the initial investment process can depend critically on project financing. The investment typically must be financed by diverting resources from elsewhere in the economy. Therefore, the net employment impact of these energy-saving investments depends not only on the labor intensity of the investment process itself, but also on the relative labor intensities of those investment and consumption processes from which the necessary investment resources are diverted. For example, as shown in Section 3.0, the positive impact of the initial capital investment is dampened considerably and may be reversed after the opportunity cost of the investment funds is taken into account.

\section{Calculate Impact of Energy Savings on Value Added and Residential Savings}

ImSET calculates economic savings associated with changes in the use of energy, labor, and materials with the improved technologies and practices. In the case of residential buildings and private transportation applications this is relatively straightforward because residential and private transportation savings are assumed to be recycled into final demand. For commercial buildings, commercial transportation, industry, and power production applications, the process is more complicated because the inter-industry relationships between specific sectors are affected, not just final demand. For example, if the commercial building saves electricity, the business sectors operating/occupying these buildings would have lower purchases from the electric utility industry per dollar of output; thus, the coefficients in the utility industry row of the input/output structure of the economy must be reduced. Results from Step 3 are inserted into the ImSET model in the inter-industry portion of the I-O table (shown as Productivity Changes in the last box of Figure 2.1); then the model is run with the automatically recomputed table. Because the energy and maintenance intensity of the commercial sector changes continuously, the coefficients of the I-O structure are automatically recalculated at each time step. 


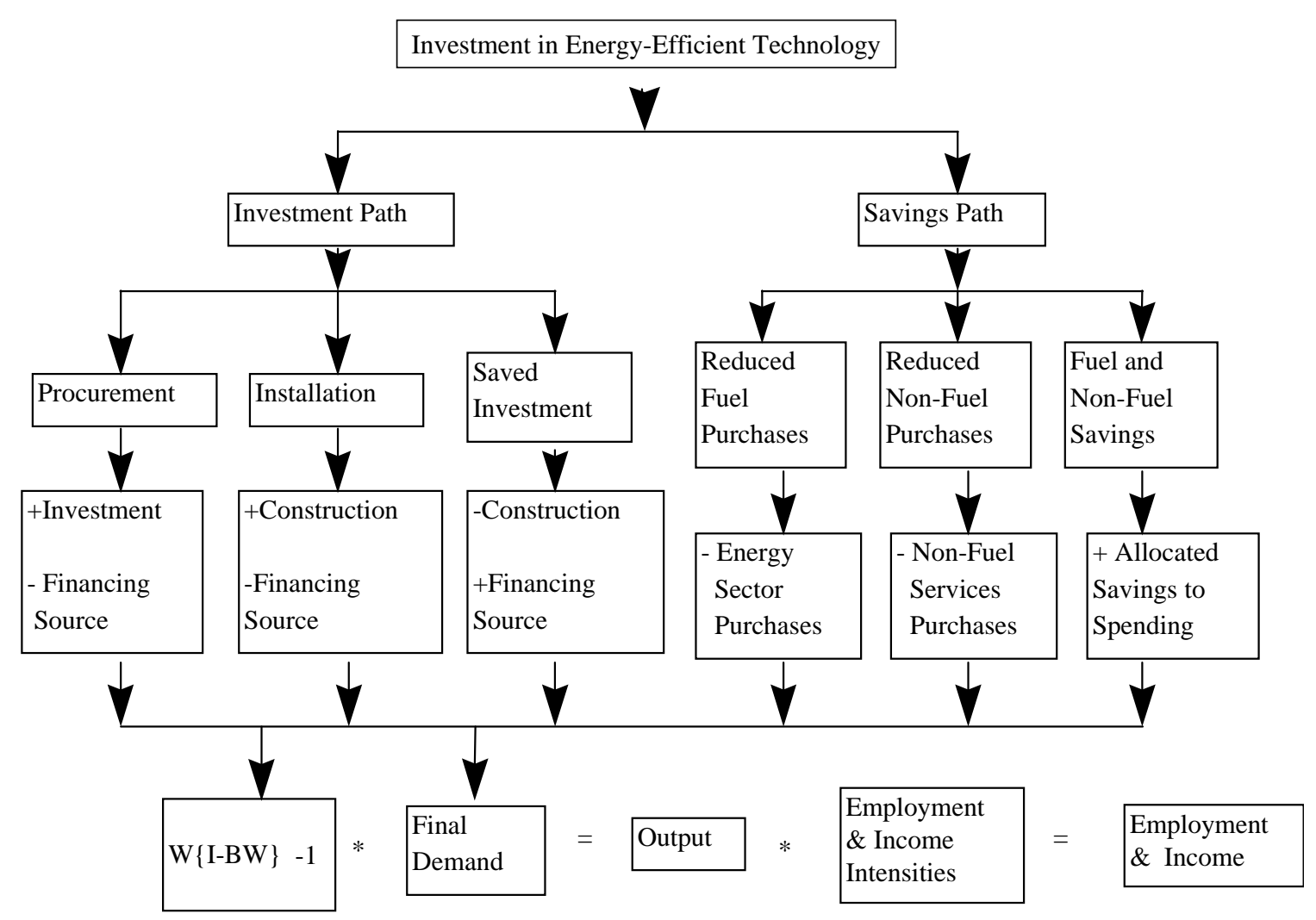

Figure 2-2. Detailed Calculations of the ImSET Model

The financial impacts of energy and non-energy savings in the commercial building, commercial transportation, industry, and power production sectors (for example, savings in building maintenance) are computed by the model. These savings are treated as an increase in value added that is available to be saved or invested by the sector collecting the income.

The energy and non-energy savings do not affect employment in the national economy until they are reinvested or spent. For purposes of the analysis conducted for this report, the increments to value added (savings) are assumed to be allocated to final demand as with all other value added in each sector. That is, the additional income of these sectors is assumed to be spent on final demand. These increments to value added increase GDP, so they are accumulated and are used to modify the vector of final demands (in equal proportions) so that the sum of value added and GDP are again in balance. Thus an energy savings that occurs for industry, transportation, or commercial activity is assumed to contribute to value added and thus increases overall GDP, however slightly.

\section{Calculate Economic Impact of Value Added and Residential Savings}

ImSET accumulates the energy and non-energy savings in the residential buildings and personal transportation sector and the value-added changes associated with energy and non-energy savings within the commercial buildings, industrial, power production, or commercial transportation sectors. The model then calculates spending impacts associated with these savings by proportionately increasing final demand across all sectors as noted, while at the same time reducing final demand in the sectors that supplied the saved resources. This step accounts for the spending associated with the monetary savings and improvements in technological efficiency and for the associated shift from energy to non-energy 
spending. It also accounts for changes in the patterns of economic activity within the economy, due to technological changes caused by the EERE programs (for example, in retailing less electricity is used per dollar of output because of more efficient lighting). ${ }^{3}$ This calculation is shown in the last row of Figure 2.2 (the first box represents the recalculation of the direct and indirect requirements matrix as these technological changes occur - see Lawson, et al., 2002).

ImSET collects the estimates of the initial investments, energy and non-energy savings, and economic activity associated with spending of the savings (increases in final demand in personal consumption, business investment, and government spending), and provides overall estimates of the change in national output for each NAICS sector using the adjusted I-O matrix. Finally, the model applies estimates of employment and wage income per dollar of economic output for each sector and calculates impacts on national employment and wage income.

When finished, the results of ImSET model runs can be saved by running an imbedded dialog designed for this purpose.

\subsection{Components of Impacts: A Once-Only Investment}

Energy conservation technology affects the activity level of the U.S. economy through three primary mechanisms. First, if the incremental capital costs of the new technology per installed unit are different than those of the conventional technology, changes in final demand will occur in the sectors involved in manufacturing, distribution, and installation for both technologies, changing the level of overall economic activity. ${ }^{4}$ Second, depending on how the efficiency investment is financed, it may "crowd out" other domestic saving, investments, and consumer spending, somewhat reducing overall economic activity. Third, energy and non-energy expenditures are reduced. On the one hand, this reduction lowers final demand in the electric and gas utility sectors, as well as the trade and services sectors that provide maintenance, parts, and services. On the other hand, it increases net disposable income of households and businesses and increases general consumer and business spending in all sectors (including some increases in expenditures for electric and gas utility services and retail trade and services).

Figure 2.3 demonstrates how these mechanisms work by showing the effect of a hypothetical onceonly investment in residential energy conservation technology in the ImSET model. It is assumed that consumers spend a premium of \$100 million on more-efficient residential appliances in the year 2000 that each year thereafter saves \$15 million of electricity, \$30 million in natural gas, and \$5 million building

${ }^{3}$ ImSET does not account for all of the long run impacts of technological change. The change in energy using capital in the commercial sector would alter the marginal value of all of the factors of production (including labor and capital) and would induce a rearrangement of capital and labor that ultimately results in an increase in output and in final demand. We show part of this effect - that of the initial spending associated with the savings, but not the effect of increased capital stock that would be created by the investment portion of the spending. Most economic models, including many dynamic simulation models, do not completely reflect the effect of capital accumulation and growth in capacity on final output and employment.

${ }^{4}$ Frequently, a premium is present in the cost of purchase and installation of a new technology, over and above the cost of an alternative conventional system. We have assumed the premium attached to the new technology is due entirely to the differential cost of manufacturing the equipment. Distributor markups and dealer costs are assumed to be unaffected. The share of the premium due to incremental installation costs, if any, may be assigned to the construction sector or some other sector performing the installation, as appropriate. 
maintenance expenditures, for annual savings of \$50 million. This \$50 million annual savings yields a simple payback period of 2 years. The first two cases in Figure 2.3 show only the employment effects of the $\$ 50$ million savings. In the first case, the savings are confined to the residential sector. The second case shows how the impacts would change if these energy savings had instead been experienced in the commercial sector, where the savings are initially experienced as an increase in the profitability of those businesses saving the energy. These profits are assumed to be recycled in the economy as spending by workers, spending by the firms themselves, and by governments experiencing increases in tax collections. In the first case, the energy savings in the residential sector of \$50 million have a net impact on the U.S. economy of about 230 jobs, or about 4.6 additional jobs per million dollars of direct energy savings. The impact is somewhat smaller if the energy savings occur in the commercial sector, 170 jobs, because the employment intensity of the spending mix of businesses, their workers, and government associated with commercial savings is slightly different from the spending intensity of the household sector alone, which is associated with residential savings.

Next, Figure 2.3 adds a third and fourth case to show the employment impacts of the $\$ 100$ million investment itself. The third case shows the impact of the investment premium. In this case, even though investment in the technology itself generates employment, the short run net employment impact is quite small (10 jobs) because the opportunity cost of the investment premium is the dollar amount the investment would have produced elsewhere in the U.S. economy, which on average is almost exactly as labor-intensive as the specific manufacturing sector (Sector 94, Heating and Air Conditions Equipment) that makes the new technology. ${ }^{5}$ Typically, efficiency programs are considered relatively labor-intensive, but this is not always the case. Heating and air conditioning manufacture, for example, has a capitalintensity that is very similar to the overall economy. The strength and direction of the investment effect depends on the size of the investment premium and its combined domestic U.S. direct and indirect labor intensity, relative to that of other domestic spending (the opportunity cost of the investment). For the employment impact of the investment to be positive, the sectors supplying the new technology must on average create more domestic jobs per dollar of spending than does other domestic spending. An extreme form of this positive investment effect would occur if the investment were financed internationally (that is, no domestic opportunity cost is included). This is the fourth case in Figure 2.3, which shows a shortrun jobs impact of five times the initial capital expense, 50 jobs, with an employment impact as a result of the energy savings unchanged from case one. The fourth case also corresponds, at the national level, to the assumption made in many regional analyses of energy conservation impacts, where the investment funds are assumed to come from somewhere else and have no opportunity cost in the region.

\footnotetext{
${ }^{5}$ Strictly speaking, the labor intensity that counts is the employment, direct and indirect, that is created by each dollar of spending. Thus, it is theoretically possible for a capital-intensive industry to buy lots of labor-intensive inputs from other industries and the total effect to be labor intensive as a result.
} 


\section{Incremental Jobs (thousands)}

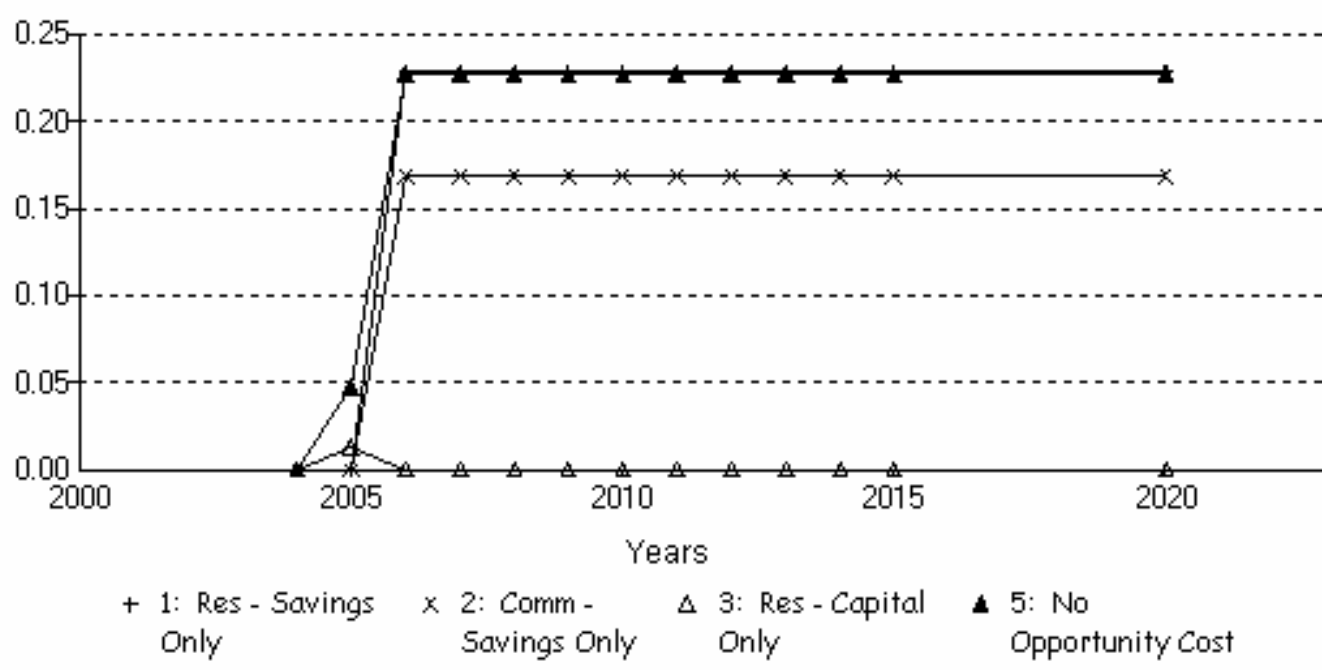

Figure 2-3. Impact on National Employment of a Hypothetical Once-Only Investment in Appliance Efficiency (Case 1 and 5 overlap) 


\subsection{ImSET Model Results for Example EERE Programs}

This section discusses the results obtained by using the ImSET model to calculate the employment and income consequences of three specific building technologies as they are expected to be introduced into the U.S. residential, commercial, and industrial sectors. The three technologies were chosen because they represent a diversity of EERE program characteristics, are likely to affect the economy in different ways, and illustrate a number of issues concerning the economic impact of energy-efficient end-use technologies.

\subsection{Comparison of Capital and Operating Cost Scenarios for Sample Technologies}

The impact of EERE technologies on the national economy depends on the market penetration of these technologies and their associated investments and operating costs. This analysis is tied to the scenarios for market conditions, costs, and energy consumption of specific technologies and programs from the EERE GPRA Metrics, a product of significant work on technology performance, costs, and markets. ${ }^{6}$ Appendix A shows the specific values of these savings and expenditures for the specific scenarios of market penetration. Figure 3.1 shows the premium in capital costs for the GPRA Metrics market penetration scenarios associated with three programs in the FY 2005 EERE Budget Request to Congress: Emerging Technology R\&D on heat pump water heaters, EPACT Energy Efficiency Standards, and three technologies in Glass Manufacturing. These choices illustrate three basic types of EERE programs: an equipment R\&D program (focused on the residential sector), an equipment efficiency standards program (focused on the commercial sector), and an industrial process program. Descriptions of these programs follow.

Heat Pump Water Heaters. The first program is Emerging Technologies R\&D on the heat pump water heater $(\mathrm{HPWH})$ and other follow-on technologies. The purpose of this program is to commercialize highly efficient water heaters for new and existing manufactured and single-family residential buildings. The general program seeks comprehensive solutions for water heating consumption (low cost heat pump water heaters, condensing gas water heaters, waste heat recovery, and water conservation devices), and wants them well established in the market. Once established in the mainstream market, the technologies can become the basis for other approaches, such as Energy Star labeling or minimum efficiency standards.

Heat Pump Water Heater

Market introduction: 2005

Performance Target: 2.47 Energy Factor (demonstrated)

Sales Target: $\quad 10 \%$ by 2015

Installed cost: $\quad$ Initial installation cost of \$700 dropping to \$650 in 2007

Lifetime: $\quad 10$ Years

${ }^{6}$ This report used EERE program data reported in the EERE FY05 Budget Request submitted to the Office of Management and Budget on February 2, 2004, as well as program information from Elliott et al. (2004) that PNNL updated by and with DOE/EE program managers to produce the descriptions shown here. 


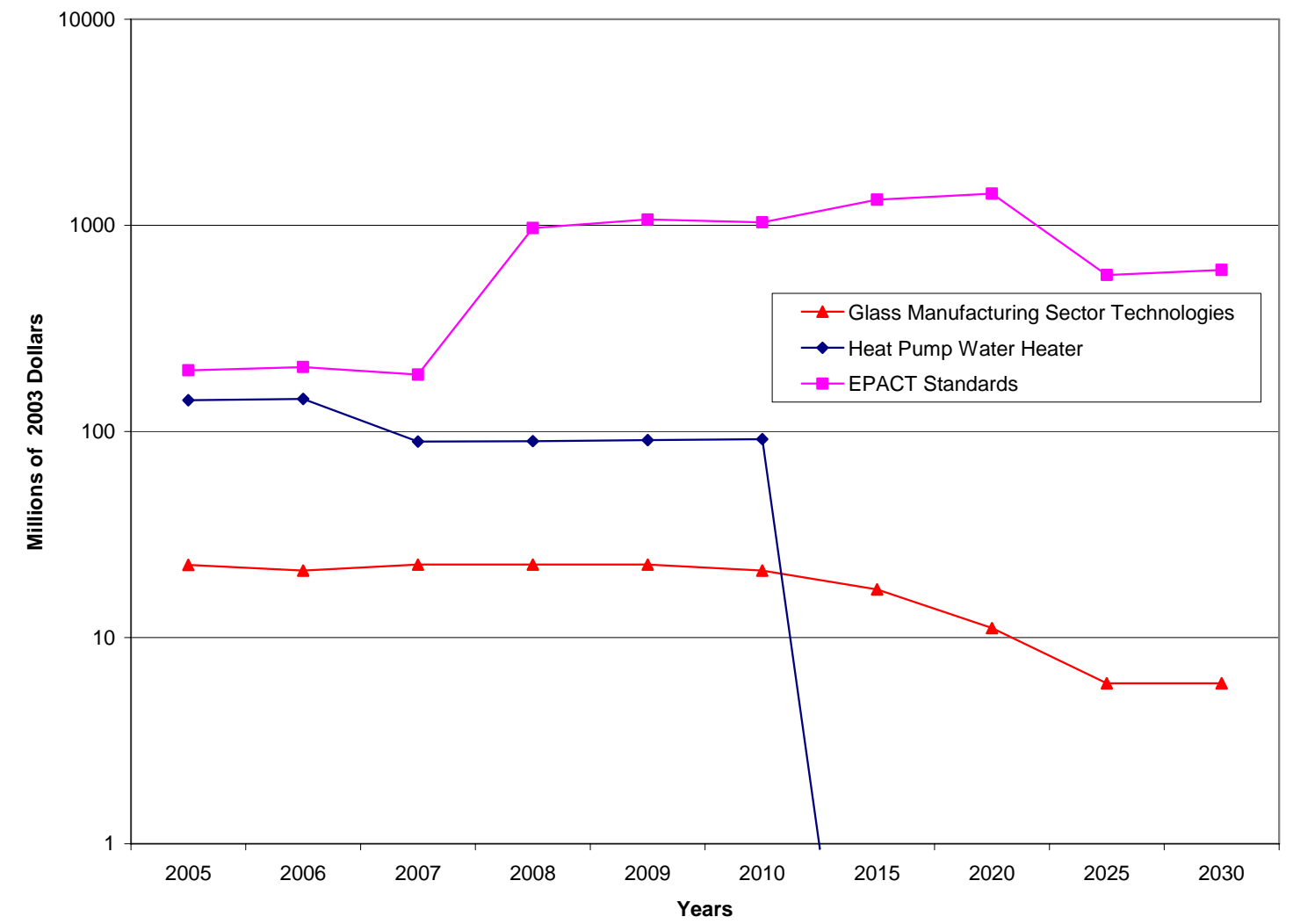

Figure 3-1. Incremental Capital Costs by Year for GPRA Metrics Market Scenarios of Heat Pump Water Heater, EPACT Efficiency Standards, and Glass Manufacturing Technologies

EPACT Energy Efficiency Standards. The second program is EPACT Energy Efficiency Standards. The DOE program is continuing the development that will make a number of types of commercial space conditioning and other equipment commercially feasible. The mission of the overall lighting and appliance standards program is to achieve significant energy savings, consumer cost savings, and reduced air emissions through standards rulemaking. The program also prescribes test procedures that measure energy efficiency and energy use and provide an estimate of the annual operating cost of each appliance.

The long-term goal of the program is the setting of efficiency standards that lead to substantial increases in the average efficiency of new building equipment. The assumption for GPRA is that work will continue in FY2004 for products for which cost-effective additional energy savings may be large. For this version of the GPRA process, these products include boilers, three-phase residential-size cooling equipment, packaged terminal air conditioning and package terminal heat pump equipment, and large rooftop air conditioning equipment. 
Three basic kinds of commercial air conditioning equipment are considered, at various sizes. In general, the goal for these units is to increase their Seasonal Energy Efficiency Rating (SEER) from roughly $8-10$ to around $10-12$ by the year 2008 :

Table 3-1. Efficiency Standards and Energy Savings for Commercial Air Conditioning Equipment

\begin{tabular}{|l|l|l|l|l|l|l|l|}
\hline & Efficiency (SEER, EER) & \multicolumn{3}{|c|}{ Energy Savings by Year (TBtu) } \\
\hline Equipment Category & EPAct & New Std & Eff. Date & 2010 & 2020 & 2030 & Cum. \\
\hline 3-Phase S. Package, Air Source AC, $<65 \mathrm{kBtu} / \mathrm{h}$ & 9.7 & 12.0 & 2005 & 4.6 & 21.0 & 26.5 & 396.0 \\
\hline $\begin{array}{l}\text { 3-Phase S. Package, Air Source Heat Pump, } \\
\text { <65 kBtu/h }\end{array}$ & 9.7 & 12.0 & 2005 & 1.2 & 3.1 & 3.4 & 60.2 \\
\hline 3-Phase Split, Air Source AC, $<65 \mathrm{kBtu} / \mathrm{h}$ & 9.7 & 11.0 & 2005 & 0.9 & 4.1 & 5.2 & 78.1 \\
\hline 3-Phase Split, Air Source HP, $<65 \mathrm{kBtu} / \mathrm{h}$ & 9.7 & 12.0 & 2005 & 9.1 & 24.0 & 26.5 & 463.0 \\
\hline Central, Water Source HP, $>17,<65 \mathrm{kBtu} / \mathrm{h}$ & 9.3 & 12.5 & 2008 & 1.8 & 7.1 & 11.1 & 146.9 \\
\hline Central, Air Source AC, $>=65,<135 \mathrm{kBtu} / \mathrm{h}$ & 8.9 & 11.0 & 2008 & 5.5 & 25.0 & 31.6 & 471.6 \\
\hline Central, Air Source AC, >=135, <240 kBtu/h & 8.5 & 11.0 & 2008 & 5.4 & 24.6 & 31.0 & 463.1 \\
\hline Packaged Terminal AC, 7-10 kBtu/h & 8.6 & 10.8 & 2008 & 0.4 & 1.8 & 2.2 & 33.3 \\
\hline Packaged Terminal AC, $10-13 \mathrm{kBtu} / \mathrm{h}$ & 8.1 & 10.2 & 2008 & 0.6 & 2.6 & 3.3 & 49.5 \\
\hline SEER= seasonal energy efficiency ratio; EER energy efficiency ratio & & & & \\
\hline
\end{tabular}

Glass Manufacturing Improvements. The third program is focused on improving the energy efficiency of the glass manufacturing process in the U.S. There are three component technologies or practices:

- Oxygen enrichment for glass furnace; expected life: 15 years

- Cullet preheating for glass; expected life: 15 years

- $\quad$ Glass temperature sensor; expected life: 7 years

Oxygen enrichment increases the efficiency of the furnace and reduces pollutants by cutting down on $\mathrm{NO}_{\mathrm{X}}$ and other emissions. Cullet (i.e., the raw material for glass - basically sand) preheating reduces fuel use in the furnace by reducing the melt time. Glass temperature sensors improve the throughput of the process and assure quality of the final product. The program is expected to result in the installation through the year 2030 of about 100 units each of oxygen enrichment units and cullet preheaters, and several thousand temperature sensors. One interesting feature of these industrial technologies is that they have an impact on non-energy operations and maintenance cost. In addition, these technologies also have an associated installation cost premium.

Figure 3.2 shows the associated energy and non-energy savings (reduction in operating costs) compared with conventional technologies. All cost premiums and savings are measured relative to baseline conditions by the GPRA Metrics program. These figures represent total increases or decreases in cash outlays in the year shown and not the annualized savings or costs. ${ }^{7}$ Cash outlays vary not only because of the characteristics of the technologies themselves, but also because the market penetration of each technology is expected to change over time as a result of EERE program success.

${ }^{7}$ We do this because economic impacts, such as employment, will occur when the money is actually being spent, not when the economic entities incur the costs associated with the spending. Thus, for purposes of this analysis, if an investment is made in the year 2000, the jobs created are the same whether the money to pay the workers is accumulated cash or borrowed funds. The impact of the opportunity cost is more of a question, as financing theoretically could change the time distribution of the impact on the cost side. We have chosen to show the impact as if it all occurred in the same year as the investment in energy efficiency. 
Capital expenditures shown in Figure 3.1 represent the premium of investment cost over the money that otherwise would have been spent to equip the same residential and commercial building stock with baseline technologies. The costs shown are dependent not only on the cost per unit of the new technology but also on the costs of the technology with which it is assumed to compete. The glass manufacturing technologies are fairly narrow in scope, resulting in investment costs that are an order of magnitude smaller than those of the other two programs. EPACT Standards result in investments that are an order of magnitude higher. Because of variation in the rate of building and relative reduction in costs for new technology over time, EPACT at first peaks and then declines. The peak occurs as program-related investment grows in size relative to current technology, then declines as program-related investment is overtaken by the advanced technology installation that would have occurred anyway in the absence of the program.

All three programs show significant energy cost savings in Figure 3.2. These cost savings depend on the cumulative number of units installed compared with the same market developed with more conventional technology, the relative amount of energy used or saved, and any additional non-energy costs or savings.

The GPRA numbers, used as inputs to ImSET, are derived from different programs that are treated in isolation. That is, each of the programs assumes that it has no impact on any other program. Ignoring interactions may possibly overstate the total benefits when all technologies are aggregated, but corrections for this interaction is done after the analysis performed here.

\subsection{Heat Pump Water Heater}

Figure 3.3 shows the employment impacts associated with variations of the GPRA Metrics heat pump water heater scenario. An essential feature of this scenario is the accelerating investment in heat pump water heaters throughout the forecast period out to 2010, with a high level of new investment thereafter. This investment path means that in any time period, the economy is experiencing a mix of consequences from energy savings and new energy efficiency investment, with the prospect that negative investment consequences could dominate. In fact, however, the energy savings dominate. The line in Figure 3.3 marked Savings Only demonstrates that eventually, the energy savings in the scenario could generate a considerable economic surplus with the potential to create up to several thousand jobs. ${ }^{8}$ The Base Case includes the negative net impact on jobs of the investment in water heaters (spending is transferred from labor-intensive to capital-intensive sectors). Thus, the Base Case lies slightly below the Savings-Only Case. Next, we consider the effect of energy conservation on investment in capital by electric utilities and gas utilities. If energy consumption decreases, it may be possible for utilities to defer investments they otherwise would make in plant and equipment.

${ }^{8}$ Whether the jobs actually would be created depends on future labor market supply conditions and macroeconomic policy. See, for example, Solow (1994) or Moscovitch (1994). 


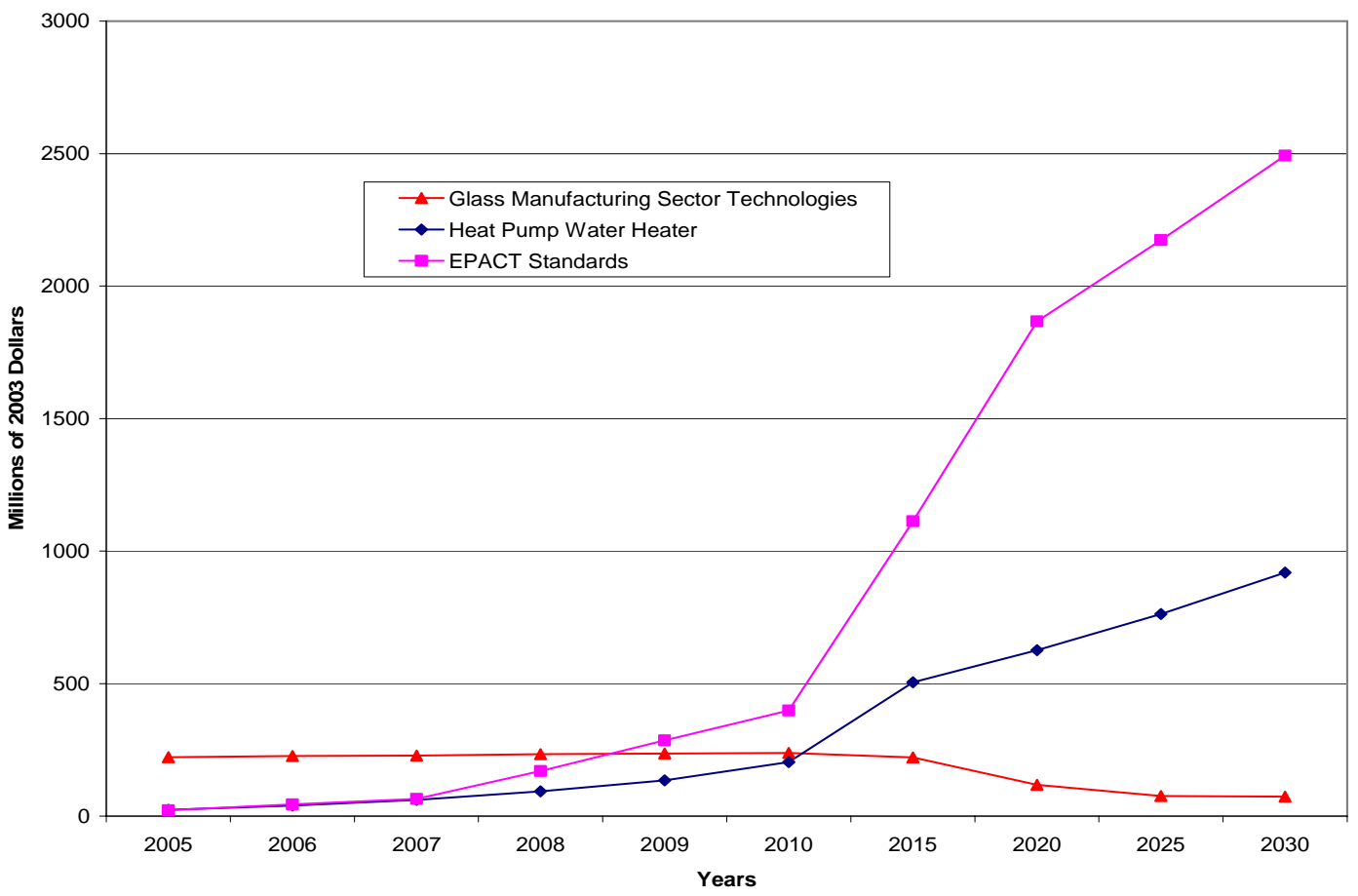

Figure 3-2. Value of Energy Savings by Year Relative to Baseline for GPRA Metrics Market Scenarios

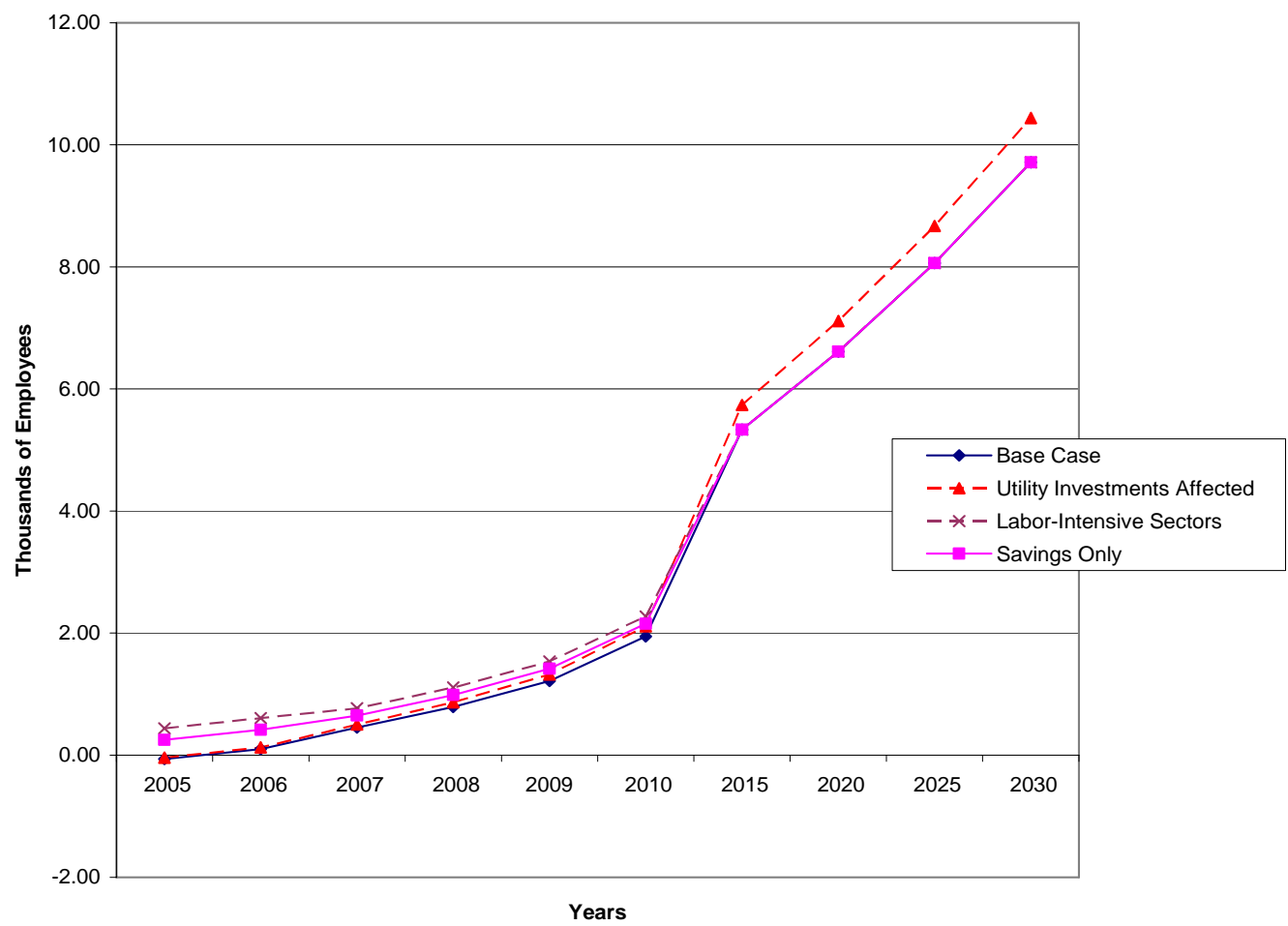

Figure 3-3. Employment Impacts of Investment in Heat Pump Water Heaters 
To analyze this question, we assume that each reduction of 1 trillion Btu of annual electrical energy demand saves \$32.9 million of electric utility investment (about \$590 per kW of capacity) and every trillion Btu of natural gas saved in annual demand saves $\$ 5.29$ million of gas utility investment. ${ }^{9}$ Reduced investment by utilities releases resources from the utility construction sector, which is relatively capital-intensive, to the economy as a whole, which is slightly less so. The net effect is small —an increase of just 1000 jobs (the net employment impact is about 9800 instead of 8800). Thus, saved utility investment, to the extent it occurs, has a slightly positive impact on employment. ${ }^{10}$

So far, this analysis has assumed that the cost premium for heat pump water heaters is entirely due to their manufacture. The case in Figure 3.3 marked Labor-Intensive Sectors is a sensitivity case that shows if more labor-intensive appliance distribution sectors of the economy were affected by the initial investment (not just appliance manufacturing), the net employment effects of the investment premium would be higher, and the overall net effects could be above those of the energy savings alone. ${ }^{11}$ However, we have no reason to believe that traditional percentage wholesale and retail trade markups would necessarily be maintained in the face of the higher manufacturing cost. It is more likely that distribution, marketing, and installation costs would be about the same for the HPWH and the competitor unit.

Figure 3.4 shows that financing affects the size of the projected net employment effect. The net effect depends on the market penetration scenario itself (that is, how fast and at what cost the technologies enter the market) and on what activity in the U.S. economy is displaced by the investment in water heaters. Employment impacts are estimated for the HPWH market penetration of the GPRA Metrics scenarios under differing scenarios concerning the financing of substantial up-front investment. For example, in the base case, the funds necessary to finance the water heater investment are drawn proportionately from the all sectors of the economy. ${ }^{12}$ In the highest scenario in Figure 3.4 (Free Financing), the assumption is the investment does not impinge on U.S. economic activity, and thus, the entire incremental investment adds to U.S. final demand and domestic product. A number of reasons exist why this could happen. From a macroeconomic perspective, two plausible reasons are that consumers decide to spend previously accumulated savings or else the international financial markets judge the investment to be a cost-effective use of their loanable funds, so that investments in some other country are crowded out.

${ }^{9}$ For this report, we estimated electric power plant construction savings at about $\$ 590 / \mathrm{kW}$ of delivered electric energy, based on data in EIA (1997). The equivalent value for natural gas, is about $\$ 1.20$ /cubic foot/day capacity, based on EIA (1996).

${ }^{10}$ This analysis assumes that saved utility investment funds would be recycled in the economy, as are ordinary earnings. If these funds were used to make foreign investments, for example, the negative impact would be much greater.

${ }^{11}$ The differential employment impact of the HPWH investment arises because the appliance manufacturing sector and its suppliers are slightly more capital-intensive as a group than the economy as a whole. Thus, diverting investment funds from the rest of the economy to appliance manufacturing tends to reduce employment. If the investment cost premium were spread among more labor-intensive sectors, such as wholesale and retail trade, the average employment intensity of the HPWH investment would be much closer to the national average. For the sensitivity case in the figure, we assumed that manufacturing took $46 \%$ of the investment premium; wholesale and retail trade, $37 \%$; and construction, $17 \%$. These proportions are normal industry averages.

${ }^{12}$ Personal (household) consumption is assumed to represent $70 \%$ of spending; gross private fixed investment, 10\%; federal defense spending, $9 \%$; federal non-defense spending, $6 \%$; and state and local government spending, about $5 \%$. These percentages are close to the actual distribution of final demand among these sectors. 


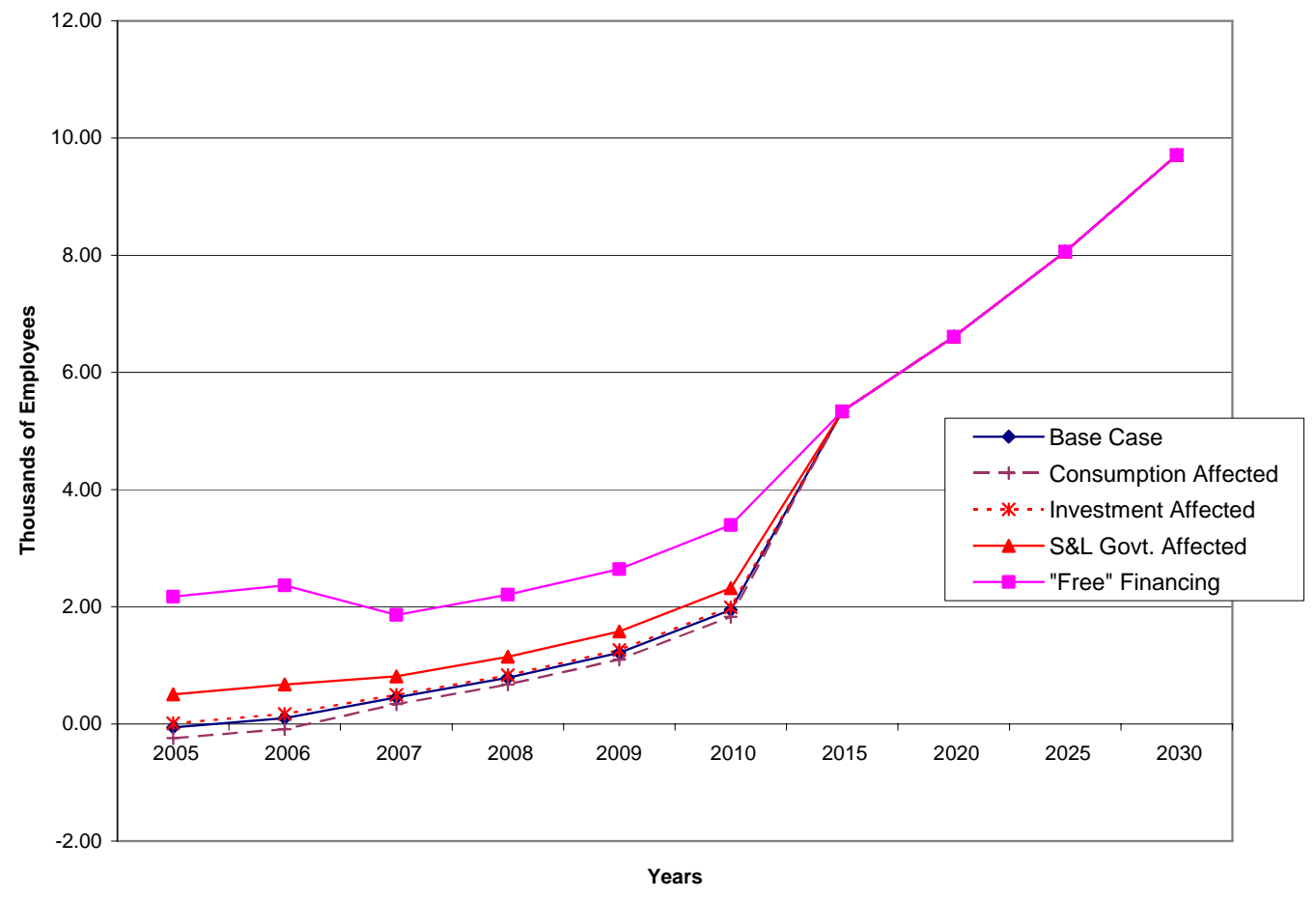

Figure 3-4. Effect of HPWH Financing on Employment

This results in the maximum possible impact on U.S. employment from the investment, an impact large enough to dominate other macroeconomic effects of the technology in some years.

The other scenarios in Figure 3.4 demonstrate, to slight-but-varying degrees, that the employment impact would be temporary, if the new incremental investment in water heaters displaces enough other consumer spending or business investment. ${ }^{13}$ However, because the effects of energy savings are relatively large, the net effect on employment is positive. A major reason for the slight negative investment impact is, although the HPWH technology is cost-effective, it is slightly less employmentintensive than the general economy. ${ }^{14}$

Because the amount of the funds needed for investment in heat pump water heaters is the same in each scenario in Figure 3.4, the level of the offsetting impact depends on the relative employment intensity of economic activity in the various sectors from which the investment funds come. Overall,

${ }^{13}$ The financing effects could be thought of in the following ways. If consumer spending is the only sector affected, it might be because consumers reduce their purchases of consumer durables like washing machines (or buy less expensive ones) to afford the additional water heater investments. Business investments could be reduced instead because lenders provide loans to households to pay water heaters instead of loans to business to buy plant and equipment. Finally, state and local government spending could be reduced because tax credits are allowed on state and local income taxes for investments of this type.

${ }^{14}$ Although a HPWH investment may be cost-effective in comparison with the alternative energy technology, these impact calculations do not address whether the HPWH investment provides as many net economic benefits to the economy as other, non-energy investments with which it also competes. 
although government activity is particularly labor intensive, the differences in employment that would occur if domestic spending were reduced in different ways to make the HPWH investments are very small.

Of course, jobs are not the only metric by which we can measure the macroeconomic impact of energy efficiency programs. Because different industries pay different wages on average, it is theoretically possible to create a number of low-paying jobs while reducing the number of well-paying jobs and overall income. Thus, it is worth looking at the impact on earnings as well as employment. Figure 3.5 illustrates the effects on national earned income of the various scenarios, previously shown in Figure 3.4, with their different sources of investment capital.

Figure 3.5 illustrates that, as before with employment, the impact of the water heater investments and savings on the national economic activity are positive when the investment does not crowd out domestic spending and investment. With the source of investment funds being the entire economy (Base Case), the net impact on national incomes is positive, as also was shown in Figure 3.4 for employment. As was true with employment, the impact on wage income is generally reduced (but not negative) if normal domestic investments are foreclosed by water heater investments. The difference if government investment is crowded out is slightly positive in the short run.

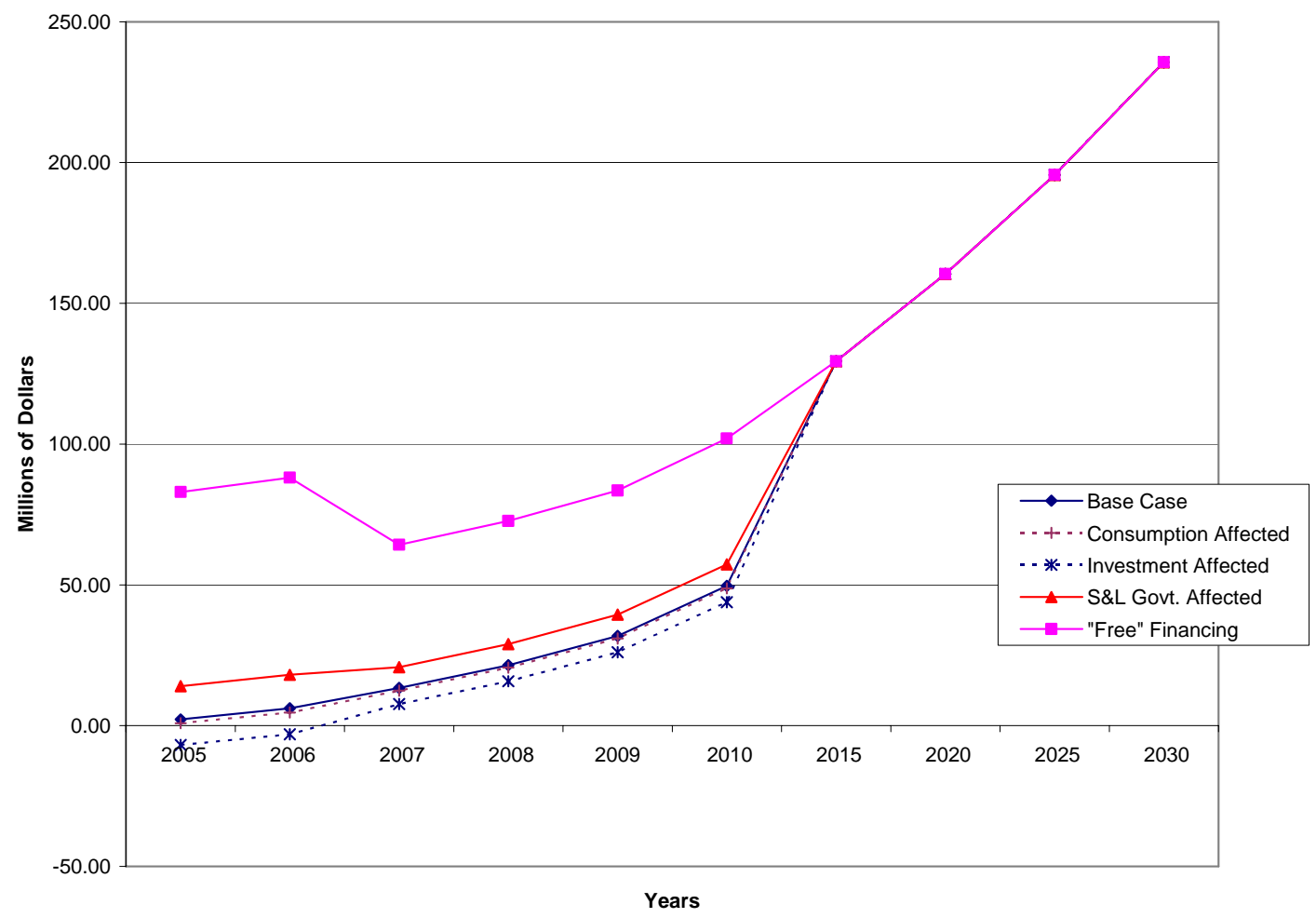

Figure 3-5. Impact of HPWH Investment on National Wage Income (\$2003)

Figure 3.6 is the wage income equivalent of Figure 3.3, but does not show the same results. Because the initial investment has a larger gross product multiplier than the economy as a whole and occurs in a high-wage, capital-intensive sector, activity created in water heater manufacturing and its supplying industries employs fewer workers per dollar of activity than the national average but generates more-thanaverage income. Energy savings, if they are large enough, also could reduce utility investment in new 
plant and equipment (mostly construction). Should this occur, Figure 3.6 shows that reducing construction activity frees up dollars that tend to have a slightly less positive impact on national wage income when spent on personal consumption, business investment, and government programs than if they had been spent in construction. ${ }^{15}$ Thus, the net impact on national wage income is very slight decrease relative to the base case.

Finally, the figure shows that if the investment in water heaters were distributed across more laborintensive industries rather than just appliance manufacturing, there would be a the net increase in national wage income because the altered investment pattern would then represent a diversion of investment dollars into labor-intensive retail and wholesale distribution as well as high-wage construction and capital-intensive manufacturing. ${ }^{16}$ As before, however, it is likely that most of the premium in cost would be the additional cost of manufacturing.

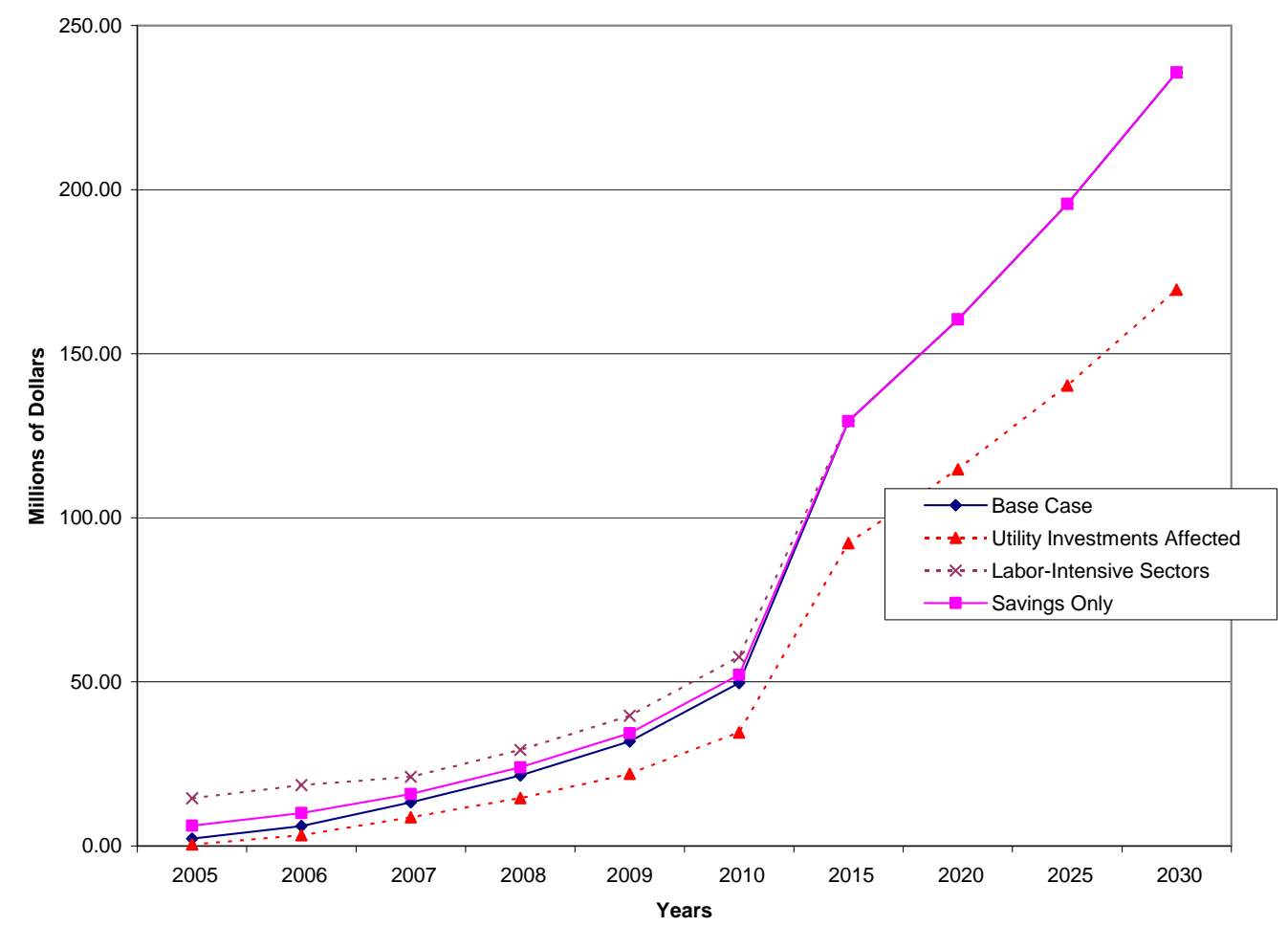

Figure 3-6. Sensitivity of Impacts on National Wage Income to HPWH Investments (\$2003)

\footnotetext{
${ }^{15}$ In the case analyzed, this sign is the opposite of the comparable employment effect and is the combined result of inter-sector purchases and the wage rates in the affected sectors. The net effect is small, however, and could be of either sign, depending on exactly which sectors are affected. When relatively capitalintensive sectors spend the released investment funds, the effect is negative for both employment and income; when labor intensive sectors spend the money, the net effect is positive for both. The illustrated case involves a mix of sectors.

${ }^{16}$ In this case, the investment premium was distributed $46 \%$ to appliance manufacturing, $37 \%$ to the wholesale and retail trade, and $17 \%$ to the construction sector for installation.
} 


\subsection{EPACT (Commercial Air Conditioning) Efficiency Standards}

High-efficiency air conditioners (HEACs) installed in commercial buildings are expected to require an incremental investment, but they affect the economy somewhat differently than HPWH investments. The HPWH and HEAC scenarios differ because the target market for HEAC is in commercial buildings. From a macroeconomic point of view, this difference is important because the destination for the energy/non-energy operational savings in the commercial sector is not obvious. Potentially, energy savings would increase the profitability of firms that installed HEAC; however, the additional valueadded per dollar of output could well be shared with the work force (in the form of higher wages due to higher productivity and effective bargaining by labor) and with the government (in the form of additional tax collections). With respect to business profits, it is not clear how much would be spent or invested, how much saved, and so on.

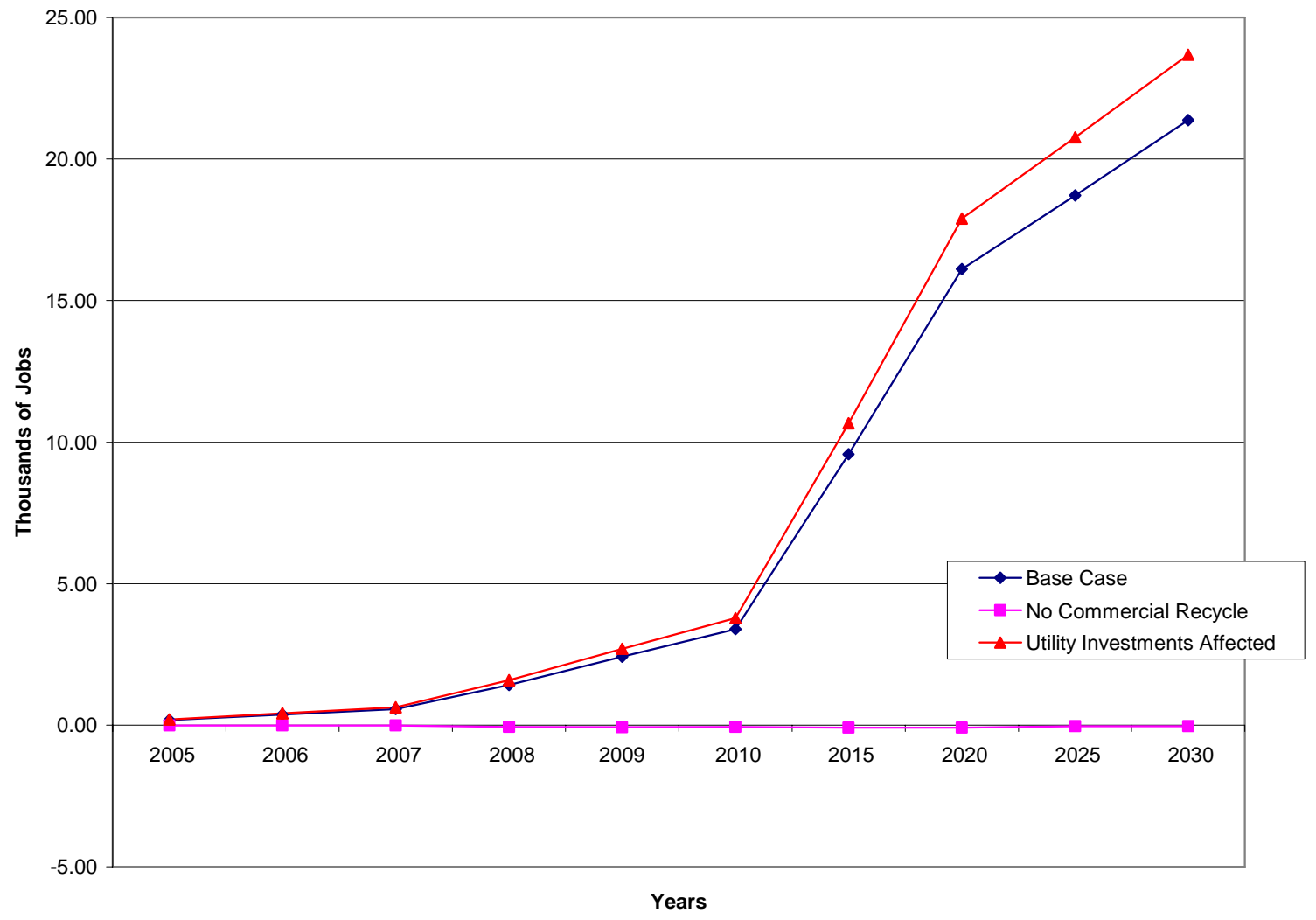

Figure 3-7. Impact on National Employment of EPACT Standards

However, even if a particular business had no immediate investment plans for the funds provided by energy savings, the economy as a whole would have abundant investment options available and the capital markets could readily absorb any savings. Therefore, we assume that energy savings by business (proportionately allocated to labor earnings, business profits, and taxes) are immediately recycled in the economy as consumer spending, business investment, and government spending. If the cost savings were not re-spent inside the U.S. economy (for example, they were invested in telecommunications in Asia), then that portion of the energy savings would have no positive effect on the economy as a whole. This is illustrated as the No Commercial Recycle case in the figure. As before, if the energy savings allow for the 
deferral of electric and gas utility infrastructure investments, there is a (very slight) positive impact on overall employment.

Figure 3.8 shows the net impact of the HEAC investments on the wage economy is significant and also positive.

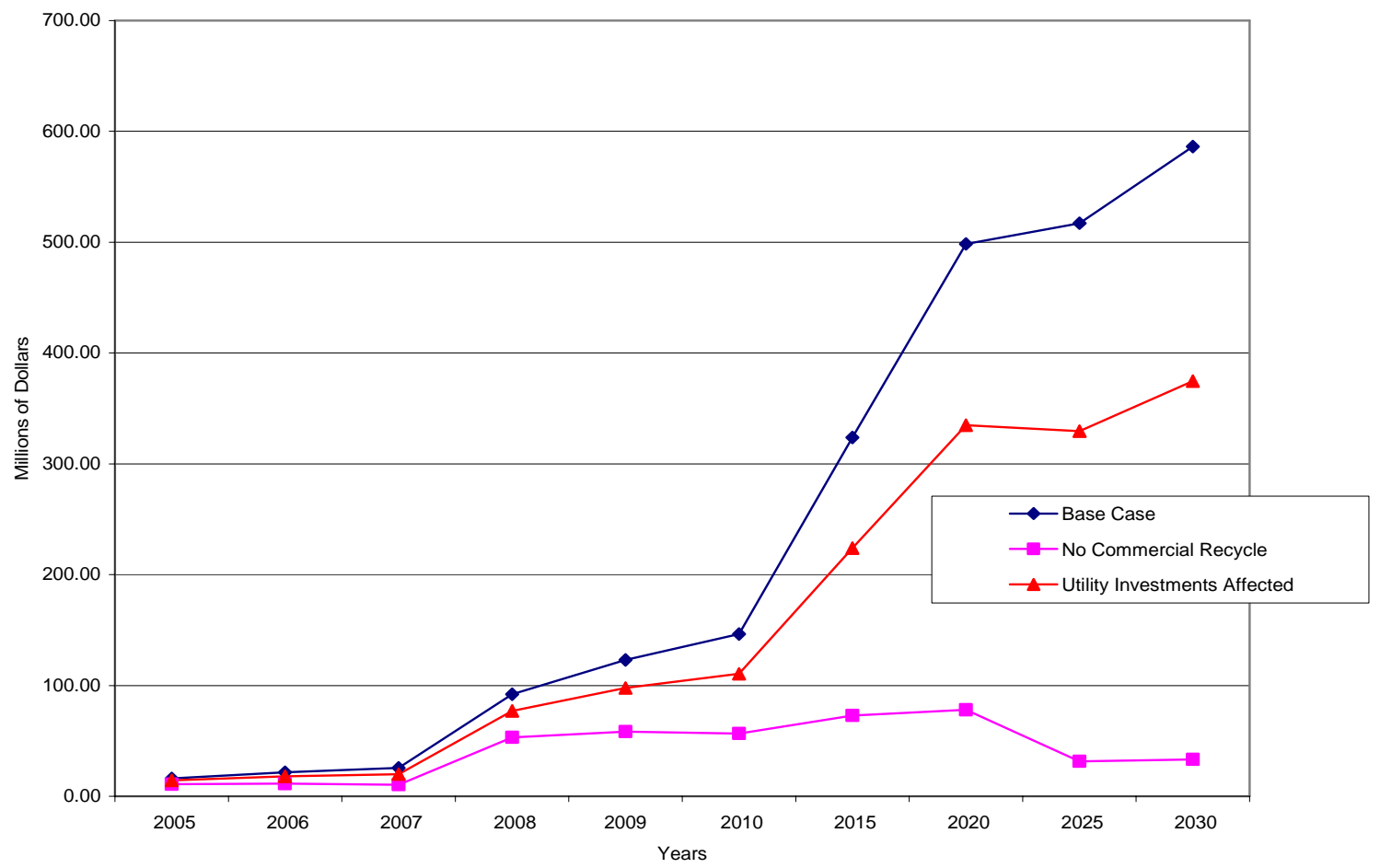

Figure 3-8. Impact of EPACT Standards Energy Savings on National Wage Income (\$2003)

\subsection{Glass Manufacturing Technologies}

The three industrial energy-saving technologies in higher efficiency glass manufacturing save the economy about \$200 million to \$235 million per year, at an incremental investment of about \$20 million in most years. As a consequence, the investment in these technologies also adds to the level of macroeconomic activity, as measured by jobs and wage income, as shown in Figures 3.9 and 3.10. The savings occur fairly early in the period in the adoption scenario illustrated, in effect an acceleration of energy savings that may have occurred anyway at a later date. See Anderson et al. 2003 for a more complete discussion.) Later on, the savings due to the EERE program decline as the equipment depreciates and is replaced by still more efficient equipment, and as the energy savings acceleration begins to approach the date by which the savings would have occurred as a result of the normal functioning of the marketplace.

Similar to the previous cases, "free financing " produces the largest impact, while the impacts of the energy savings are partially offset by the opportunity costs of the funds required for the associated investment. 


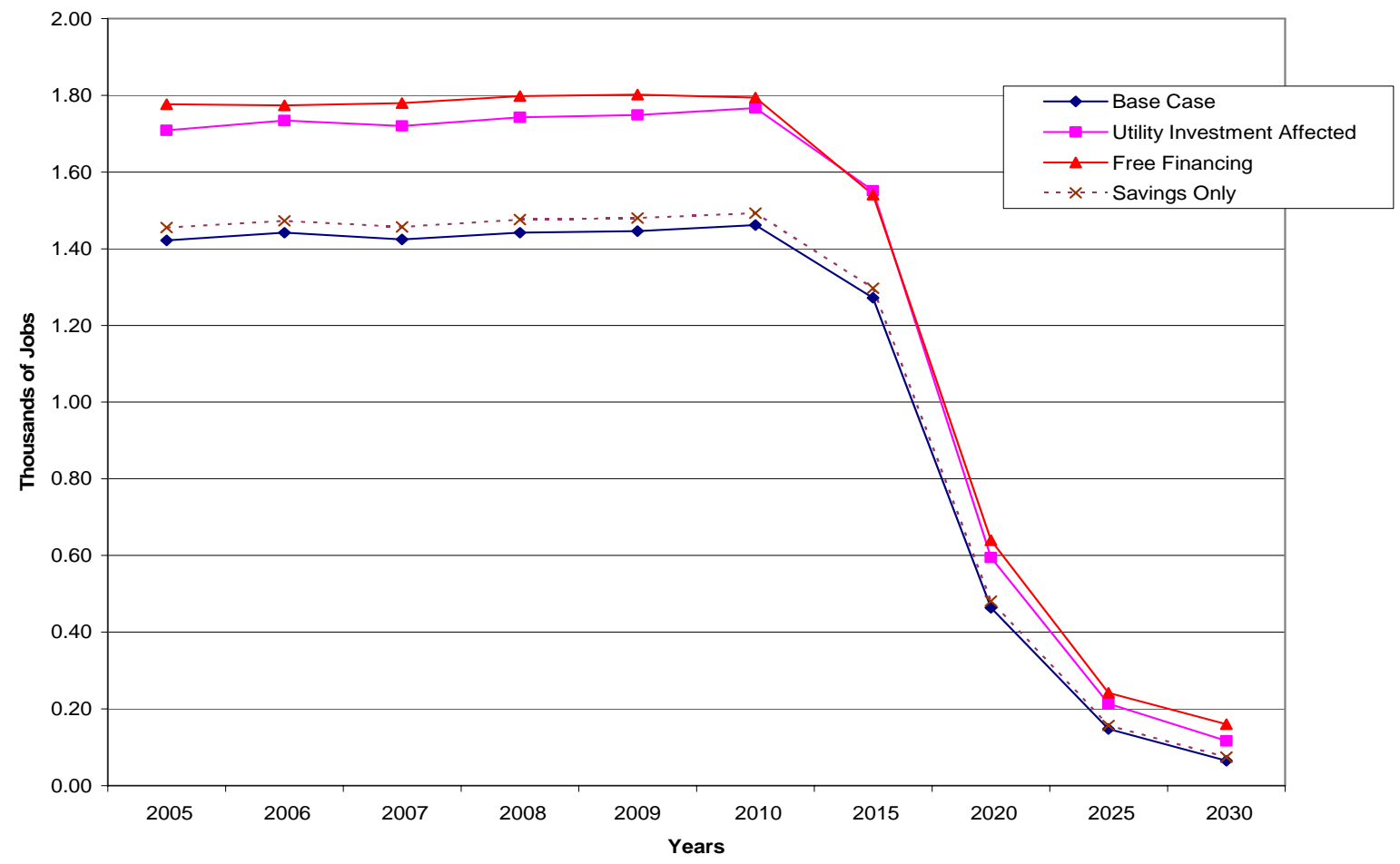

Figure 3-9. Impact of Glass Manufacturing Sector Savings on National Employment

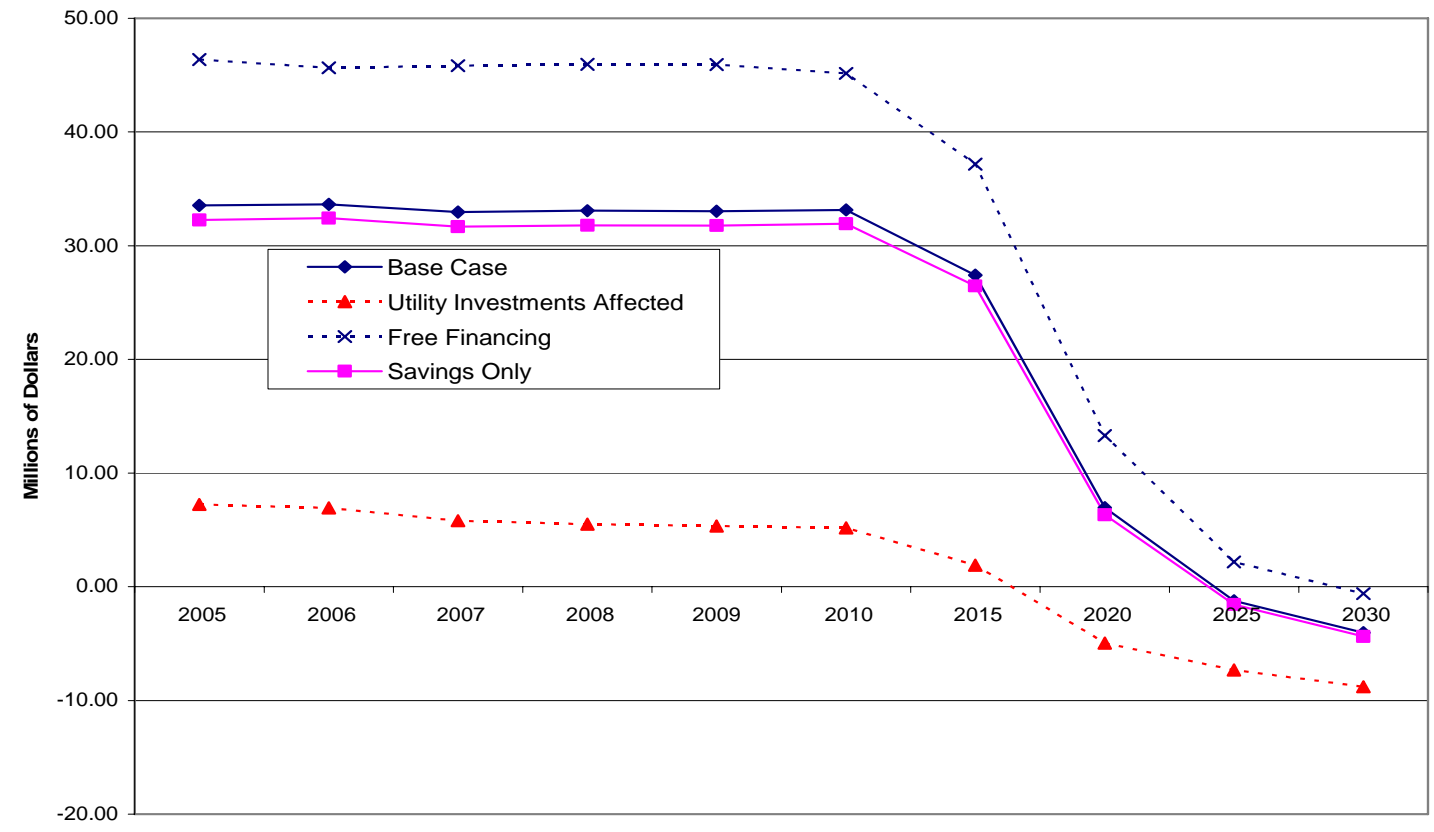

Years

Figure note: Base Case and Utility Investment Cases are nearly identical

Figure 3-10. Impact of Glass Manufacturing Sector Savings on National Wage Income (\$2003) 


\subsection{Comparison with Other Studies: An Update}

Since the publication of the Users' Guide to the predecessor version of ImSET, ImBuild II (Scott, et al., 2002), a number of papers have appeared that are compared to the current version of ImSET. While our conclusions generally remain the same, that is, that the results, compared to other models, are quite similar, there are some differences from previously published work, in large measure due to the difference in sector aggregation and to a few critical assumptions where honest disagreement is possible. Since considerable attention was paid to these differences in the previous publication, that discussion will be briefly summarized, then the current version will be compared to recent studies and the previous version.

\subsection{A Summary of Previous Findings}

Much of the discussion in the previous Users' Guide was a comparison of the predecessor model with a study by the American Council for an Energy Efficient Economy (ACEEE) (Geller et al. 1992). The differences between ImBuild II and the ACEEE model could be explained by differences in the sectoring plan and the fact that the ACEEE report was based on the 1987 Benchmark I-O table while ImBuild II was based on the 1992 Benchmark I-O table. Another source of differences in results arose from the way that programs were implemented in the analysis. For example, the source of funding for incremental investment in a technology in the ACEEE report might have been financed by a reduction in demand for the sector using the technology (i.e., a change in demand) rather than a change that reflected supply-side impacts. ${ }^{17}$

In addition to the extended discussion about the ACEEE study, the previous Users' Guide also examined several other reports, but none of these could be easily compared with the methodology used by ImBuild II (see, for example, Laitner, et al. 1998). In summary, the report concluded that ImBuild II's results were roughly comparable to those of other recent analysis.

\subsection{Comparisons of ImSET to Recent Studies}

As a framework for differentiating between different approaches, Berck and Hoffmann (2002) provide a taxonomy of five approaches. In order of complexity, the approaches are 1) supply and demand analysis of the affected industry, 2) partial equilibrium analysis of multiple markets, 3) fixed-price general equilibrium simulations, 4) non-linear computable general equilibrium (CGE) simulations models), and 5) econometric estimation of the adjustment process. Included in the third approach are both input-output (I-O) and social accounting matrix (SAM) models, in which ImSET fits. Berck and Hoffmann note (page 135) that I-O, SAM, and CGE represent a continuum of approaches, with I-O and SAM models providing an upper bound to the employment impacts because factor substitution does not occur as a result of the assumption that the production function is linear. In a classical CGE model, which operates with a fully employed labor force, factor substitution would be complete and there would be no net employment impacts in the economy, though there might be income impacts as a result of the migration of labor from one industry to another. Berck and Hoffmann apply the I-O/SAM approach to estimating the employment impacts of a decline in redwood timber sales from Del Norte and Humboldt counties in northern California. (See Xie, [2000] for an application of SAM to environmental policy in China..) In pointing out the limitations of the third approach, Berck and Hoffmann note that, “. . . with policies that do not

${ }^{17}$ See text on pages 4-1, 4-5, and 4-6, (Scott et al. 2002), for a more detailed discussion. 
affect relative prices, linear models are more likely to provide good approximations of actual changes than in situations where the policy impact is large enough to affect relative prices” (p. 145). Earlier we made the case that that the technology changes we examine in ImSET are usually so small relative to the size of the economy and the economic sectors affected that relative prices are unlikely to be affected, and therefore, the I-O approach will provide reasonably good estimates of the impacts of the penetration of DOE technologies into the economy.

Kaiser and Pulsipher (2003), along with their colleagues (Kaiser et al. $2004^{18}$ ), have used a similar approach to estimate the impact of establishing a (proposed, but not enacted) Louisiana Public Benefit Fund which would levying a 1-mill/kWh surcharge on all electricity sales, then leverage these funds with other public and private funds to provide low-income energy bill assistance, low-income weatherization assistance programs, and residential and commercial energy conservation programs. They use an IMPLAN I-O table of Louisiana provided by MIG, Inc., to estimate the economic impacts of the Public Benefit Fund. Their expected outcome would see over 32,000 residential homes insulated, nearly 19,000 commercial buildings improved with energy savings of $\$ 26.6$ million and a benefit/cost ratio of 1.7. Their expectation is that there would be 1671 jobs created, additional tax revenues to the state of $\$ 8.3$ million and a net economic benefit of \$345.9 million.

This approach is similar to ImSET, but does not modify the Use matrix to show the impact of adopted technologies on expenditures by commercial and industrial firms (see section 2.1). Our interpretation of the Kaiser et al. (2004) results suggests that a distribution of benefits and costs $\left(30^{\text {th }}, 50^{\text {th }}\right.$, and $80^{\text {th }}$ percentiles) were estimated using multipliers from the IMPLAN model to determine output, value added, and through these output changes, employment changes to the Louisiana economy. Specific discussion of the financing of the investments is absent, suggesting that the treatment is as if the costs and benefits are on an annualized life-cycle cost basis or on a net present value basis.

The final addition to the literature is by Nayak (2005) and Economic Research Associates (2005) of Alexandria, Virginia, who examine the economic and consumer benefits of clean energy policies. The input-output model used in Nayak's study and is very similar in spirit to the Geller et al. (1992) study. The national model is 15 sectors, with direct expenditures energy savings taken into account for 10 years. The payback period for any energy efficiency project is assumed to be 4 years; the financing of the project would be at $80 \%$ of the cost, at $8 \%$ interest; and both productivity and price effects are factored in to the analysis. ${ }^{19}$ Over that time period, labor productivity changes would occur and these would reduce jobs per unit of output in all but the energy savings sector. Energy prices would have no effect on building improvements or revenues, but would increase final demand by $8 \%$ for energy savings and reduce demand by $6 \%$ for utility revenues. Interest changes would increase final demand by $2 \%$ in both the buildings improvement sector and the revenue impacts, but have not impact on energy savings or utility revenues. The state model(s? $)^{20}$ derived from the national model is designed to allow for specific effects, as requested by the PIRG Education Fund.

\footnotetext{
${ }^{18}$ The Kaiser, et al. (2005) paper uses the approach to measure the impact of the (enacted) Louisiana Energy Fund, a public/private cooperative, effort partially funded by tax-exempt state bonds, to fund energy and water conservation projects.

${ }^{19}$ Exactly how this is done is not explained. It is clear from the example in the Nayak report that these effects are multiplicative: the table on p. 4 shows what effect labor productivity, price effects, and interest rate changes have on final demand, but the derivation of the prices and interest rate changes is not explained. With a 4-year payback, the 10 -year energy saving would be $\$ 2.5$ million. Presumably the productivity impacts are derived from BLS estimates, as explained in the first paragraph on p. 6.

${ }^{20}$ Again, neither the number of state models nor the specific states are identified. It is not clear whether these are composite state models derived from the national model or specific states constructed from IPLAN data files.
} 
The study is designed to examine the impact of two major policy changes: 1) shifting government expenditures from subsidizing fossil and nuclear industries under the prior proposal to instead, spending the $\$ 35$ billion on renewable energy and energy efficiency; and 2) enacting a 20 percent national renewable energy portfolio standard, which would require that the U. S. generate 20 percent of its electricity from clean energy by 2020. Nayak shows results for three scenarios: the 2004 Energy Proposal, the 20\% Renewable Energy Standard, and the Clean Energy Package which is the 20\% standard plus shifting \$35 billion from the proposed legislation to renewables and energy efficiency. The net impact from Scenario 1 to Scenario 3 in 2020 is about 130,000 jobs and an increase of nearly \$4.5 billion in GDP.

While it is not possible to make direct comparisons between ImSET and the model used by the U. S. PIRG Educational Fund, it is possible to roughly compare impact multipliers for jobs, as is done in the following table. "Roughly" because we have taken a simple average of the set of industries represented by the sectors reported in Nayak's paper rather than aggregate and properly weight the impacts by output measures. While these are indicative, it is fair to say that the impact multipliers are very similar; where the definitions are very similar-coal mining, electricity utilities, construction, wholesale and retail trade, finance-the numbers are quite close.

Table 4.1. Employment Multipliers, Nayak, and Selected ImSET Industries

\begin{tabular}{|l|c|c|}
\hline \multicolumn{1}{|c|}{ Sector } & $\begin{array}{c}\text { Employment Multipliers, } \\
\text { Nayak }\end{array}$ & $\begin{array}{c}\text { ImSET Employment } \\
\text { Multipliers (Simple Average) }\end{array}$ \\
\hline Agriculture & 24.2 & 14.0 \\
\hline Oil and Gas Extraction & 9.1 & 13.1 \\
\hline Coal Mining & 9.9 & 9.7 \\
\hline Other Mining & 11.1 & 10.9 \\
\hline Electric Utilities & 6.1 & 6.5 \\
\hline Natural Gas Distribution & 7.1 & 14.3 \\
\hline Construction & 18.3 & 17.0 \\
\hline Manufacturing & 11.6 & 13.8 \\
\hline Wholesale Trade & 11.5 & 12.6 \\
\hline Transport and Utilities & 15.9 & 17.5 \\
\hline Retail Trade & 25.0 & 25.1 \\
\hline Services & 15.4 & 18.0 \\
\hline Finance & 11.1 & 11.4 \\
\hline Source: & Nayak, p. 20 & ImSET, selected industries \\
\hline
\end{tabular}




\subsection{Operating the ImSET Model}

To use ImSET a user would necessarily have had to install the software with the SETUP.EXE program provided. This will ensure that all components of the model are properly installed. Once ImSET is installed on a desktop PC, the user starts the program as per normal Windows program methods.

Once started, the ImSET program will display an introductory splash screen, then present the user with an introductory instruction screen. The user should select Continue to advance to the main "Run specifications" screen. It is in this screen that the user will add records to represent specific program assumptions.

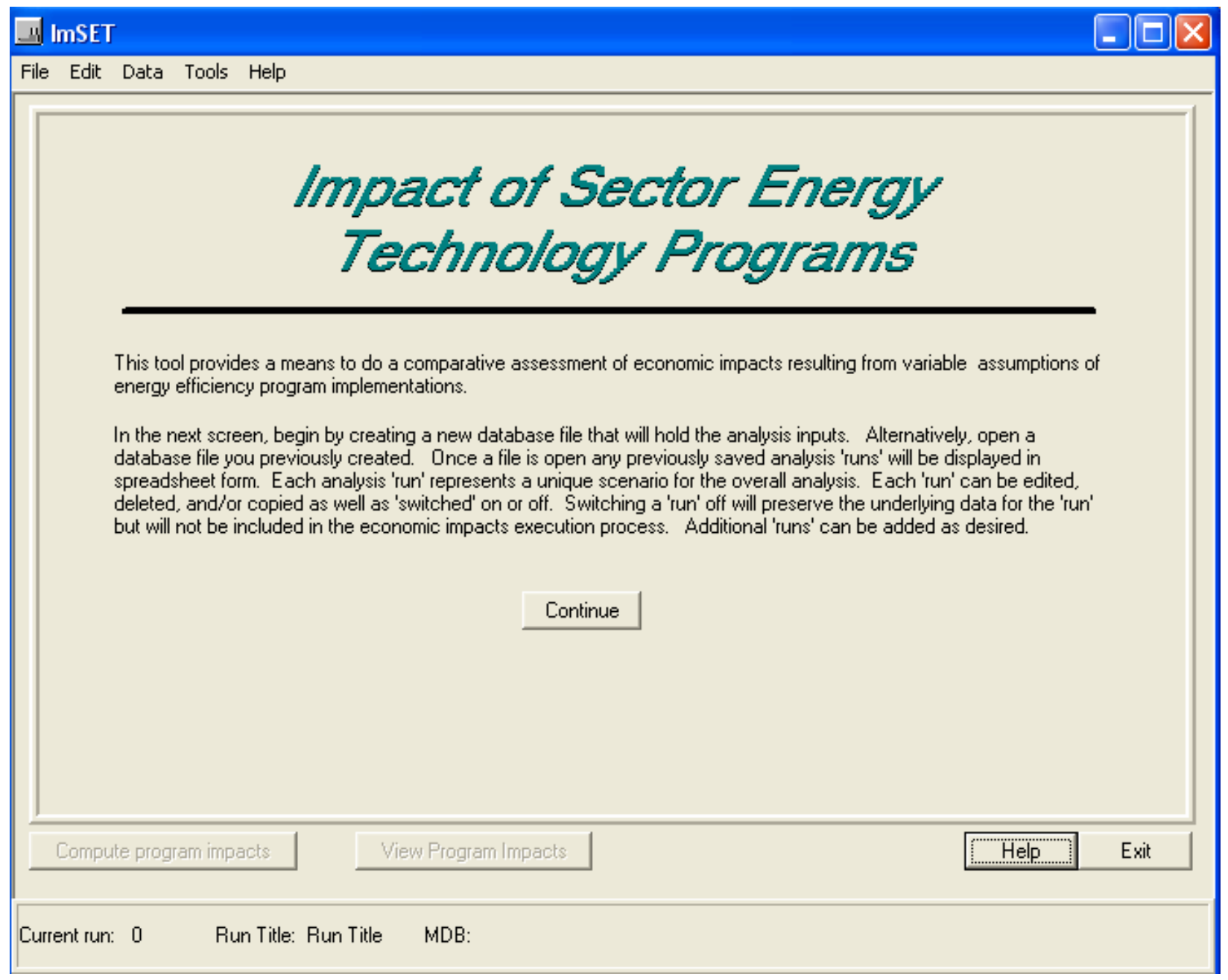

Figure 5-1. ImSET Title Page 


\subsection{ImSET Options}

The "Run specification" screen is used to specify unique program scenarios. Add as many records as there are unique scenarios to be compared. Only the records that have "Execute run" checked will be run and displayed in the results screen. Before specifying "run specifications" the user must first create a new "run database" using the menu options under the "File" menu. The "run database" will hold all information and results specific to the scenarios established and specified. Thus, a user can make any number of "run databases" for specifying unique scenarios.

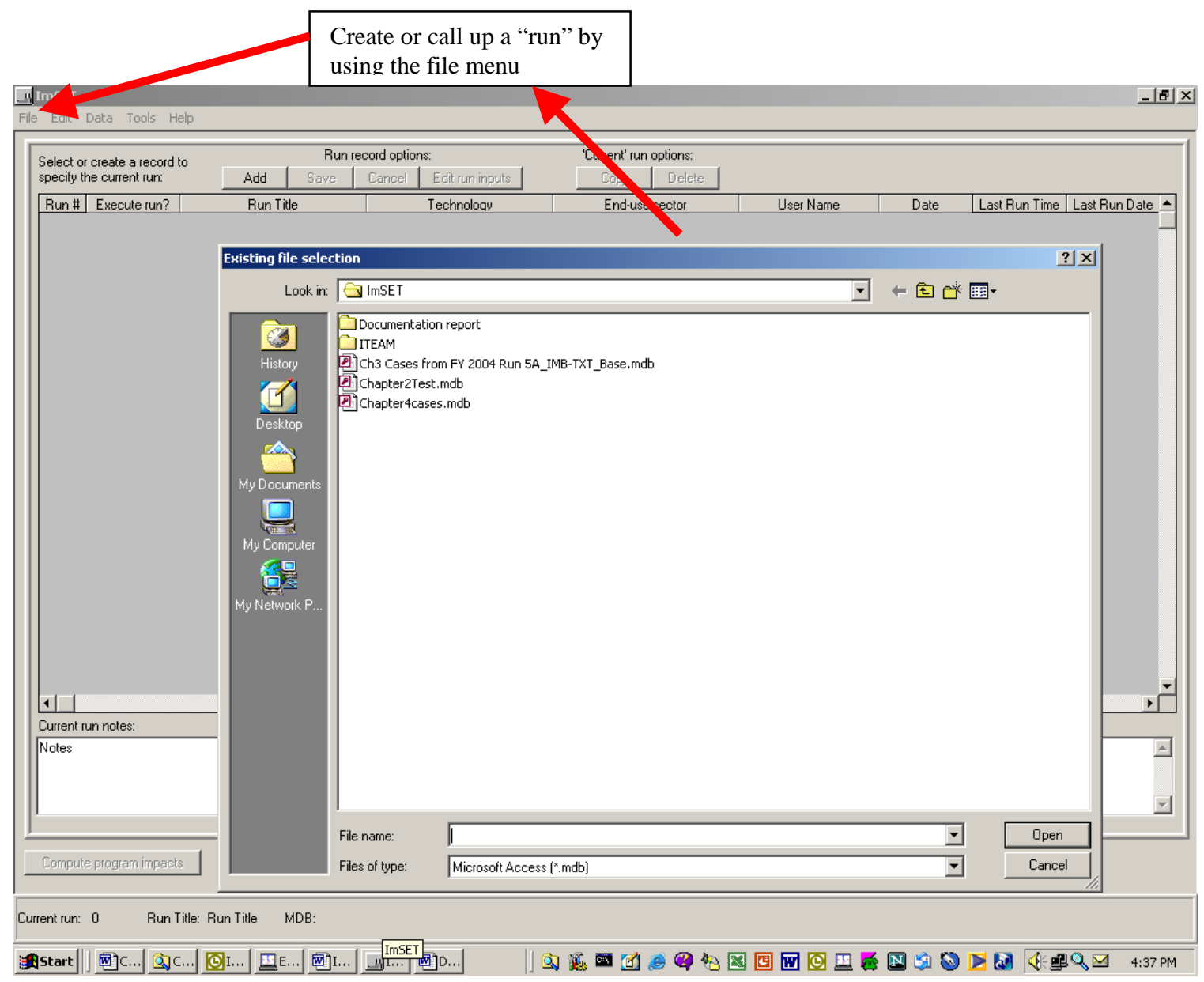

Figure 5-2. Run Specifications Screen

The "Run specification" screen is used to specify unique program scenarios. Add as many records as there are unique scenarios to be compared. Only the records that have "Execute run" checked will be run and displayed in the results screen.

Functionality of this screen is described below: Add - Adds a "run" record to the spreadsheet. 
Save - Saves the current "run specification" records to the currently opened database file.

Cancel - Cancels any changes to the "run specification" spreadsheet and refreshes the display.

Edit run inputs - Displays a screen of detailed "run inputs" that can be edited by the user.

Copy - Copies the currently selected "run record" (indicated by yellow marker in left most column and/or in status bar at the bottom of the screen.

Delete - Deletes the currently selected "run record" from the spreadsheet and the database. A

"confirmation prompt" will be displayed to verify the request. The "confirmation prompt" can be "turned off" for future deletions by checking the appropriate check box in the "confirmation prompt" screen.

Compute program impacts - Computations of program/technology impacts will be run on all "run specifications" that have the "Execute run" column checked. After computations are done the results screen will be displayed.

View program impacts - Displays the results screen without running computations. Results will be displayed for the last computed impacts.

Help - Displays the help file.

Exit - Exits the ImSET program.

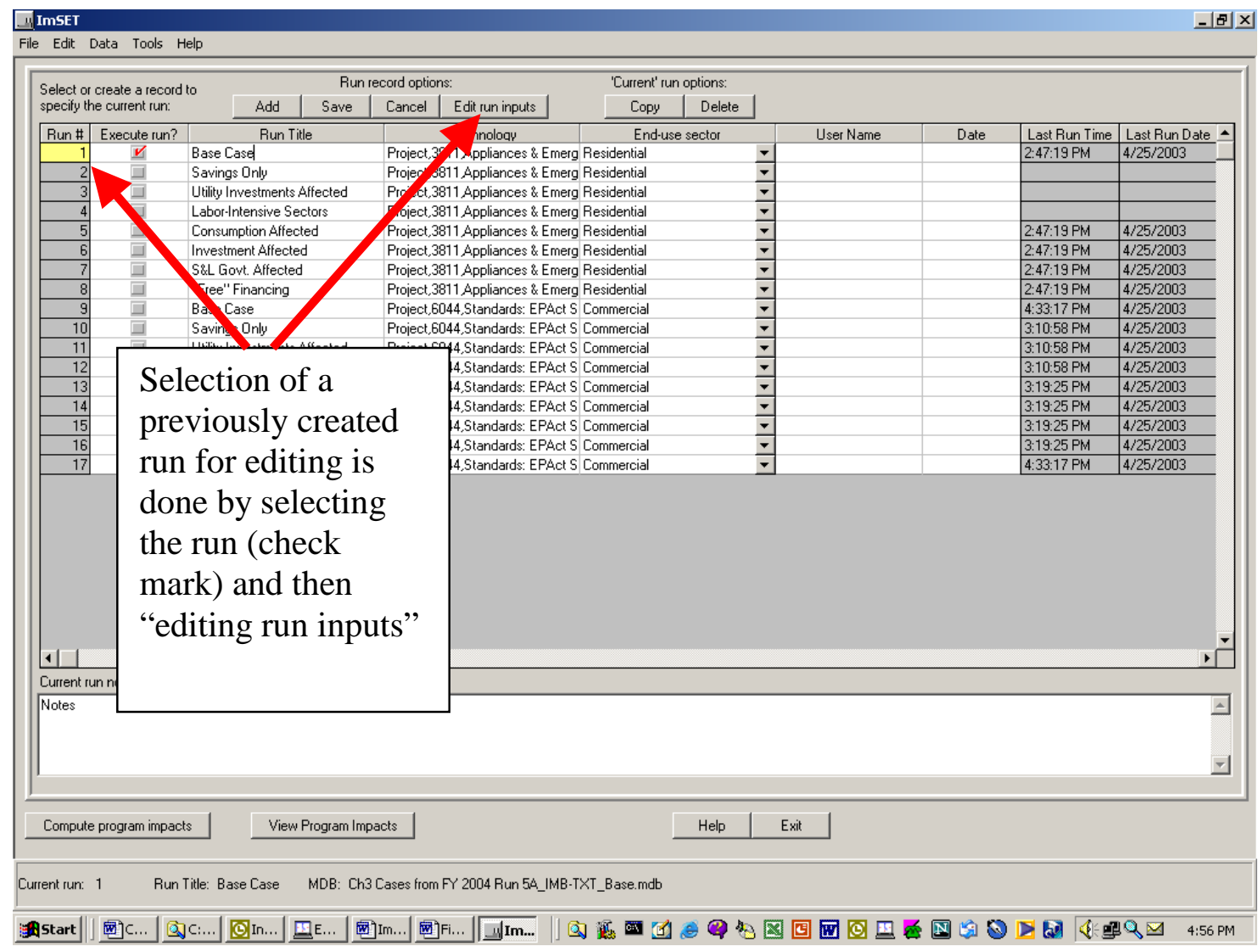

Figure 5-3. Run Specification Spreadsheet

\section{“Run specification” spreadsheet columns -}

Run \# - A unique identifier for a "run specification" record. This is a non-editable column and is determined programmatically.

Run title - User provided description of the "run specification”. 
Technology - The technology/program that is assigned to the "run specification". When a "run specification" record is added the technology list will be displayed as a drop-down list containing all default technologies/programs. Select the appropriate choice.

Note: you cannot change your technology choice after you have saved the "run specification" record. However, after saving the record, you can edit the technology description and edit its underlying data and/or copy the edited technology to another "run specification" record.

End-use sector - Identifies the appropriate end-use sector for the "run specification" record. The selection determines what set of economic sector distribution factors you will have access to in the "run inputs" screen.

User name - User provided name for reference purposes only.

Date - User provided date for reference purposes only.

Last run time - Indicates the time the record impacts were last evaluated.

Last run date - Indicates the date the record impacts were last evaluated.

If a new "run database" has been newly created, it will appear without any "run specification" records. Click the "Add" button to add a new record then fill in the cells. All cells except user name and date must be specified. Select "Save" to save any new records or changes to existing "run specification" records.

To access the underlying economic and technical data of the "run specification" record, select the "Edit run inputs" button and review/edit the data as needed.

When all data have been specified the user should select "Compute program impacts" to do the actual calculations and display the results. Note that only those "run specification" records that have "Execute run" checked will be included in the calculation process and displayed in the results screen. If there are no changes since the last calculations were run and the user simply wants to review the results then select the "View program impacts" button.

\subsection{Technology Data}

The technology data spreadsheet is used to specify the incremental programmatic impacts on capital cost, installation cost, energy or resource cost, O\&M cost, and energy or resource savings. The appropriate units for each are displayed in the row headings. Note that all data are specific to the "run specification" described in the drop-down list at the top of the screen. Furthermore, the rows that are displayed in the spreadsheet are dependent on the "end-use sector" that is selected for the "run specification". To see other technology data select a different "run specification" record at the top of the screen.

Add technology to list of default technologies - Enables the user to add a technology to the "default " technology list. This feature allows the user to establish customized versions of a technology that can then be used repeatedly when adding new "run specification” records. More specifically, the user may have a particular set of technology data and years that are not currently represented in the "default" technology list. To create a new "default” technology simply select an existing "default” technology, modify its data accordingly, save any changes, then select the "Add technology to list of default technologies" pop-up choice. You would then see a new "Add technology" screen appear in which you enter a unique technology name where requested then select "Add" and "Close". At this point you can return to the "run specification" screen and if you add new "run specification" records the newly created technology will appear in the drop-down list of "default" technologies. 


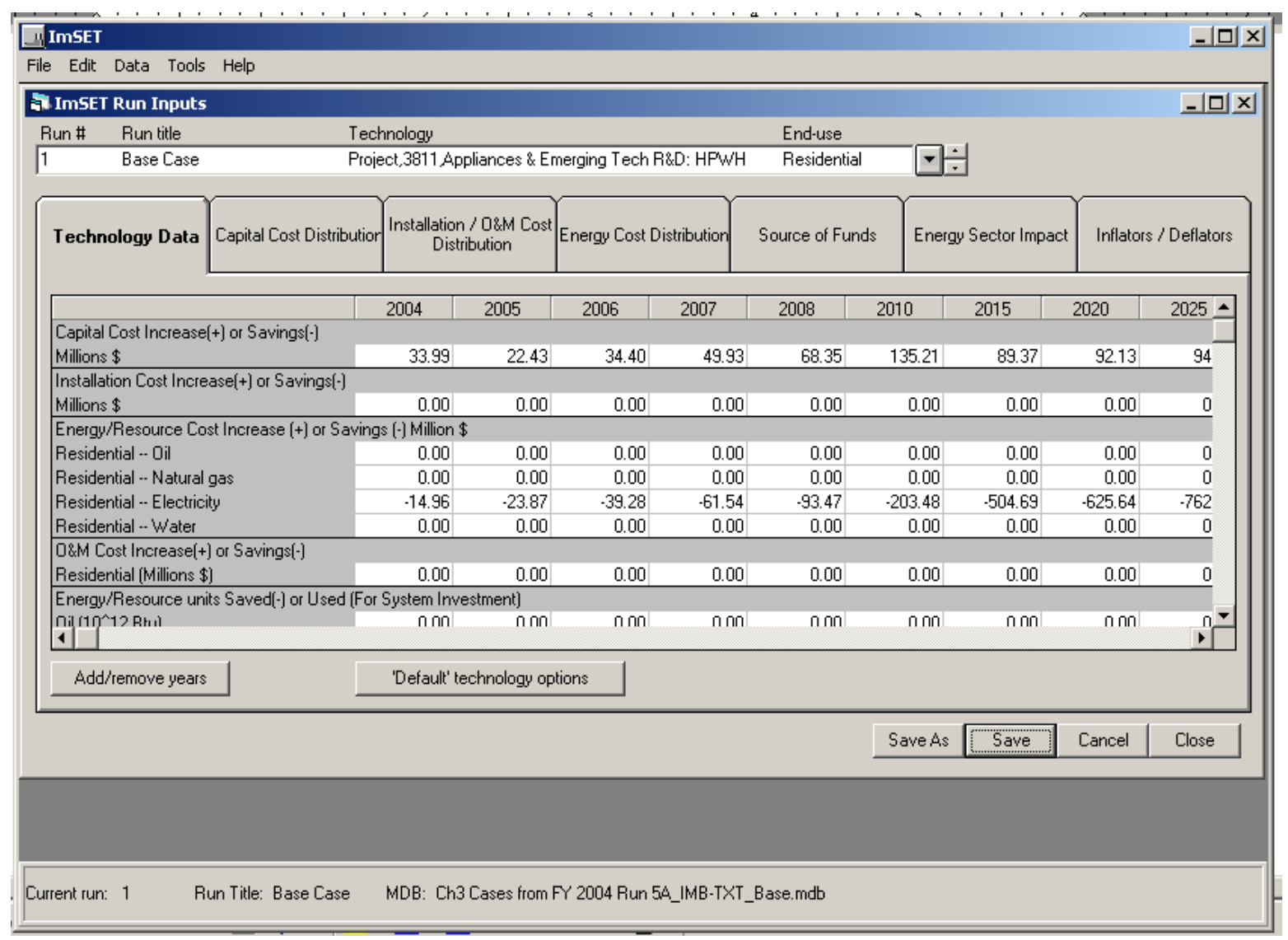

Figure 5-4. Technology Spreadsheet

\subsubsection{Technology Data}

The technology data spreadsheet is used to specify the incremental programmatic impacts on capital cost, installation cost, energy or resource cost, O\&M cost, and energy or resource savings. The appropriate units for each are displayed in the row headings. Note that all data are specific to the "run specification" described in the drop-down list at the top of the screen. Furthermore, the rows that are displayed in the spreadsheet are dependent on the "end-use sector" that is selected for the "run specification." To see other technology data select a different "run specification" record at the top of the screen.

The data on the technology data screen can be input or edited by hand. The years covered by the scenario also can be adjusted. Note that all costs or savings are considered to relate to differences from the conventional competing technology. For example, in example shown in Figure 5.4, the technology costs the economy an additional \$33.99 million in investment during the year 2004. The annual level energy and water impact in the same year is \$14.96 million saved in electricity, and no change to oil, natural gas, or water use, no change to non-energy operating costs. The energy, water, and operating cost savings are annual levels in the year shown that depend on cumulative investments. The capital costs are the cash investments in the year shown. This accounting is required by the input-output model's requirements for annual cash flow.

The following are some key functions: 
Advanced technology options - Enables the user to add a technology to the "default" technology list and/or delete technologies from the "default" technology list. This feature allows the user to establish customized versions of a technology that can then be used repeatedly when adding new "run specification” records.

Add/remove years - Enables the user to add and/or remove years from the currently displayed "run specification".

Note: The choices only affect the currently displayed "run specification”. Before "runs” can be processed all "run specifications" must have the same set of years.

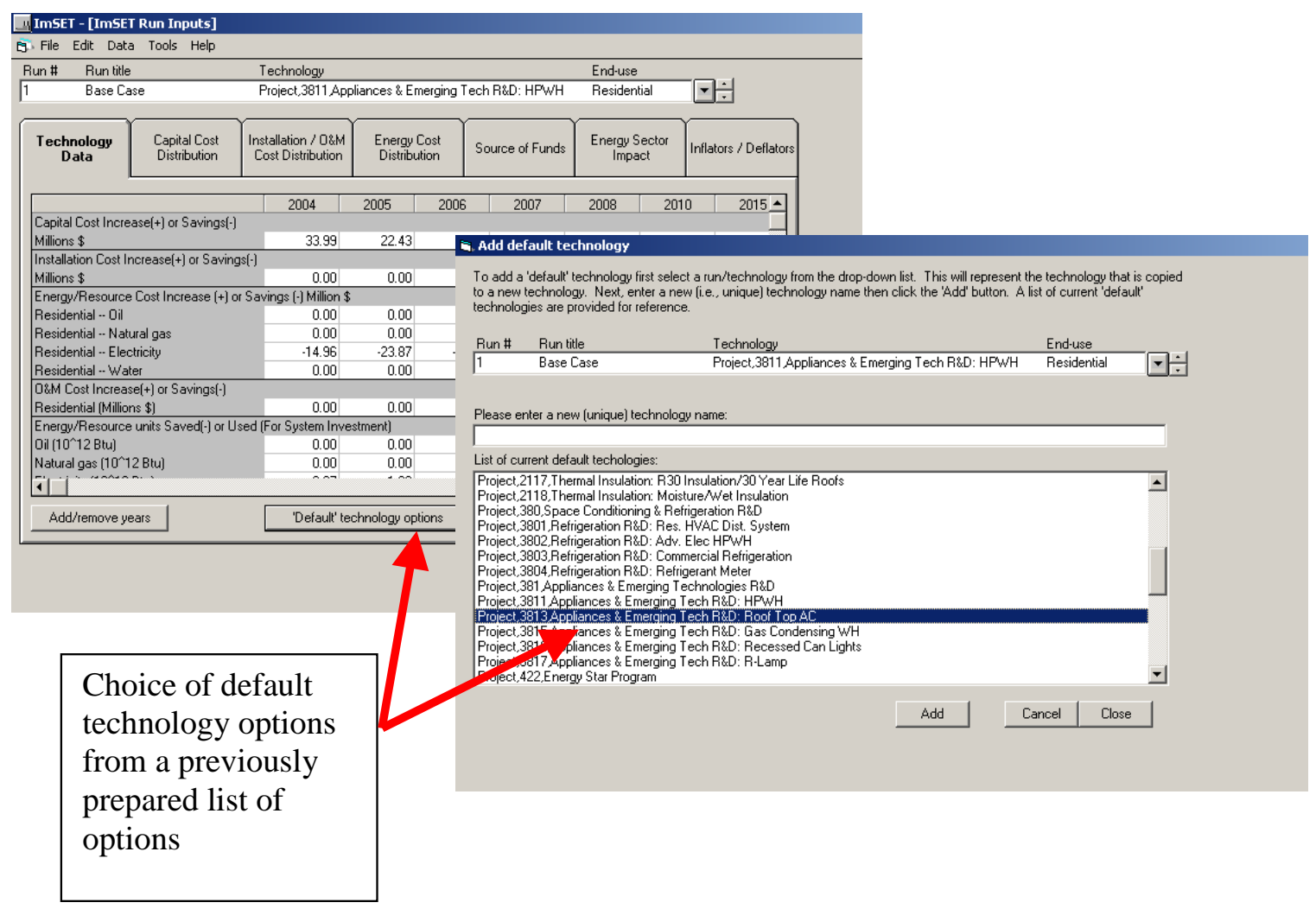

Figure 5-5. Adding to the Technology Options

\section{Changing the default technology options}

Add technology to list of default technologies - Enables the user to add a technology to the "default" technology list. This feature allows the user to establish customized versions of a technology that can then be used repeatedly when adding new "run specification” records. More specifically, the user may have a particular set of technology data and years that are not currently represented in the "default" technology list. To create a new "default" technology simply select an existing "default” technology, modify its data accordingly, save any changes, then select the "Add technology to list of default technologies" pop-up choice. The user would then see a new "Add technology" screen appear in which he enters a unique technology name where requested, then select s "Add" and "Close". At this point return to the "run specification" screen. If the user adds new "run specification” records, the newly created technology will appear in the drop-down list of "default" technologies. 
Delete technology from list of default technologies - Enables the user to delete technologies from the "default" technology list. Note: the deletion of a technology only affects the "default" technology list and in no way deletes records from the user database file.

\subsubsection{Capital cost distribution}

Enter the percentage values (enter $50 \%$ as 50 ) that represent the distribution of capital cost premiums for the applicable sectors. The total of all values must equal 100. In the example shown in Figure 5.6, $100 \%$ of the capital cost premium is spent on household appliances, not elsewhere classified (Sector 61).

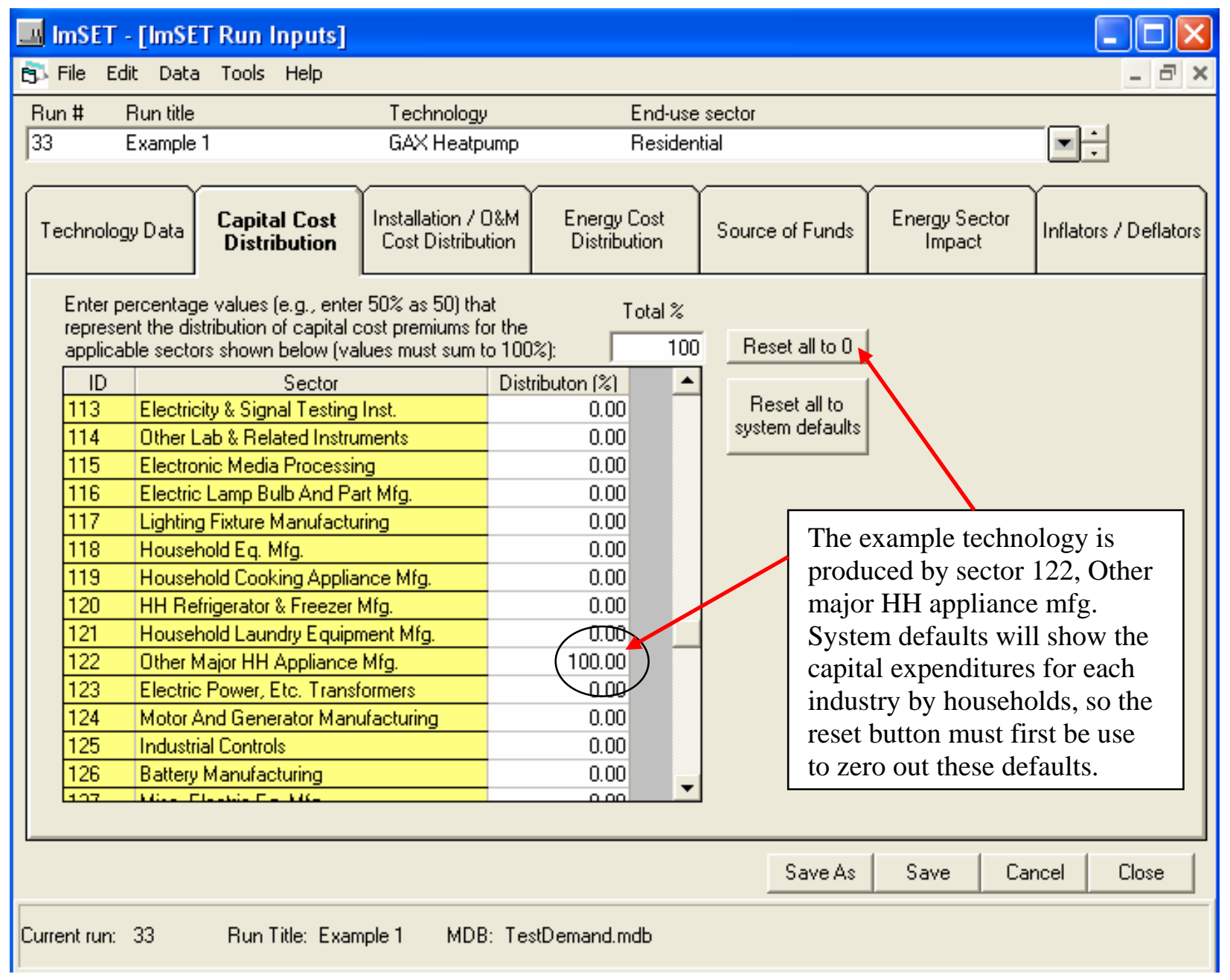

Figure 5-6. Allocation of Capital Cost

\subsubsection{Energy and Water Cost Savings Distribution}

Enter the percentage values (enter $50 \%$ as 50 ) that represent the distribution of energy and water cost savings for the applicable sectors. The total of all values must equal 100. Note that the sectors shown will be dependent on the end-use sector targeted by the technology/program. For example, commercial enduse sectors will be the sectors numbered 82 through 95, industrial end-use sectors will be sectors 1 through 72, transportation will be sectors 73 through 77. Residential end-use technology/program cost savings will all impact final demand; thus, there will be no industry sectors to specify. 
Energy savings in commercial buildings can be allocated to sectors 82-95 in proportion to each sector's likely purchase of each fuel; e.g., if Sector 82, Wholesale and Retail Trade, purchased 30.00 percent of baseline electricity purchased in sectors 82-95, Sector 82 likely would have seen 30.00 percent of the savings as well. The user is free to change these proportions. The model also includes water cost savings. This is important for some water-using equipment such as laundry equipment.

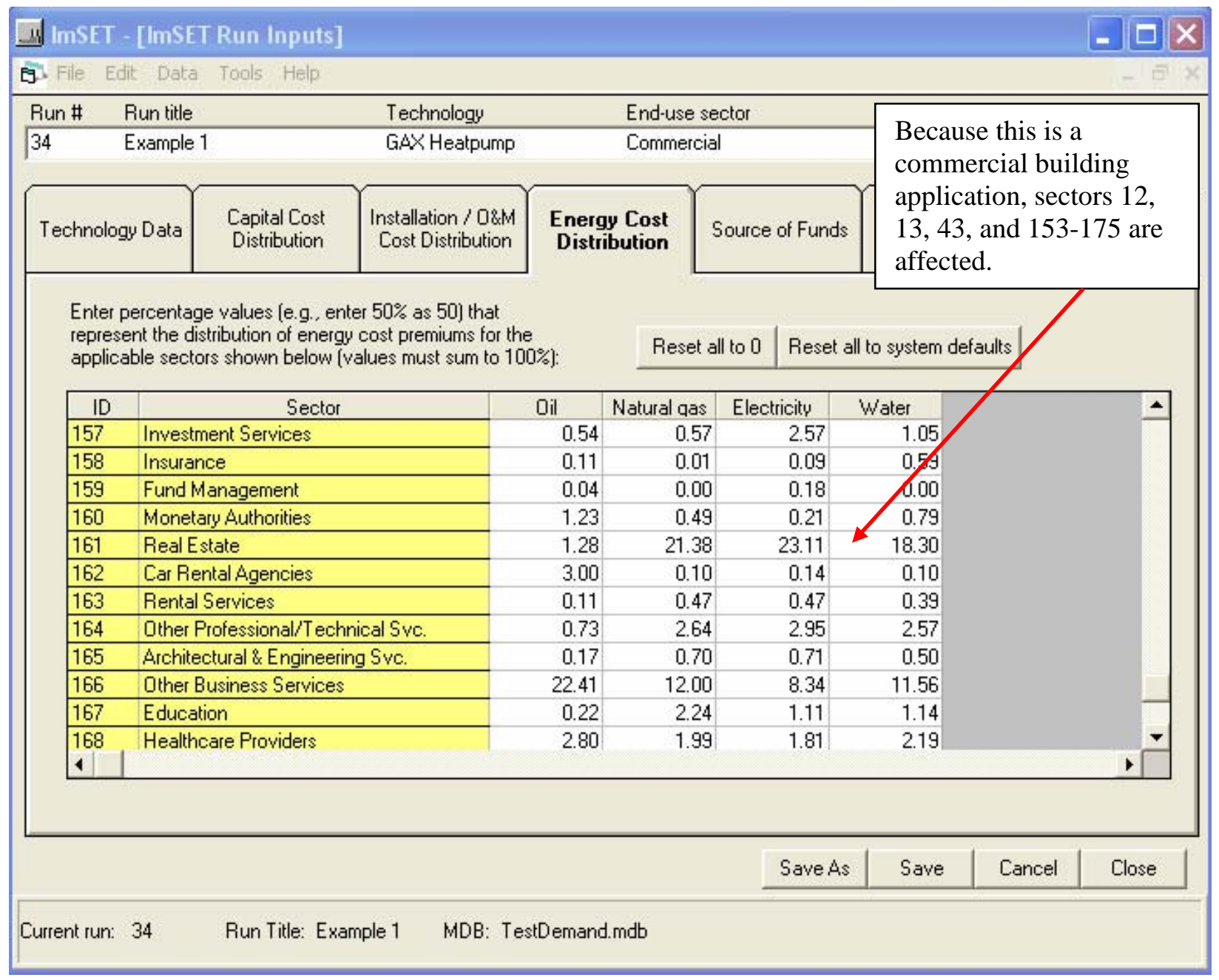

Figure 5-7. Energy/Water Cost Savings Distribution Across Sectors

\subsubsection{Allocation of O\&M Costs}

Default allocations for each of the end-use sectors currently are shown on the page, but these can be modified to suit the user. Operating and maintenance activities, if they are purchased from one of the sectors shown, would probably all be spent on personal services. Distributions for the other end-use sectors were calculated by summing the purchases from these four sectors then dividing each sector's sales by the total. The modest activities that transportation services sell to the commercial sector were deemed to be activities other than O\&M, so this cell is specified as zero in default.

In the previous version of the model, these costs/savings were embedded in the use table as interindustry transactions. With 188 sectors, this would generate many changes to the model, and would likely eventually cause an excess of changes to the FORTRAN program (the current limit is 350). Accordingly, 
rather than construct a distribution of O\&M expenditures for each of the end-use sectors, we treat these changes as applying to final demands. Thus at most, there will be four changes for O\&M costs or savings that are input to the calculator.

Sensitivity tests were run to see if this would make a substantial difference in the output of the model and we found the changes to be modest, in the extreme-in the thousandths of a percentage point for reasonable estimates of $\mathrm{O} \& \mathrm{M}$ costs/savings.

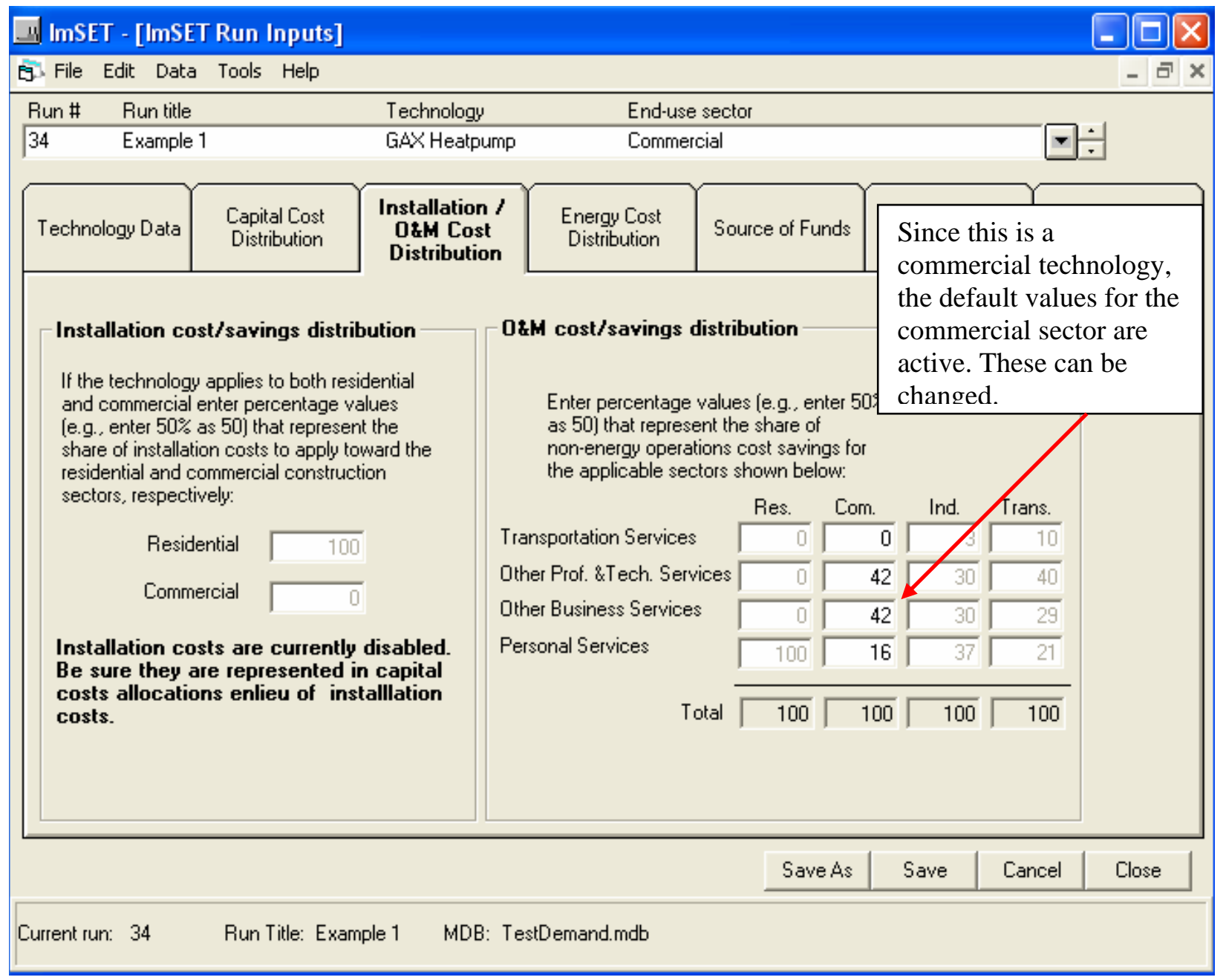

Figure 5-8. O\&M Cost Savings Distribution for Commercial Sector

\subsubsection{Source of Investment Funds}

Investment funds spent on energy-efficient equipment have an opportunity cost; that is, they would have been spent somewhere else in the domestic economy or overseas if they were not spent on energyefficient equipment. The source of funds sheet allows the user to specify the source of the funds used for investment. Enter the percentage values (e.g., enter 50\% as 50) that represent the share of investment funding provided by each applicable. The sum of the sector allocations does not need to equal $100 \%$, but if it does not, the model will allocate the remaining percentage to sum to $100 \%$ unless it is overridden, 
and will allocate spending reductions within the remainder using the average proportions in all final demand. However, even if all of the explicit shares are set to zero, each sector will have its spending reduced by the proportion it represents of all final demand unless the override box is checked. The override check box allows some or all of the opportunity cost of invested funds to not be counted against domestic final demand.

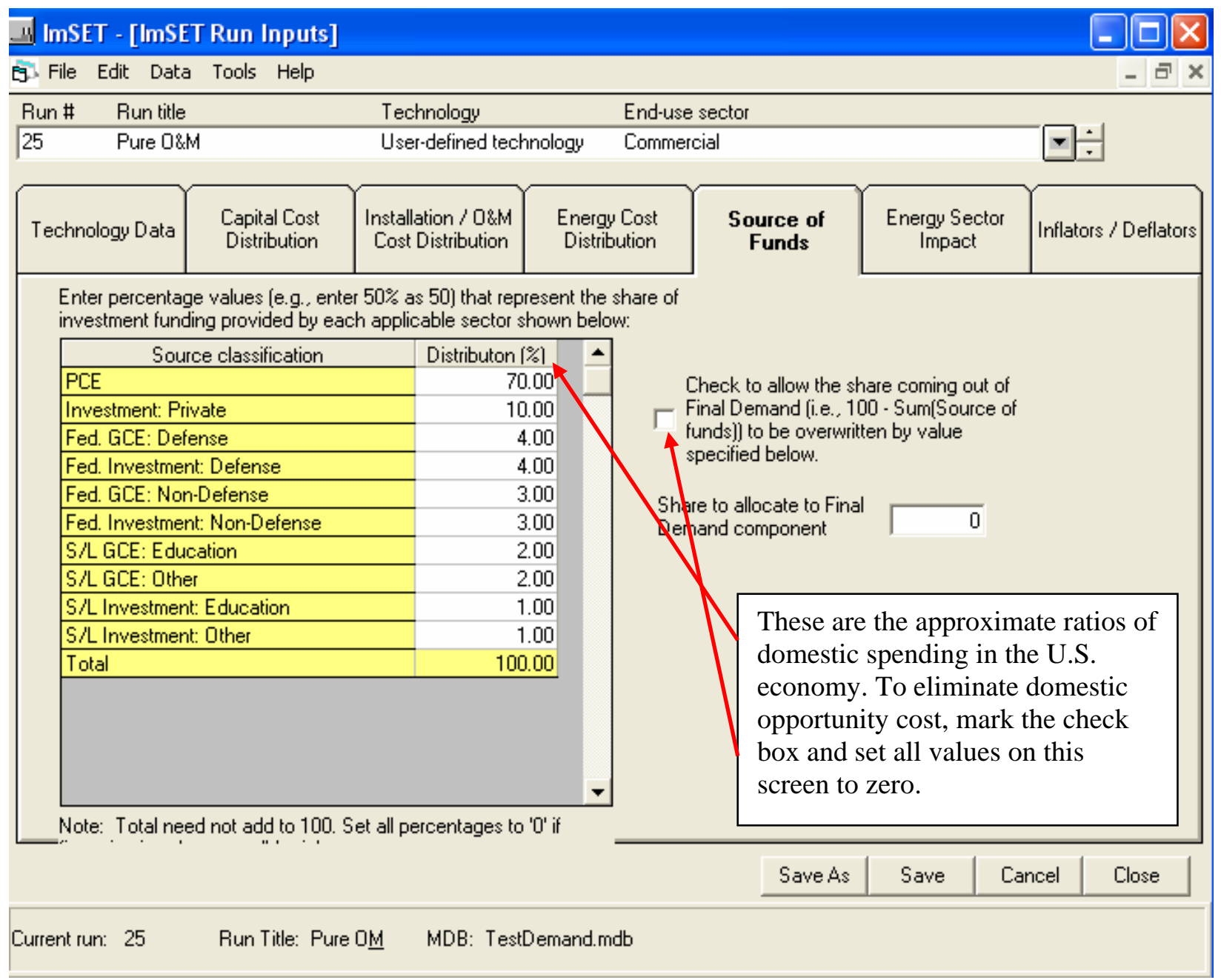

Figure 5-9. Opportunity Cost of Invested Funds

There are occasions when the user may not want to consider the opportunity cost of the funds used for investment. If, for example, only the impacts on a local region were being considered and the funds came from the national financial markets, then the local area might see the positive impact of the investment as well as any energy savings, but would not experience the costs to the national economy. These costs would be "somewhere else." Another reason might be if the displaced spending were somewhere else in the world and only the domestic impact was important. If opportunity cost of the investment funds is irrelevant to the analysis or the source of funds is "magic," then all values can be set to 0 . To do this, set all of the sectors to zero, check the check box, and then set the remainder box to zero as well. The most common assumption is that investment funds will come proportionately from all domestic spending. 


\subsubsection{Energy Sector Impact}

This screen allows the user to specify how the technology/program impacts will affect the investment in the energy sector, in particular the electricity and industries. Significant energy savings might allow electricity and natural gas production, transmission, and distribution companies to reduce the amount of investment that they undertake, which frees up investment capital for the general economy (this is the mirror image of the "source of funds" allocation). If reductions in investment occur due to the technology/program then enter "Yes" for the applicable question and enter any changes to load/capacity factors and costs as necessary. If either "Yes" is selected then enter where (percentage shares) investment dollars would be going to (what sectors would benefit) in the right hand box. In the example in Figure 5.9, the investment is proportionately distributed to the economy as a whole. Note that in this case the sum of those shares is handled the same way as the as the opportunity cost of invested funds. The "benefit" of investment savings need not remain in the region of interest.

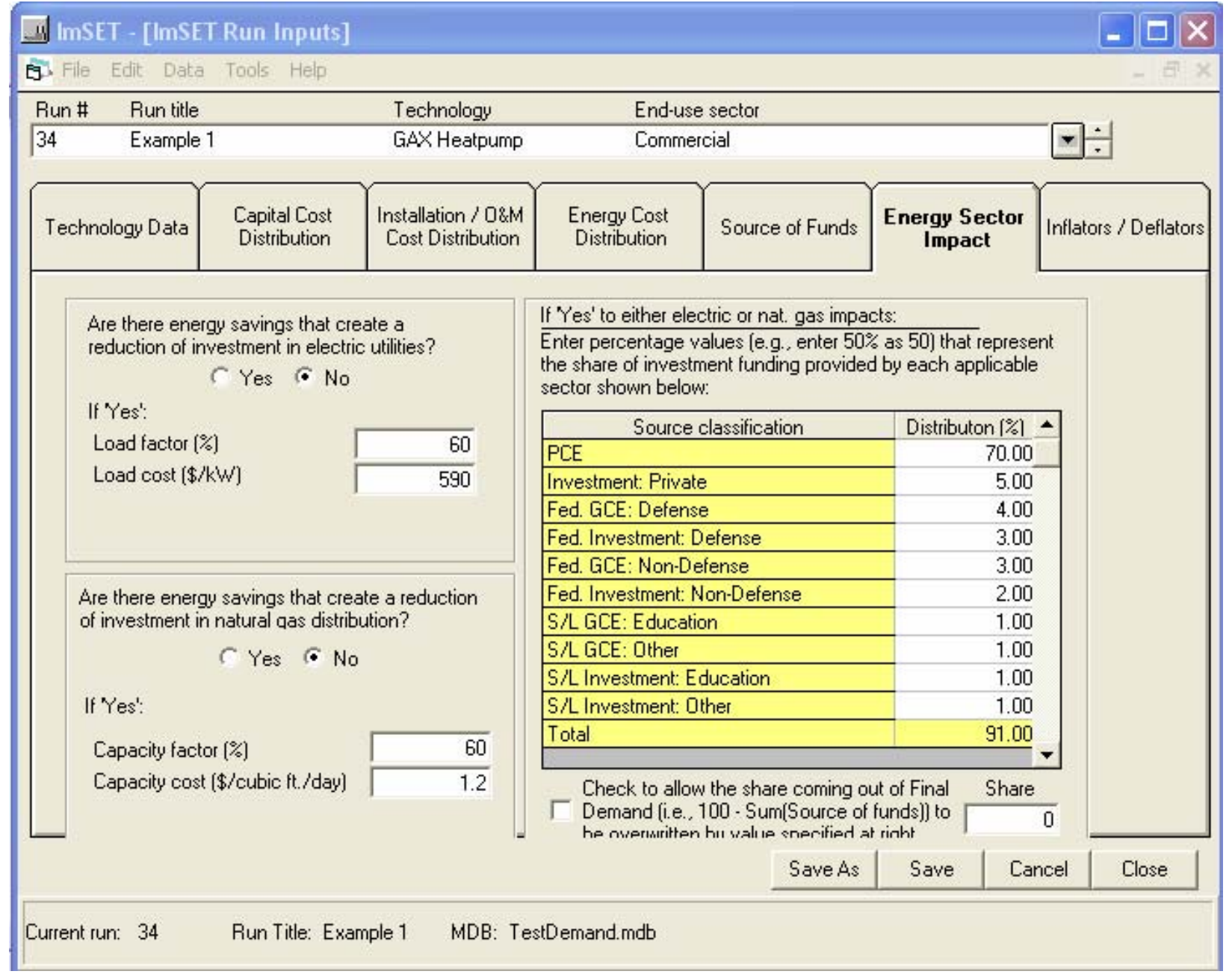

Figure 5-10. Impact of Energy Savings on Energy Sector Investments

\subsubsection{Inflators / Deflators}

The inflators/deflators page is designed to allow easy conversion of costs and savings to the appropriate year's dollars. The input-output table at the core of ImSET is in 1997 dollars, so inputs to the model need to be converted to a 1997 basis. In the example in Figure 5.10, capital costs and savings 
originally available to the analysts were expressed in 2000 dollars, which needed to be converted to 1997 dollars. This is the purpose of the deflators. On the other hand, for reporting purposes many users would like to see earnings numbers in some later year's constant dollars, not 1997. For example, in recent use of the model, results have been reported in constant 2002 dollars. This is the purpose of the inflators. Enter the appropriate inflators /deflators to use in the model. Note that capital cost deflators are used to adjust capital cost, installation costs, and utility impact costs to the base input-output year (1997). Operations cost deflators are used to adjust energy costs and O\&M costs to the base input-output year and to adjust the base input-output results for 'output' dollars back to the year assumed in the technology data. Both of these are based on Gross Domestic Product deflators. The inflator input is based on the appropriate year's Consumer Price Index and is used to adjust base input-output results for earnings to the technology data base year, or to some other year for reporting purposes.

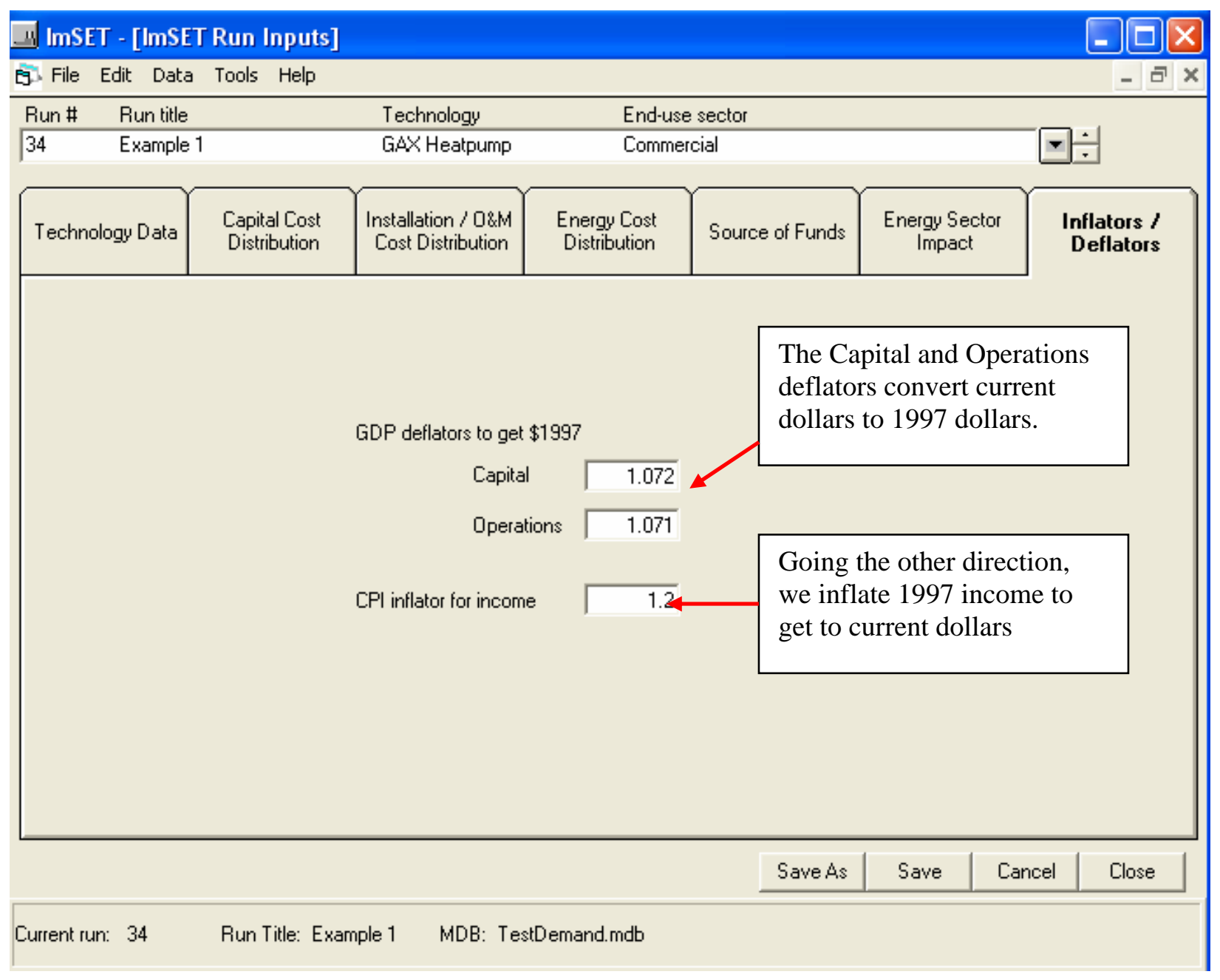

Figure 5-11. Assigning Inflators and Deflators

\subsection{Computing Program Impacts}

Selecting the "Compute program impacts" will run the computations for determining the impacts of the "run specifications". Only those records marked with "Execute run" will be processed. Before running 
computations the program checks for a common set of years between all technologies/programs. It will also test for conditions where there are no years represented.

With data integrity checks complete, the process loops through each "run scenario" and, in turn, creates an associated ASCII file of data that will be read by the ImSET model. The processing code (QMIO.EXE) is then called and when finished, the process retrieves the ASCII output file created by the model and parses and stores the results to the user database file. With that process complete, the ImSET tool opens the results screen and presents the calculated impacts in spreadsheet and graphical form.

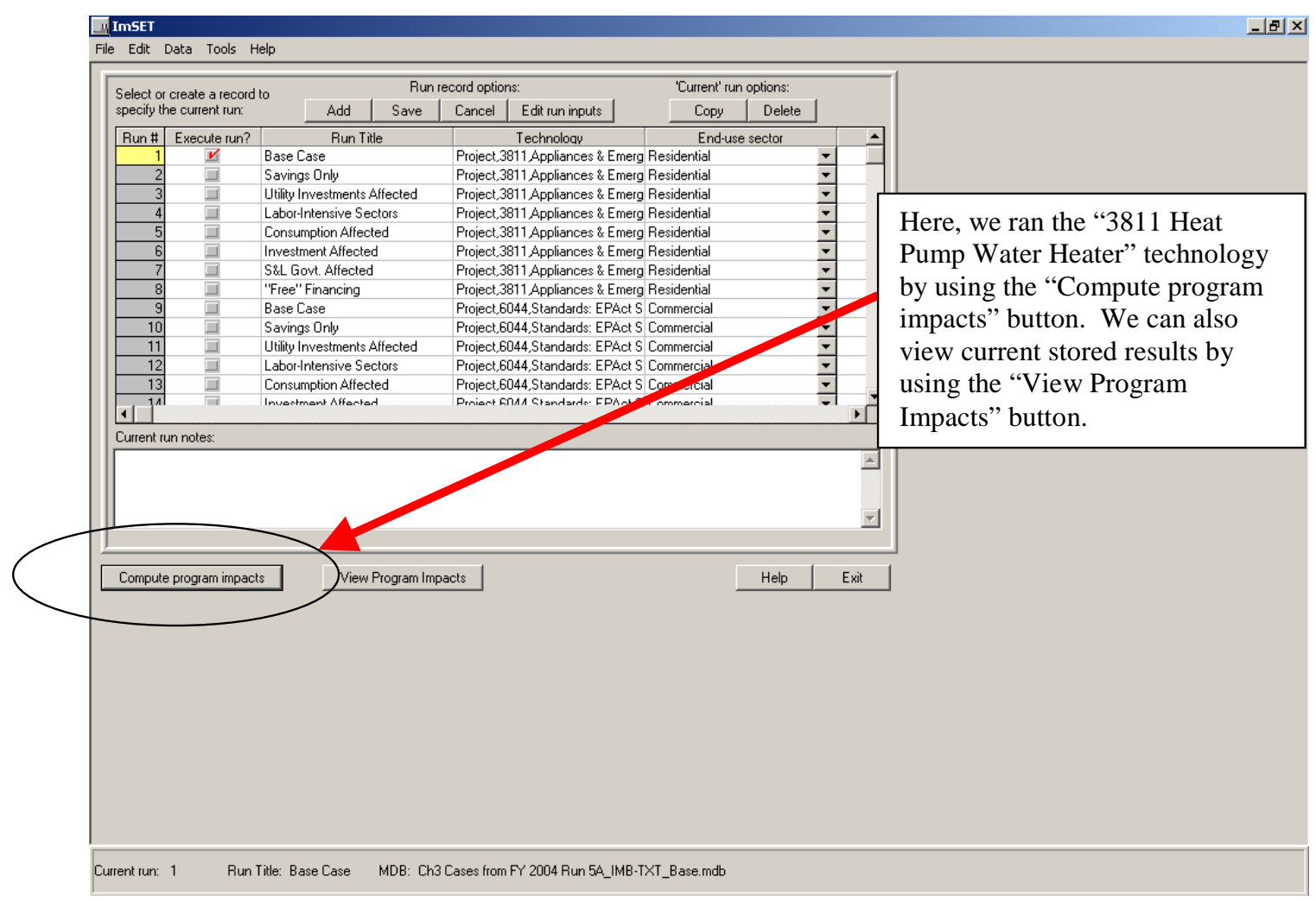

Figure 5-12. Running the ImSET Mode

\subsection{Viewing Program Impacts}

If the user wishes to view the last computed impacts without rerunning the calculations then he/she should select the "View program impacts" button. The results can be viewed in two display formats. The first will be in a spreadsheet form and second will be a graphical form. In either form the displayed data will be dependent on the "Impacts data type" choice that is available at the top of the screen. Additional options in this screen include printing the spreadsheet and all the data types and exporting all impact data types to an Excel spreadsheet file. The name assigned to the Excel file will be the same as the user database file. The graphical portion of the "Results" screen offers the user a rich set of options for changing the graph displayed. The user should feel free to "play" with the different option available including printing the graph to file or printer.

\section{Results presentation}


There are two styles of results presentation. The first style shows the results in tabular form and in graphical form presented in individual "tab" frames. Use the "Results type" drop-down list at the top of the screen to select the individual results data that are available. Select the "Print" button to print these as they appear on the screen. In this presentation style the user has liberty to access the graph properties pages to customize and print the graph in a customized fashion. The user also has the option of selecting which results to graph by selecting the appropriate button. The second results presentation is made available by clicking the "Reports manager" button in the "Results" screen. The "Report Manager" screen will present a spreadsheet contained all available reports. Each of these types of reports will display both a graph (Figure 5.13) and cross-tabbed table (Figure 5.14) of the selected results. This presentation of the results enables the user to export the results to a host of file formats. Data also may be exported and stored in Excel spreadsheet format for additional manipulation.

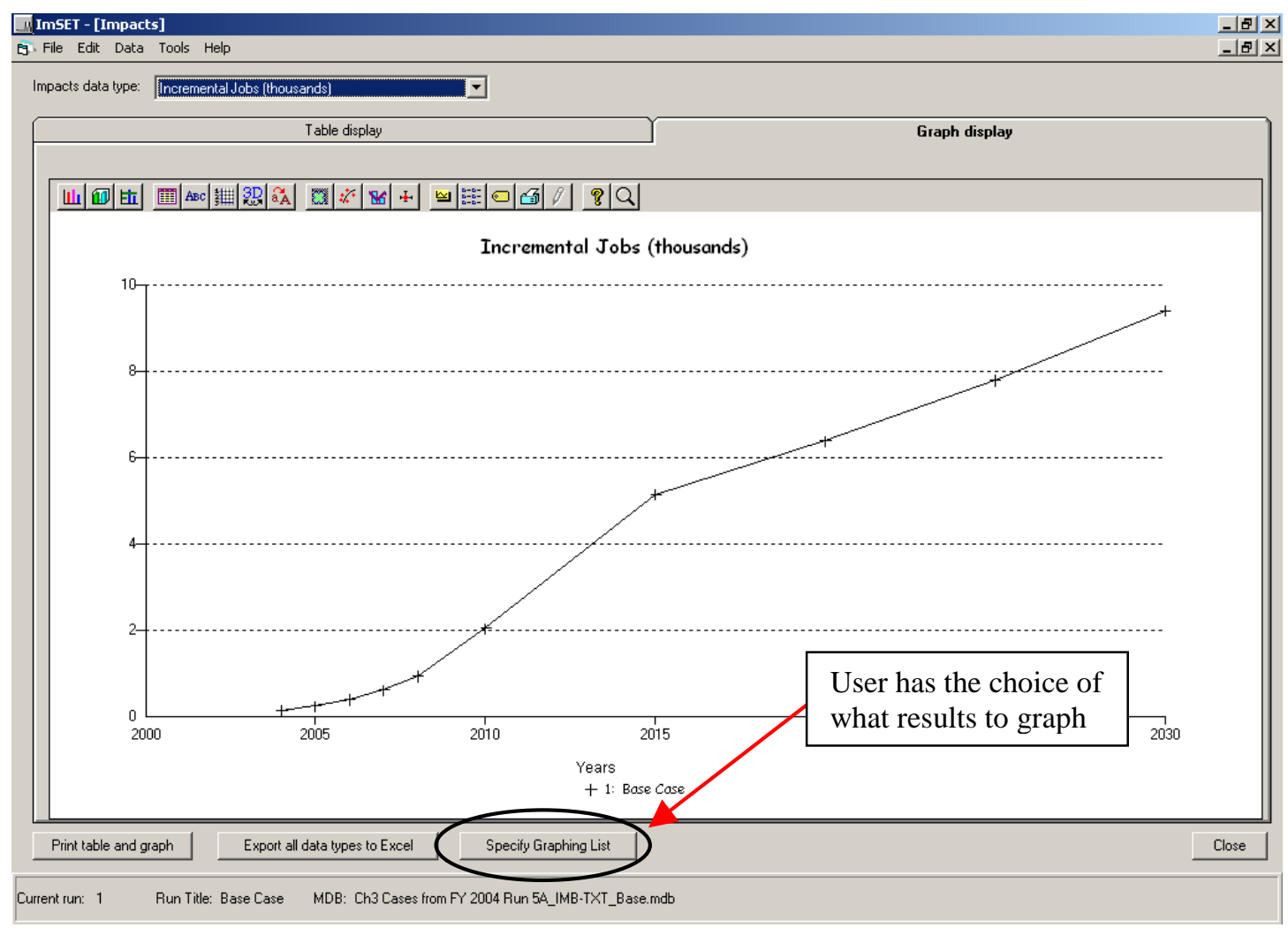

Figure 5-13. Report Manager Screens for Output (Graphical Display) 


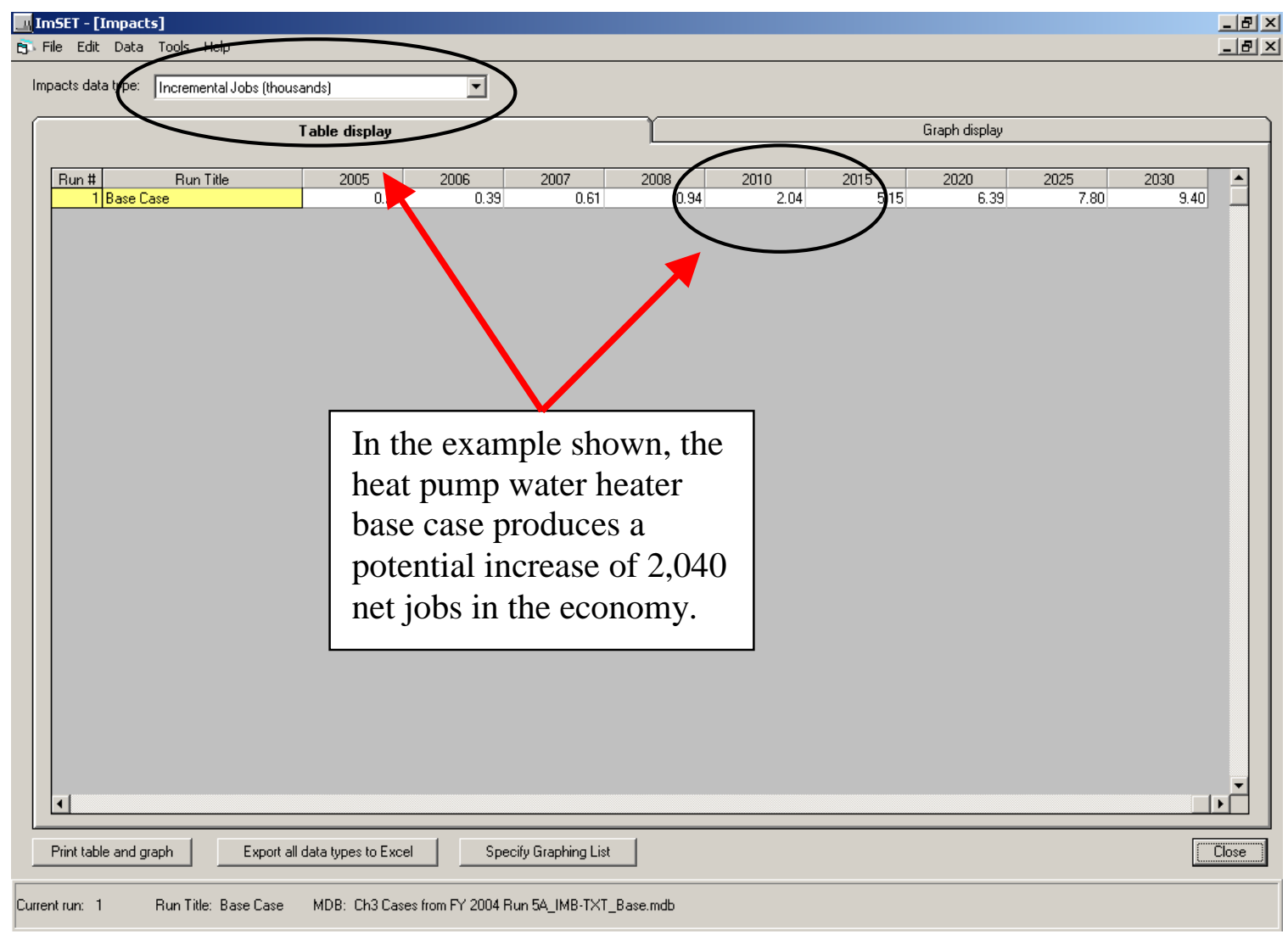

Figure 5-14 Report Manager Screens for Output (Table Display) 


\subsection{References}

Anderson, D.M., D.B. Belzer, K.A. Cort, J.A. Dirks, D.B. Elliott, D.J. Hostick, and M.J. Scott. 2003. Methodological Framework for Analysis GPRA Metrics: Application to FY04 Projects in BT and WIP. PNNL-14231. Pacific Northwest National Laboratory, Richland, Washington.

Berck, Peter and Sandra Hoffmann. 2002. "Assessing the Employment Impacts of Environmental and Natural Resource Policy,” Environmental and Resource Economics. 22: 133-156.

Economic Research Associates. 2005. Modeling the Economic Impacts of National and State Energy Policy Scenarios. A Working Paper for the U.S. PIRG Education Fund.

Elliott, D.B., Anderson, D.M., Belzer, D.B., Cort, K.A., Dirks, J.A., and Hostick D.J.: 2004, Methodological Framework for Analysis of Buildings-Related Programs: GPRA Metrics Effort, PNNL-14697, Richland, WA, Pacific Northwest National Laboratory.

Energy Information Administration (EIA). 1996. Natural Gas 1996: Issues and Trends. DOE/EIA0560(96). Energy Information Administration, U.S. Department of Energy, Washington, D.C.

Energy Information Administration (EIA). 1997. Annual Energy Outlook 1998. DOE/EIA-0383(98). Energy Information Administration, U.S. Department of Energy, Washington, D.C.

Geller, H., J. DeCicco, and S. Laitner. 1992. Energy Efficiency and Job Creation: The Employment and Income Benefits from Investing in Energy Conserving Technologies. Washington, D.C.: The American Council for an Energy-Efficient Economy.

Kaiser, M. J. and A. G. Pulsipher. 2003. "A generalized modeling framework for public benefit program valuation,” Energy: The International Journal. 28 (6): 519-538.

Kaiser, M. J., A. G. Pulsipher, and R. H. Baumann. 2004. “The potential economic and Environmental impact of a Public Benefit Fund in Louisiana,” Energy Policy. 32 (2): 191-206.

Kaiser, M. J., W. O. Olatubi, and A. G. Pulsipher. 2005. "Economic, energy, and environmental impact of the Louisiana Energy Fund,” Energy Policy. 33 (7): 873-883.

Laitner, S. 1992. "Missouri’s Two-Percent Solution: Energy Efficiency for Economic Development and the Environment.” Summary Report. Eugene, Oregon: Economic Research Associates.

Lawson, Ann M., Kurt S. Bersani, Mahnaz Fahim-Nader, and Jiemin Guo. 2002. "Benchmark InputOutput Accounts of the U. S. Economy, 1997,” Survey of Current Business, December, pp. 19117.

Moscovitch, E. 1994. "DSM in the Broader Economy: The Economic Impacts of Utility Efficiency Programs,” The Electricity Journal, 7(4): 14-28. 
Nayak, Navin. 2005. Redirecting America's Energy: The Economic and Consumer Benefits of Clean Energy Policies. U. S. PIRG Education Fund, Washington, D. C. Available at: http://www.uspirg.org, accessed 5 May 2005.

Scott, M. J., D. J. Hostick, and D. B. Belzer. 1998. ImBuild: Impact of Building Energy Efficiency Programs. PNNL-11884. Pacific Northwest National Laboratory, Richland, Washington.

Scott M. J., Roop J. M., and Schultz R. W. 2002. "ImBuild II: Impact of Technologies on Energy Efficiency Programs". PNNL-13926. Pacific Northwest National Laboratory, Richland, Washington.

Solow, R. M. 1994. “DSM: Not for Jobs, but on its Merits.” The Electricity Journal, 7(4):80-81.

Xie, Jian. 2000. “An Environmentally Extended Social Accounting Matrix: Conceptual

Framework and Application to Environmental Policy Analysis in China." Environmental and Resource Economics, 16: 391-406. 


\section{Appendix A. Base Cases for Energy Efficiency Technologies}

\section{Heat Pump Water Heater Base Case}

\begin{tabular}{|c|c|c|c|c|c|c|c|c|c|c|}
\hline \multirow[t]{2}{*}{ Base Case } & \multicolumn{10}{|c|}{ Heat Pump Water Heater } \\
\hline & 2005 & 2006 & 2007 & 2008 & 2009 & 2010 & 2015 & 2020 & 2025 & 2030 \\
\hline \multicolumn{11}{|c|}{ Capital and Installation Cost Increase (+) or Savings(-) Million \$ } \\
\hline & 141.66 & 143.83 & 89.37 & 89.87 & 90.70 & 91.84 & 0.01 & 0.01 & 0.01 & 0.01 \\
\hline \multicolumn{11}{|c|}{ Energy/Resource Cost Increase (+) or Savings (-) Million \$ } \\
\hline Residential -- Oil & 0 & 0 & 0 & 0 & 0 & 0 & 0 & 0 & 0 & 0 \\
\hline $\begin{array}{l}\text { Residential -- Natural } \\
\text { gas }\end{array}$ & 0 & 0 & 0 & 0 & 0 & 0 & 0 & 0 & 0 & 0 \\
\hline \multicolumn{11}{|l|}{ Residential -- } \\
\hline Electricity & -23.87 & -39.28 & -61.54 & -93.47 & -133.97 & -203.48 & -504.69 & -625.64 & -762.9 & -919.02 \\
\hline Residential -- Water & 0 & 0 & 0 & 0 & 0 & 0 & 0 & 0 & 0 & 0 \\
\hline Commercial -- Oil & 0 & 0 & 0 & 0 & 0 & 0 & 0 & 0 & 0 & 0 \\
\hline $\begin{array}{l}\text { Commercial -- Natural } \\
\text { gas }\end{array}$ & 0 & 0 & 0 & 0 & 0 & 0 & 0 & 0 & 0 & 0 \\
\hline $\begin{array}{l}\text { Commercial -- } \\
\text { Electricity }\end{array}$ & 0 & 0 & 0 & 0 & 0 & 0 & 0 & 0 & 0 & 0 \\
\hline ercial -- Water & 0 & 0 & 0 & 0 & 0 & 0 & 0 & 0 & 0 & 0 \\
\hline Industrial -- Oil & 0 & 0 & 0 & 0 & 0 & 0 & 0 & 0 & 0 & 0 \\
\hline $\begin{array}{l}\text { Industrial -- Natural } \\
\text { gas }\end{array}$ & 0 & 0 & 0 & 0 & 0 & 0 & 0 & 0 & 0 & 0 \\
\hline Industrial -- Electricity & 0 & 0 & 0 & 0 & 0 & 0 & 0 & 0 & 0 & 0 \\
\hline Industrial -- Water & 0 & 0 & 0 & 0 & 0 & 0 & 0 & 0 & 0 & 0 \\
\hline Transportation -- Oil & 0 & 0 & 0 & 0 & 0 & 0 & 0 & 0 & 0 & 0 \\
\hline $\begin{array}{l}\text { Transportation -- } \\
\text { Natural gas }\end{array}$ & 0 & 0 & 0 & 0 & 0 & 0 & 0 & 0 & 0 & 0 \\
\hline $\begin{array}{l}\text { Transportation -- } \\
\text { Electricity }\end{array}$ & 0 & 0 & 0 & 0 & 0 & 0 & 0 & 0 & 0 & 0 \\
\hline $\begin{array}{l}\text { Transportation -- } \\
\text { Water }\end{array}$ & 0 & 0 & 0 & 0 & 0 & 0 & 0 & 0 & 0 & 0 \\
\hline \multicolumn{11}{|c|}{ or Savings (-) (Million \$) } \\
\hline Residential & 0 & 0 & 0 & 0 & 0 & 0 & 0 & 0 & 0 & 0 \\
\hline Comı & 0 & 0 & 0 & 0 & 0 & 0 & 0 & 0 & 0 & 0 \\
\hline Indus & 0 & 0 & 0 & 0 & 0 & 0 & 0 & 0 & 0 & 0 \\
\hline Transportation & 0 & 0 & 0 & 0 & 0 & 0 & 0 & 0 & 0 & 0 \\
\hline \multicolumn{11}{|c|}{ Energy/Resource Units Saved (-) or Used (For System Investment) } \\
\hline Oil $\left(10^{12} \mathrm{Btu}\right)$ & 0 & 0 & 0 & 0 & 0 & 0 & 0 & 0 & 0 & 0 \\
\hline Natural gas $\left(10^{12}\right.$ Btu) & 0 & 0 & 0 & 0 & 0 & 0 & 0 & 0 & 0 & 0 \\
\hline Electricity $\left(10^{12} \mathrm{Btu}\right)$ & -1.09 & -1.78 & -2.81 & -4.27 & -6.12 & -9.3 & -22.93 & -28.22 & -34.18 & -40.9 \\
\hline Water (109 Gallons) & 0 & 0 & 0 & 0 & 0 & 0 & 0 & 0 & 0 & 0 \\
\hline
\end{tabular}




\section{EPACT Standards Base Case}

\begin{tabular}{|c|c|c|c|c|c|c|c|c|c|c|}
\hline \multirow[t]{2}{*}{ Base Case } & \multicolumn{10}{|c|}{ EPACT Standards } \\
\hline & 2005 & 2006 & 2007 & 2008 & 2009 & 2010 & 2015 & 2020 & 2025 & 2030 \\
\hline \multicolumn{11}{|c|}{ Capital and Installation Cost Increase (+) or Savings (-) Million \$ } \\
\hline & & & & & $\$ 1,066$. & $\$ 1,036$. & & & & \\
\hline & $\$ 198.2$ & $\$ 205.4$ & $\$ 189.0$ & $\$ 971.2$ & 6 & 1 & $\$ 1,331.9$ & $\$ 1,424.3$ & $\$ 574.7$ & $\$ 606.7$ \\
\hline \multicolumn{11}{|c|}{ Energy/Resource Cost Increase (+) or Savings (-) Million \$ } \\
\hline Residential -- Oil & 0 & 0 & 0 & 0 & 0 & 0 & 0 & 0 & 0 & 0 \\
\hline $\begin{array}{l}\text { Residential -- } \\
\text { Natural gas }\end{array}$ & 0 & 0 & 0 & 0 & 0 & 0 & 0 & 0 & 0 & 0 \\
\hline $\begin{array}{l}\text { Residential -- } \\
\text { Electricity }\end{array}$ & 0 & 0 & 0 & 0 & 0 & 0 & 0 & 0 & 0 & 0 \\
\hline Residential -- Water & 0 & 0 & 0 & 0 & 0 & 0 & 0 & 0 & 0 & 0 \\
\hline Commercial -- Oil & 0 & 0 & 0 & 0 & 0 & 0 & 0 & 0 & 0 & 0 \\
\hline Commercial -- & & & & & & & & & & \\
\hline $\begin{array}{l}\text { Natural gas } \\
\text { Commercial -- }\end{array}$ & $\$ 0.0$ & $\$ 0.0$ & $\$ 0.0$ & $-\$ 4.9$ & $-\$ 10.4$ & $-\$ 16.0$ & $-\$ 43.5$ & $-\$ 74.2$ & $-\$ 100.5$ & $-\$ 127.9$ \\
\hline Electricity & $-\$ 21.5$ & $-\$ 43.9$ & $-\$ 64.4$ & $-\$ 165.1$ & $-\$ 275.5$ & $-\$ 382.6$ & $-\$ 1,068.5$ & $-\$ 1,792.1$ & $-\$ 2,072.8$ & $-\$ 2,364.7$ \\
\hline $\begin{array}{l}\text { Commercial -- } \\
\text { Water }\end{array}$ & 0 & 0 & 0 & 0 & 0 & 0 & 0 & 0 & 0 & 0 \\
\hline Industrial -- Oil & 0 & 0 & 0 & 0 & 0 & 0 & 0 & 0 & 0 & 0 \\
\hline $\begin{array}{l}\text { Industrial -- Natural } \\
\text { gas }\end{array}$ & 0 & 0 & 0 & 0 & 0 & 0 & 0 & 0 & 0 & 0 \\
\hline $\begin{array}{l}\text { Industrial -- } \\
\text { Electricity }\end{array}$ & 0 & 0 & 0 & 0 & 0 & 0 & 0 & 0 & 0 & 0 \\
\hline Industrial -- Water & 0 & 0 & 0 & 0 & 0 & 0 & 0 & 0 & 0 & 0 \\
\hline tation -- Oil & 0 & 0 & 0 & 0 & 0 & 0 & 0 & 0 & 0 & 0 \\
\hline $\begin{array}{l}\text { Transportation -- } \\
\text { Natural gas }\end{array}$ & 0 & 0 & 0 & 0 & 0 & 0 & 0 & 0 & 0 & 0 \\
\hline $\begin{array}{l}\text { Transportation -- } \\
\text { Electricity }\end{array}$ & 0 & 0 & 0 & 0 & 0 & 0 & 0 & 0 & 0 & 0 \\
\hline $\begin{array}{l}\text { Transportation -- } \\
\text { Water }\end{array}$ & 0 & 0 & 0 & 0 & 0 & 0 & 0 & 0 & 0 & 0 \\
\hline O\&M Cost Increa & +) or Sa & vings $(-$ & ) (Mill & ion \$) & & & & & & \\
\hline Residenti & 0 & 0 & 0 & 0 & 0 & 0 & 0 & 0 & 0 & 0 \\
\hline Commercial & 0 & 0 & 0 & 0 & 0 & 0 & 0 & 0 & 0 & 0 \\
\hline Industrial & -2.38 & -2.55 & -2.78 & -3 & -3.12 & -3.18 & -3.87 & -6.01 & -5.88 & -6.25 \\
\hline Transportation & 0 & 0 & 0 & 0 & 0 & 0 & 0 & 0 & 0 & 0 \\
\hline Energy/Resource Un & s Saved & (-) or I & Jsed (F & or Sys & tem Inv & estment & & & & \\
\hline Oil (10 $12 \mathrm{Btu})$ & 0 & 0 & 0 & 0 & 0 & 0 & 0 & 0 & 0 & 0 \\
\hline Natural gas $\left(10^{12}\right.$ & & & & & & & & & & \\
\hline Btu) & 0 & 0 & 0 & -0.9 & -1.9 & -2.9 & -7.9 & -13 & -17.3 & -21.6 \\
\hline Electricity $\left(10^{12} \mathrm{Btu}\right)$ & -1.1 & -2.3 & -3.5 & -9.1 & -15.4 & -21.7 & -60.3 & -98.9 & -112.9 & -127 \\
\hline Water (10 ${ }^{9}$ Gallons) & 0 & 0 & 0 & 0 & 0 & 0 & 0 & 0 & 0 & 0 \\
\hline
\end{tabular}




\section{Glass Manufacturing Base Case}

\begin{tabular}{|c|c|c|c|c|c|c|c|c|c|c|}
\hline \multirow[t]{2}{*}{ Base Case } & \multicolumn{10}{|c|}{ Residential Technology Research and Development } \\
\hline & 2003 & 2004 & 2005 & 2006 & 2007 & 2010 & 2015 & 2020 & 2025 & 2030 \\
\hline \multicolumn{11}{|c|}{ Capital and Installation Cost Increase (+) or Savings(-) Million \$ } \\
\hline & 22.53 & 21.1 & 22.6 & 22.6 & 22.6 & 21.1 & 17.11 & 11.12 & 6 & 6 \\
\hline \multicolumn{11}{|c|}{ Energy/Resource Cost Increase (+) or Savings (-) Million \$ } \\
\hline Residential -- Oil & 0 & 0 & 0 & 0 & 0 & 0 & 0 & 0 & 0 & 0 \\
\hline esidential -- Natural ga & 0 & 0 & 0 & 0 & 0 & 0 & 0 & 0 & 0 & 0 \\
\hline esic & 0 & 0 & 0 & 0 & 0 & 0 & 0 & 0 & 0 & 0 \\
\hline esidential -- Water & 0 & 0 & 0 & 0 & 0 & 0 & 0 & 0 & 0 & 0 \\
\hline Lomr & 0 & 0 & 0 & 0 & 0 & 0 & 0 & 0 & 0 & 0 \\
\hline $\begin{array}{l}\text { Commercial -- Natural } \\
\text { gas }\end{array}$ & 0 & 0 & 0 & 0 & 0 & 0 & 0 & 0 & 0 & 0 \\
\hline ommerci & 0 & 0 & 0 & 0 & 0 & 0 & 0 & 0 & 0 & 0 \\
\hline Som & 0 & 0 & 0 & 0 & 0 & 0 & 0 & 0 & 0 & 0 \\
\hline ndu & -0.98 & -1 & -1.01 & -1.03 & -1.04 & -1.04 & -0.9 & -0.46 & -0.14 & 0 \\
\hline Industrial -- Natural gas & -67.98 & -71.32 & -75.22 & -79.21 & -80.98 & -82.77 & -86.87 & -72.64 & -65.67 & -72.72 \\
\hline Industrial -- Electricity & -152.58 & -154.14 & -151.91 & -153.43 & -153.73 & -154.94 & 132.91 & -44.84 & -9.94 & 0 \\
\hline ndustrial -- Water & 0 & 0 & 0 & 0 & 0 & 0 & 0 & 0 & 0 & 0 \\
\hline Tran & 0 & 0 & 0 & 0 & 0 & 0 & 0 & 0 & 0 & 0 \\
\hline $\begin{array}{l}\text { Transportation -- Natural } \\
\text { gas }\end{array}$ & 0 & 0 & 0 & 0 & 0 & 0 & 0 & 0 & 0 & 0 \\
\hline $\begin{array}{l}\text { Transportation -- } \\
\text { Electricity }\end{array}$ & 0 & 0 & 0 & 0 & 0 & 0 & 0 & 0 & 0 & 0 \\
\hline Transportation -- Water & 0 & 0 & 0 & 0 & 0 & 0 & 0 & 0 & 0 & 0 \\
\hline \multicolumn{11}{|c|}{ O\&M Cost Increase (+) or Savings(-) (Million \$) } \\
\hline Residential & 0 & 0 & 0 & 0 & 0 & 0 & 0 & 0 & 0 & 0 \\
\hline Con & 0 & 0 & 0 & 0 & 0 & 0 & 0 & 0 & 0 & 0 \\
\hline & 0 & 0 & 0 & 0 & 0 & 0 & 0 & 0 & 0 & 0 \\
\hline Transportation & 0 & 0 & 0 & 0 & 0 & 0 & 0 & 0 & 0 & 0 \\
\hline \multicolumn{11}{|c|}{ Energy/Resource units Saved (-) or Used (For System Investment) } \\
\hline Oil (10^12 Btu) & -0.18 & -0.18 & -0.18 & -0.18 & -0.18 & -0.18 & -0.16 & -0.08 & -0.02 & 0 \\
\hline Natural ga & -22.04 & -22.75 & -23.61 & -24.47 & -24.82 & -25.17 & -25.66 & -20.74 & -17.58 & -18.25 \\
\hline Elect & -12.7 & -12.83 & -12.96 & -13.09 & -13.11 & -13.22 & -11.63 & -4.03 & -0.92 & 0 \\
\hline Water (10^9 Gallons) & 0 & 0 & 0 & 0 & 0 & 0 & 0 & 0 & 0 & 0 \\
\hline
\end{tabular}




\section{Appendix B. Sectoral Detail}

\section{Table B.1 Cross Reference Between ImSET Sectors and 1997 U.S. Input-Output Table Sectors}

$\begin{array}{rll}\text { IO_IND } & \text { IOcode } & \text { Industry (1997 Benchmark IO) } \\ 1 & 1111 \mathrm{~A} 0 & \text { Oilseed farming } \\ 2 & 1111 \mathrm{~B} 0 & \text { Grain farming } \\ 3 & 111200 & \text { Vegetable and melon farming } \\ 4 & 111335 & \text { Tree nut farming } \\ 5 & 1113 \mathrm{~A} 0 & \text { Fruit farming } \\ 6 & 111400 & \text { Greenhouse and nursery production } \\ 7 & 111910 & \text { Tobacco farming } \\ 8 & 111920 & \text { Cotton farming } \\ 9 & 1119 \mathrm{~A} 0 & \text { Sugarcane and sugar beet farming } \\ 10 & 1119 \mathrm{~B} 0 & \text { All other crop farming } \\ 11 & 112100 & \text { Cattle ranching and farming } \\ 12 & 112300 & \text { Poultry and egg production } \\ 13 & 112 \mathrm{~A} 00 & \text { Animal production, except cattle and poultry and eggs } \\ 14 & 113300 & \text { Logging } \\ 15 & 113 \mathrm{~A} 00 & \text { Forest nurseries, forest products, and timber tracts } \\ 16 & 114100 & \text { Fishing } \\ 17 & 114200 & \text { Hunting and trapping } \\ 18 & 115000 & \text { Agriculture and forestry support activities } \\ 19 & 211000 & \text { Oil and gas extraction } \\ 20 & 212100 & \text { Coal mining } \\ 21 & 212210 & \text { Iron ore mining } \\ 22 & 212230 & \text { Copper, nickel, lead, and zinc mining }\end{array}$

$\begin{aligned} \text { ImSET } & \text { ImSET Name } \\ 1 & \text { Crop Farming } \\ 1 & \text { Crop Farming } \\ 1 & \text { Crop Farming } \\ 1 & \text { Crop Farming } \\ 1 & \text { Crop Farming } \\ 1 & \text { Crop Farming } \\ 1 & \text { Crop Farming } \\ 1 & \text { Crop Farming } \\ 1 & \text { Crop Farming } \\ 1 & \text { Crop Farming } \\ 2 & \text { Animal Farming } \\ 2 & \text { Animal Farming } \\ 2 & \text { Animal Farming } \\ 3 & \text { Forest Products } \\ 3 & \text { Forest Products } \\ 4 & \text { Fish/Hunt/Ag Support } \\ 4 & \text { Fish/Hunt/Ag Support } \\ 4 & \text { Fish/Hunt/Ag Support } \\ 5 & \text { Oil and Gas Extraction } \\ 6 & \text { Coal Mining } \\ 7 & \text { Metal Mining } \\ 7 & \text { Metal Mining } \\ & \end{aligned}$




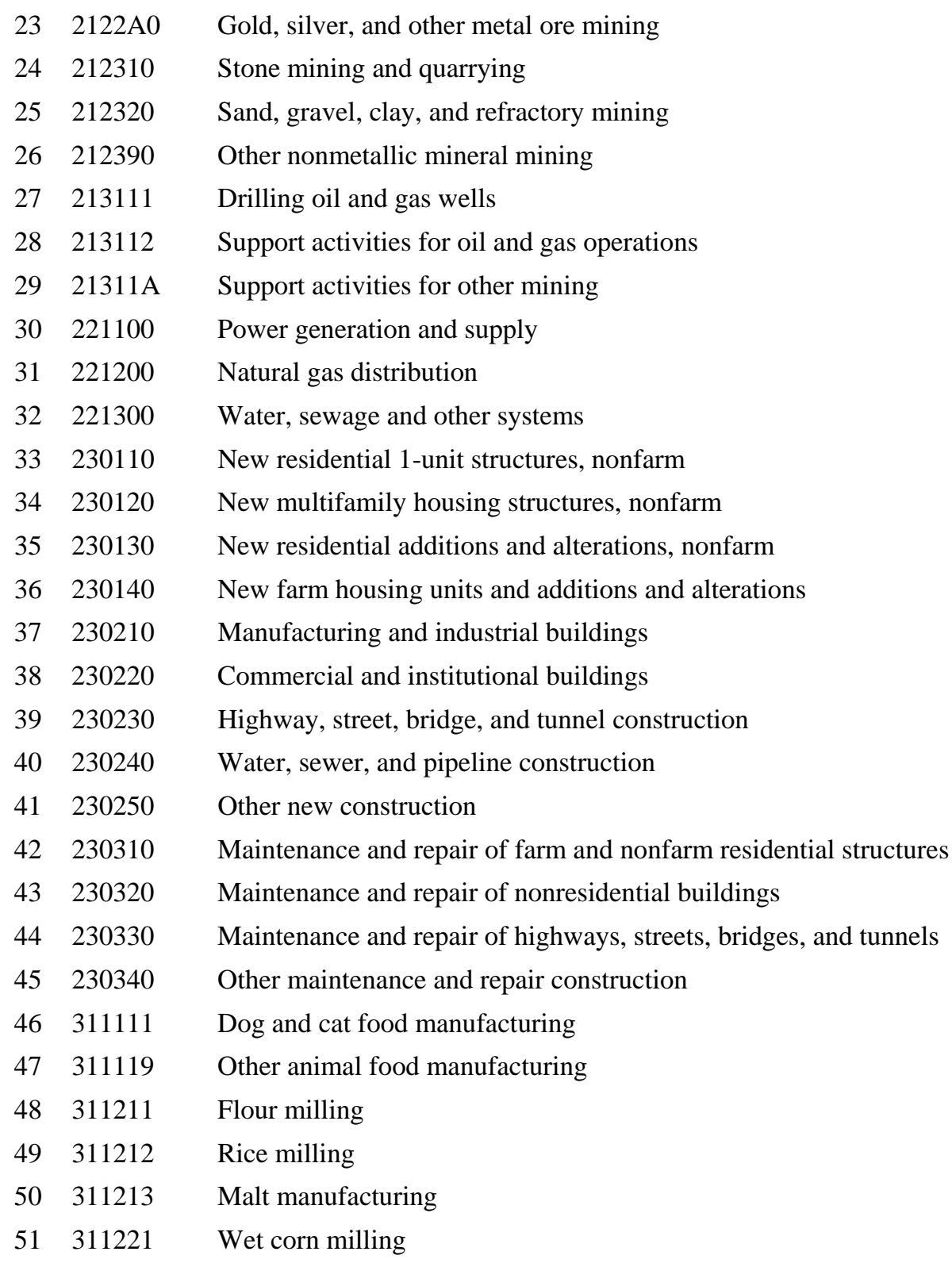

7 Metal Mining

8 Nonmetalic Mineral Mining

8 Nonmetalic Mineral Mining

8 Nonmetalic Mineral Mining

9 Oil and Gas Drilling

10 Oil and Gas Support

11 Other Mining Support

12 Electricity Gen. and Trans.

13 Natural Gas Distribution

14 Water/Sewer, Other Systems

15 New Single-Family Const.

16 New Multifamily Const.

17 New Residential Remodeling Const.

18 New Farm Housing

19 Industrial Building Construction

20 Commercial Building Construction

21 Road Construction

21 Pipeline Construction

22 Other New Construction

23 Res. Maintenance \& Repair

23 Non-Res. Maintenance \& Repair

23 Road Maintenance \& Repair

23 Other Maintenance \& Repair

24 Food Processing

24 Food Processing

24 Food Processing

24 Food Processing

24 Food Processing

24 Food Processing 


\begin{tabular}{lll}
52 & 311222 & Soybean processing \\
53 & 311223 & Other oilseed processing \\
54 & 311225 & Fats and oils refining and blending \\
55 & 311230 & Breakfast cereal manufacturing \\
56 & 311310 & Sugar manufacturing \\
57 & 311320 & Confectionery manufacturing from cacao beans \\
58 & 311330 & Confectionery manufacturing from purchased chocolate \\
59 & 311340 & Nonchocolate confectionery manufacturing \\
60 & 311410 & Frozen food manufacturing \\
61 & 311420 & Fruit and vegetable canning and drying \\
62 & 311511 & Fluid milk manufacturing \\
63 & 311512 & Creamery butter manufacturing \\
64 & 311513 & Cheese manufacturing \\
65 & 311514 & Dry, condensed, and evaporated dairy products \\
66 & 311520 & Ice cream and frozen dessert manufacturing \\
67 & 311611 & Animal, except poultry, slaughtering \\
68 & 311612 & Meat processed from carcasses \\
69 & 311613 & Rendering and meat byproduct processing \\
70 & 311615 & Poultry processing \\
71 & 311700 & Seafood product preparation and packaging \\
72 & 311813 & Frozen cakes and other pastries manufacturing \\
73 & 31181 A & Bread and bakery product, except frozen, manufacturing \\
74 & 311821 & Cookie and cracker manufacturing \\
75 & 311822 & Mixes and dough made from purchased flour \\
76 & 311823 & Dry pasta manufacturing \\
77 & 311830 & Tortilla manufacturing \\
78 & 311911 & Roasted nuts and peanut butter manufacturing \\
79 & 311919 & Other snack food manufacturing \\
80 & 311920 & Coffee and tea manufacturing \\
\hline
\end{tabular}

24 Food Processing

24 Food Processing

24 Food Processing

24 Food Processing

24 Food Processing

24 Food Processing

24 Food Processing

24 Food Processing

24 Food Processing

24 Food Processing

24 Food Processing

24 Food Processing

24 Food Processing

24 Food Processing

24 Food Processing

24 Food Processing

24 Food Processing

24 Food Processing

24 Food Processing

24 Food Processing

24 Food Processing

24 Food Processing

24 Food Processing

24 Food Processing

24 Food Processing

24 Food Processing

24 Food Processing

24 Food Processing

24 Food Processing 


$\begin{array}{rll}81 & 311930 & \text { Flavoring syrup and concentrate manufacturing } \\ 82 & 311941 & \text { Mayonnaise, dressing, and sauce manufacturing } \\ 83 & 311942 & \text { Spice and extract manufacturing } \\ 84 & 311990 & \text { All other food manufacturing } \\ 85 & 312110 & \text { Soft drink and ice manufacturing } \\ 86 & 312120 & \text { Breweries } \\ 87 & 312130 & \text { Wineries } \\ 88 & 312140 & \text { Distilleries } \\ 89 & 312210 & \text { Tobacco stemming and redrying } \\ 90 & 312221 & \text { Cigarette manufacturing } \\ 91 & 312229 & \text { Other tobacco product manufacturing } \\ 92 & 313100 & \text { Fiber, yarn, and thread mills } \\ 93 & 313210 & \text { Broadwoven fabric mills } \\ 94 & 313220 & \text { Narrow fabric mills and schiffli embroidery } \\ 95 & 313230 & \text { Nonwoven fabric mills } \\ 96 & 313240 & \text { Knit fabric mills } \\ 97 & 313310 & \text { Textile and fabric finishing mills } \\ 98 & 313320 & \text { Fabric coating mills } \\ 99 & 314110 & \text { Carpet and rug mills } \\ 100 & 314120 & \text { Curtain and linen mills } \\ 101 & 314910 & \text { Textile bag and canvas mills } \\ 102 & 314992 & \text { Tire cord and tire fabric mills } \\ 103 & 31499 \text { A } & \text { Other miscellaneous textile product mills } \\ 104 & 315111 & \text { Sheer hosiery mills } \\ 105 & 315119 & \text { Other hosiery and sock mills } \\ 106 & 315190 & \text { Other apparel knitting mills } \\ 107 & 315200 & \text { Cut and sew apparel manufacturing } \\ 108 & 315900 & \text { Accessories and other apparel manufacturing } \\ 109 & 316100 & \text { Leather and hide tanning and finishing } \\ & & \end{array}$

24 Food Processing

24 Food Processing

24 Food Processing

24 Food Processing

24 Food Processing

25 Alcoholic Beverage Processing

25 Alcoholic Beverage Processing

25 Alcoholic Beverage Processing

26 Tobacco Processing

26 Tobacco Processing

26 Tobacco Processing

27 Textile Mills

27 Textile Mills

27 Textile Mills

27 Textile Mills

27 Textile Mills

27 Textile Mills

27 Textile Mills

28 Textile Product Mills

28 Textile Product Mills

28 Textile Product Mills

28 Textile Product Mills

28 Textile Product Mills

29 Apparel Manufacturing

29 Apparel Manufacturing

29 Apparel Manufacturing

29 Apparel Manufacturing

29 Apparel Manufacturing

30 Leather Products Mfg. 


$\begin{array}{lll}110 & 316200 & \text { Footwear manufacturing } \\ 111 & 316900 & \text { Other leather product manufacturing } \\ 112 & 321113 & \text { Sawmills } \\ 113 & 321114 & \text { Wood preservation } \\ 114 & 321219 & \text { Reconstituted wood product manufacturing } \\ 115 & 32121 \text { A } & \text { Veneer and plywood manufacturing } \\ 116 & 32121 \text { B } & \text { Engineered wood member and truss manufacturing } \\ 117 & 321911 & \text { Wood windows and door manufacturing } \\ 118 & 321912 & \text { Cut stock, resawing lumber, and planing } \\ 119 & 321918 & \text { Other millwork, including flooring } \\ 120 & 321920 & \text { Wood container and pallet manufacturing } \\ 123 & 321999 & \text { Miscellaneous wood product manufacturing } \\ 121 & 321991 & \text { Manufactured home, mobile home, manufacturing } \\ 122 & 321992 & \text { Prefabricated wood building manufacturing } \\ 124 & 322110 & \text { Pulp mills } \\ 125 & 3221 \text { A0 } & \text { Paper and paperboard mills } \\ 126 & 322210 & \text { Paperboard container manufacturing } \\ 127 & 322225 & \text { Flexible packaging foil manufacturing } \\ 128 & 322226 & \text { Surface-coated paperboard manufactuing } \\ 129 & 32222 \mathrm{~A} & \text { Coated and laminated paper and packaging materials } \\ 130 & 32222 \mathrm{~B} & \text { Coated and uncoated paper bag manufacturing } \\ 131 & 322231 & \text { Die-cut paper office supplies manufacturing } \\ 132 & 322232 & \text { Envelope manufacturing } \\ 133 & 322233 & \text { Stationery and related product manufacturing } \\ 134 & 322291 & \text { Sanitary paper product manufacturing } \\ 135 & 322299 & \text { All other converted paper product manufacturing } \\ 136 & 323116 & \text { Manifold business forms printing } \\ 137 & 323117 & \text { Books printing } \\ 138 & 323118 & \text { Blankbook and looseleaf binder manufacturing } \\ & & \end{array}$

30 Leather Products Mfg.

30 Leather Products Mfg.

31 Lumber Mills

31 Lumber Mills

31 Lumber Mills

31 Lumber Mills

31 Lumber Mills

32 Specialized Wood Product Mfg.

32 Specialized Wood Product Mfg.

32 Specialized Wood Product Mfg.

33 Misc. Wood Product Mfg.

33 Misc. Wood Product Mfg.

34 Manufactured Buildings

34 Manufactured Buildings

35 Pulp Mills

36 Paper And Paperboard Mills

37 Paperboard Container Mfg.

38 Converted Paper Product Mfg.

38 Converted Paper Product Mfg.

38 Converted Paper Product Mfg.

38 Converted Paper Product Mfg.

38 Converted Paper Product Mfg.

38 Converted Paper Product Mfg.

38 Converted Paper Product Mfg.

38 Converted Paper Product Mfg.

38 Converted Paper Product Mfg.

39 Commercial Printing

39 Commercial Printing

39 Commercial Printing 


\begin{tabular}{lll}
139 & 32311 A & Commercial printing \\
140 & 323121 & Tradebinding and related work \\
141 & 323122 & Prepress services \\
142 & 324110 & Petroleum refineries \\
143 & 324121 & Asphalt paving mixture and block manufacturing \\
144 & 324122 & Asphalt shingle and coating materials manufacturing \\
145 & 324191 & Petroleum lubricating oil and grease manufacturing \\
146 & 324199 & All other petroleum and coal products manufacturing \\
147 & 325110 & Petrochemical manufacturing \\
148 & 325120 & Industrial gas manufacturing \\
149 & 325130 & Synthetic dye and pigment manufacturing \\
150 & 325180 & Other basic inorganic chemical manufacturing \\
151 & 325190 & Other basic organic chemical manufacturing \\
152 & 325211 & Plastics material and resin manufacturing \\
153 & 325212 & Synthetic rubber manufacturing \\
154 & 325221 & Cellulosic organic fiber manufacturing \\
155 & 325222 & Noncellulosic organic fiber manufacturing \\
156 & 325311 & Nitrogenous fertilizer manufacturing \\
157 & 325312 & Phosphatic fertilizer manufacturing \\
158 & 325314 & Fertilizer, mixing only, manufacturing \\
159 & 325320 & Pesticide and other agricultural chemical manufacturing \\
160 & 325400 & Pharmaceutical and medicine manufacturing \\
161 & 325510 & Paint and coating manufacturing \\
162 & 325520 & Adhesive manufacturing \\
163 & 325611 & Soap and other detergent manufacturing \\
164 & 325612 & Polish and other sanitation good manufacturing \\
165 & 325613 & Surface active agent manufacturing \\
166 & 325620 & Toilet preparation manufacturing \\
167 & 325910 & Printing ink manufacturing \\
& & \\
\hline
\end{tabular}

39 Commercial Printing

39 Commercial Printing

39 Commercial Printing

40 Petroleum Refineries

41 Oth. Petroleum/Coal Prod. Mfg.

41 Oth. Petroleum/Coal Prod. Mfg.

41 Oth. Petroleum/Coal Prod. Mfg.

41 Oth. Petroleum/Coal Prod. Mfg.

42 Inorganic Chemical Mfg.

42 Inorganic Chemical Mfg.

42 Inorganic Chemical Mfg.

42 Inorganic Chemical Mfg.

43 Organic Chemical Mfg.

44 Plastics Material \& Resin Mfg.

45 Synthetic Rubber Mfg.

46 Organic Fiber Mfg.

46 Organic Fiber Mfg.

47 Fertilizer \& Pesticide Mfg.

47 Fertilizer \& Pesticide Mfg.

47 Fertilizer \& Pesticide Mfg.

47 Fertilizer \& Pesticide Mfg.

48 Pharmaceutical \& Medicine Mfg.

49 Misc. Chemical Prod. Mfg.

49 Misc. Chemical Prod. Mfg.

49 Misc. Chemical Prod. Mfg.

49 Misc. Chemical Prod. Mfg.

49 Misc. Chemical Prod. Mfg.

49 Misc. Chemical Prod. Mfg.

49 Misc. Chemical Prod. Mfg. 


$\begin{array}{lll}168 & 325920 & \text { Explosives manufacturing } \\ 169 & 325991 & \text { Custom compounding of purchased resins } \\ 170 & 325992 & \text { Photographic film and chemical manufacturing } \\ 171 & 325998 & \text { Other miscellaneous chemical product manufacturing } \\ 172 & 326110 & \text { Plastics packaging materials, film and sheet } \\ 173 & 326120 & \text { Plastics pipe, fittings, and profile shapes } \\ 174 & 326130 & \text { Laminated plastics plate, sheet, and shapes } \\ 175 & 326160 & \text { Plastics bottle manufacturing } \\ 176 & 326192 & \text { Resilient floor covering manufacturing } \\ 177 & 32619 \text { A } & \text { Plastics plumbing fixtures and all other plastics products } \\ 178 & 3261 \text { A0 } & \text { Foam product manufacturing } \\ 179 & 326210 & \text { Tire manufacturing } \\ 180 & 326220 & \text { Rubber and plastics hose and belting manufacturing } \\ 181 & 326290 & \text { Other rubber product manufacturing } \\ 182 & 327111 & \text { Vitreous china plumbing fixture manufacturing } \\ 183 & 327112 & \text { Vitreous china and earthenware articles manufacturing } \\ 184 & 327113 & \text { Porcelain electrical supply manufacturing } \\ 185 & 327121 & \text { Brick and structural clay tile manufacturing } \\ 186 & 327122 & \text { Ceramic wall and floor tile manufacturing } \\ 187 & 327125 & \text { Nonclay refractory manufacturing } \\ 188 & 32712 \text { A } & \text { Clay refractory and other structural clay products } \\ 189 & 327213 & \text { Glass container manufacturing } \\ 190 & 32721 \text { A } & \text { Glass and glass products, except glass containers } \\ 191 & 327310 & \text { Cement manufacturing } \\ 192 & 327320 & \text { Ready-mix concrete manufacturing } \\ 193 & 327331 & \text { Concrete block and brick manufacturing } \\ 194 & 327332 & \text { Concrete pipe manufacturing } \\ 195 & 327390 & \text { Other concrete product manufacturing } \\ 196 & 327410 & \text { Lime manufacturing } \\ & & \end{array}$

49 Misc. Chemical Prod. Mfg.

49 Misc. Chemical Prod. Mfg.

49 Misc. Chemical Prod. Mfg.

49 Misc. Chemical Prod. Mfg.

50 Plastics \& Related Prod. Mfg.

50 Plastics \& Related Prod. Mfg.

50 Plastics \& Related Prod. Mfg.

50 Plastics \& Related Prod. Mfg.

50 Plastics \& Related Prod. Mfg.

50 Plastics \& Related Prod. Mfg.

50 Plastics \& Related Prod. Mfg.

51 Rubber Porducts Mfg.

51 Rubber Porducts Mfg.

51 Rubber Porducts Mfg.

52 China \& Porcelain Prod. Mfg.

52 China \& Porcelain Prod. Mfg.

52 China \& Porcelain Prod. Mfg.

53 Clay Products Mfg.

53 Clay Products Mfg.

53 Clay Products Mfg.

53 Clay Products Mfg.

54 Glass Container Mfg.

55 Glass and Glass Products Mfg.

56 Cement Manufacturing

57 Concrete Products Mfg.

57 Concrete Products Mfg.

57 Concrete Products Mfg.

57 Concrete Products Mfg.

58 Lime Manufacturing 


$\begin{array}{lll}197 & 327420 & \text { Gypsum product manufacturing } \\ 198 & 327910 & \text { Abrasive product manufacturing } \\ 199 & 327991 & \text { Cut stone and stone product manufacturing } \\ 200 & 327992 & \text { Ground or treated minerals and earths manufacturing } \\ 202 & 327999 & \text { Miscellaneous nonmetallic mineral products } \\ 201 & 327993 & \text { Mineral wool manufacturing } \\ 203 & 331111 & \text { Iron and steel mills } \\ 204 & 331112 & \text { Ferroalloy and related product manufacturing } \\ 205 & 331210 & \text { Iron, steel pipe and tube from purchased steel } \\ 206 & 331221 & \text { Rolled steel shape manufacturing } \\ 207 & 331222 & \text { Steel wire drawing } \\ 208 & 331311 & \text { Alumina refining } \\ 209 & 331312 & \text { Primary aluminum production } \\ 210 & 331314 & \text { Secondary smelting and alloying of aluminum } \\ 211 & 331315 & \text { Aluminum sheet, plate, and foil manufacturing } \\ 212 & 331316 & \text { Aluminum extruded product manufacturing } \\ 213 & 331319 & \text { Other aluminum rolling and drawing } \\ 214 & 331411 & \text { Primary smelting and refining of copper } \\ 215 & 331419 & \text { Primary nonferrous metal, except copper and aluminum } \\ 216 & 331421 & \text { Copper rolling, drawing, and extruding } \\ 217 & 331422 & \text { Copper wire, except mechanical, drawing } \\ 218 & 331423 & \text { Secondary processing of copper } \\ 219 & 331491 & \text { Nonferrous metal, except copper and aluminum, shaping } \\ 220 & 331492 & \text { Secondary processing of other nonferrous } \\ 221 & 331510 & \text { Ferrous metal foundaries } \\ 222 & 33152 \text { A } & \text { Aluminum foundries } \\ 223 & 33152 B & \text { Nonferrous foundries, except aluminum } \\ 224 & 332111 & \text { Iron and steel forging } \\ 225 & 332112 & \text { Nonferrous forging } \\ & & \end{array}$

59 Gypsum Product Manufacturing

60 Oth. Nonmetalic Mineral Prod.

60 Oth. Nonmetalic Mineral Prod.

60 Oth. Nonmetalic Mineral Prod.

60 Oth. Nonmetalic Mineral Prod.

61 Mineral Wool Manufacturing

62 Iron And Steel Mills

63 Ferroalloy Product Mfg.

64 Steel Shape Mfg.

64 Steel Shape Mfg.

64 Steel Shape Mfg.

65 Aluminium Mills

65 Aluminium Mills

65 Aluminium Mills

66 Aluminum Product Mfg.

66 Aluminum Product Mfg.

66 Aluminum Product Mfg.

67 Nonferrous Metals Mfg.

67 Nonferrous Metals Mfg.

67 Nonferrous Metals Mfg.

67 Nonferrous Metals Mfg.

67 Nonferrous Metals Mfg.

67 Nonferrous Metals Mfg.

67 Nonferrous Metals Mfg.

68 Ferrous Metal Foundaries

69 Aluminum Foundries

70 Other Nonferrous Foundaries

71 Iron And Steel Forging

72 Other Forging and Stamping 


\section{Custom roll forming}

All other forging and stamping

Cutlery and flatware, except precious, manufacturing

Hand and edge tool manufacturing

Saw blade and handsaw manufacturing

Kitchen utensil, pot, and pan manufacturing

Prefabricated metal buildings and components

Fabricated structural metal manufacturing

Plate work manufacturing

Metal window and door manufacturing

Sheet metal work manufacturing

Ornamental and architectural metal work manufacturing

Power boiler and heat exchanger manufacturing

Metal tank, heavy gauge, manufacturing

Metal can, box, and other container manufacturing

Hardware manufacturing

Spring and wire product manufacturing

Machine shops

Turned product and screw, nut, and bolt manufacturing

Metal heat treating

Metal coating and nonprecious engraving

Electroplating, anodizing, and coloring metal

Metal valve manufacturing

Ball and roller bearing manufacturing

Fabricated pipe and pipe fitting manufacturing

Industrial pattern manufacturing

Enameled iron and metal sanitary ware manufacturing

Miscellaneous fabricated metal product manufacturing

Small arms manufacturing
80 Other Fabricated Metal Mfg.

80 Other Fabricated Metal Mfg.

80 Other Fabricated Metal Mfg.

80 Other Fabricated Metal Mfg.

81 Ordinance and Ammunition Mfg. 
Other ordnance and accessories manufacturing

Ammunition manufacturing

Farm machinery and equipment manufacturing

Construction machinery manufacturing

Mining machinery and equipment manufacturing

Oil and gas field machinery and equipment

Lawn and garden equipment manufacturing

Sawmill and woodworking machinery

Plastics and rubber industry machinery

Paper industry machinery manufacturing

Textile machinery manufacturing

Printing machinery and equipment manufacturing

Food product machinery manufacturing

Semiconductor machinery manufacturing

All other industrial machinery manufacturing

Office machinery manufacturing

Optical instrument and lens manufacturing

Photographic and photocopying equipment manufacturing

Other commercial and service industry machinery manufacturing

Automatic vending, commercial laundry and drycleaning machinery

Air purification equipment manufacturing

Industrial and commercial fan and blower manufacturing

Heating equipment, except warm air furnaces

AC, refrigeration, and forced air heating

Industrial mold manufacturing

Metal cutting machine tool manufacturing

Metal forming machine tool manufacturing

Special tool, die, jig, and fixture manufacturing

Cutting tool and machine tool accessory manufacturing
81 Ordinance and Ammunition Mfg.

81 Ordinance and Ammunition Mfg.

82 Heavy Machinery Mfg.

82 Heavy Machinery Mfg.

82 Heavy Machinery Mfg.

82 Heavy Machinery Mfg.

83 Lawn \& Garden Eq. Mfg.

84 Wood Processing Machinery Mfg.

85 Plastics \& Rubber Machinery Mfg.

86 Paper Industry Machinery Mfg.

87 Textile Machinery Mfg.

88 Printing Industry Machinery Mfg.

89 Food Product Machinery Mfg.

89 Misc. Industrial Machinery Mfg.

89 Misc. Industrial Machinery Mfg.

90 Commercial Service Macinery Mfg.

90 Commercial Service Macinery Mfg.

90 Commercial Service Macinery Mfg.

90 Commercial Service Macinery Mfg.

90 Commercial Service Macinery Mfg.

91 Air Purification Eq. Mfg.

92 Com/Ind Fan \& Blower Mfg.

93 Nonfurnace Heating Eq. Mfg.

94 AC, Ref. \& Forced Air Heating

95 Industrial Mold Manufacturing

95 Machine Tool Manufacturing

95 Machine Tool Manufacturing

95 Machine Tool Manufacturing

95 Machine Tool Manufacturing 
284 33351A

285333611

286333618
Rolling mill and other metalworking machinery

Turbine and turbine generator set units manufacturing

Other engine equipment manufacturing

Speed changers and mechanical power transmission equipment

Pump and pumping equipment manufacturing

Air and gas compressor manufacturing

Measuring and dispensing pump manufacturing

Elevator and moving stairway manufacturing

Conveyor and conveying equipment manufacturing

Overhead cranes, hoists, and monorail systems

Industrial truck, trailer, and stacker manufacturing

Power-driven handtool manufacturing

Welding and soldering equipment manufacturing

Packaging machinery manufacturing

Industrial process furnace and oven manufacturing

Fluid power cylinder and actuator manufacturing

Fluid power pump and motor manufacturing

Scales, balances, and miscellaneous general purpose machinery

Electronic computer manufacturing

Computer storage device manufacturing

Computer terminal manufacturing

Other computer peripheral equipment manufacturing

Telephone apparatus manufacturing

Broadcast and wireless communications equipment

Other communications equipment manufacturing

Audio and video equipment manufacturing

Electron tube manufacturing

Semiconductors and related device manufacturing
Metalworking Machinery Mfg.

Turbines and Related Mfg.

Other Engine Eq. Manufacturing Power Transmission Equipment Mfg.

Pumps and Related Eq. Mfg.

Air And Gas Compressor Mfg. Measuring And Dispensing Pump

Mfg.

Other Electric Machinery Mfg.

Other Electric Machinery Mfg.

Other Electric Machinery Mfg.

Other Electric Machinery Mfg.

Other Electric Machinery Mfg.

Other Electric Machinery Mfg.

Other Electric Machinery Mfg.

Ind. Process Furnace \& Oven Mfg.

Misc. Machinery Mfg.

Misc. Machinery Mfg.

Misc. Machinery Mfg.

Computer Products Mfg.

Computer Products Mfg.

Computer Products Mfg.

Computer Products Mfg.

Communications Eq. Mfg.

Communications Eq. Mfg.

Communications Eq. Mfg.

Electronic Components Mfg.

Electronic Components Mfg.

Electronic Components Mfg. 
312 33441A

$313 \quad 334510$

314334511

315334512

316334513

$317 \quad 334514$

318334515

319334516

$320 \quad 334517$

$321 \quad 33451 \mathrm{~A}$

322334611

$323 \quad 334612$

$324 \quad 334613$

325335110

$326 \quad 335120$

$327 \quad 335211$

$328 \quad 335212$

$329 \quad 335221$

$330 \quad 335222$

331335224

$332 \quad 335228$

33333531

334335312

335335313

$336 \quad 335314$

$337 \quad 335911$

$338 \quad 335912$

339335921

$340 \quad 335929$
All other electronic component manufacturing

Electromedical apparatus manufacturing

Search, detection, and navigation instruments

Automatic environmental control manufacturing

Industrial process variable instruments

Totalizing fluid meters and counting devices

Electricity and signal testing instruments

Analytical laboratory instrument manufacturing

Irradiation apparatus manufacturing

Watch, clock, and other measuring and controlling device mfg

Software reproducing

Audio and video media reproduction

Magnetic and optical recording media manufacturing

Electric lamp bulb and part manufacturing

Lighting fixture manufacturing

Electric housewares and household fan manufacturing

Household vacuum cleaner manufacturing

Household cooking appliance manufacturing

Household refrigerator and home freezer manufacturing

Household laundry equipment manufacturing

Other major household appliance manufacturing

Electric power and specialty transformer manufacturing

Motor and generator manufacturing

Switchgear and switchboard apparatus manufacturing

Relay and industrial control manufacturing

Storage battery manufacturing

Primary battery manufacturing

Fiber optic cable manufacturing

Other communication and energy wire manufacturing
108 Electronic Components Mfg.

109 Instruments Manufacturing

109 Instruments Manufacturing

110 Automatic Environmental Controls

111 Ind. Process Variable Instruments

112 Fluid Meters \& Counting Devices

113 Electricity \& Signal Testing Inst.

114 Other Lab \& Related Instruments

114 Other Lab \& Related Instruments

114 Other Lab \& Related Instruments

115 Electronic Media Processing

115 Electronic Media Processing

115 Electronic Media Processing

116 Electric Lamp Bulb And Part Mfg.

117 Lighting Fixture Manufacturing

118 Household Eq. Mfg.

118 Household Eq. Mfg.

119 Household Cooking Appliance Mfg.

120 HH Refrigerator \& Freezer Mfg.

121 Household Laundry Equipment Mfg.

122 Other Major HH Appliance Mfg.

123 Electric Power, Etc. Transformers

124 Motor And Generator Mfg.

125 Industrial Controls

125 Industrial Controls

126 Battery Manufacturing

126 Battery Manufacturing

127 Misc. Electric Eq. Mfg.

127 Misc. Electric Eq. Mfg. 


$\begin{array}{lll}341 & 335930 & \text { Wiring device manufacturing } \\ 342 & 335991 & \text { Carbon and graphite product manufacturing } \\ 343 & 335999 & \text { Miscellaneous electrical equipment manufacturing } \\ 344 & 336110 & \text { Automobile and light truck manufacturing } \\ 346 & 336211 & \text { Motor vehicle body manufacturing } \\ 345 & 336120 & \text { Heavy duty truck manufacturing } \\ 347 & 336212 & \text { Truck trailer manufacturing } \\ 348 & 336213 & \text { Motor home manufacturing } \\ 349 & 336214 & \text { Travel trailer and camper manufacturing } \\ 350 & 336300 & \text { Motor vehicle parts manufacturing } \\ 351 & 336411 & \text { Aircraft manufacturing } \\ 352 & 336412 & \text { Aircraft engine and engine parts manufacturing } \\ 353 & 336413 & \text { Other aircraft parts and equipment } \\ 354 & 336414 & \text { Guided missile and space vehicle manufacturing } \\ 355 & 33641 \text { A } & \text { Propulsion units and parts for space vehicles and guided missiles } \\ 356 & 336500 & \text { Railroad rolling stock manufacturing } \\ 357 & 336611 & \text { Ship building and repairing } \\ 358 & 336612 & \text { Boat building } \\ 359 & 336991 & \text { Motorcycle, bicycle, and parts manufacturing } \\ 360 & 336992 & \text { Military armored vehicles and tank parts manufacturing } \\ 361 & 336999 & \text { All other transportation equipment manufacturing } \\ 362 & 337110 & \text { Wood kitchen cabinet and countertop manufacturing } \\ 363 & 337121 & \text { Upholstered household furniture manufacturing } \\ 364 & 337122 & \text { Nonupholstered wood household furniture manufacturing } \\ 366 & 337127 & \text { Institutional furniture manufacturing } \\ 367 & 33712 \text { A } & \text { Other household and institutional furniture } \\ 365 & 337124 & \text { Metal household furniture manufacturing } \\ 368 & 337211 & \text { Wood office furniture manufacturing } \\ 370 & 337214 & \text { Office furniture, except wood, manufacturing } \\ & & \end{array}$

127 Misc. Electric Eq. Mfg.

127 Misc. Electric Eq. Mfg.

127 Misc. Electric Eq. Mfg.

128 Car and Light Truck Mfg.

128 Car and Light Truck Mfg.

129 Truck Manufacturing

129 Truck Manufacturing

130 RV Manufacturing

130 RV Manufacturing

131 Motor Vehicle Parts Manufacturing

132 Aerospace Product Manufacturing

132 Aerospace Product Manufacturing

132 Aerospace Product Manufacturing

132 Aerospace Product Manufacturing

132 Aerospace Product Manufacturing

133 Railroad Rolling Stock Mfg.

134 Ship Building And Repairing

135 Boat/Cycle \& Parts Mfg.

135 Boat/Cycle \& Parts Mfg.

136 Other Transportation Eq.

136 Other Transportation Eq.

137 HH \& Institutional Furniture

137 HH \& Institutional Furniture

137 HH \& Institutional Furniture

137 HH \& Institutional Furniture

137 HH \& Institutional Furniture

138 Office Furniture Mfg.

138 Office Furniture Mfg.

138 Office Furniture Mfg. 
Showcases, partitions, shelving, and lockers

Custom architectural woodwork and millwork

Mattress manufacturing

Blind and shade manufacturing

Laboratory apparatus and furniture manufacturing

Surgical and medical instrument manufacturing

Surgical appliance and supplies manufacturing

Dental equipment and supplies manufacturing

Ophthalmic goods manufacturing

Dental laboratories

Jewelry and silverware manufacturing

Sporting and athletic goods manufacturing

Doll, toy, and game manufacturing

Office supplies, except paper, manufacturing

Sign manufacturing

Gasket, packing, and sealing device manufacturing

Musical instrument manufacturing

Broom, brush, and mop manufacturing

Burial casket manufacturing

Buttons, pins, and all other miscellaneous manufacturing

Wholesale trade

Air transportation

Rail transportation

Water transportation

Truck transportation

Transit and ground passenger transportation

Pipeline transportation

Scenic and sightseeing transport \& support activities for transport

Postal service
138 Office Furniture Mfg.

139 Custom Woodwork And Millwork

140 Misc. Furniture Mfg.

140 Misc. Furniture Mfg.

141 Laboratory Instruments \& Eq.

141 Laboratory Instruments \& Eq.

141 Laboratory Instruments \& Eq.

141 Laboratory Instruments \& Eq.

141 Laboratory Instruments \& Eq.

141 Laboratory Instruments \& Eq.

141 Laboratory Instruments \& Eq.

142 Misc. Manufacturing

142 Misc. Manufacturing

142 Misc. Manufacturing

142 Misc. Manufacturing

142 Misc. Manufacturing

142 Misc. Manufacturing

142 Misc. Manufacturing

142 Misc. Manufacturing

142 Misc. Manufacturing

143 Wholesale Trade

144 Air Transportation

145 Rail Transportation

146 Water Transportation

147 Truck Transportation

148 Transit \& Related Services

149 Pipeline Transportation

150 Sightseeing Transportation

151 Postal and Courier Services 
Couriers and messengers

Warehousing and storage

Retail trade

Newpaper publishers

Periodical publishers

Book publishers

Database, directory, and other publishers

Software publishers

Motion picture and video industries

Sound recording industries

Radio and television broadcasting

Cable networks and program distribution

Telecommunications

Information services

Data processing services

Nondepository credit intermediation and related activities

Securities, commodity contracts, investments

Insurance carriers

Insurance agencies, brokerages, and related

Funds, trusts, and other financial vehicles

Monetary authorities and depository credit intermediation

Real estate

Automotive equipment rental and leasing

Video tape and disc rental

Machinery and equipment rental and leasing

General and consumer goods rental except video tapes and discs

Lessors of nonfinancial intangible assets

Legal services

Accounting and bookkeeping services
151 Postal and Courier Services

152 Warehousing And Storage

153 Retail Trade

154 Publishers

154 Publishers

154 Publishers

154 Publishers

154 Publishers

155 Telecom \& Entertainment

155 Telecom \& Entertainment

155 Telecom \& Entertainment

155 Telecom \& Entertainment

155 Telecom \& Entertainment

155 Telecom \& Entertainment

155 Telecom \& Entertainment

156 Credit Counseling

157 Investment Services

158 Insurance

158 Insurance

159 Fund Management

160 Monetary Authorities

161 Real Estate

162 Car Rental Agencies

163 Rental Services

163 Rental Services

163 Rental Services

163 Rental Services

164 Other Professional/Technical Svc.

164 Other Professional/Technical Svc. 
$428 \quad 541300$

$429 \quad 54140$

430541511

431541512

432 54151A

433541610

434 5416A0

$435 \quad 541700$

$436 \quad 541800$

$437 \quad 541920$

438541940

439 5419A0

440550000

441561100

442561200

443561300

444561400

$445 \quad 561500$

446561600

$447 \quad 561700$

$448 \quad 561900$

449562000

$450 \quad 611100$

451 611A00

452 611B00

453621600

454 621A00

455 621B00

$456 \quad 622000$
Architectural and engineering services

Specialized design services

Custom computer programming services

Computer systems design services

Other computer related services, including facilities management

Management consulting services

Environmental and other technical consulting services

Scientific research and development services

Advertising and related services

Photographic services

Veterinary services

All other miscellaneous professional and technical services

Management of companies and enterprises

Office administrative services

Facilities support services

Employment services

Business support services

Travel arrangement and reservation services

Investigation and security services

Services to buildings and dwellings

Other support services

Waste management and remediation services

Elementary and secondary schools

Colleges, universities, and junior colleges

Other educational services

Home health care services

Offices of physicians, dentists, and other health practioners

Other ambulatory health care services

Hospitals
165 Architectural \& Engineering Svc.

164 Other Professional/Technical Svc.

164 Other Professional/Technical Svc.

164 Other Professional/Technical Svc.

164 Other Professional/Technical Svc.

164 Other Professional/Technical Svc.

164 Other Professional/Technical Svc.

164 Other Professional/Technical Svc.

164 Other Professional/Technical Svc.

164 Other Professional/Technical Svc.

164 Other Professional/Technical Svc.

164 Other Professional/Technical Svc.

166 Other Business Services

166 Other Business Services

166 Other Business Services

166 Other Business Services

166 Other Business Services

166 Other Business Services

166 Other Business Services

166 Other Business Services

166 Other Business Services

166 Other Business Services

167 Education

167 Education

167 Education

168 Healthcare Providers

168 Healthcare Providers

168 Healthcare Providers

169 Hospitals and Residential Care 


$\begin{array}{lll}457 & 623000 & \text { Nursing and residential care facilities } \\ 458 & 624400 & \text { Child day care services } \\ 459 & 624 \mathrm{~A} 00 & \text { Social assistance, except child day care services } \\ 460 & 711100 & \text { Performing arts companies } \\ 461 & 711200 & \text { Spectator sports } \\ 462 & 711500 & \text { Independent artists, writers, and performers } \\ 463 & 711 \text { A00 } & \text { Promoters of performing arts \& sports \& agents for public figures } \\ 464 & 712000 & \text { Museums, historical sites, zoos, and parks } \\ 465 & 713940 & \text { Fitness and recreational sports centers } \\ 466 & 713950 & \text { Bowling centers } \\ 467 & 713 \text { A00 } & \text { Other amusement, gambling, and recreation industries } \\ 468 & 7211 \text { A0 } & \text { Hotels and motels, including casino hotels } \\ 469 & 721 \text { A00 } & \text { Other accommodations } \\ 470 & 722000 & \text { Food services and drinking places } \\ 471 & 811192 & \text { Car washes } \\ 472 & 8111 \text { A0 } & \text { Automotive repair and maintenance, except car washes } \\ 473 & 811200 & \text { Electronic equipment repair and maintenance } \\ 474 & 811300 & \text { Commercial machinery repair and maintenance } \\ 475 & 811400 & \text { Household goods repair and maintenance } \\ 476 & 812100 & \text { Personal care services } \\ 477 & 812200 & \text { Death care services } \\ 478 & 812300 & \text { Drycleaning and laundry services } \\ 479 & 812900 & \text { Other personal services } \\ 480 & 813100 & \text { Religious organizations } \\ 481 & 813 \mathrm{~A} 00 & \text { Grantmaking and giving and social advocacy organizations } \\ 482 & 813 \mathrm{~B} 00 & \text { Civic, social, professional and similar organizations } \\ 483 & 814000 & \text { Private households } \\ 484 & \text { S00101 } & \text { Federal electric utilities } \\ 485 & \text { S00102 } & \text { Other Federal Government enterprises } \\ & & \end{array}$

169 Hospitals and Residential Care

170 Day Care and Social Assistance

170 Day Care and Social Assistance

171 Amusement \& Recreation

171 Amusement \& Recreation

171 Amusement \& Recreation

171 Amusement \& Recreation

171 Amusement \& Recreation

171 Amusement \& Recreation

171 Amusement \& Recreation

171 Amusement \& Recreation

172 Lodging

172 Lodging

173 Food \& Beverage Services

174 Personal Services

174 Personal Services

174 Personal Services

174 Personal Services

174 Personal Services

174 Personal Services

174 Personal Services

174 Personal Services

174 Personal Services

175 Other Services

175 Other Services

175 Other Services

176 Households

177 Federal Electric Utilities

178 Other Fed. Gov. Enterprises 
486 S00201 State and local government passenger transit

487 S00202 State and local government electric utilities

488 S00203 Other State and local government enterprises

489 S00300 Noncomparable imports

$490 \quad$ S00401 Scrap

491 S00402 Used and secondhand goods

$492 \quad 500500$

$493 \quad 500600$

$494 \quad 500700$

$495 \quad 500800$

V00100

V0010

V00200

V00300

F01000

F02000

F04000

F05000

F06C00

F06I00

F07C00

F07I00

F08C00

F08I00

F09C00

F09I00
General government industry

Rest of the world adjustment to final uses

Inventory valuation adjustment

Owner-occupied dwellings

Compensation of employees

Indirect business tax and nontax liability

Other value added

Personal consumption expenditures

Private fixed investment + Change in private inventories

Exports of goods and services

Imports of goods and services

National defense: Consumption expenditures

National defense: Gross investment

Nondefense: Consumption expenditures

Nondefense: Gross investment

State and local government consumption expenditures, education

State and local government gross investment, education

State and local consumption expenditures, other

State and local government gross investment, other
S/L Government Passenger Transit S/L Government Electric Utilities Other S/L Government Enterprises Noncomparable Imports

Scrap

Used And Secondhand Goods

General Government Industry

RTW Adjustment

Inventory Valuation Adjustment

Owner-Occupied Dwellings 


\section{Appendix C. FORTRAN Calculator}

This appendix describes the input file generated by the Visual Basic program ImSET 2.0, three FORTRAN routines used to do the calculations, and the output file that returns the calculations to ImSET 2.0.

\section{C.1 The Input File}

The FORTRAN calculator is designed to process a data stream generated by the program ImSET 2.0. Such a file, labeled "qminput.txt," is shown below in the box.

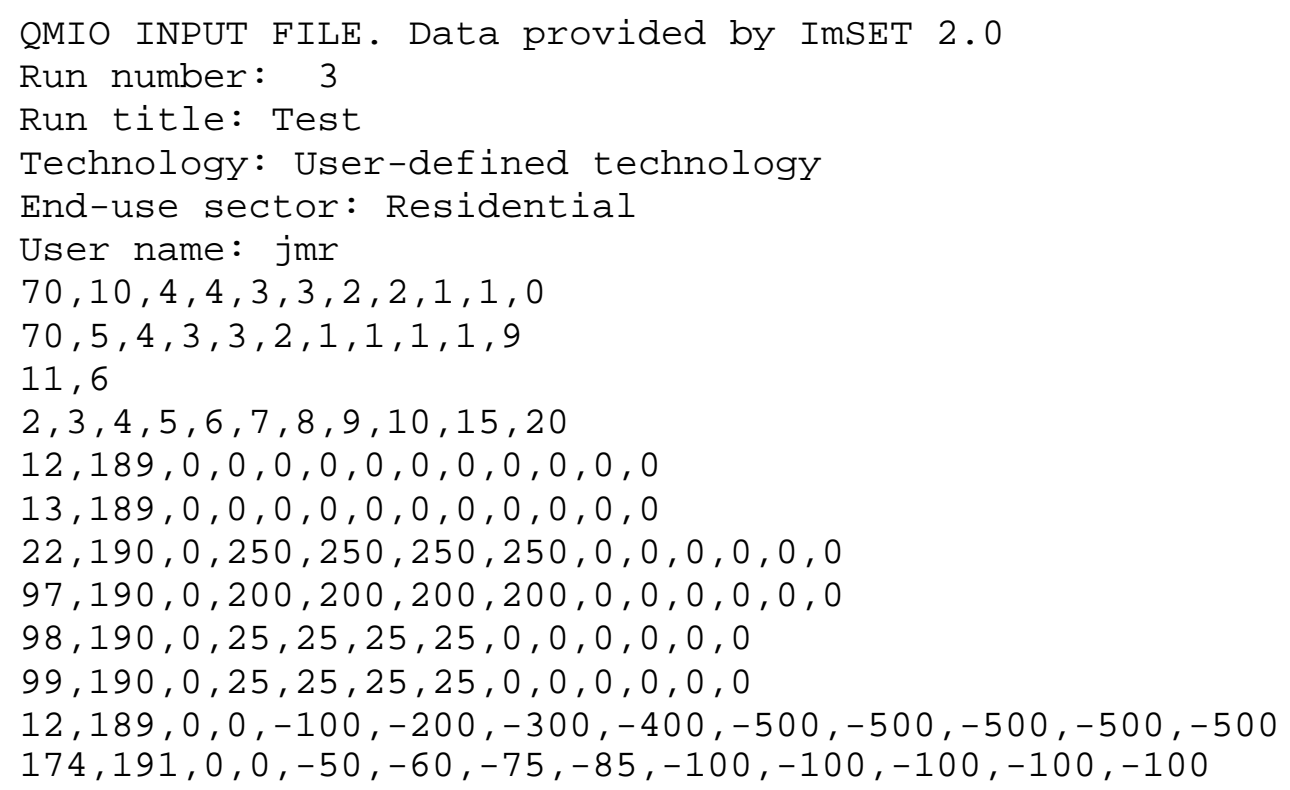

The file contains six lines of text ending with the user name. The text is followed by two sets of seven weights (the two lines beginning with 70,10 , etc.), a line that tells the calculator how many years of data are included (10) and the number of changes to read (6), and the year numbers (2,3, etc.). These year numbers are added to 2000 so the results are reported as 2002, 2003, etc. Following the year numbers, there are two lines that report the capacity adjustments as a result of energy savings, one for electricity (12) and one for gas utilities (13). In this case, there are no changes to capacity, so all ten of the numbers are zero. Following these capacity changes are six sets of changes to the data, one for each of the sectors 22, 97, 98, 99, 12, and 174. Cross referencing these sectors (see Appendix B) reveals that the capital changes are for other construction (22), turbines and related manufacturing (97), other engine equipment manufacturing (98), and power transmission equipment manufacturing (99). These capital equipment changes give rise to electricity (sector 12) savings by the residential sector and a series of O\&M savings (that for residential buildings go to sector 174, personal services) beginning in 2005 and peaking in 2009 at $\$ 500 \mathrm{M}$ and $\$ 100 \mathrm{M}$ respectively.

The second index number, for capital expenditures 190, indicates that these changes are to be made to the final demand vector, specifically to investment. If commercial equipment was considered rather than residential equipment, there would be changes to other industry sectors which would be represented by 
the second index number and would be one of the 188 industries identified in Appendix B. For fuel savings, the second index number is 189, indicating that the savings, for the residential sector, occur in the consumption vector. The operations and maintenance expenditures have a second index that is 191 . While these are treated much like capital expenses, these are separately identified so that the final demand vector can be adjusted without concerns about financing.

\section{C.2 The FORTRAN Programs}

There is a FORTRAN main program, IMSET, which calls a FORTRAN subroutine, QM3, which then calls subroutine DEMAND. The main program reads in the data file described above and transfers the data to the calculating subroutine QM3, which returns the results to the main program and writes the data file that is then read by the Visual Basic (VB) program. The subroutine QM3 first reads the core data from a binary file that holds the 1997 Benchmark I-O data, then calculates the base period employment, earnings, and output. It then loops through each of the years to be processed, changing the Use matrix data or the final demand data, then recalculating the employment, earnings and output. When all years are processed, the routine transfers the results back to the main program. In the course of this processing, QM3 calls the DEMAND subroutine to make adjustments to final demands and assure that the final demand vector is appropriately rescaled. In addition, there are five other routines that multiply, add, and invert matrices, which are briefly described but not shown here.

\section{C.2.1 The Main Program, ImSET}

The main program, ImSET, is shown in the text boxes on the next two pages. While comments in the code explain most of the operations, this explanation will be cued to the input file, shown above. After a number of parameter and variable definitions, the program opens two files, the input file above, and the file to which the results will be printed, QM-CHG.DAT. The program then skips over the six lines of text that are not used by the calculator. The next read statements put the first set of eleven weights into the variable iwgt, and the second set of weights into the variable jwgt. Since these are read in as integer percentages, they are converted to floating point decimal numbers in the loop that begins, DO 14. Since the final demand vectors include both exports and imports, two additional weights (both zero) are added to be consistent with the structure of final demand. The next two read statements (in the continuation text box) assign the number of years processed to JYR and the number of changes to be made to N. The next two read statements read the capacity changes into the variable y. The read that completes the input file reads the two variables, inx and indx, that hold the set of industry or final demand indexes, along with all the I-O changes into $\mathrm{X}$.

At this point the program has input the data stream and turns over processing to QM3. When the results are returned from QM3, they are contained in six variables: SUMJ, SUMH, and SUMQ contain the base period jobs, earnings and total output. The vectors SJ, SH, and SQ contain the calculated model results, one for each year, of which there are JYR $(=10)$ years. The program next prints the base period values to the output file, then calculates and prints out the difference between subsequent years calculated values and the base period values to this same file.

The program is then completed, so control is transferred back to the VB program. 


\begin{tabular}{|c|c|}
\hline $\mathrm{C}$ & PROGRAM ImSET \\
\hline C & This program will read in data, make a few calculations, then \\
\hline C & transfer operation to QM3, which does the work: Changes the \\
\hline C & Use matrix, then calculate output then multiply the outputs by \\
\hline C & the employment intensities, after adjusting final demands by \\
\hline C & iwgt. JYR is the number of years. JWGT is used for capital \\
\hline C & distribution. The years for analysis are then read in as 2,3 , \\
\hline C & etc., then these are added to 2000 to construct the vector of \\
\hline C & years reported. There are twelve categories of final demand: $\mathrm{C}$, \\
\hline C & I, X, M, FI, for both Defense and Nondefense $(D, N)$, FC for both \\
\hline C & D\&N, SLI for Education and Other $(E \& 0)$ and SLC $(E \& 0)$, \\
\hline C & but just ten are read in - no $X$ or $M$ (weights for these are \\
\hline C & set to zero. The thirteenth column is total final demand. \\
\hline C & If iwgt $(11)=100$ changes are just made to the total vector. \\
\hline C & This version allows up to 350 changes and 50 years of data. \\
\hline $\mathrm{C}$ & INTEGER MP NY \\
\hline & PARAMETER $(M P=350, N Y=50)$ \\
\hline & INTEGER iyr(NY), JYR, inx $(2,2)$ \\
\hline & INTEGER $i, j, m, \operatorname{ind} x(M P, 2), 11,12, n$, iwgt(11), jwgt(11) \\
\hline & $\mathrm{REAL}^{\star} 8 \mathrm{X}(\mathrm{MP}, \mathrm{NY}), \mathrm{SUMH}, \mathrm{SUMJ}, \mathrm{SUMQ}, \mathrm{SH}(\mathrm{NY}), \mathrm{SJ}(\mathrm{NY}), \mathrm{SQ}(\mathrm{NY}), \operatorname{wgt}(13)$ \\
\hline & $R E A L * 8$ wgt2 $(13), Y(2, N Y)$ \\
\hline & CHARACTER ${ }^{1} 1 \mathrm{~A}(1)$ \\
\hline & OPEN (10, FILE= 'QM-CHG.DAT' ) \\
\hline & $\begin{array}{l}\operatorname{OPEN}(11, \text { FILE= ' QMINPUT . TXT' }) \\
i=0\end{array}$ \\
\hline C & \\
\hline C & This section reads in the input file, for one technology \\
\hline C & First skip the first 6 lines, then read in two sets of 7 weights \\
\hline C & one for final demand (wgt), one for capacity savings (wgt2) \\
\hline C & These integer values are divided by 100 as floating point \#s \\
\hline C & $D F A D(11 *)$ \\
\hline & $\operatorname{READ}\left(11,{ }^{*}\right) \mathrm{A}$ \\
\hline & $\operatorname{READ}\left(11,{ }^{*}\right) \mathrm{A}$ \\
\hline & $\operatorname{READ}\left(11,{ }^{*}\right) \mathrm{A}$ \\
\hline & $\operatorname{READ}\left(11,{ }^{*}\right) \mathrm{A}$ \\
\hline & $\operatorname{READ}\left(11,{ }^{*}\right) \mathrm{A}$ \\
\hline & $\operatorname{READ}\left(11,{ }^{*}\right) \mathrm{A}$ \\
\hline & $\operatorname{READ}\left(11,{ }^{*}\right)(\operatorname{iwgt}(I), I=1,11)$ \\
\hline & $\operatorname{READ}(11, *) \quad(\mathrm{JWGT}(\mathrm{I}), \mathrm{I}=1,11)$ \\
\hline C & WRITE $\left(*,{ }^{*}\right)$ iwgt \\
\hline C & WRITE $\left(*,{ }^{*}\right)$ jwgt \\
\hline C & \\
\hline C & NOTE! 11 weights are read in but 13 are passed to the calculator \\
\hline C & The difference is, we construct zero weights for $M, x$. \\
\hline$\tau^{2}$ & Do $14, j=1,11$ \\
\hline & $\mathrm{k}=\mathrm{j}$ \\
\hline & $\operatorname{If}(j . g t .2) \quad k=j+2$ \\
\hline & $\operatorname{wgt}(k)=i w g t(j)$ \\
\hline & $\operatorname{wgt2}(k)=j w g t(j)$ \\
\hline 14 & wgt2 $(k)=$ wgt2 $(k) / 100$ \\
\hline 14 & $\operatorname{Wg} \tau(K)=W g \tau(K) / 100$ \\
\hline C & Now read the $\#$ of years and number of changes to read in \\
\hline
\end{tabular}




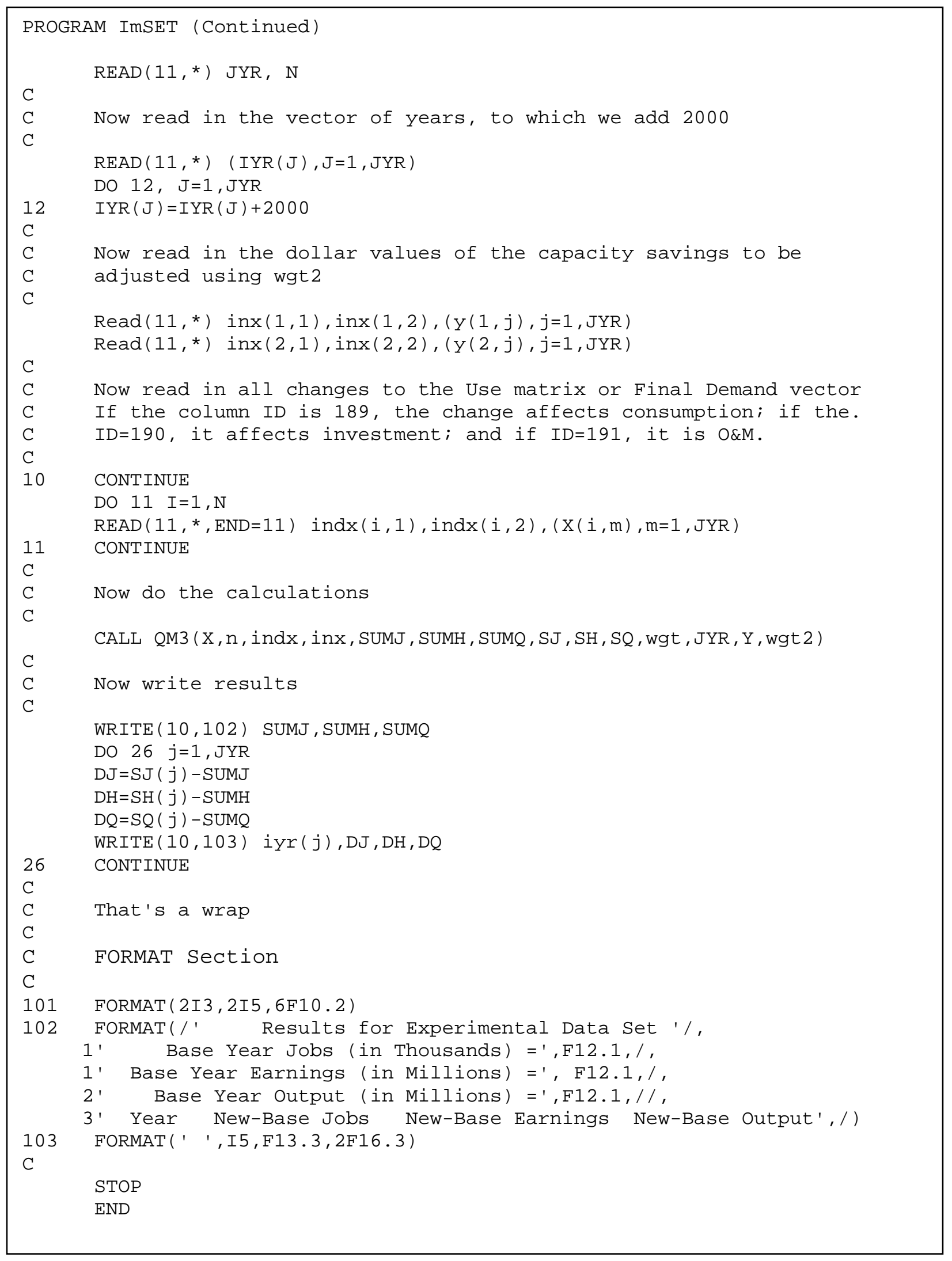




\section{C.2.2 The Calculator - QM3}

The lengthy text box on pages C-6 through C-8 is a listing of the calculation routine, QM3. The first set of comments explains how the naming convention changes from the main program within this routine. Parameters and variables are than defined and the binary file that contains the 1997 Benchmark I-O data is opened. The variables read from this file are $\mathrm{D}$, the market share matrix (derived from the make matrix), U, the use matrix, Q, the vector of industry outputs, DF, the final demand matrix, EI, the matrix of employment and earnings intensity by industry and $\mathrm{P}$, the fraction of scrap produced by each industry. The dimensionality of each of these variables can be determined from the variable definitions at the beginning of the program.

Once the I-O data is returned, the data are used to construct the base period employment, earnings and output. Base period results are constructed by multiplying industry output, the first column of Q, by two sets of industry intensities. These intensities are found in the variable EI, with the first column job intensities and the second earnings intensities. Multiplying each industry's output by these intensities yields jobs and earning, which are cumulated over all industries. Total output is also cumulated and returned in the scalar variables SUJ, SUE, and SUQ, as indicated in the comments on page C-6 in the comments after statement numbered 63.

The loop beginning with DO 40, on the next page, processes each year's data. The processing of each year begins by rewinding and re-reading the binary file that contains the I-O data, to assure that any changes will be made to the original data, since the changes to this data will be different for each year. The next set of statements zero out the set of variables used to differentiate between changes to capital purchases, changes to fuel use, changes in water use, and changes in O\&M expenses. Then vectors are defined that allow the program to identify which changes fall into each of these categories. These are the vectors, FL, KL, WL, and OM, consisting of zeros and ones, where the units identify the change as falling into the specific categories, with F, K, W, and OM referencing fuel, capital water and O\&M changes, respectively.

After these assignments, QM3 begins processing each year's data. Then after zeroing out two variables to hold the sum of final demand and the sum of changes to value added, identified by fuel type, the total to capacity adjustment is calculated for this year. That is stored in the variable ADJK. Then the changes to final demand and the use matrix are made, identifying the capital and O\&M, fuel, and water final demand changes separately. The value-added changes to the use matrix are made to each of the appropriate columns, then cumulated into sva and O\&M changes are cumulated into OAM. While specific industries have their use of the fuels adjusted within the use matrix, the impact on the fuel supplying industry is applied to the final demand vector.

Once these changes are made and results for this year have been zeroed out, I-O data are processed to create a total requirements matrix. This is done by creating a matrix, $\mathrm{B}$, which is derived from the use matrix by dividing each element in the columns by that industry's output. This loop is also used to create the identity matrix ai. First $\mathrm{W}$ is constructed by premultiplying PH by D the market share matrix - this is derived from the make matrix. Then $\mathrm{W}$ is premultiplied by $\mathrm{B}$. These matrix multiplications rely on calls to a matrix multiply subroutine, MMULT, which multiplies a matrix of dimension ( $\mathrm{k} \mathrm{x} \mathrm{n}$ ) by a second (n $\mathrm{x} \mathrm{m})$ matrix and returns a $(\mathrm{k} \mathrm{x} \mathrm{m})$ matrix. A similar routine, MMULT1, multiplies a ( $\mathrm{k} \mathrm{n})$ matrix by an ( $\mathrm{x}$ 1) vector to create a ( $\mathrm{k} \times 1)$ vector. This $\mathrm{B}^{*} \mathrm{~W}$ matrix (called "a" in the program) is then subtracted from the identity matrix, ai, using the subroutine MADD (which adds or subtracts, depending on the value 
of $\mathrm{j},-1$ in this case for subtraction). The result, which replaces the Use matrix, is then inverted using two subroutine from Numerical Recipes ${ }^{21}$.

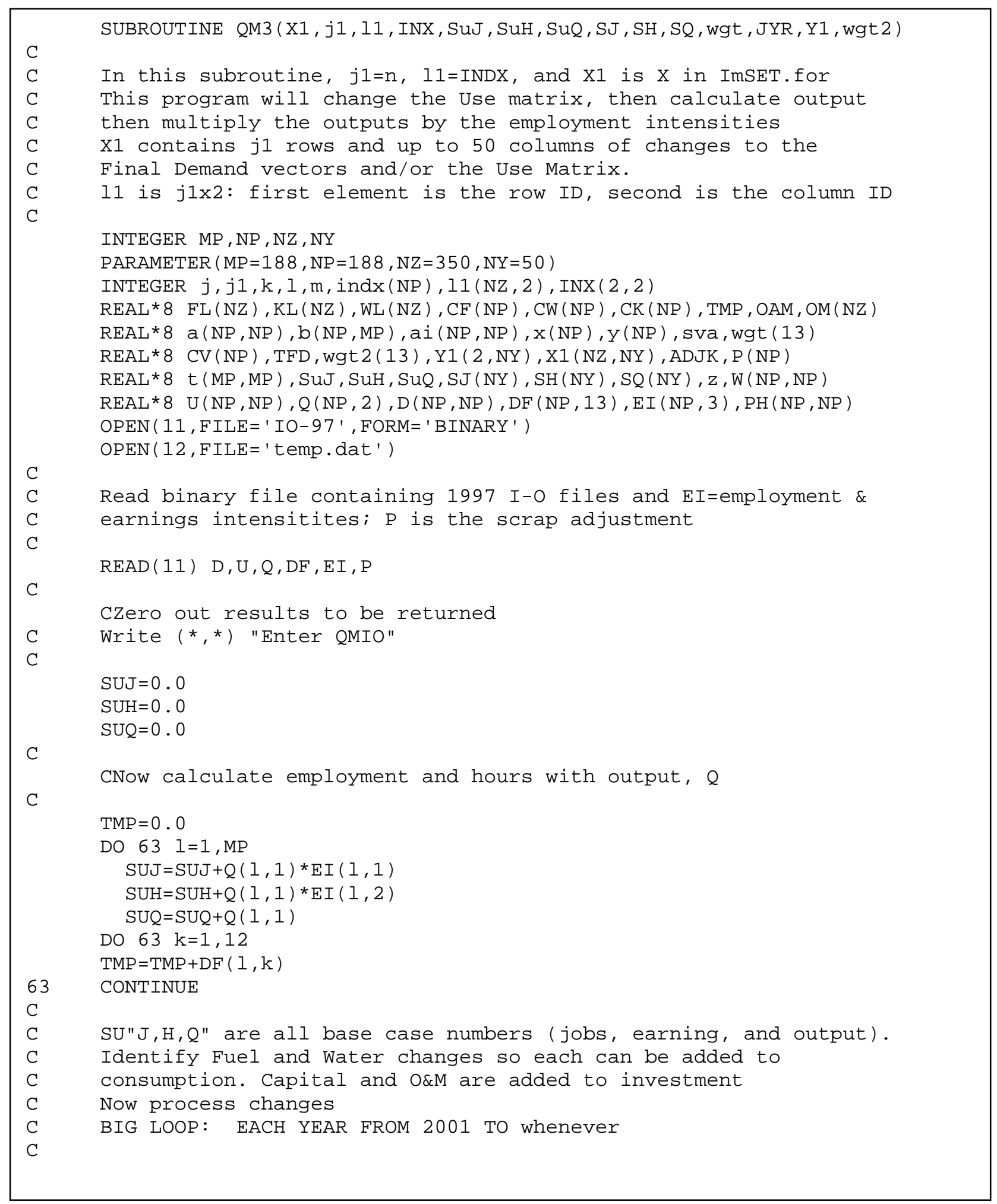

${ }^{21}$ Press, William H., et al. 1986. Numerical Recipes: The Art of Scientific Computing. New York: Cambridge University Press. For matrix inversion, see p. 38. 


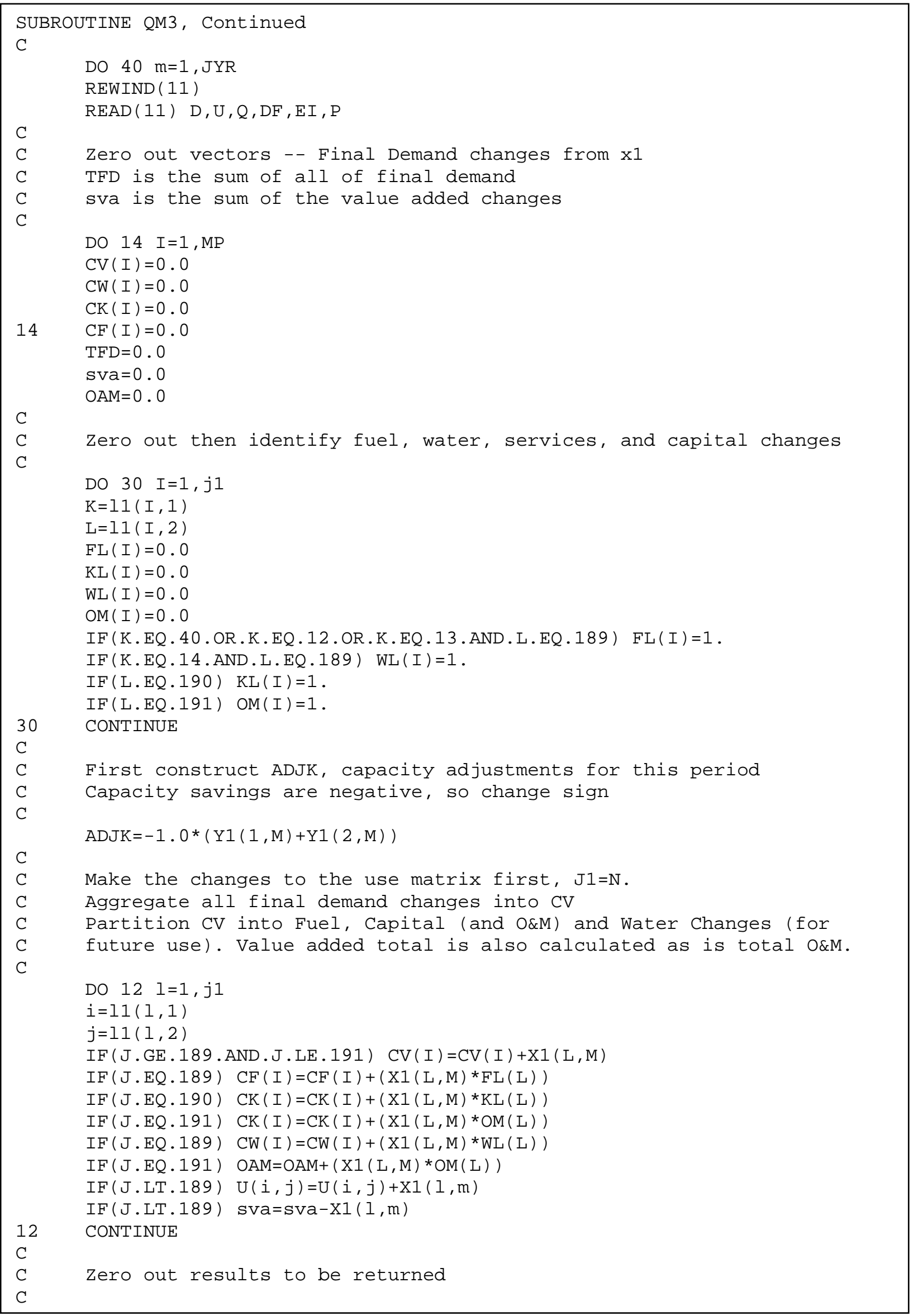




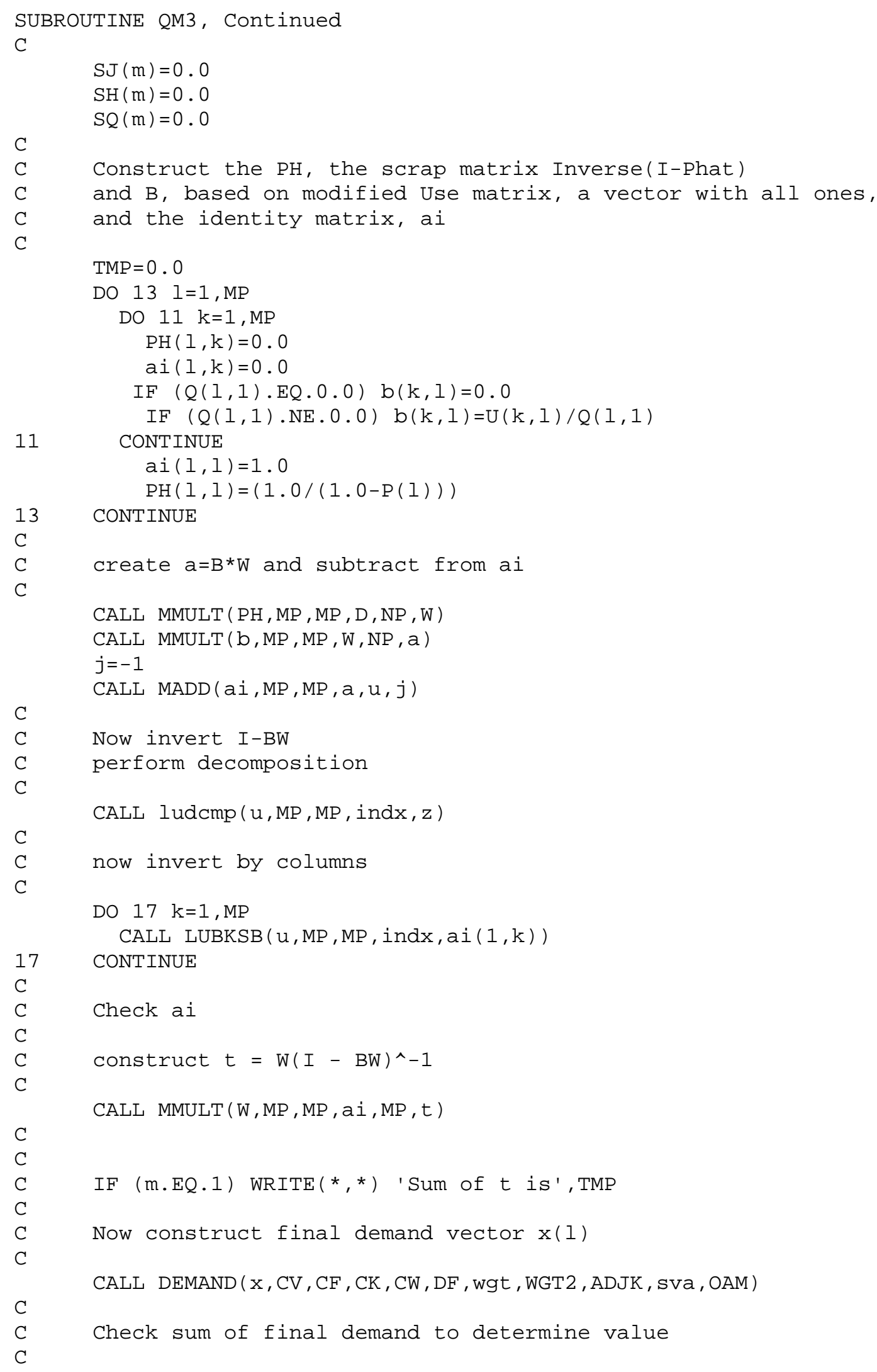




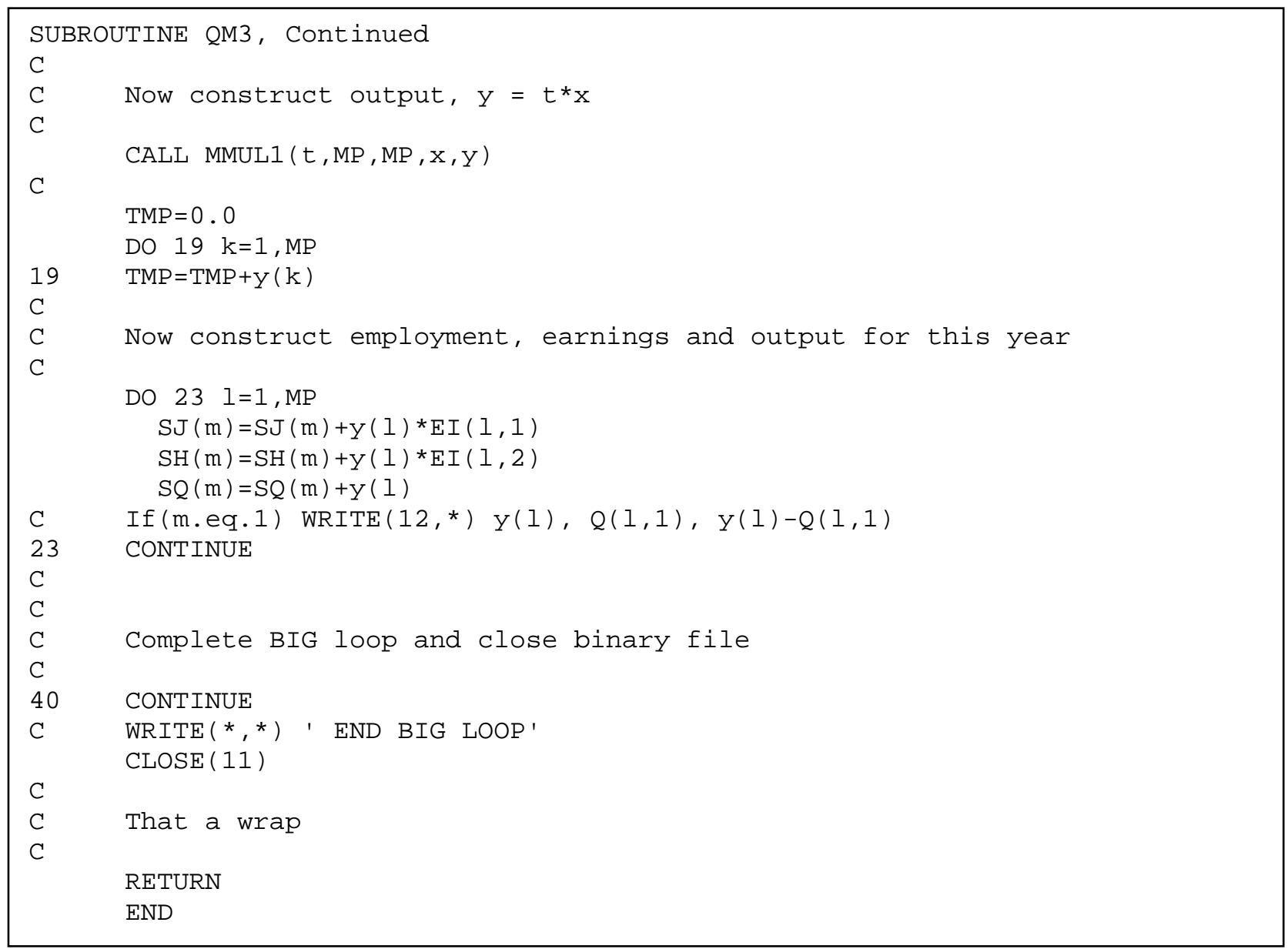

The resulting inverse (replacing ai) then is premultiplied by the modified market share matrix, $\mathrm{W}$, to yield the total requirements matrix, labeled $t$. At this point, we are ready to create the final demand vector, so a call is made to the subroutine DEMAND. This returns the final demand vector $\mathrm{x}$, which is then premultiplied by the total requirements matrix, $t$, to yield the output vector, $y$. Output then is multiplied by each column of the intensity matrix to yield this year's jobs, and earnings. This period's output is then just the sum of all of the industry outputs. When each of the JYRs of data have been processed, the big loop is complete and the results are returned to the main program.

\section{C.2.3 Changing Final Demands -- DEMAND}

The call to this subroutine transfers the changes to final demand read in by the main program, contained in the vectors CV, CF, CK, and CW, and the array of final demands, DF, read in from the binary file. In addition, the weights to distribute the financing charges and the weights to allocate the capacity changes are transferred in the wgt and WGT2, along with the value of the capacity changes, contained in ADJK. Finally, all the value-added variables, a total and a variable for each of the fuel changes, and the total value of O\&M changes contained in OAM are transferred. The first set of statements below the initial comments zero out accumulator variables, aggregate the finance and capacity weights, and sum each of the components of final demand. The $13^{\text {th }}$ column in this array is the total final demand vector, with the other columns corresponding to consumption, investment, exports, imports, various Federal government investment and consumption and various state and local investment and 
consumption. The next block of calculations zero out the vector of final demands to be returned and cumulates the changes to final demand partitioning these changes into capital and O\&M purchases, which affect investment, and fuel and water purchases, which affect consumption.

The capital and O\&M changes (all those changes to final demand expect for changes to the fuel vectors) are added to the investment vector, just as the fuel savings are subtracted from the consumption vector. These investments need to be financed by "taxing" some component of final demand, after adjusting for O\&M expenses, which are not "financed.". The strategy is this version of the model is to first determine how the different components of final demand are to be taxed; then adjust components of final demand for the tax, carrying along all changes to the twelve vectors that constitute the components of final demand. In the event that all the "tax" applies to the aggregated component, then these weights for the various components are zero and no adjustment occurs. From a computational point of view, this simply means that the components are not modified when adjustments are made. Once the aggregation occurs, if then a portion of the "tax" is applied to the aggregate component, then that is treated. A similar scheme is used if the "savings" achieved by a reduction in the building of energy capacity is distributed back to final demand or applies to the aggregate.

Accordingly, the first step is to adjust the consumption vector for the fuel savings and redistribute these savings back to other consumption; this is done in the loop beginning DO 20. Similarly, adjustments to the investment vector are made according to the distribution of capital expenditures after adjusting for O\&M changes (in our example on page C1, these capital expenses occur for sectors 22, 97, 98, and 99), then each of the vectors of final demand are "taxed" my multiplying the weight associated with this component of GDP (which in our example, is the first string of numbers beginning with $70,10, \ldots$ ) by the total capital expense and rescaling each component of GDP to reflect the cost of financing the investment. (Note, that if the investment costs are nil, then no scaling occurs, but the adjustment proceeds as if the weights were there.) Then if there are capacity adjustments to be made, these are subtracted from the "Other New Construction" activity that is in row 22 of the final demand vector. The scalars provided by the user to make these adjustments are used to expand (or contract) the vector of final demand so it is scaled appropriately. Note also that if the capital costs are not financed, then the total of final demand will expand by that capital expense just as if the capacity savings are not redistributed to other sectors, then these savings are "lost" and the total of final demand is reduced.

Capital costs and capacity adjustments might not be fully added back in, depending on sum of the weights provided in wgt and WGT2.

Before final adjustments are made, the 12 components of final demand are aggregated to a single vector. Then the program branches to the concluding section that makes adjustments if there is a non-zero weight in component 13 of the two weighting vectors (note that in the example, these numbers are zero). The next step adjusts this aggregate vector for the changes either to the financing of capital expenditures or for the distribution of capacity savings changes. As with each component of final demand, we construct a scalar that integrates the financing proportion or the capacity adjustment used to scale the total final demand vector. The $13^{\text {th }}$ weight in each case is used to construct a scalar, Z1, which is the total of final demand minus the $13^{\text {th }}$ weight times the capital change divided by the total of final demand. In symbols, as in the code, $\mathrm{z1}=(\mathrm{ztot}-\mathrm{WGT}(13) * \mathrm{SCK}) / \mathrm{ztot}$ (note that this is one if WGT(13) is zero). The remaining task is the adjustment for changes in value-added if changes were made to the use matrix. (The continuation statement 45 shows the entry point from the section where final demand is treated as a single vector; recall that the same variable, SCV, was used to sum total final demand.) A scaling multiplier, z1, is constructed by adding the sum of value added, SVA, to SCV, then dividing by SCV. Z1 is then used to multiply each element of the final demand vector $\mathrm{x}$, which is then returned to QM3. 


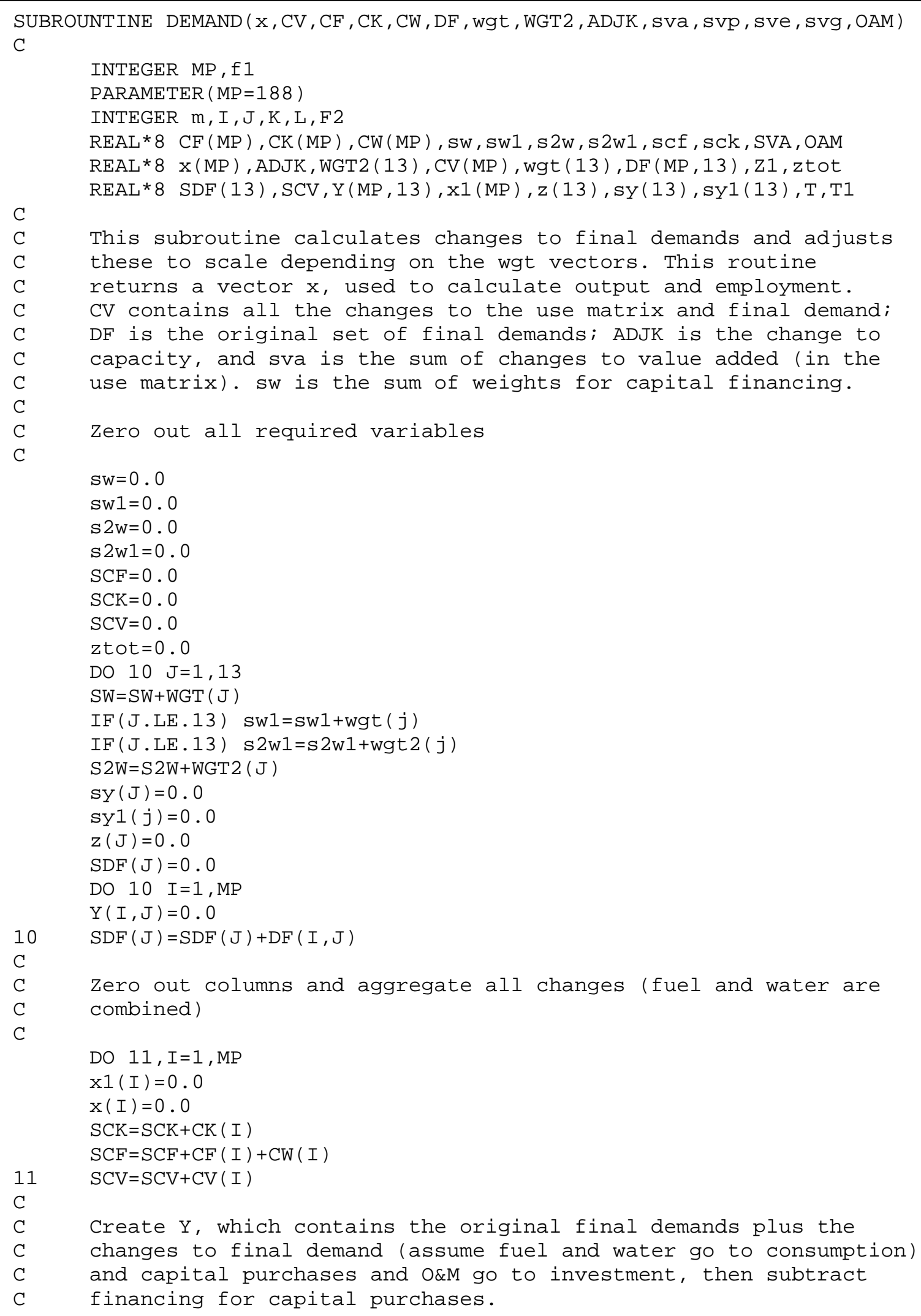




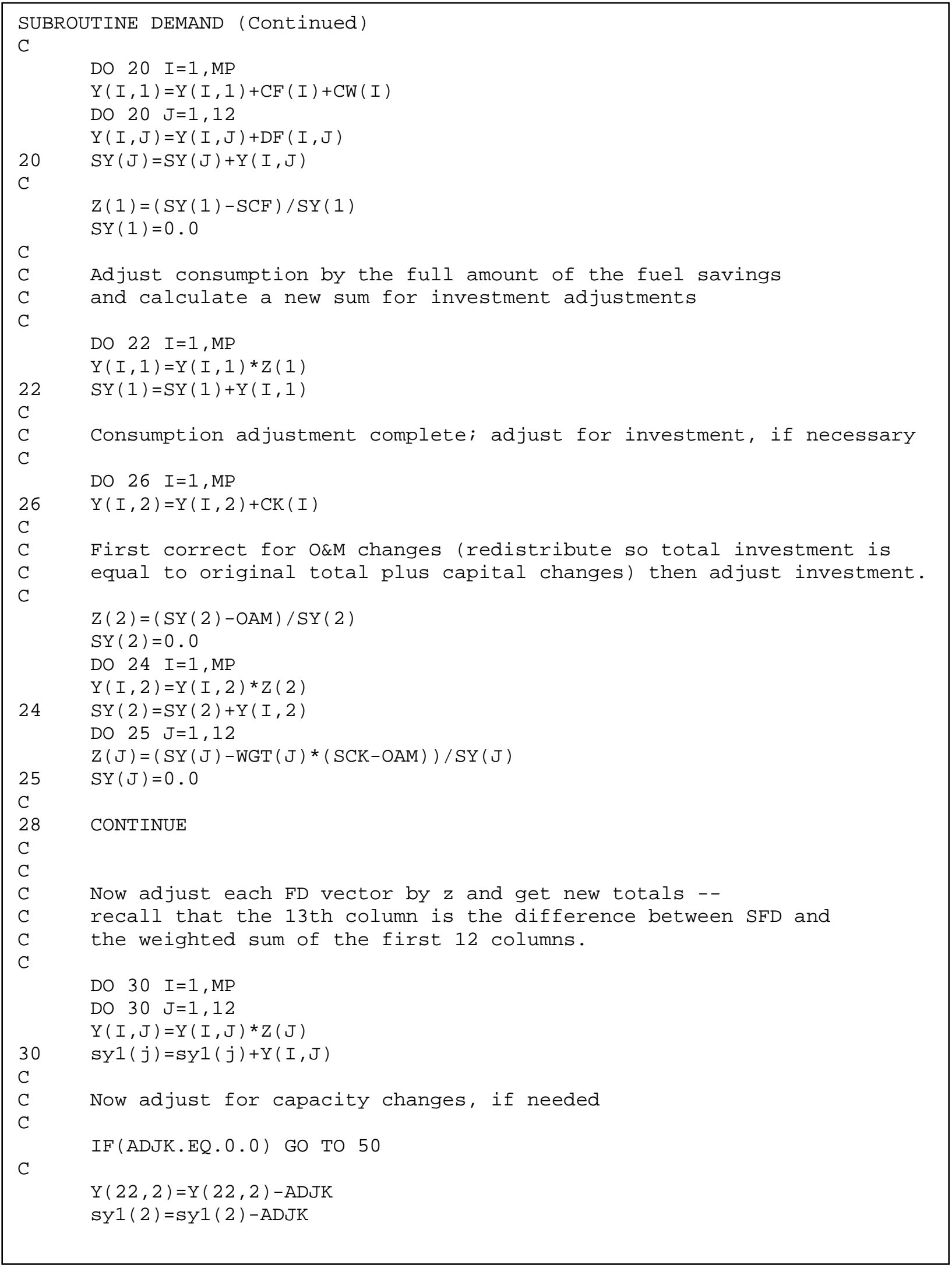




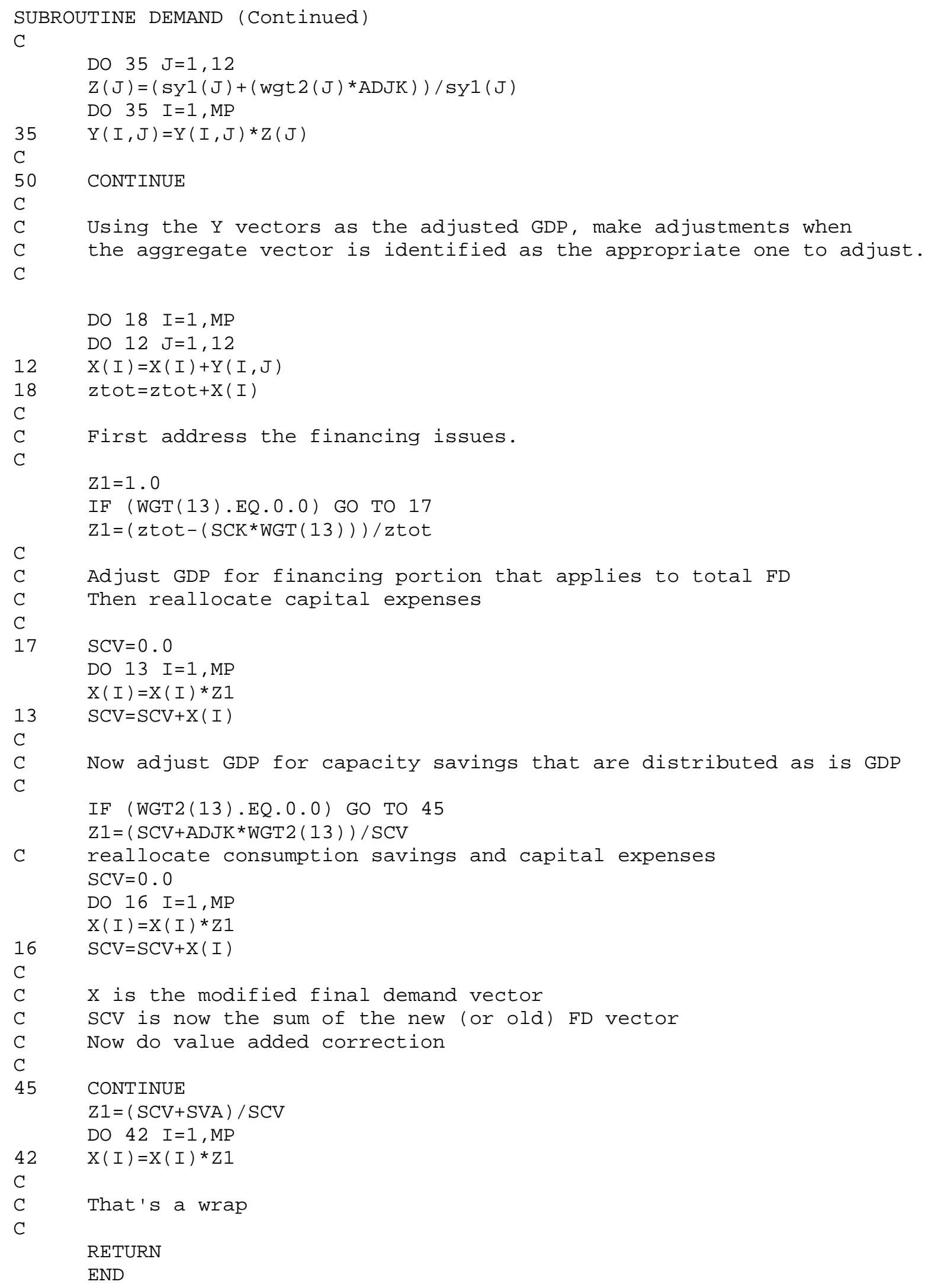




\section{C.3 The Output File}

The calculations from the ImSET FORTRAN Engine generate a file called QM-CHG.DAT, which contains the results of the calculation, and is shown in the text box below. This file is read back into ImSET 2.0 to provide the data and graphics shown below in Figure C.1. The numbers graphed are the same as the right-hand column of outputs shown in the text box.

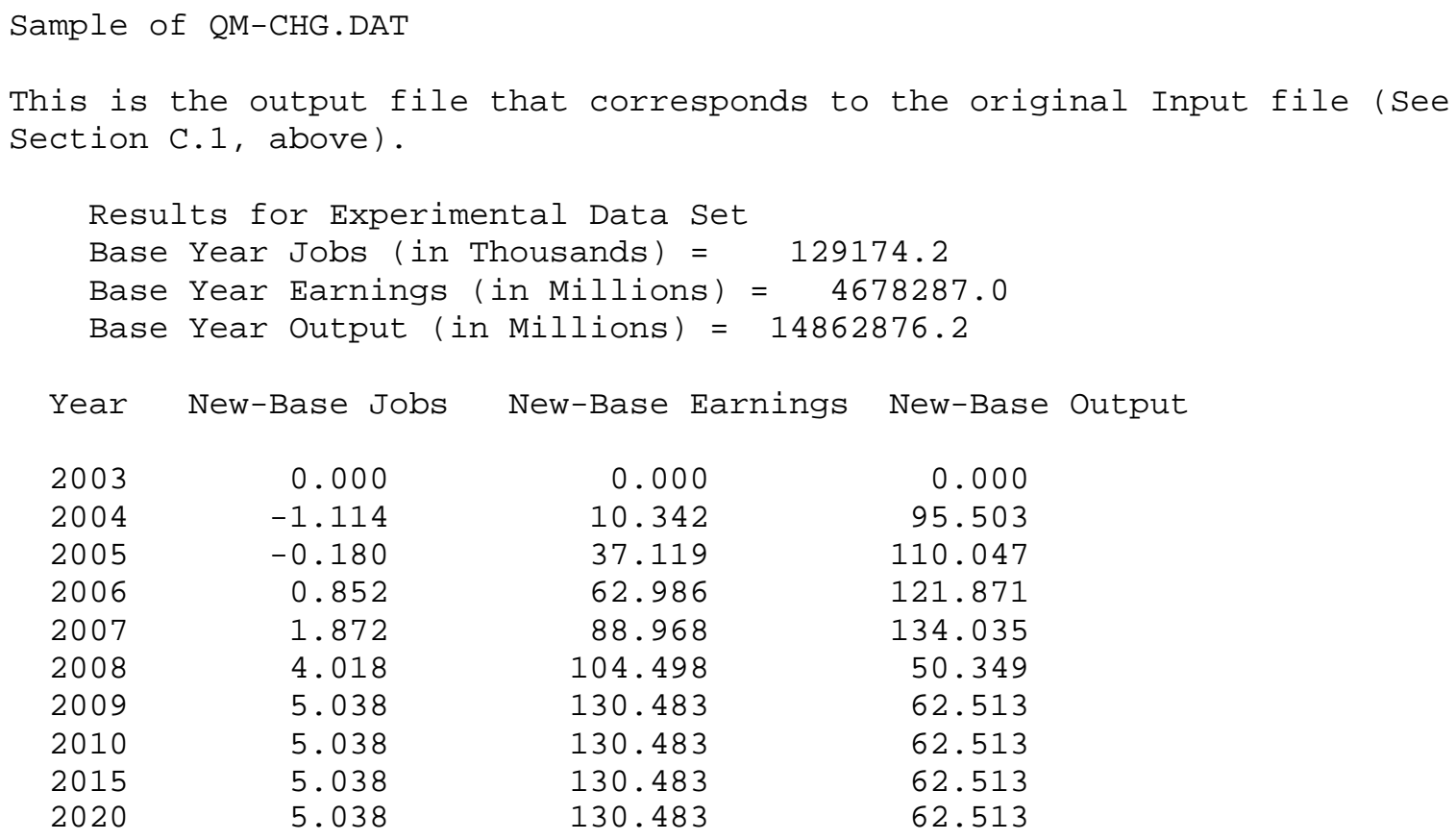




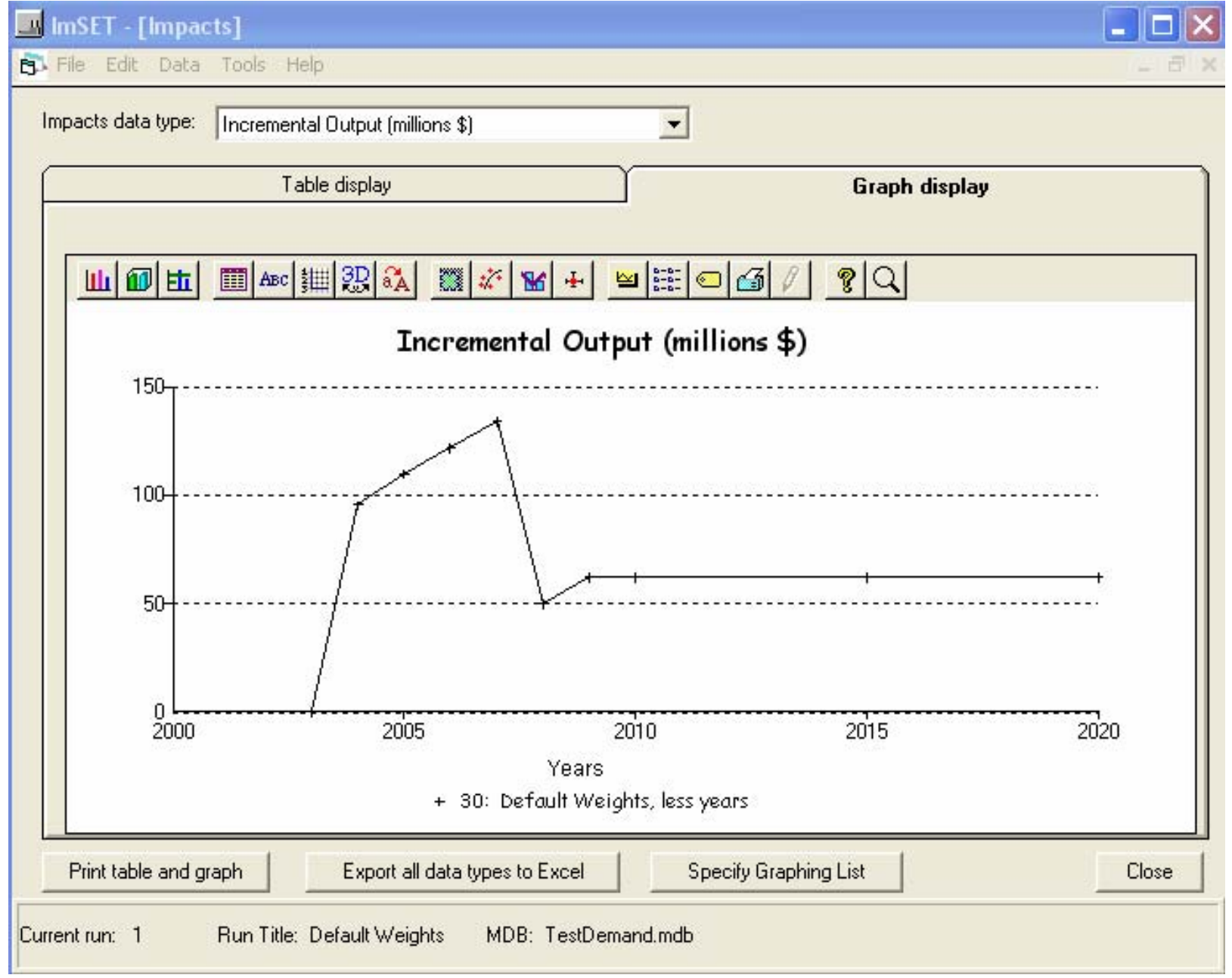

Figure C.1: Graph of Output Changes Shown in Previous Text Box 


\section{DISCLAIMER}

This report was prepared as an account of work sponsored by an agency of the United States Government. Neither the United States Government nor any agency thereof, nor Battelle Memorial Institute, nor any of their employees, makes any warranty, express or implied, or assumes any legal liability or responsibility for the accuracy, completeness, or usefulness of any information, apparatus, product, or process disclosed, or represents that its use would not infringe privately owned rights. Reference herein to any specific commercial product, process, or service by trade name, trademark, manufacturer, or otherwise does not necessarily constitute or imply its endorsement, recommendation, or favoring by the United States Government or any agency thereof, or Battelle Memorial Institute. The views and opinions of authors expressed herein do not necessarily state or reflect those of the United States Government or any agency thereof.

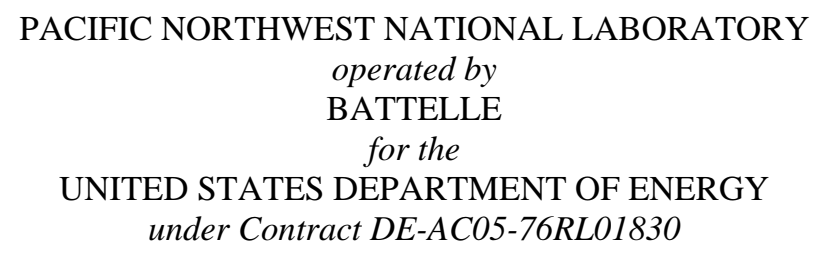

Printed in the United States of America

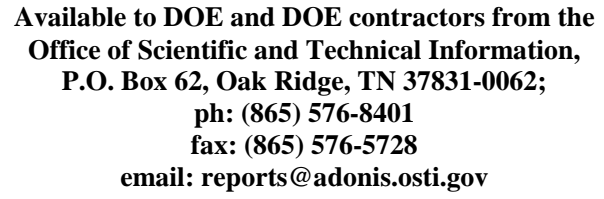

Available to the public from the National Technical Information Service, U.S. Department of Commerce, 5285 Port Royal Rd., Springfield, VA 22161 ph: (800) 553-6847 fax: (703) 605-6900 email: orders@ntis.fedworld.gov online ordering: http://www.ntis.gov/ordering.htm 
PNNL-15273

\title{
ImSET: Impact of Sector Energy Technologies
}

\author{
J. M. Roop \\ M. J. Scott \\ R. W. Schultz
}

July 2005

Prepared for

the U.S. Department of Energy under Contract DE-AC05-76RL01830

Pacific Northwest National Laboratory Richland, Washington 99352 


\section{Summary}

This version of the Impact of Sector Energy Technologies (ImSET) model represents the next generation of the previously developed Visual Basic model (ImBUILD 2.0) that was developed in 2003 to estimate the macroeconomic impacts of energy-efficient technology in buildings. More specifically, a special-purpose version of the Benchmark National Input-Output (I-O) model was designed specifically to estimate the national employment and income effects of the deployment of Office of Energy Efficiency and Renewable Energy (EERE)-developed energy-saving technologies. In comparison with the previous versions of the model, this version allows for more complete and automated analysis of the essential features of energy efficiency investments in buildings, industry, transportation, and the electric power sectors. ImSET is also easier to use than extant macroeconomic simulation models and incorporates information developed by each of the EERE offices as part of the requirements of the Government Performance and Results Act. While it does not include the ability to model certain dynamic features of markets for labor and other factors of production featured in the more complex models, for most purposes these excluded features are not critical. The analysis is credible as long as the assumption is made that relative prices in the economy would not be substantially affected by energy efficiency investments. In most cases, the expected scale of these investments is small enough that neither labor markets nor production cost relationships should seriously affect national prices as the investments are made. The exact timing of impacts on gross product, employment, and national wage income from energy efficiency investments is not well-enough understood that much special insight can be gained from the additional dynamic sophistication of a macroeconomic simulation model. Thus, we believe that this version of ImSET is a cost-effective solution to estimating the economic impacts of the development of energyefficient technologies. 


\section{Contents}

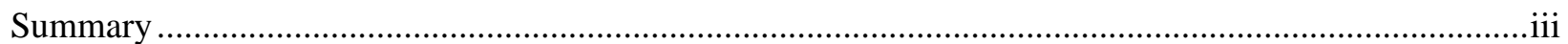

1.0 Introduction: A Method for Assessing Economic Impacts of Energy-Efficient Technologies......1-1

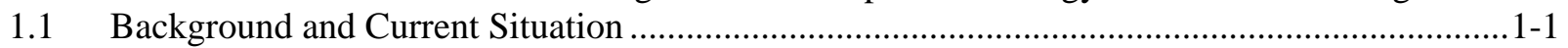

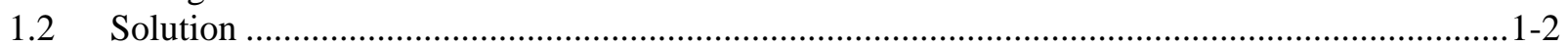

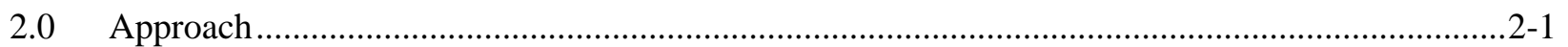

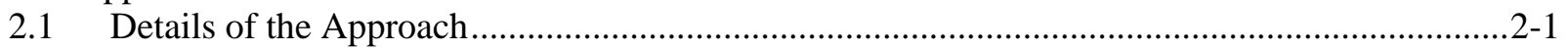

2.2 Components of Impacts: A Once-Only Investment ........................................................2-5

3.0 ImSET Model Results for Example EERE Programs ...............................................................

3.1 Comparison of Capital and Operating Cost Scenarios for Sample Technologies .......................3-1

3.2 Heat Pump Water Heater ...............................................................................................

3.3 EPACT (Commercial Air Conditioning) Efficiency Standards .............................................3-10

3.4 Glass Manufacturing Technologies ................................................................................

4.0 Comparison with Other Studies: An Update............................................................................

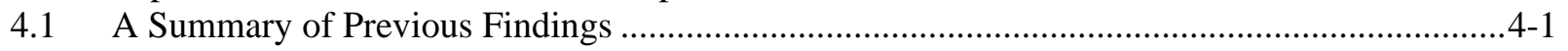

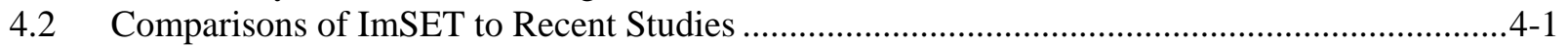

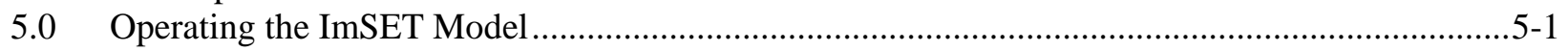

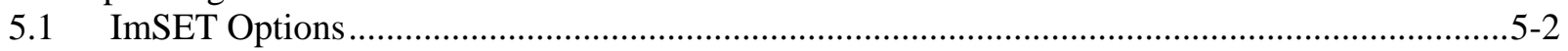

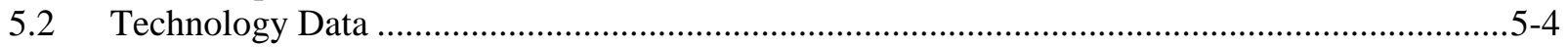

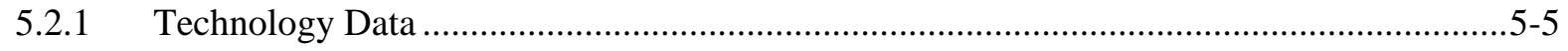

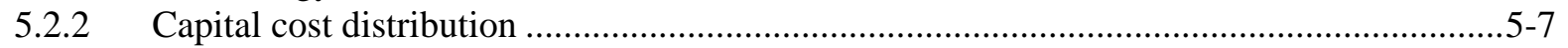

5.2.3 Energy and Water Cost Savings Distribution .................................................................. $5-7$

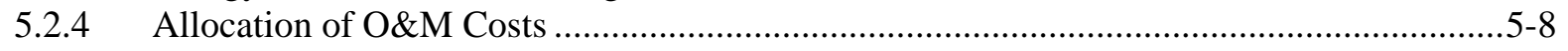

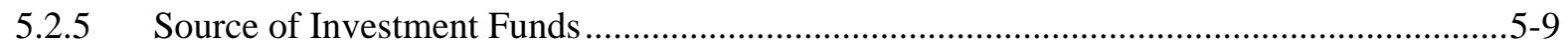

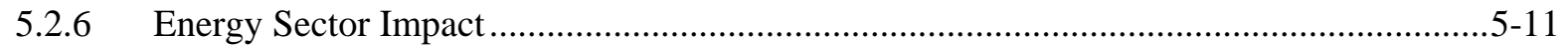

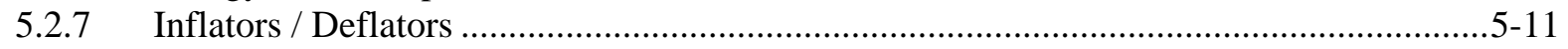

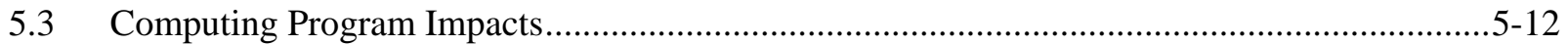

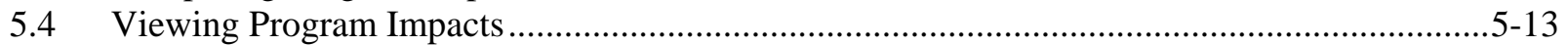

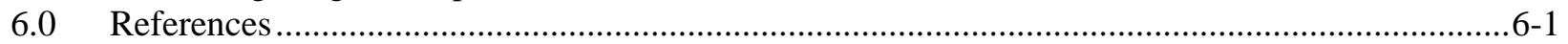

Appendix A. Base Cases for Energy Efficiency Technologies................................................................... 1

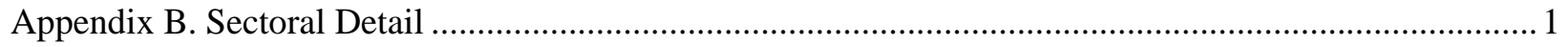

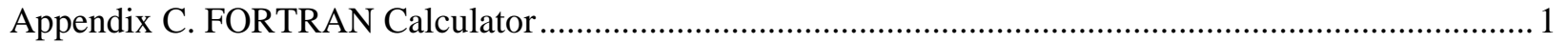

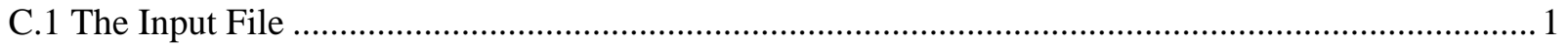

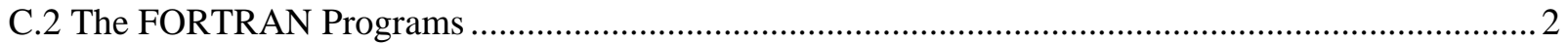

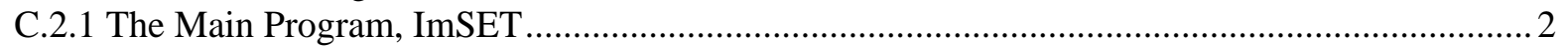

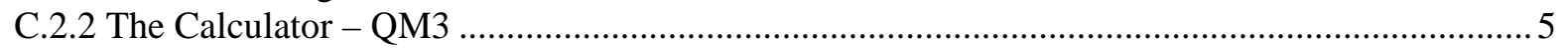

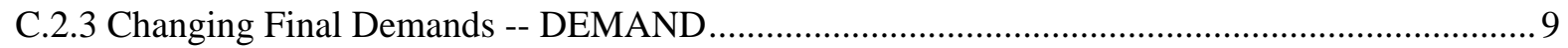

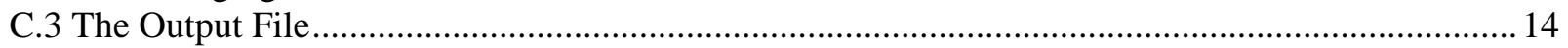




\section{Figures}

Figure 2-1. Process for Analyzing Economic Impact of Energy Efficiency Programs ............................2-2

Figure 2-2. Detailed Calculations of the ImSET Model .................................................................2-4

Figure 2-3. Impact on National Employment of a Hypothetical Once-Only Investment in Appliance

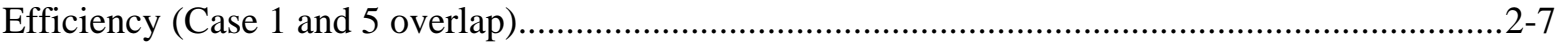

Figure 3-1. Incremental Capital Costs by Year for GPRA Metrics Market Scenarios of Heat Pump Water

Heater, EPACT Efficiency Standards, and Glass Manufacturing Technologies ..............................3-2

Figure 3-2. Value of Energy Savings by Year Relative to Baseline for GPRA Metrics Market Scenarios.35

Figure 3-3. Employment Impacts of Investment in Heat Pump Water Heaters .......................................3-5

Figure 3-4. Effect of HPWH Financing on Employment …..............................................................

Figure 3-5. Impact of HPWH Investment on National Wage Income (\$2003) ......................................3-8

Figure 3-6. Sensitivity of Impacts on National Wage Income to HPWH Investments (\$2003) ................3-9

Figure 3-7. Impact on National Employment of EPACT Standards ...................................................3-10

Figure 3-8. Impact of EPACT Standards Energy Savings on National Wage Income (\$2003) ..............3-11

Figure 3-9. Impact of Glass Manufacturing Sector Savings on National Employment..........................3-12

Figure 3-10. Impact of Glass Manufacturing Sector Savings on National Wage Income (\$2003) ..........3-12

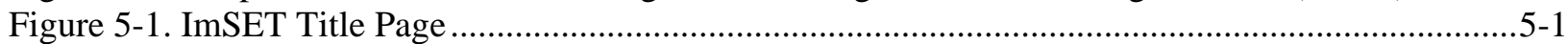

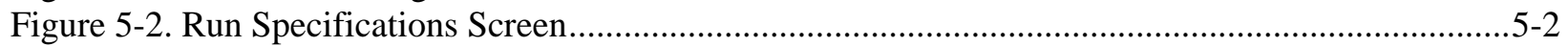

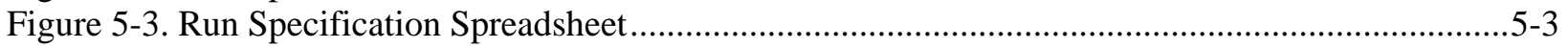

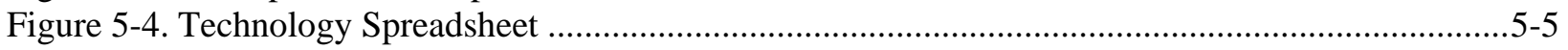

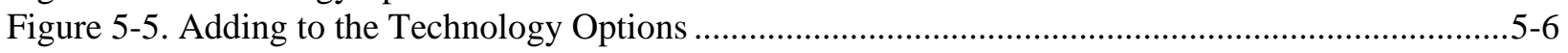

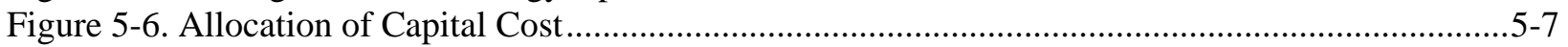

Figure 5-7. Energy/Water Cost Savings Distribution Across Sectors ..................................................5-8

Figure 5-8. O\&M Cost Savings Distribution for Commercial Sector......................................................5-9

Figure 5-9. Opportunity Cost of Invested Funds ................................................................................5-10

Figure 5-10. Impact of Energy Savings on Energy Sector Investments ...............................................5-11

Figure 5-11. Assigning Inflators and Deflators...................................................................................12

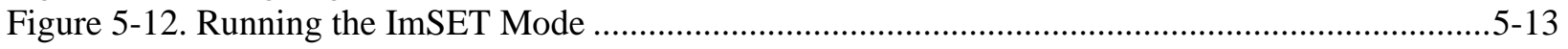

Figure 5-13. Report Manager Screens for Output (Graphical Display) .................................................5-14

Figure 5-14 Report Manager Screens for Output (Table Display)........................................................5-15

\section{Table}

Table 3-1. Efficiency Standards and Energy Savings for Commercial Air Conditioning Equipment 3-3

Table 4.1. Employment Multipliers, Nayak, and Selected ImSET Industries ........................................ 4-3 


\subsection{Introduction: A Method for Assessing Economic Impacts of Energy-Efficient Technologies}

\subsection{Background and Current Situation}

As part of measuring the impact of government programs in improving the energy efficiency of the nation's infrastructure, the U.S. Department of Energy's Office of Energy Efficiency and Renewable Energy (EERE) is interested in assessing the economic impacts of these programs, specifically on national employment and wage income. As a consequence, EERE funded Pacific Northwest National Laboratory (PNNL) to develop a simple-to-use method for in-house estimation of economic impacts of individual programs. After surveying three fundamental methods available to estimate employment and wage income impacts for selected energy efficiency improvements in the U.S. economy (multipliers input-output [I-O] models, and macroeconomic simulation models), the I-O approach was selected for the original version of Impact of Sector Energy Technologies (ImSET) model, known as ImBuild, because of its focus on technologies for residential and commercial buildings (for an overview of each of these approaches, see the original documentation in Scott et al. 1998). The current (third) version of the model also deals with impacts of technologies designed to reduce energy use in industrial processes, transportation, and electric power generation.

This version of ImSET uses essentially the same methodology as the previous version (see Scott, Roop, and Schultz, 2002), but greatly expands the scope of the model to include more sectors of the economy and thus covers a wider array of technologies. By covering more sectors, the model lends itself to assessing the impacts of evaluating technologies developed outside the original model's scope, including power, industrial, and transportation technologies. The major features of ImSET are:

- The Input-Output structure is based on the 1997 Benchmark U.S. table (Lawson, et al. 2002), specially aggregated for this project to 188 sectors (ImBuild II featured 98 sectors).

- Associated FORTRAN programs have been extensively revised.

- The treatment of Operating and Maintenance (O\&M) costs has been substantially revised.

- The time scale of the model has been extended to 50 years.

The model is a static input-output model, which allows a great deal of flexibility concerning the types of energy efficiency effects that can be accommodated. For example, certain economic effects of energy efficiency improvements require an assessment of inter-industry purchases. Some energy efficiency investments will not only reduce the costs of energy but the costs of labor and other goods and services as well. In the language of economics, this represents an investment-specific increase in productivity and value-added $^{1}$ and a change to the input-output structure, differing from a case in which a constant I-O structure is applied to a change in investment. Yet, this effect is at the heart of many investment decisions.

\footnotetext{
${ }^{1}$ Value-added is the difference between the value of the output of a sector and the costs of the purchased goods and services that go into the sector. It is mainly composed of labor and proprietor income, retained earnings of corporations, rents, and taxes.
} 
Savings in the energy, labor, materials, and services from improved productivity are the source of subsequent rounds of investment and economic growth.

I-O models such as ImSET can be used to estimate the impact of changes in overall efficiency and productivity in the economic sectors that make energy-efficiency investments. As an example, ImSET could apply to an investment by a paper mill in more energy-efficient equipment, the investment by an electric utility in more efficient plant, or improvements in transportation infrastructure. An I-O model also can keep track of the potential increases in value-added that result from the improvement in efficiency and can, with appropriate assumptions, calculate the macroeconomic effects associated with spending of this increased income.

While ImSET is greatly expanded in its capabilities, it has a user-friendly shell that makes it easy to use, with the advantage that it provides more theoretically plausible and comprehensive results than alternative models.

The chief drawbacks of this, or any I-O model, are that 1) they do not provide information on the timing of impacts (for example, they do not say how long an investment in efficiency will take to work its way through the economy), and 2) because no prices or explicit behavioral adjustment mechanisms are found in I-O models, no internal market features are present, such as increasing prices for sector output or for factors of production that automatically limit the size of impacts. In an I-O model, it is assumed that inputs needed for production in each sector are available without limit in constant proportions at constant unit cost. Thus, when analyzed in an I-O model, even very large scale investments that increase the scale of an industry many times over would not encounter either labor or material shortages that might cause prices to rise in the real world and dampen the economic response.

While we acknowledge these drawbacks, the scale of most energy-efficiency improvements, relative to the overall economy, are small enough to make this an inconsequential effect. To analyze larger scale efficiency improvements or investments, a macroeconomic simulation model would be more appropriate, as it would account for changes in relative prices that could be expected from very large investment cases.

\subsection{Solution}

The programmatic needs of EERE suggest that a simple, flexible, user-friendly method is needed to derive national employment income and output impacts of EERE programs. This special-purpose version of the national 1997 I-O table was designed specifically to estimate the employment, income, and output effects of building and other EE-sponsored energy efficiency technologies. In comparison with alternative models, ImSET allows for more complete and automated analysis of the essential features of energy efficiency investments. ImSET is also easier to use than extant macroeconomic simulation models. It does not include the ability to model certain dynamic features of markets for labor and other factors of production featured in the more complex models, but for most purposes these excluded features are not critical. Analysis using ImSET should be credible as long as the assumption is made that relative prices in the economy would not be substantially affected by energy efficiency investments. In most cases, the expected scale of these investments is small enough that neither labor markets nor production cost relationships should seriously affect national prices as the investments are made. The exact timing of impacts on gross product, employment, and national wage income from energy efficiency investments is 
not well-enough understood that much special insight can be gained from the additional dynamic sophistication of a macroeconomic simulation model. Thus, we believe that ImSET is a cost-effective solution to the problem at hand. 


\subsection{Approach}

The macroeconomic impacts of EERE programs can be analyzed using the following four-step process, illustrated in Figure 2.1. The first three steps are conducted as part of the normal analysis of costs and energy savings associated in the Government Performance and Results Act (GPRA) Metrics process; however, the fourth step (calculating the economic impacts) has been automated in ImSET. The goal of the model-building process was to create a computerized tool that required only a knowledge of ImSET technologies to run. The national I-O model is a $188 \times 188$-sector version of the $495-\times 495$-sector benchmark U. S. Input-Output table for 1997. The 188 sectors are those deemed most important for analyzing economic impacts of EERE technologies; it is comprehensive enough to cover all energyefficient technologies produced within EERE.

\subsection{Details of the Approach}

\section{Step 1. Identify Program Economic Characteristics}

To analyze existing EERE R\&D programs, a set of assumptions must be developed concerning the effects in the marketplace when more efficient technologies are developed or adopted as a result of the programs. The relevant program information includes size of the incremental investment in the technology over time compared with the conventional technology it replaces, corresponding extra energy savings by fuel type in physical and monetary terms (may include additional use of some fuels when one type of fuel replaces another), and non-energy operations savings (if any) in comparison with current (conventional) technology. Sufficient information of this type currently exists on many of the EERE technology development and deployment projects as a result of the GPRA Metrics process. Three technologies are used as examples in this report. They were chosen to demonstrate different types of programs, as well as some related macroeconomic issues.

- Residential Heat Pump Water Heater. The purpose of the DOE program in this area is to develop and commercialize highly efficient water heaters. The technology is expected to displace the next generation of already highly-efficient conventional water heaters. ${ }^{2}$

- Energy Policy Act of 1992 (EPACT) Commercial Building Standards-Air Conditioning. The DOE program is continuing the development of efficiency standards for commercial air conditioning that will improve the comfort and reduce the cost of air conditioning commercial retail and office space.

- Glass Manufacture: The final example is a group of three technologies focused on the glass manufacturing process. These technologies are oxygen enrichment for the glass furnace, cullet preheating for glass, and a new type of glass temperature sensor.

\footnotetext{
${ }^{2}$ Heat Pump Water Heaters are no longer an active DOE research and development effort, but they serve as a good application of the tool.
} 


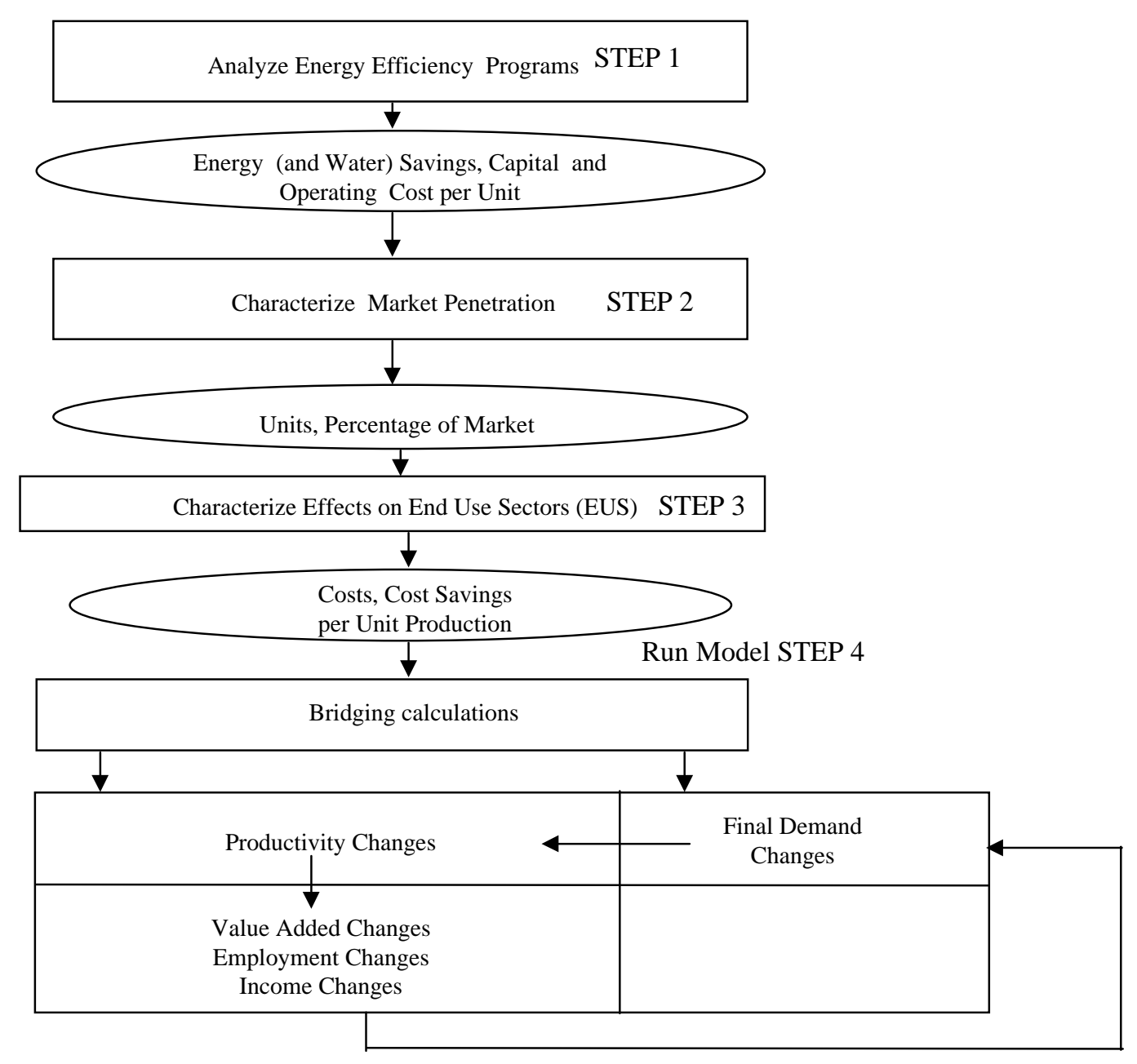

Figure 2-1. Process for Analyzing Economic Impact of Energy Efficiency Programs

Together, these examples demonstrate the impact of programs aimed at residential technology development, programs aimed at commercial technology development, and programs aimed at industrial process energy efficiency knowledge and products.

\section{Step 2. Characterize Market Penetration of the New Technologies}

Existing research on the size and characteristics of the market niche(s) being addressed by the EERE technologies or programs is used to estimate market penetration of the new technologies or programs (see Elliott et al. 2004). The GPRA Metrics effort produces this type of information.

\section{Step 3. Characterize Effects of the EERE Programs on End Use Sectors (Residential, and Commercial Buildings, Industrial, Transportation and Power Production Sectors)}

Effects of the program on the end-use sectors, using the technology or results of the program, must be characterized. This step combines analysis from Steps 1 and 2. A bridging matrix is used to match buildings and equipment investments in end-use sectors (for example, classes of commercial buildings) to the economic sectors that construct, operate or occupy these buildings. This process is necessary because, 
although the EERE programs are organized around the principal energy-consuming sectors of the economy and their end uses, I-O models use economic sectors organized according to North American Industry Classification System (NAICS) codes (these have supplanted the standard industrial classification [SIC] system since 1997). For purposes of the empirical analysis in this report, economic sectors occupying commercial buildings are assumed to experience savings in proportion to their baseline expenditures on energy and building maintenance goods and services.

\section{Step 4. Calculate Economic Impacts}

Given the data developed in Steps 1-3, the ImSET model then calculates the impacts of energy efficiency programs on employment in the following three sub-steps.

\section{Initial Investment Impacts}

First, the model calculates the gross output, income, and employment effects of initial spending on energy efficiency investments. (These impacts include the initial spending on plant and equipment by businesses and households that adopt the new energy-efficient equipment and practices. The impact of spending by the EERE programs on services provided in government, universities, and other contractors is not computed.) In an I-O model, this impact is estimated by changing expenditure levels in the government, household consumption, and business investment columns of final demand and in the productivity changes box of Figure 2.1. The left-hand side of Figure 2.2 illustrates the necessary calculations in more detail. The residential and commercial buildings investments are estimated, based on Step 2, and then allocated to business sectors through the bridging calculations. This calculation is done directly in the business sector for industrial processes, transportation, and power production.

An important finding of this project is that the size and algebraic sign of the employment impacts of the initial investment process can depend critically on project financing. The investment typically must be financed by diverting resources from elsewhere in the economy. Therefore, the net employment impact of these energy-saving investments depends not only on the labor intensity of the investment process itself, but also on the relative labor intensities of those investment and consumption processes from which the necessary investment resources are diverted. For example, as shown in Section 3.0, the positive impact of the initial capital investment is dampened considerably and may be reversed after the opportunity cost of the investment funds is taken into account.

\section{Calculate Impact of Energy Savings on Value Added and Residential Savings}

ImSET calculates economic savings associated with changes in the use of energy, labor, and materials with the improved technologies and practices. In the case of residential buildings and private transportation applications this is relatively straightforward because residential and private transportation savings are assumed to be recycled into final demand. For commercial buildings, commercial transportation, industry, and power production applications, the process is more complicated because the inter-industry relationships between specific sectors are affected, not just final demand. For example, if the commercial building saves electricity, the business sectors operating/occupying these buildings would have lower purchases from the electric utility industry per dollar of output; thus, the coefficients in the utility industry row of the input/output structure of the economy must be reduced. Results from Step 3 are inserted into the ImSET model in the inter-industry portion of the I-O table (shown as Productivity Changes in the last box of Figure 2.1); then the model is run with the automatically recomputed table. Because the energy and maintenance intensity of the commercial sector changes continuously, the coefficients of the I-O structure are automatically recalculated at each time step. 


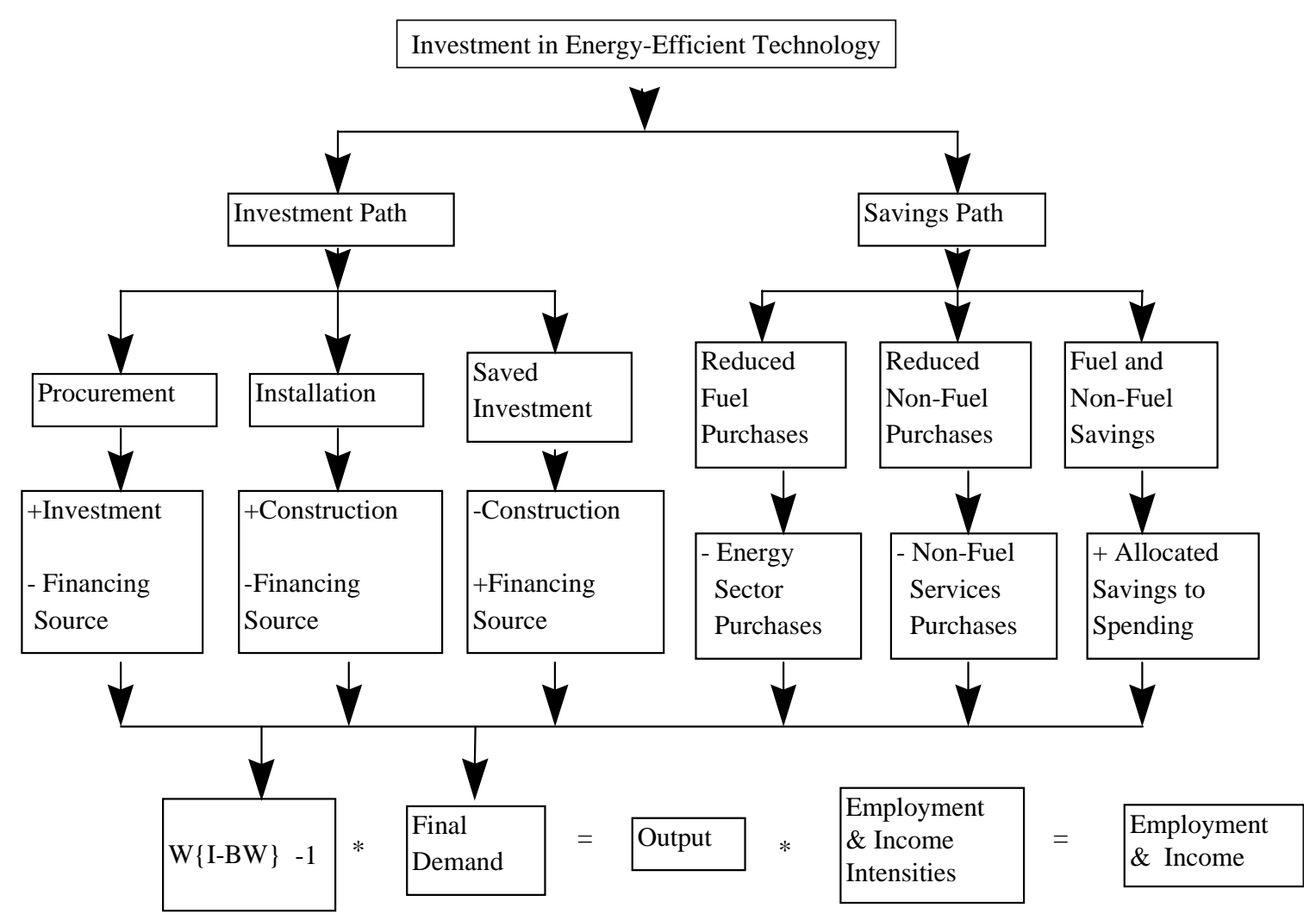

Figure 2-2. Detailed Calculations of the ImSET Model

The financial impacts of energy and non-energy savings in the commercial building, commercial transportation, industry, and power production sectors (for example, savings in building maintenance) are computed by the model. These savings are treated as an increase in value added that is available to be saved or invested by the sector collecting the income.

The energy and non-energy savings do not affect employment in the national economy until they are reinvested or spent. For purposes of the analysis conducted for this report, the increments to value added (savings) are assumed to be allocated to final demand as with all other value added in each sector. That is, the additional income of these sectors is assumed to be spent on final demand. These increments to value added increase GDP, so they are accumulated and are used to modify the vector of final demands (in equal proportions) so that the sum of value added and GDP are again in balance. Thus an energy savings that occurs for industry, transportation, or commercial activity is assumed to contribute to value added and thus increases overall GDP, however slightly.

\section{Calculate Economic Impact of Value Added and Residential Savings}

ImSET accumulates the energy and non-energy savings in the residential buildings and personal transportation sector and the value-added changes associated with energy and non-energy savings within the commercial buildings, industrial, power production, or commercial transportation sectors. The model then calculates spending impacts associated with these savings by proportionately increasing final demand across all sectors as noted, while at the same time reducing final demand in the sectors that supplied the saved resources. This step accounts for the spending associated with the monetary savings and improvements in technological efficiency and for the associated shift from energy to non-energy 
spending. It also accounts for changes in the patterns of economic activity within the economy, due to technological changes caused by the EERE programs (for example, in retailing less electricity is used per dollar of output because of more efficient lighting). ${ }^{3}$ This calculation is shown in the last row of Figure 2.2 (the first box represents the recalculation of the direct and indirect requirements matrix as these technological changes occur - see Lawson, et al., 2002).

ImSET collects the estimates of the initial investments, energy and non-energy savings, and economic activity associated with spending of the savings (increases in final demand in personal consumption, business investment, and government spending), and provides overall estimates of the change in national output for each NAICS sector using the adjusted I-O matrix. Finally, the model applies estimates of employment and wage income per dollar of economic output for each sector and calculates impacts on national employment and wage income.

When finished, the results of ImSET model runs can be saved by running an imbedded dialog designed for this purpose.

\subsection{Components of Impacts: A Once-Only Investment}

Energy conservation technology affects the activity level of the U.S. economy through three primary mechanisms. First, if the incremental capital costs of the new technology per installed unit are different than those of the conventional technology, changes in final demand will occur in the sectors involved in manufacturing, distribution, and installation for both technologies, changing the level of overall economic activity. ${ }^{4}$ Second, depending on how the efficiency investment is financed, it may "crowd out" other domestic saving, investments, and consumer spending, somewhat reducing overall economic activity. Third, energy and non-energy expenditures are reduced. On the one hand, this reduction lowers final demand in the electric and gas utility sectors, as well as the trade and services sectors that provide maintenance, parts, and services. On the other hand, it increases net disposable income of households and businesses and increases general consumer and business spending in all sectors (including some increases in expenditures for electric and gas utility services and retail trade and services).

Figure 2.3 demonstrates how these mechanisms work by showing the effect of a hypothetical onceonly investment in residential energy conservation technology in the ImSET model. It is assumed that consumers spend a premium of \$100 million on more-efficient residential appliances in the year 2000 that each year thereafter saves \$15 million of electricity, \$30 million in natural gas, and \$5 million building

${ }^{3}$ ImSET does not account for all of the long run impacts of technological change. The change in energy using capital in the commercial sector would alter the marginal value of all of the factors of production (including labor and capital) and would induce a rearrangement of capital and labor that ultimately results in an increase in output and in final demand. We show part of this effect - that of the initial spending associated with the savings, but not the effect of increased capital stock that would be created by the investment portion of the spending. Most economic models, including many dynamic simulation models, do not completely reflect the effect of capital accumulation and growth in capacity on final output and employment.

${ }^{4}$ Frequently, a premium is present in the cost of purchase and installation of a new technology, over and above the cost of an alternative conventional system. We have assumed the premium attached to the new technology is due entirely to the differential cost of manufacturing the equipment. Distributor markups and dealer costs are assumed to be unaffected. The share of the premium due to incremental installation costs, if any, may be assigned to the construction sector or some other sector performing the installation, as appropriate. 
maintenance expenditures, for annual savings of \$50 million. This \$50 million annual savings yields a simple payback period of 2 years. The first two cases in Figure 2.3 show only the employment effects of the $\$ 50$ million savings. In the first case, the savings are confined to the residential sector. The second case shows how the impacts would change if these energy savings had instead been experienced in the commercial sector, where the savings are initially experienced as an increase in the profitability of those businesses saving the energy. These profits are assumed to be recycled in the economy as spending by workers, spending by the firms themselves, and by governments experiencing increases in tax collections. In the first case, the energy savings in the residential sector of \$50 million have a net impact on the U.S. economy of about 230 jobs, or about 4.6 additional jobs per million dollars of direct energy savings. The impact is somewhat smaller if the energy savings occur in the commercial sector, 170 jobs, because the employment intensity of the spending mix of businesses, their workers, and government associated with commercial savings is slightly different from the spending intensity of the household sector alone, which is associated with residential savings.

Next, Figure 2.3 adds a third and fourth case to show the employment impacts of the $\$ 100$ million investment itself. The third case shows the impact of the investment premium. In this case, even though investment in the technology itself generates employment, the short run net employment impact is quite small (10 jobs) because the opportunity cost of the investment premium is the dollar amount the investment would have produced elsewhere in the U.S. economy, which on average is almost exactly as labor-intensive as the specific manufacturing sector (Sector 94, Heating and Air Conditions Equipment) that makes the new technology. ${ }^{5}$ Typically, efficiency programs are considered relatively labor-intensive, but this is not always the case. Heating and air conditioning manufacture, for example, has a capitalintensity that is very similar to the overall economy. The strength and direction of the investment effect depends on the size of the investment premium and its combined domestic U.S. direct and indirect labor intensity, relative to that of other domestic spending (the opportunity cost of the investment). For the employment impact of the investment to be positive, the sectors supplying the new technology must on average create more domestic jobs per dollar of spending than does other domestic spending. An extreme form of this positive investment effect would occur if the investment were financed internationally (that is, no domestic opportunity cost is included). This is the fourth case in Figure 2.3, which shows a shortrun jobs impact of five times the initial capital expense, 50 jobs, with an employment impact as a result of the energy savings unchanged from case one. The fourth case also corresponds, at the national level, to the assumption made in many regional analyses of energy conservation impacts, where the investment funds are assumed to come from somewhere else and have no opportunity cost in the region.

\footnotetext{
${ }^{5}$ Strictly speaking, the labor intensity that counts is the employment, direct and indirect, that is created by each dollar of spending. Thus, it is theoretically possible for a capital-intensive industry to buy lots of labor-intensive inputs from other industries and the total effect to be labor intensive as a result.
} 


\section{Incremental Jobs (thousands)}

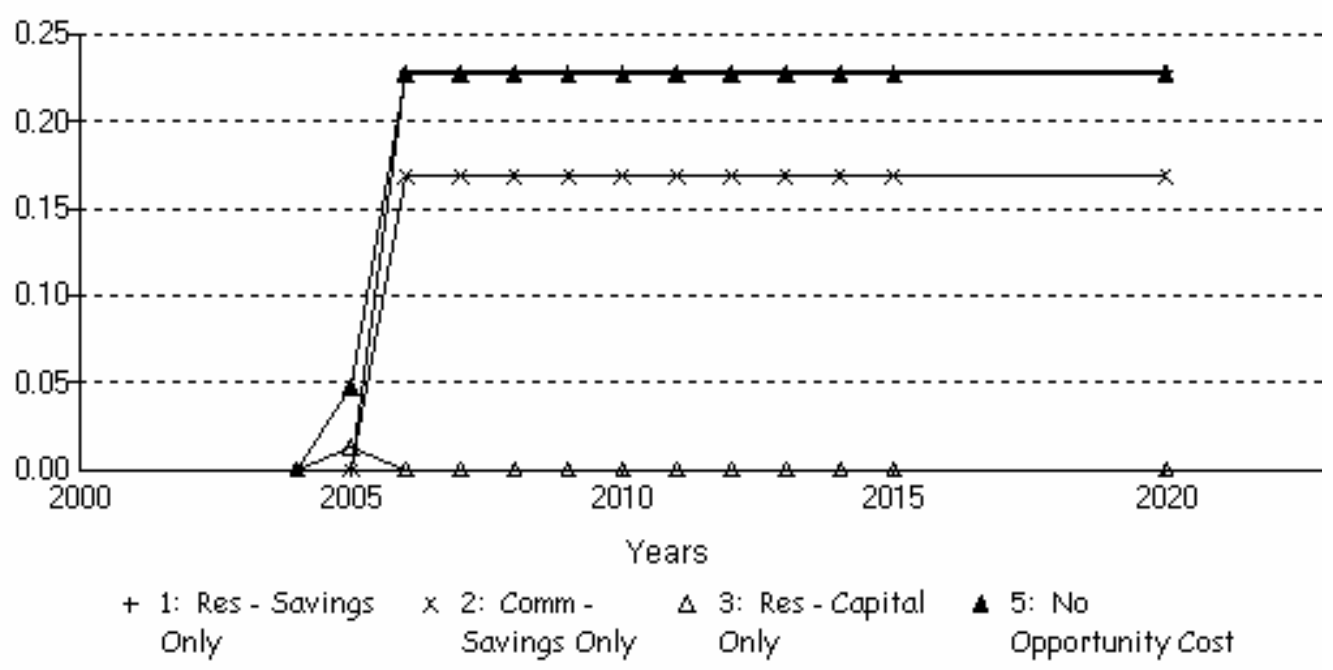

Figure 2-3. Impact on National Employment of a Hypothetical Once-Only Investment in Appliance Efficiency (Case 1 and 5 overlap) 


\subsection{ImSET Model Results for Example EERE Programs}

This section discusses the results obtained by using the ImSET model to calculate the employment and income consequences of three specific building technologies as they are expected to be introduced into the U.S. residential, commercial, and industrial sectors. The three technologies were chosen because they represent a diversity of EERE program characteristics, are likely to affect the economy in different ways, and illustrate a number of issues concerning the economic impact of energy-efficient end-use technologies.

\subsection{Comparison of Capital and Operating Cost Scenarios for Sample Technologies}

The impact of EERE technologies on the national economy depends on the market penetration of these technologies and their associated investments and operating costs. This analysis is tied to the scenarios for market conditions, costs, and energy consumption of specific technologies and programs from the EERE GPRA Metrics, a product of significant work on technology performance, costs, and markets. ${ }^{6}$ Appendix A shows the specific values of these savings and expenditures for the specific scenarios of market penetration. Figure 3.1 shows the premium in capital costs for the GPRA Metrics market penetration scenarios associated with three programs in the FY 2005 EERE Budget Request to Congress: Emerging Technology R\&D on heat pump water heaters, EPACT Energy Efficiency Standards, and three technologies in Glass Manufacturing. These choices illustrate three basic types of EERE programs: an equipment R\&D program (focused on the residential sector), an equipment efficiency standards program (focused on the commercial sector), and an industrial process program. Descriptions of these programs follow.

Heat Pump Water Heaters. The first program is Emerging Technologies R\&D on the heat pump water heater $(\mathrm{HPWH})$ and other follow-on technologies. The purpose of this program is to commercialize highly efficient water heaters for new and existing manufactured and single-family residential buildings. The general program seeks comprehensive solutions for water heating consumption (low cost heat pump water heaters, condensing gas water heaters, waste heat recovery, and water conservation devices), and wants them well established in the market. Once established in the mainstream market, the technologies can become the basis for other approaches, such as Energy Star labeling or minimum efficiency standards.

Heat Pump Water Heater

Market introduction: 2005

Performance Target: 2.47 Energy Factor (demonstrated)

Sales Target: $\quad 10 \%$ by 2015

Installed cost: $\quad$ Initial installation cost of \$700 dropping to \$650 in 2007

Lifetime: $\quad 10$ Years

${ }^{6}$ This report used EERE program data reported in the EERE FY05 Budget Request submitted to the Office of Management and Budget on February 2, 2004, as well as program information from Elliott et al. (2004) that PNNL updated by and with DOE/EE program managers to produce the descriptions shown here. 


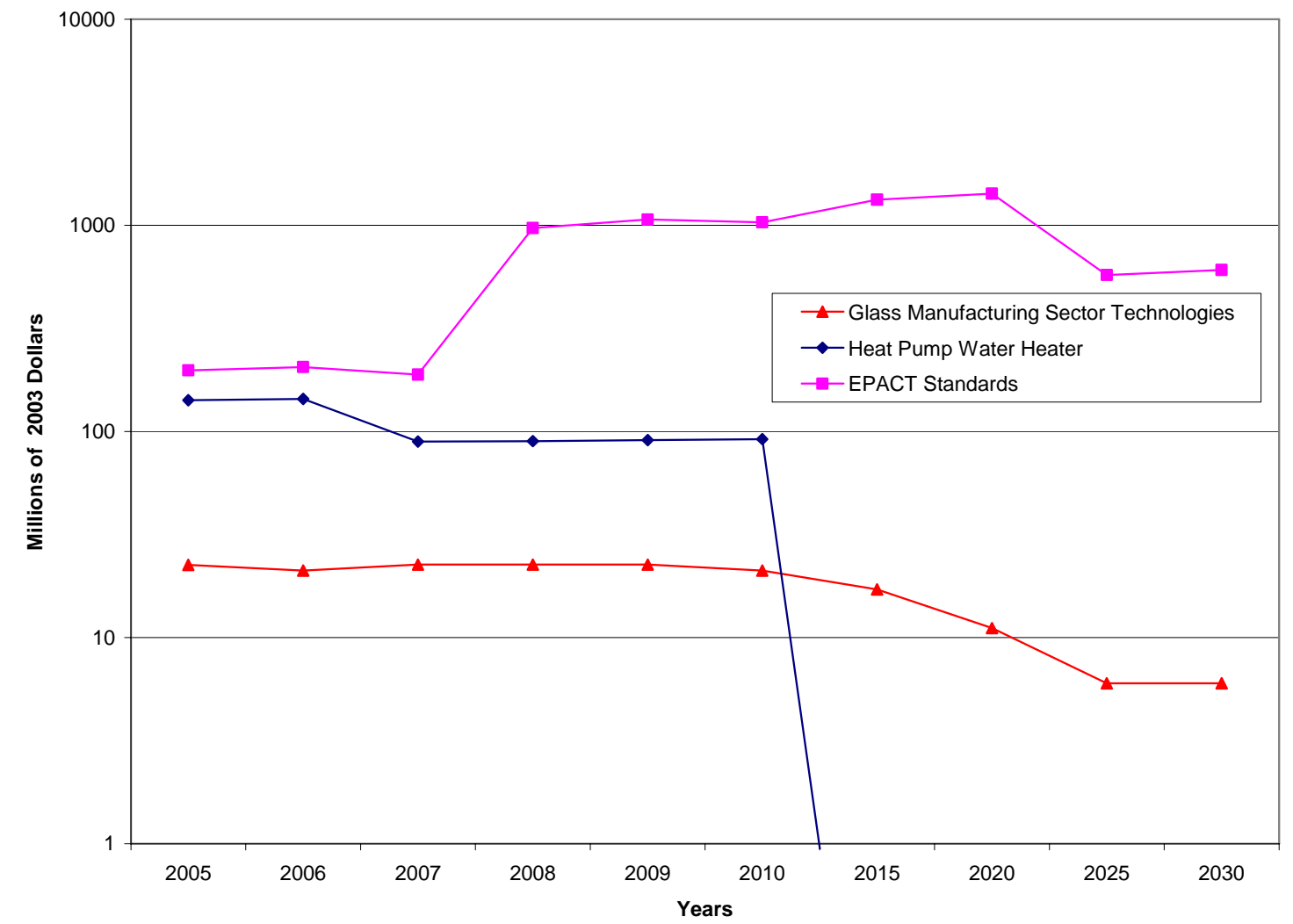

Figure 3-1. Incremental Capital Costs by Year for GPRA Metrics Market Scenarios of Heat Pump Water Heater, EPACT Efficiency Standards, and Glass Manufacturing Technologies

EPACT Energy Efficiency Standards. The second program is EPACT Energy Efficiency Standards. The DOE program is continuing the development that will make a number of types of commercial space conditioning and other equipment commercially feasible. The mission of the overall lighting and appliance standards program is to achieve significant energy savings, consumer cost savings, and reduced air emissions through standards rulemaking. The program also prescribes test procedures that measure energy efficiency and energy use and provide an estimate of the annual operating cost of each appliance.

The long-term goal of the program is the setting of efficiency standards that lead to substantial increases in the average efficiency of new building equipment. The assumption for GPRA is that work will continue in FY2004 for products for which cost-effective additional energy savings may be large. For this version of the GPRA process, these products include boilers, three-phase residential-size cooling equipment, packaged terminal air conditioning and package terminal heat pump equipment, and large rooftop air conditioning equipment. 
Three basic kinds of commercial air conditioning equipment are considered, at various sizes. In general, the goal for these units is to increase their Seasonal Energy Efficiency Rating (SEER) from roughly $8-10$ to around $10-12$ by the year 2008 :

Table 3-1. Efficiency Standards and Energy Savings for Commercial Air Conditioning Equipment

\begin{tabular}{|l|l|l|l|l|l|l|l|}
\hline & Efficiency (SEER, EER) & \multicolumn{3}{|c|}{ Energy Savings by Year (TBtu) } \\
\hline Equipment Category & EPAct & New Std & Eff. Date & 2010 & 2020 & 2030 & Cum. \\
\hline 3-Phase S. Package, Air Source AC, $<65 \mathrm{kBtu} / \mathrm{h}$ & 9.7 & 12.0 & 2005 & 4.6 & 21.0 & 26.5 & 396.0 \\
\hline $\begin{array}{l}\text { 3-Phase S. Package, Air Source Heat Pump, } \\
\text { <65 kBtu/h }\end{array}$ & 9.7 & 12.0 & 2005 & 1.2 & 3.1 & 3.4 & 60.2 \\
\hline 3-Phase Split, Air Source AC, $<65 \mathrm{kBtu} / \mathrm{h}$ & 9.7 & 11.0 & 2005 & 0.9 & 4.1 & 5.2 & 78.1 \\
\hline 3-Phase Split, Air Source HP, $<65 \mathrm{kBtu} / \mathrm{h}$ & 9.7 & 12.0 & 2005 & 9.1 & 24.0 & 26.5 & 463.0 \\
\hline Central, Water Source HP, $>17,<65 \mathrm{kBtu} / \mathrm{h}$ & 9.3 & 12.5 & 2008 & 1.8 & 7.1 & 11.1 & 146.9 \\
\hline Central, Air Source AC, $>=65,<135 \mathrm{kBtu} / \mathrm{h}$ & 8.9 & 11.0 & 2008 & 5.5 & 25.0 & 31.6 & 471.6 \\
\hline Central, Air Source AC, >=135, <240 kBtu/h & 8.5 & 11.0 & 2008 & 5.4 & 24.6 & 31.0 & 463.1 \\
\hline Packaged Terminal AC, 7-10 kBtu/h & 8.6 & 10.8 & 2008 & 0.4 & 1.8 & 2.2 & 33.3 \\
\hline Packaged Terminal AC, $10-13 \mathrm{kBtu} / \mathrm{h}$ & 8.1 & 10.2 & 2008 & 0.6 & 2.6 & 3.3 & 49.5 \\
\hline SEER= seasonal energy efficiency ratio; EER energy efficiency ratio & & & & \\
\hline
\end{tabular}

Glass Manufacturing Improvements. The third program is focused on improving the energy efficiency of the glass manufacturing process in the U.S. There are three component technologies or practices:

- Oxygen enrichment for glass furnace; expected life: 15 years

- Cullet preheating for glass; expected life: 15 years

- $\quad$ Glass temperature sensor; expected life: 7 years

Oxygen enrichment increases the efficiency of the furnace and reduces pollutants by cutting down on $\mathrm{NO}_{\mathrm{X}}$ and other emissions. Cullet (i.e., the raw material for glass - basically sand) preheating reduces fuel use in the furnace by reducing the melt time. Glass temperature sensors improve the throughput of the process and assure quality of the final product. The program is expected to result in the installation through the year 2030 of about 100 units each of oxygen enrichment units and cullet preheaters, and several thousand temperature sensors. One interesting feature of these industrial technologies is that they have an impact on non-energy operations and maintenance cost. In addition, these technologies also have an associated installation cost premium.

Figure 3.2 shows the associated energy and non-energy savings (reduction in operating costs) compared with conventional technologies. All cost premiums and savings are measured relative to baseline conditions by the GPRA Metrics program. These figures represent total increases or decreases in cash outlays in the year shown and not the annualized savings or costs. ${ }^{7}$ Cash outlays vary not only because of the characteristics of the technologies themselves, but also because the market penetration of each technology is expected to change over time as a result of EERE program success.

${ }^{7}$ We do this because economic impacts, such as employment, will occur when the money is actually being spent, not when the economic entities incur the costs associated with the spending. Thus, for purposes of this analysis, if an investment is made in the year 2000, the jobs created are the same whether the money to pay the workers is accumulated cash or borrowed funds. The impact of the opportunity cost is more of a question, as financing theoretically could change the time distribution of the impact on the cost side. We have chosen to show the impact as if it all occurred in the same year as the investment in energy efficiency. 
Capital expenditures shown in Figure 3.1 represent the premium of investment cost over the money that otherwise would have been spent to equip the same residential and commercial building stock with baseline technologies. The costs shown are dependent not only on the cost per unit of the new technology but also on the costs of the technology with which it is assumed to compete. The glass manufacturing technologies are fairly narrow in scope, resulting in investment costs that are an order of magnitude smaller than those of the other two programs. EPACT Standards result in investments that are an order of magnitude higher. Because of variation in the rate of building and relative reduction in costs for new technology over time, EPACT at first peaks and then declines. The peak occurs as program-related investment grows in size relative to current technology, then declines as program-related investment is overtaken by the advanced technology installation that would have occurred anyway in the absence of the program.

All three programs show significant energy cost savings in Figure 3.2. These cost savings depend on the cumulative number of units installed compared with the same market developed with more conventional technology, the relative amount of energy used or saved, and any additional non-energy costs or savings.

The GPRA numbers, used as inputs to ImSET, are derived from different programs that are treated in isolation. That is, each of the programs assumes that it has no impact on any other program. Ignoring interactions may possibly overstate the total benefits when all technologies are aggregated, but corrections for this interaction is done after the analysis performed here.

\subsection{Heat Pump Water Heater}

Figure 3.3 shows the employment impacts associated with variations of the GPRA Metrics heat pump water heater scenario. An essential feature of this scenario is the accelerating investment in heat pump water heaters throughout the forecast period out to 2010, with a high level of new investment thereafter. This investment path means that in any time period, the economy is experiencing a mix of consequences from energy savings and new energy efficiency investment, with the prospect that negative investment consequences could dominate. In fact, however, the energy savings dominate. The line in Figure 3.3 marked Savings Only demonstrates that eventually, the energy savings in the scenario could generate a considerable economic surplus with the potential to create up to several thousand jobs. ${ }^{8}$ The Base Case includes the negative net impact on jobs of the investment in water heaters (spending is transferred from labor-intensive to capital-intensive sectors). Thus, the Base Case lies slightly below the Savings-Only Case. Next, we consider the effect of energy conservation on investment in capital by electric utilities and gas utilities. If energy consumption decreases, it may be possible for utilities to defer investments they otherwise would make in plant and equipment.

${ }^{8}$ Whether the jobs actually would be created depends on future labor market supply conditions and macroeconomic policy. See, for example, Solow (1994) or Moscovitch (1994). 


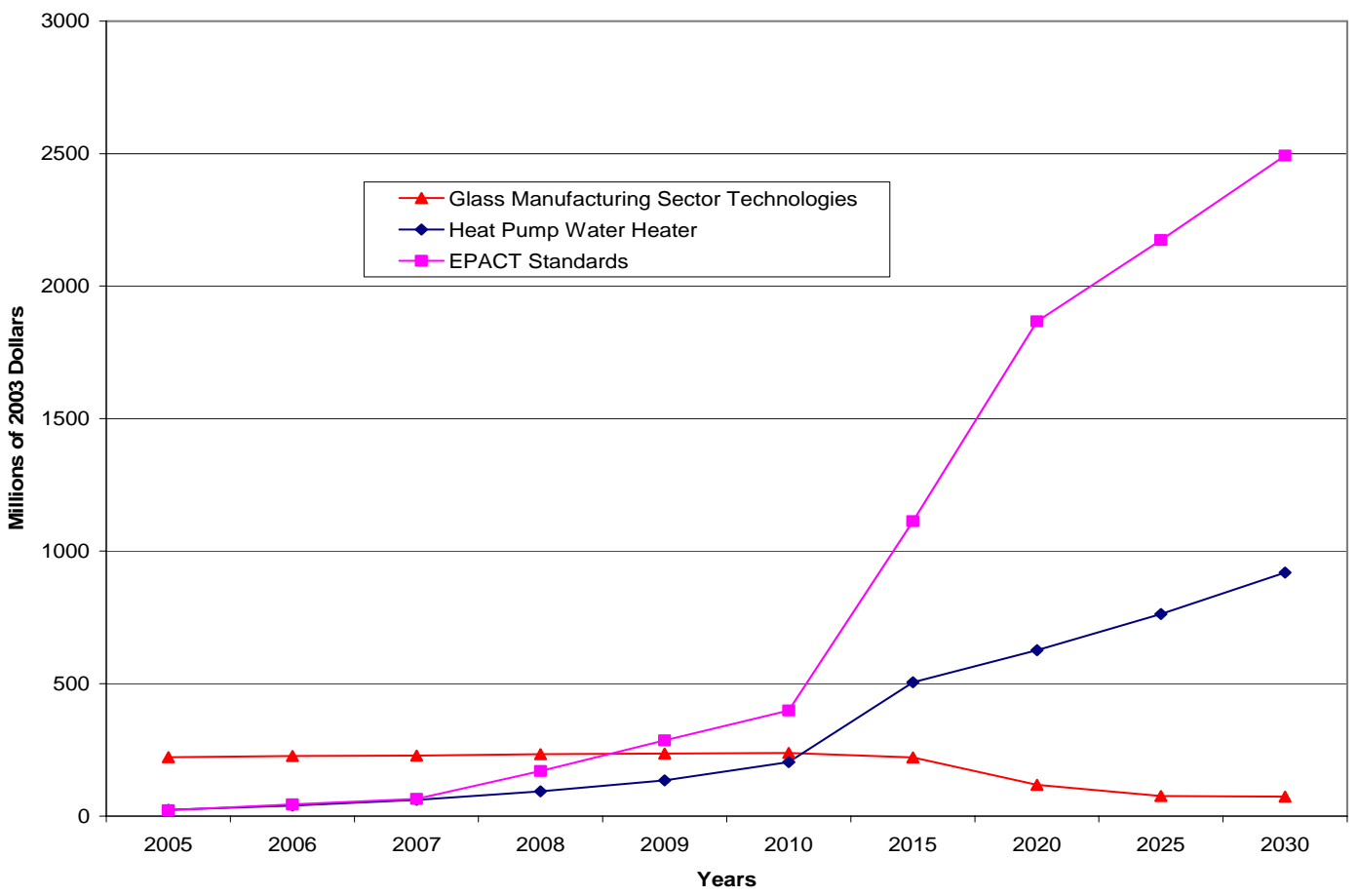

Figure 3-2. Value of Energy Savings by Year Relative to Baseline for GPRA Metrics Market Scenarios

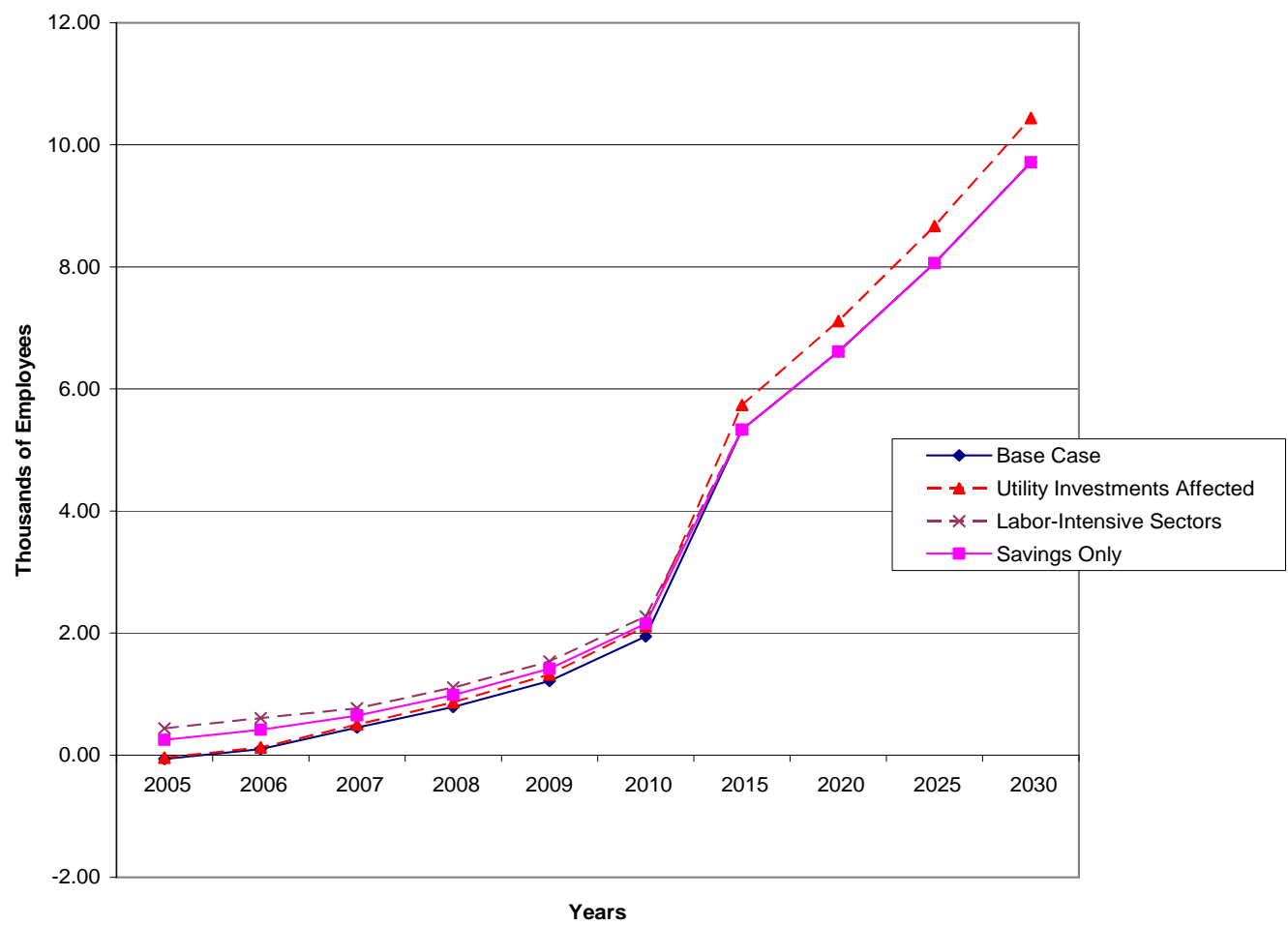

Figure 3-3. Employment Impacts of Investment in Heat Pump Water Heaters 
To analyze this question, we assume that each reduction of 1 trillion Btu of annual electrical energy demand saves \$32.9 million of electric utility investment (about \$590 per kW of capacity) and every trillion Btu of natural gas saved in annual demand saves $\$ 5.29$ million of gas utility investment. ${ }^{9}$ Reduced investment by utilities releases resources from the utility construction sector, which is relatively capital-intensive, to the economy as a whole, which is slightly less so. The net effect is small —an increase of just 1000 jobs (the net employment impact is about 9800 instead of 8800). Thus, saved utility investment, to the extent it occurs, has a slightly positive impact on employment. ${ }^{10}$

So far, this analysis has assumed that the cost premium for heat pump water heaters is entirely due to their manufacture. The case in Figure 3.3 marked Labor-Intensive Sectors is a sensitivity case that shows if more labor-intensive appliance distribution sectors of the economy were affected by the initial investment (not just appliance manufacturing), the net employment effects of the investment premium would be higher, and the overall net effects could be above those of the energy savings alone. ${ }^{11}$ However, we have no reason to believe that traditional percentage wholesale and retail trade markups would necessarily be maintained in the face of the higher manufacturing cost. It is more likely that distribution, marketing, and installation costs would be about the same for the HPWH and the competitor unit.

Figure 3.4 shows that financing affects the size of the projected net employment effect. The net effect depends on the market penetration scenario itself (that is, how fast and at what cost the technologies enter the market) and on what activity in the U.S. economy is displaced by the investment in water heaters. Employment impacts are estimated for the HPWH market penetration of the GPRA Metrics scenarios under differing scenarios concerning the financing of substantial up-front investment. For example, in the base case, the funds necessary to finance the water heater investment are drawn proportionately from the all sectors of the economy. ${ }^{12}$ In the highest scenario in Figure 3.4 (Free Financing), the assumption is the investment does not impinge on U.S. economic activity, and thus, the entire incremental investment adds to U.S. final demand and domestic product. A number of reasons exist why this could happen. From a macroeconomic perspective, two plausible reasons are that consumers decide to spend previously accumulated savings or else the international financial markets judge the investment to be a cost-effective use of their loanable funds, so that investments in some other country are crowded out.

${ }^{9}$ For this report, we estimated electric power plant construction savings at about $\$ 590 / \mathrm{kW}$ of delivered electric energy, based on data in EIA (1997). The equivalent value for natural gas, is about $\$ 1.20$ /cubic foot/day capacity, based on EIA (1996).

${ }^{10}$ This analysis assumes that saved utility investment funds would be recycled in the economy, as are ordinary earnings. If these funds were used to make foreign investments, for example, the negative impact would be much greater.

${ }^{11}$ The differential employment impact of the HPWH investment arises because the appliance manufacturing sector and its suppliers are slightly more capital-intensive as a group than the economy as a whole. Thus, diverting investment funds from the rest of the economy to appliance manufacturing tends to reduce employment. If the investment cost premium were spread among more labor-intensive sectors, such as wholesale and retail trade, the average employment intensity of the HPWH investment would be much closer to the national average. For the sensitivity case in the figure, we assumed that manufacturing took $46 \%$ of the investment premium; wholesale and retail trade, $37 \%$; and construction, $17 \%$. These proportions are normal industry averages.

${ }^{12}$ Personal (household) consumption is assumed to represent $70 \%$ of spending; gross private fixed investment, 10\%; federal defense spending, $9 \%$; federal non-defense spending, $6 \%$; and state and local government spending, about $5 \%$. These percentages are close to the actual distribution of final demand among these sectors. 


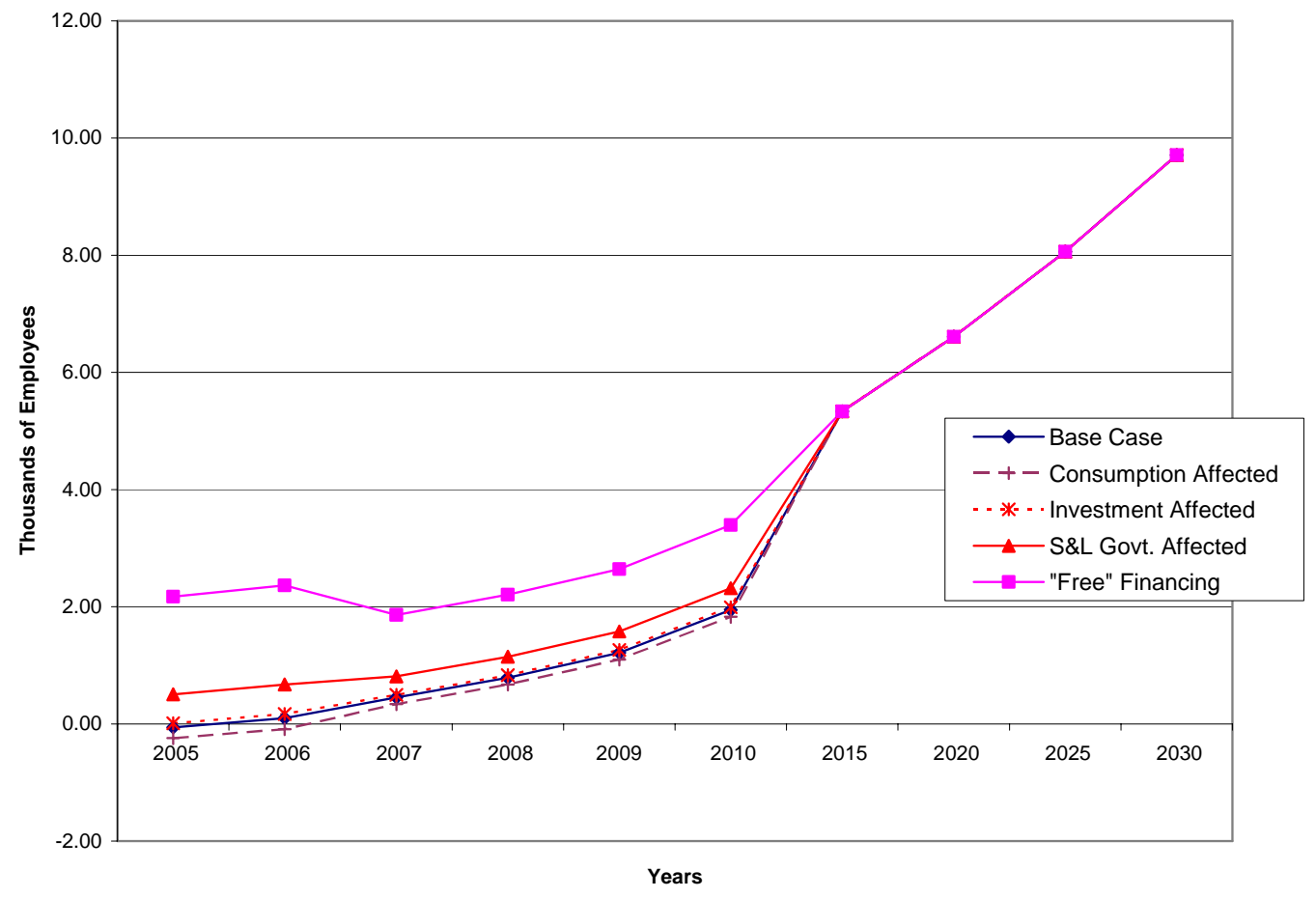

Figure 3-4. Effect of HPWH Financing on Employment

This results in the maximum possible impact on U.S. employment from the investment, an impact large enough to dominate other macroeconomic effects of the technology in some years.

The other scenarios in Figure 3.4 demonstrate, to slight-but-varying degrees, that the employment impact would be temporary, if the new incremental investment in water heaters displaces enough other consumer spending or business investment. ${ }^{13}$ However, because the effects of energy savings are relatively large, the net effect on employment is positive. A major reason for the slight negative investment impact is, although the HPWH technology is cost-effective, it is slightly less employmentintensive than the general economy. ${ }^{14}$

Because the amount of the funds needed for investment in heat pump water heaters is the same in each scenario in Figure 3.4, the level of the offsetting impact depends on the relative employment intensity of economic activity in the various sectors from which the investment funds come. Overall,

${ }^{13}$ The financing effects could be thought of in the following ways. If consumer spending is the only sector affected, it might be because consumers reduce their purchases of consumer durables like washing machines (or buy less expensive ones) to afford the additional water heater investments. Business investments could be reduced instead because lenders provide loans to households to pay water heaters instead of loans to business to buy plant and equipment. Finally, state and local government spending could be reduced because tax credits are allowed on state and local income taxes for investments of this type.

${ }^{14}$ Although a HPWH investment may be cost-effective in comparison with the alternative energy technology, these impact calculations do not address whether the HPWH investment provides as many net economic benefits to the economy as other, non-energy investments with which it also competes. 
although government activity is particularly labor intensive, the differences in employment that would occur if domestic spending were reduced in different ways to make the HPWH investments are very small.

Of course, jobs are not the only metric by which we can measure the macroeconomic impact of energy efficiency programs. Because different industries pay different wages on average, it is theoretically possible to create a number of low-paying jobs while reducing the number of well-paying jobs and overall income. Thus, it is worth looking at the impact on earnings as well as employment. Figure 3.5 illustrates the effects on national earned income of the various scenarios, previously shown in Figure 3.4, with their different sources of investment capital.

Figure 3.5 illustrates that, as before with employment, the impact of the water heater investments and savings on the national economic activity are positive when the investment does not crowd out domestic spending and investment. With the source of investment funds being the entire economy (Base Case), the net impact on national incomes is positive, as also was shown in Figure 3.4 for employment. As was true with employment, the impact on wage income is generally reduced (but not negative) if normal domestic investments are foreclosed by water heater investments. The difference if government investment is crowded out is slightly positive in the short run.

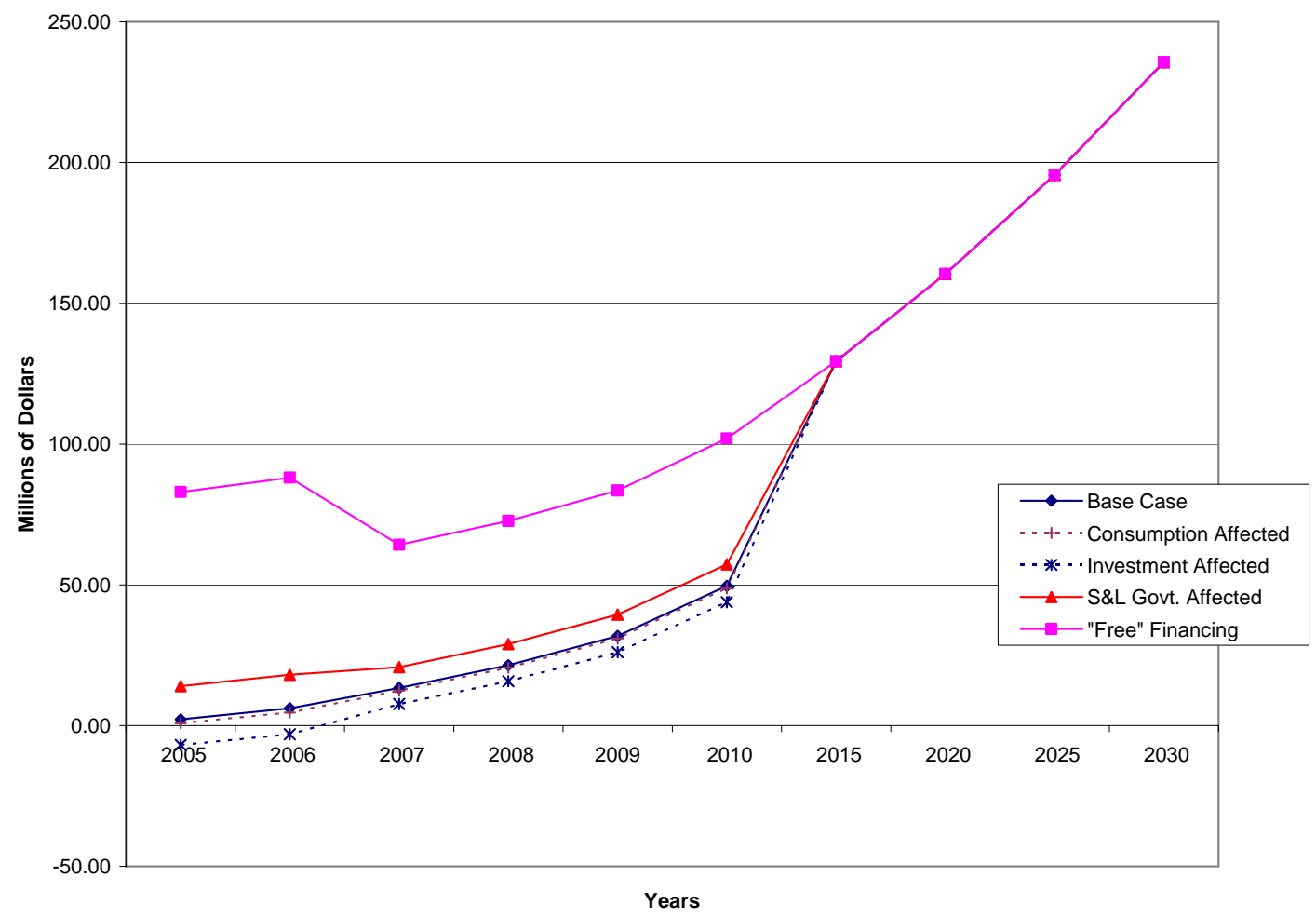

Figure 3-5. Impact of HPWH Investment on National Wage Income (\$2003)

Figure 3.6 is the wage income equivalent of Figure 3.3, but does not show the same results. Because the initial investment has a larger gross product multiplier than the economy as a whole and occurs in a high-wage, capital-intensive sector, activity created in water heater manufacturing and its supplying industries employs fewer workers per dollar of activity than the national average but generates more-thanaverage income. Energy savings, if they are large enough, also could reduce utility investment in new 
plant and equipment (mostly construction). Should this occur, Figure 3.6 shows that reducing construction activity frees up dollars that tend to have a slightly less positive impact on national wage income when spent on personal consumption, business investment, and government programs than if they had been spent in construction. ${ }^{15}$ Thus, the net impact on national wage income is very slight decrease relative to the base case.

Finally, the figure shows that if the investment in water heaters were distributed across more laborintensive industries rather than just appliance manufacturing, there would be a the net increase in national wage income because the altered investment pattern would then represent a diversion of investment dollars into labor-intensive retail and wholesale distribution as well as high-wage construction and capital-intensive manufacturing. ${ }^{16}$ As before, however, it is likely that most of the premium in cost would be the additional cost of manufacturing.

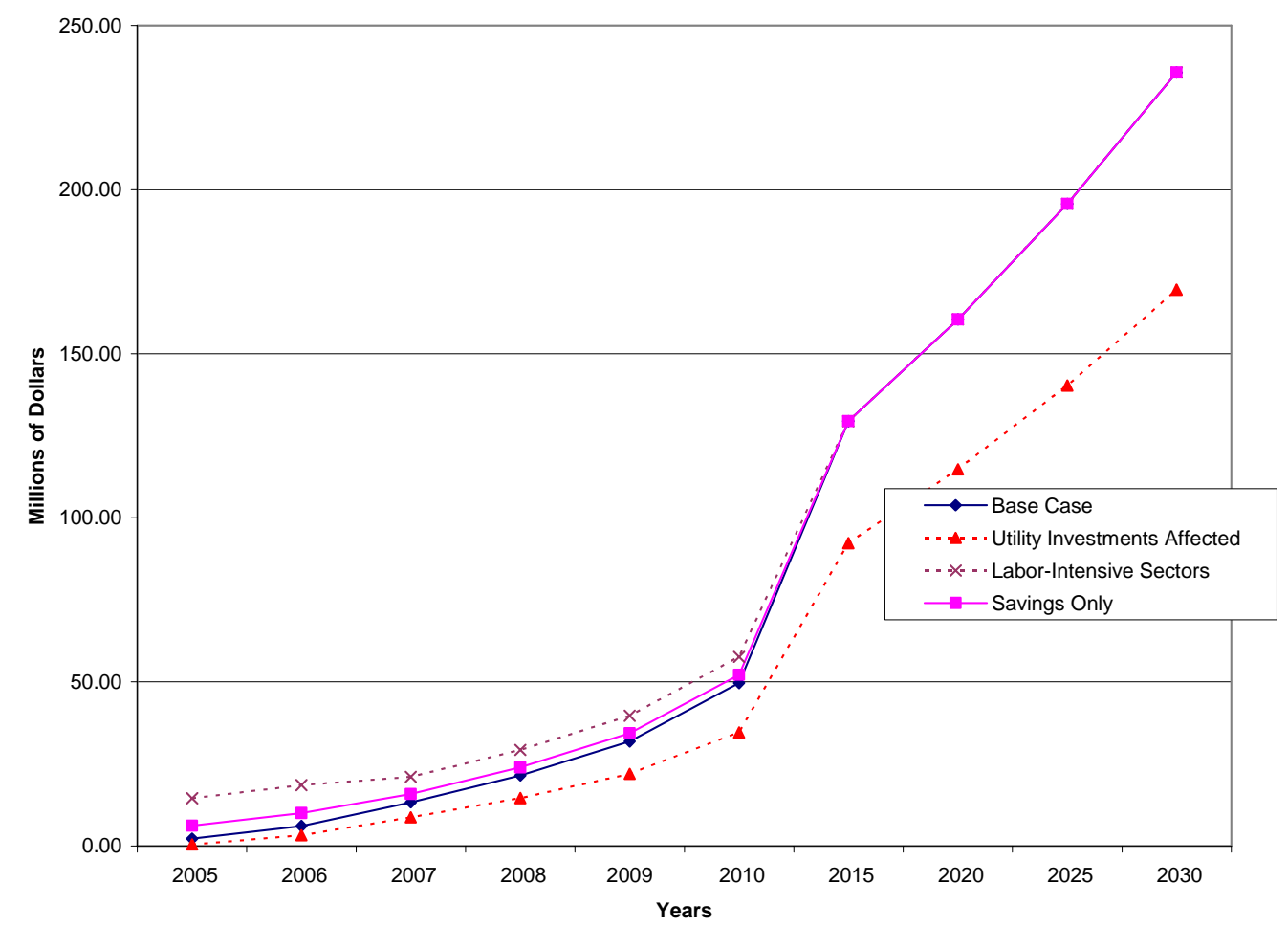

Figure 3-6. Sensitivity of Impacts on National Wage Income to HPWH Investments (\$2003)

\footnotetext{
${ }^{15}$ In the case analyzed, this sign is the opposite of the comparable employment effect and is the combined result of inter-sector purchases and the wage rates in the affected sectors. The net effect is small, however, and could be of either sign, depending on exactly which sectors are affected. When relatively capitalintensive sectors spend the released investment funds, the effect is negative for both employment and income; when labor intensive sectors spend the money, the net effect is positive for both. The illustrated case involves a mix of sectors.

${ }^{16}$ In this case, the investment premium was distributed $46 \%$ to appliance manufacturing, $37 \%$ to the wholesale and retail trade, and $17 \%$ to the construction sector for installation.
} 


\subsection{EPACT (Commercial Air Conditioning) Efficiency Standards}

High-efficiency air conditioners (HEACs) installed in commercial buildings are expected to require an incremental investment, but they affect the economy somewhat differently than HPWH investments. The HPWH and HEAC scenarios differ because the target market for HEAC is in commercial buildings. From a macroeconomic point of view, this difference is important because the destination for the energy/non-energy operational savings in the commercial sector is not obvious. Potentially, energy savings would increase the profitability of firms that installed HEAC; however, the additional valueadded per dollar of output could well be shared with the work force (in the form of higher wages due to higher productivity and effective bargaining by labor) and with the government (in the form of additional tax collections). With respect to business profits, it is not clear how much would be spent or invested, how much saved, and so on.

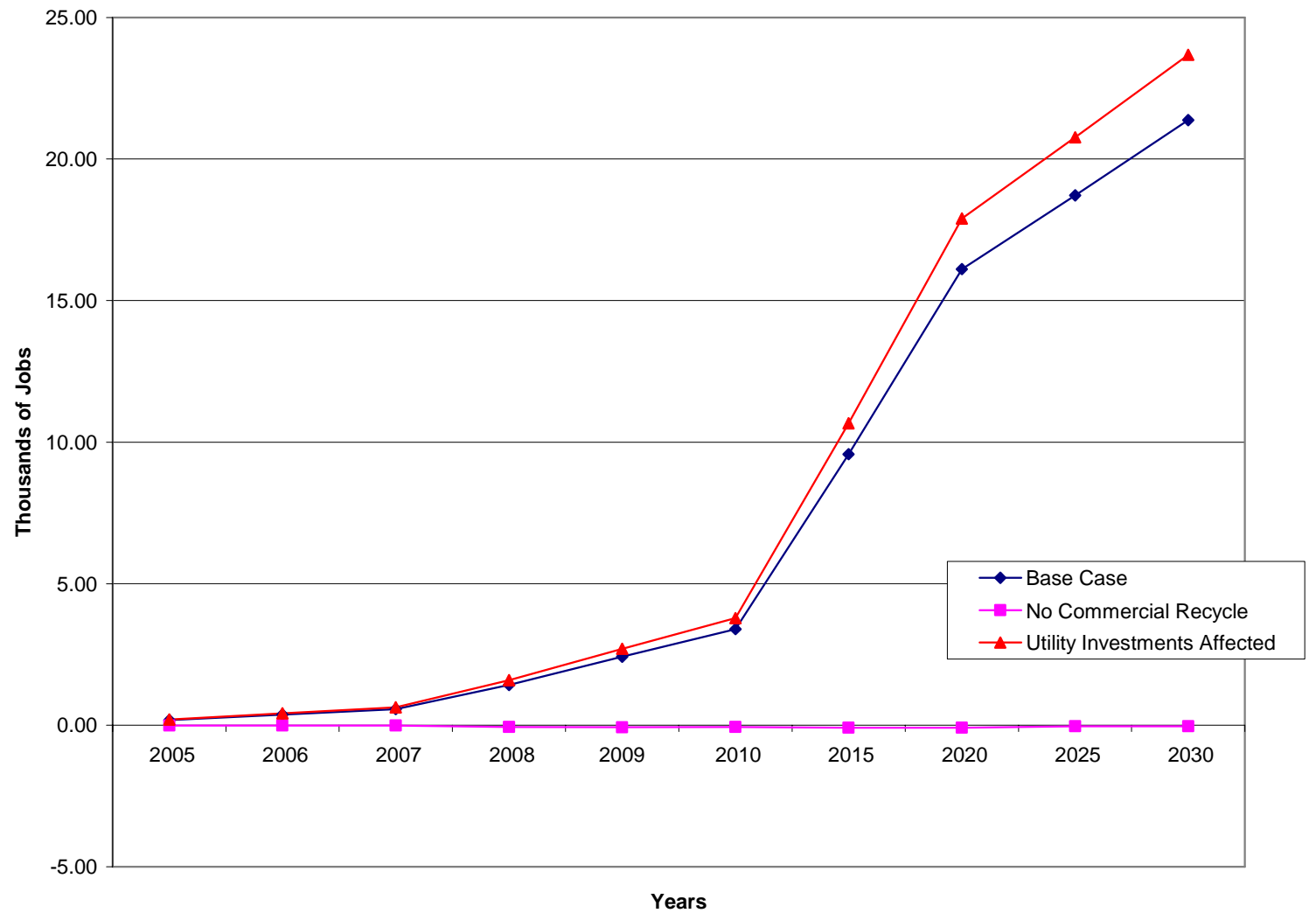

Figure 3-7. Impact on National Employment of EPACT Standards

However, even if a particular business had no immediate investment plans for the funds provided by energy savings, the economy as a whole would have abundant investment options available and the capital markets could readily absorb any savings. Therefore, we assume that energy savings by business (proportionately allocated to labor earnings, business profits, and taxes) are immediately recycled in the economy as consumer spending, business investment, and government spending. If the cost savings were not re-spent inside the U.S. economy (for example, they were invested in telecommunications in Asia), then that portion of the energy savings would have no positive effect on the economy as a whole. This is illustrated as the No Commercial Recycle case in the figure. As before, if the energy savings allow for the 
deferral of electric and gas utility infrastructure investments, there is a (very slight) positive impact on overall employment.

Figure 3.8 shows the net impact of the HEAC investments on the wage economy is significant and also positive.

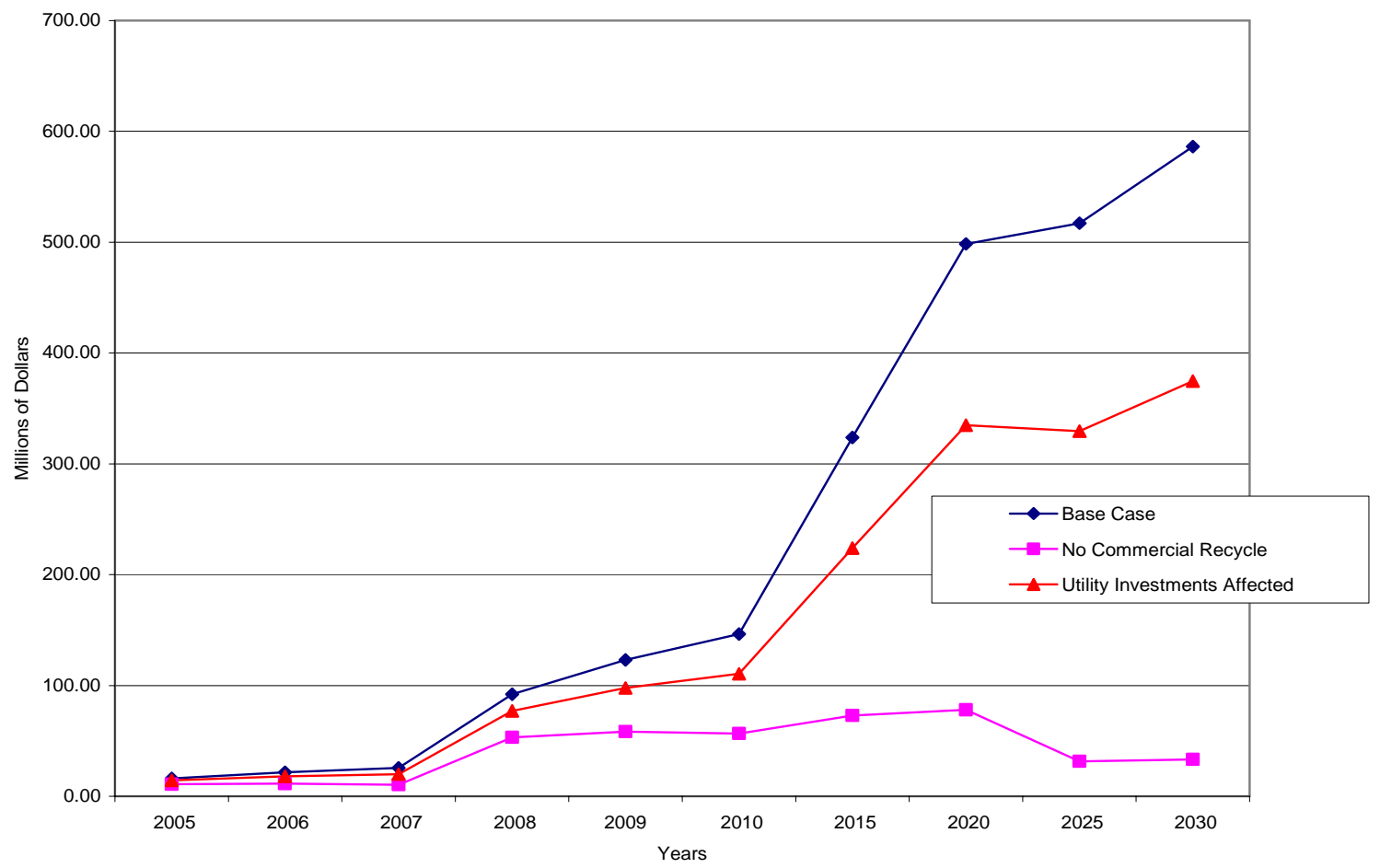

Figure 3-8. Impact of EPACT Standards Energy Savings on National Wage Income (\$2003)

\subsection{Glass Manufacturing Technologies}

The three industrial energy-saving technologies in higher efficiency glass manufacturing save the economy about \$200 million to \$235 million per year, at an incremental investment of about \$20 million in most years. As a consequence, the investment in these technologies also adds to the level of macroeconomic activity, as measured by jobs and wage income, as shown in Figures 3.9 and 3.10. The savings occur fairly early in the period in the adoption scenario illustrated, in effect an acceleration of energy savings that may have occurred anyway at a later date. See Anderson et al. 2003 for a more complete discussion.) Later on, the savings due to the EERE program decline as the equipment depreciates and is replaced by still more efficient equipment, and as the energy savings acceleration begins to approach the date by which the savings would have occurred as a result of the normal functioning of the marketplace.

Similar to the previous cases, "free financing " produces the largest impact, while the impacts of the energy savings are partially offset by the opportunity costs of the funds required for the associated investment. 


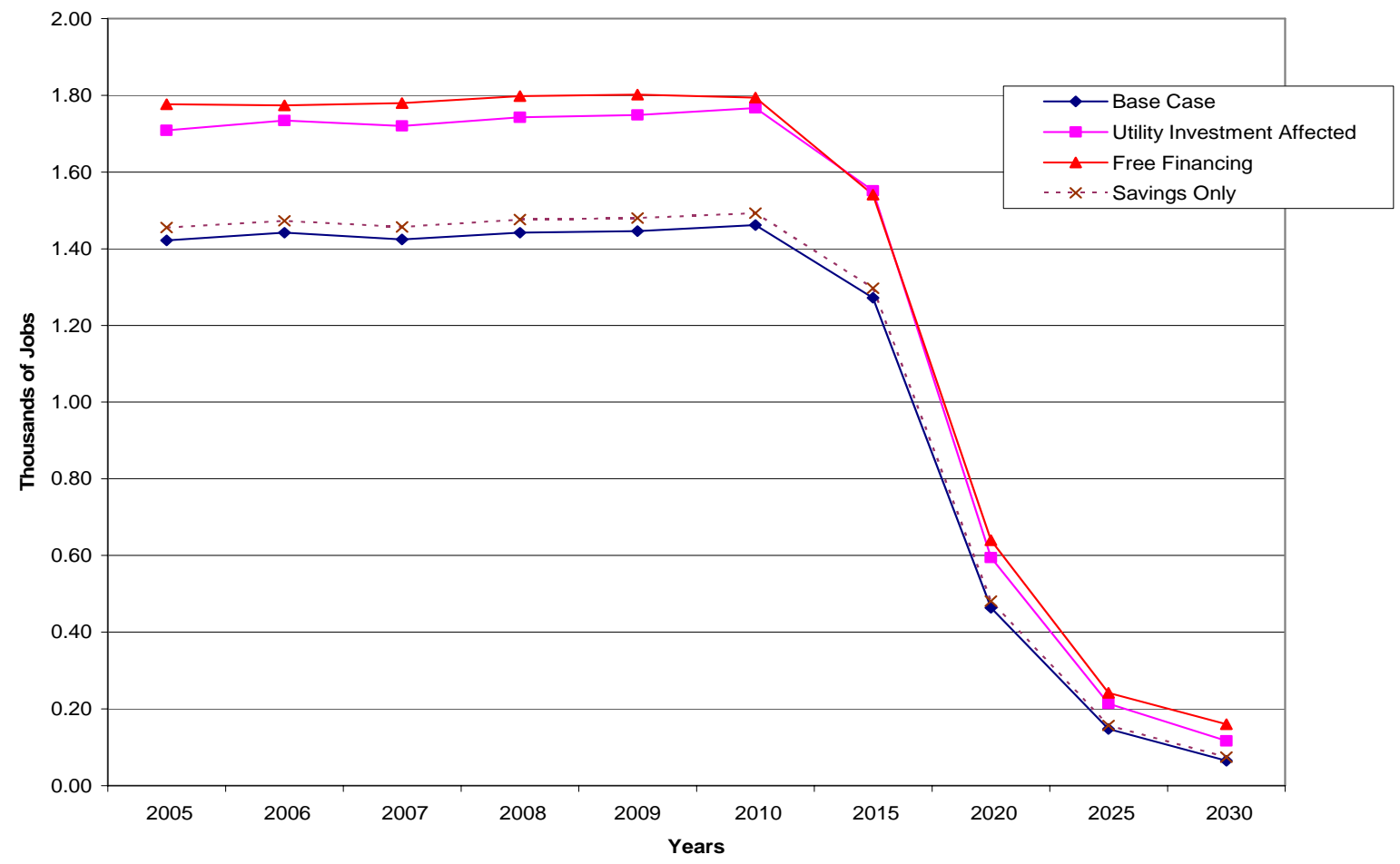

Figure 3-9. Impact of Glass Manufacturing Sector Savings on National Employment

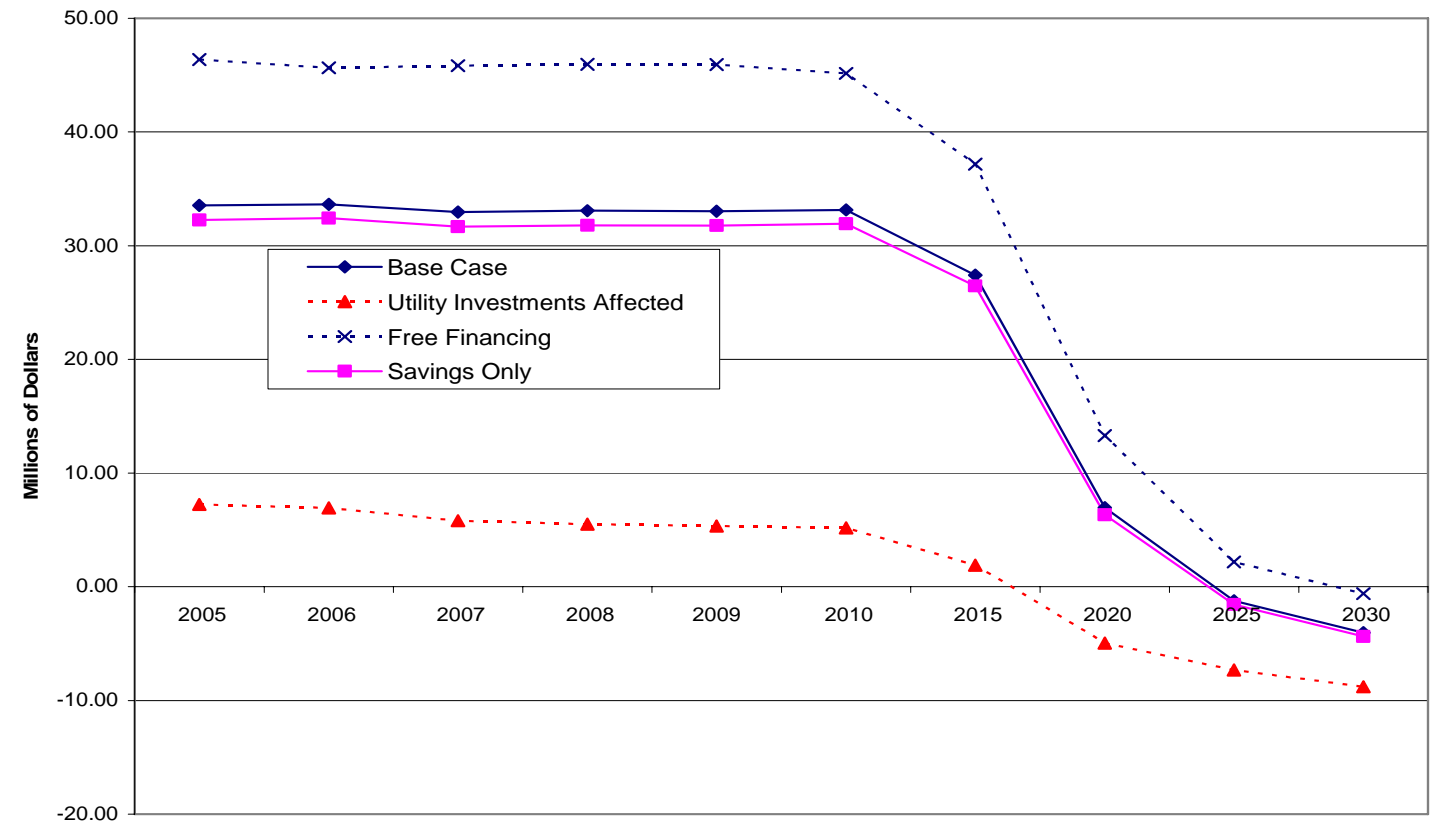

Years

Figure note: Base Case and Utility Investment Cases are nearly identical

Figure 3-10. Impact of Glass Manufacturing Sector Savings on National Wage Income (\$2003) 


\subsection{Comparison with Other Studies: An Update}

Since the publication of the Users' Guide to the predecessor version of ImSET, ImBuild II (Scott, et al., 2002), a number of papers have appeared that are compared to the current version of ImSET. While our conclusions generally remain the same, that is, that the results, compared to other models, are quite similar, there are some differences from previously published work, in large measure due to the difference in sector aggregation and to a few critical assumptions where honest disagreement is possible. Since considerable attention was paid to these differences in the previous publication, that discussion will be briefly summarized, then the current version will be compared to recent studies and the previous version.

\subsection{A Summary of Previous Findings}

Much of the discussion in the previous Users' Guide was a comparison of the predecessor model with a study by the American Council for an Energy Efficient Economy (ACEEE) (Geller et al. 1992). The differences between ImBuild II and the ACEEE model could be explained by differences in the sectoring plan and the fact that the ACEEE report was based on the 1987 Benchmark I-O table while ImBuild II was based on the 1992 Benchmark I-O table. Another source of differences in results arose from the way that programs were implemented in the analysis. For example, the source of funding for incremental investment in a technology in the ACEEE report might have been financed by a reduction in demand for the sector using the technology (i.e., a change in demand) rather than a change that reflected supply-side impacts. ${ }^{17}$

In addition to the extended discussion about the ACEEE study, the previous Users' Guide also examined several other reports, but none of these could be easily compared with the methodology used by ImBuild II (see, for example, Laitner, et al. 1998). In summary, the report concluded that ImBuild II's results were roughly comparable to those of other recent analysis.

\subsection{Comparisons of ImSET to Recent Studies}

As a framework for differentiating between different approaches, Berck and Hoffmann (2002) provide a taxonomy of five approaches. In order of complexity, the approaches are 1) supply and demand analysis of the affected industry, 2) partial equilibrium analysis of multiple markets, 3) fixed-price general equilibrium simulations, 4) non-linear computable general equilibrium (CGE) simulations models), and 5) econometric estimation of the adjustment process. Included in the third approach are both input-output (I-O) and social accounting matrix (SAM) models, in which ImSET fits. Berck and Hoffmann note (page 135) that I-O, SAM, and CGE represent a continuum of approaches, with I-O and SAM models providing an upper bound to the employment impacts because factor substitution does not occur as a result of the assumption that the production function is linear. In a classical CGE model, which operates with a fully employed labor force, factor substitution would be complete and there would be no net employment impacts in the economy, though there might be income impacts as a result of the migration of labor from one industry to another. Berck and Hoffmann apply the I-O/SAM approach to estimating the employment impacts of a decline in redwood timber sales from Del Norte and Humboldt counties in northern California. (See Xie, [2000] for an application of SAM to environmental policy in China..) In pointing out the limitations of the third approach, Berck and Hoffmann note that, “. . . with policies that do not

${ }^{17}$ See text on pages 4-1, 4-5, and 4-6, (Scott et al. 2002), for a more detailed discussion. 
affect relative prices, linear models are more likely to provide good approximations of actual changes than in situations where the policy impact is large enough to affect relative prices” (p. 145). Earlier we made the case that that the technology changes we examine in ImSET are usually so small relative to the size of the economy and the economic sectors affected that relative prices are unlikely to be affected, and therefore, the I-O approach will provide reasonably good estimates of the impacts of the penetration of DOE technologies into the economy.

Kaiser and Pulsipher (2003), along with their colleagues (Kaiser et al. $2004^{18}$ ), have used a similar approach to estimate the impact of establishing a (proposed, but not enacted) Louisiana Public Benefit Fund which would levying a 1-mill/kWh surcharge on all electricity sales, then leverage these funds with other public and private funds to provide low-income energy bill assistance, low-income weatherization assistance programs, and residential and commercial energy conservation programs. They use an IMPLAN I-O table of Louisiana provided by MIG, Inc., to estimate the economic impacts of the Public Benefit Fund. Their expected outcome would see over 32,000 residential homes insulated, nearly 19,000 commercial buildings improved with energy savings of $\$ 26.6$ million and a benefit/cost ratio of 1.7. Their expectation is that there would be 1671 jobs created, additional tax revenues to the state of $\$ 8.3$ million and a net economic benefit of \$345.9 million.

This approach is similar to ImSET, but does not modify the Use matrix to show the impact of adopted technologies on expenditures by commercial and industrial firms (see section 2.1). Our interpretation of the Kaiser et al. (2004) results suggests that a distribution of benefits and costs $\left(30^{\text {th }}, 50^{\text {th }}\right.$, and $80^{\text {th }}$ percentiles) were estimated using multipliers from the IMPLAN model to determine output, value added, and through these output changes, employment changes to the Louisiana economy. Specific discussion of the financing of the investments is absent, suggesting that the treatment is as if the costs and benefits are on an annualized life-cycle cost basis or on a net present value basis.

The final addition to the literature is by Nayak (2005) and Economic Research Associates (2005) of Alexandria, Virginia, who examine the economic and consumer benefits of clean energy policies. The input-output model used in Nayak's study and is very similar in spirit to the Geller et al. (1992) study. The national model is 15 sectors, with direct expenditures energy savings taken into account for 10 years. The payback period for any energy efficiency project is assumed to be 4 years; the financing of the project would be at $80 \%$ of the cost, at $8 \%$ interest; and both productivity and price effects are factored in to the analysis. ${ }^{19}$ Over that time period, labor productivity changes would occur and these would reduce jobs per unit of output in all but the energy savings sector. Energy prices would have no effect on building improvements or revenues, but would increase final demand by $8 \%$ for energy savings and reduce demand by $6 \%$ for utility revenues. Interest changes would increase final demand by $2 \%$ in both the buildings improvement sector and the revenue impacts, but have not impact on energy savings or utility revenues. The state model(s? $)^{20}$ derived from the national model is designed to allow for specific effects, as requested by the PIRG Education Fund.

\footnotetext{
${ }^{18}$ The Kaiser, et al. (2005) paper uses the approach to measure the impact of the (enacted) Louisiana Energy Fund, a public/private cooperative, effort partially funded by tax-exempt state bonds, to fund energy and water conservation projects.

${ }^{19}$ Exactly how this is done is not explained. It is clear from the example in the Nayak report that these effects are multiplicative: the table on p. 4 shows what effect labor productivity, price effects, and interest rate changes have on final demand, but the derivation of the prices and interest rate changes is not explained. With a 4-year payback, the 10 -year energy saving would be $\$ 2.5$ million. Presumably the productivity impacts are derived from BLS estimates, as explained in the first paragraph on p. 6.

${ }^{20}$ Again, neither the number of state models nor the specific states are identified. It is not clear whether these are composite state models derived from the national model or specific states constructed from IPLAN data files.
} 
The study is designed to examine the impact of two major policy changes: 1) shifting government expenditures from subsidizing fossil and nuclear industries under the prior proposal to instead, spending the $\$ 35$ billion on renewable energy and energy efficiency; and 2) enacting a 20 percent national renewable energy portfolio standard, which would require that the U. S. generate 20 percent of its electricity from clean energy by 2020. Nayak shows results for three scenarios: the 2004 Energy Proposal, the 20\% Renewable Energy Standard, and the Clean Energy Package which is the 20\% standard plus shifting \$35 billion from the proposed legislation to renewables and energy efficiency. The net impact from Scenario 1 to Scenario 3 in 2020 is about 130,000 jobs and an increase of nearly \$4.5 billion in GDP.

While it is not possible to make direct comparisons between ImSET and the model used by the U. S. PIRG Educational Fund, it is possible to roughly compare impact multipliers for jobs, as is done in the following table. "Roughly" because we have taken a simple average of the set of industries represented by the sectors reported in Nayak's paper rather than aggregate and properly weight the impacts by output measures. While these are indicative, it is fair to say that the impact multipliers are very similar; where the definitions are very similar-coal mining, electricity utilities, construction, wholesale and retail trade, finance-the numbers are quite close.

Table 4.1. Employment Multipliers, Nayak, and Selected ImSET Industries

\begin{tabular}{|l|c|c|}
\hline \multicolumn{1}{|c|}{ Sector } & $\begin{array}{c}\text { Employment Multipliers, } \\
\text { Nayak }\end{array}$ & $\begin{array}{c}\text { ImSET Employment } \\
\text { Multipliers (Simple Average) }\end{array}$ \\
\hline Agriculture & 24.2 & 14.0 \\
\hline Oil and Gas Extraction & 9.1 & 13.1 \\
\hline Coal Mining & 9.9 & 9.7 \\
\hline Other Mining & 11.1 & 10.9 \\
\hline Electric Utilities & 6.1 & 6.5 \\
\hline Natural Gas Distribution & 7.1 & 14.3 \\
\hline Construction & 18.3 & 17.0 \\
\hline Manufacturing & 11.6 & 13.8 \\
\hline Wholesale Trade & 11.5 & 12.6 \\
\hline Transport and Utilities & 15.9 & 17.5 \\
\hline Retail Trade & 25.0 & 25.1 \\
\hline Services & 15.4 & 18.0 \\
\hline Finance & 11.1 & 11.4 \\
\hline Source: & Nayak, p. 20 & ImSET, selected industries \\
\hline
\end{tabular}




\subsection{Operating the ImSET Model}

To use ImSET a user would necessarily have had to install the software with the SETUP.EXE program provided. This will ensure that all components of the model are properly installed. Once ImSET is installed on a desktop PC, the user starts the program as per normal Windows program methods.

Once started, the ImSET program will display an introductory splash screen, then present the user with an introductory instruction screen. The user should select Continue to advance to the main "Run specifications" screen. It is in this screen that the user will add records to represent specific program assumptions.

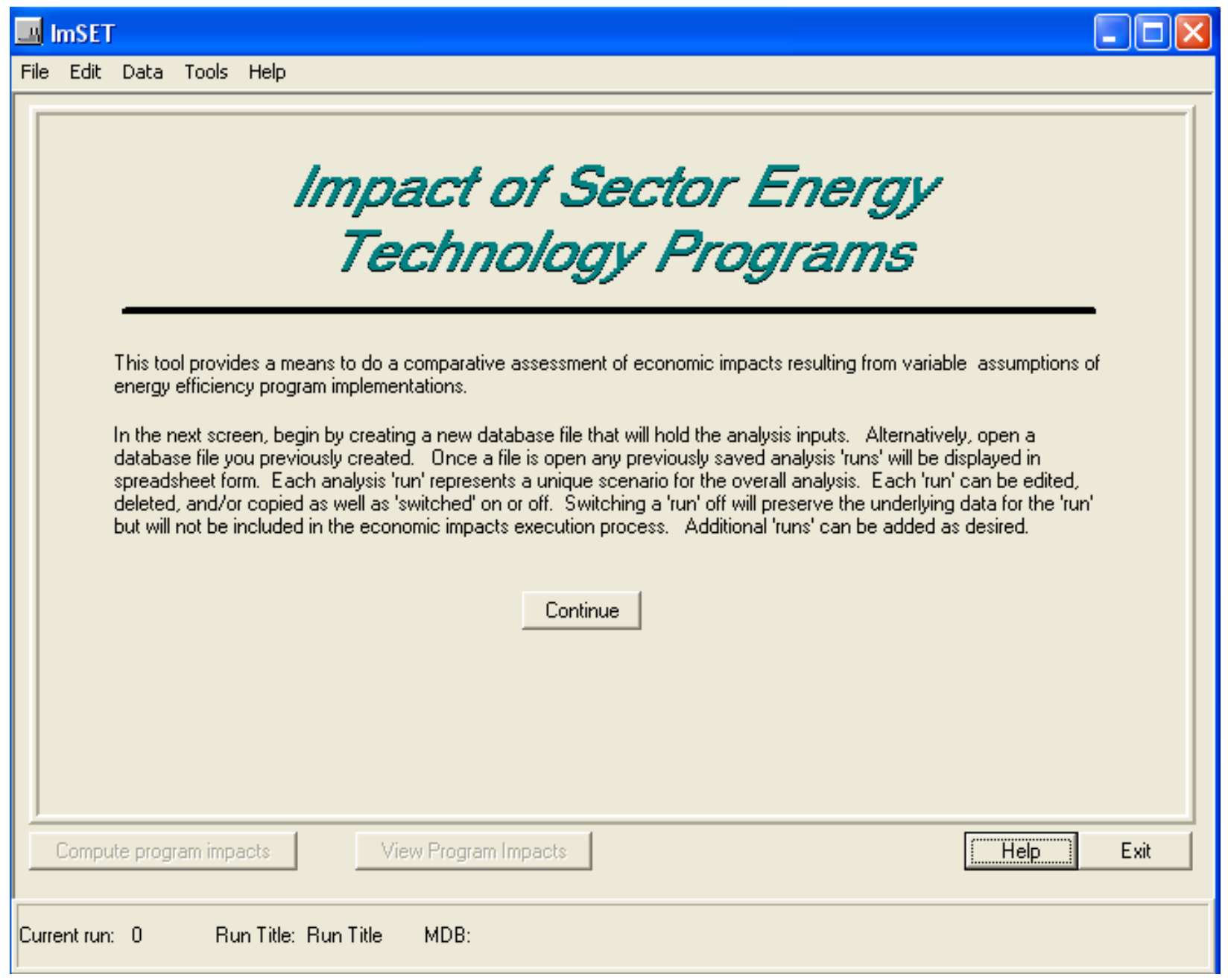

Figure 5-1. ImSET Title Page 


\subsection{ImSET Options}

The "Run specification" screen is used to specify unique program scenarios. Add as many records as there are unique scenarios to be compared. Only the records that have "Execute run" checked will be run and displayed in the results screen. Before specifying "run specifications" the user must first create a new "run database" using the menu options under the "File" menu. The "run database" will hold all information and results specific to the scenarios established and specified. Thus, a user can make any number of "run databases" for specifying unique scenarios.

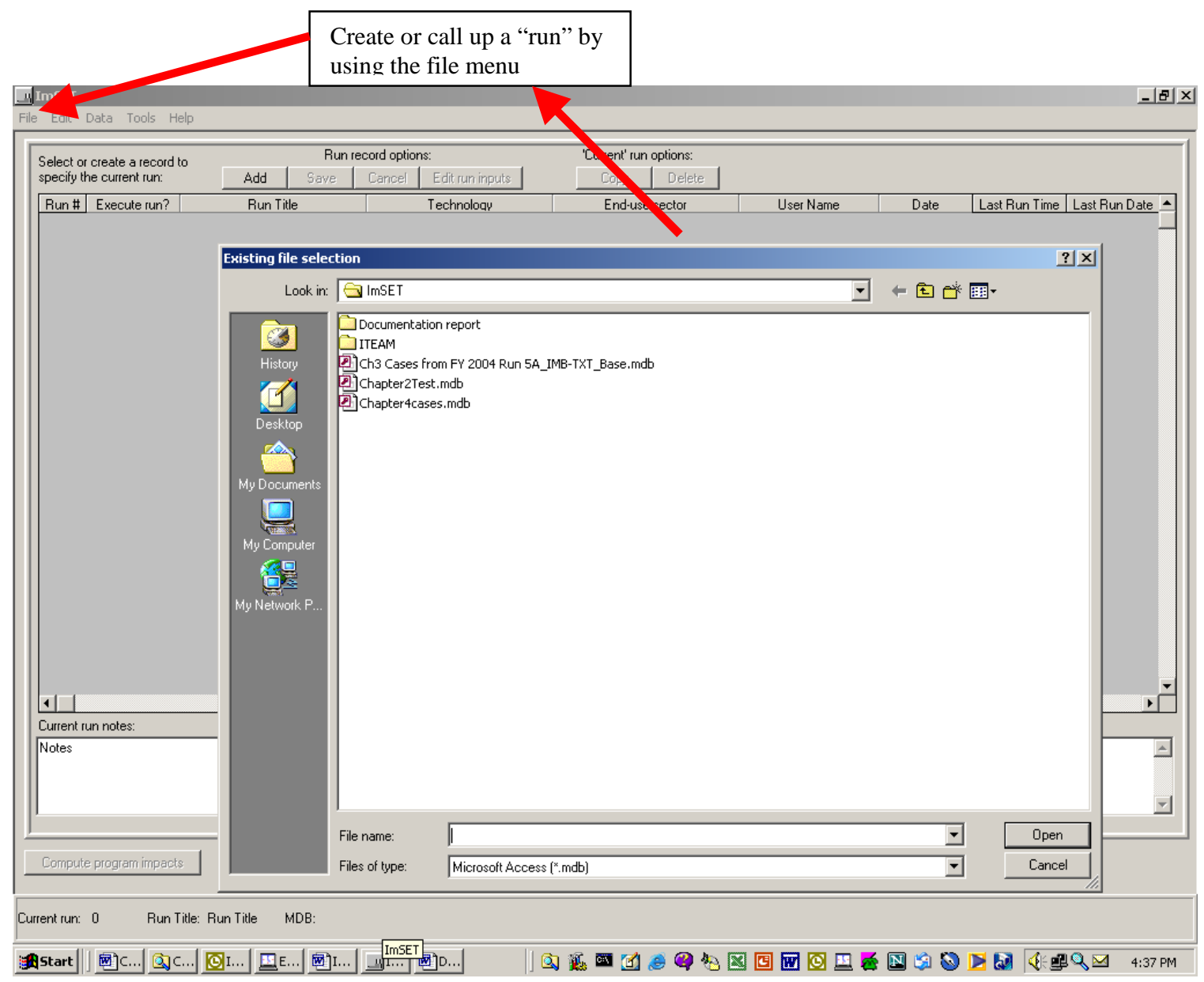

Figure 5-2. Run Specifications Screen

The "Run specification" screen is used to specify unique program scenarios. Add as many records as there are unique scenarios to be compared. Only the records that have "Execute run" checked will be run and displayed in the results screen.

Functionality of this screen is described below: Add - Adds a "run" record to the spreadsheet. 
Save - Saves the current "run specification" records to the currently opened database file.

Cancel - Cancels any changes to the "run specification" spreadsheet and refreshes the display.

Edit run inputs - Displays a screen of detailed "run inputs" that can be edited by the user.

Copy - Copies the currently selected "run record" (indicated by yellow marker in left most column and/or in status bar at the bottom of the screen.

Delete - Deletes the currently selected "run record" from the spreadsheet and the database. A

"confirmation prompt" will be displayed to verify the request. The "confirmation prompt" can be "turned off" for future deletions by checking the appropriate check box in the "confirmation prompt" screen.

Compute program impacts - Computations of program/technology impacts will be run on all "run specifications" that have the "Execute run" column checked. After computations are done the results screen will be displayed.

View program impacts - Displays the results screen without running computations. Results will be displayed for the last computed impacts.

Help - Displays the help file.

Exit - Exits the ImSET program.

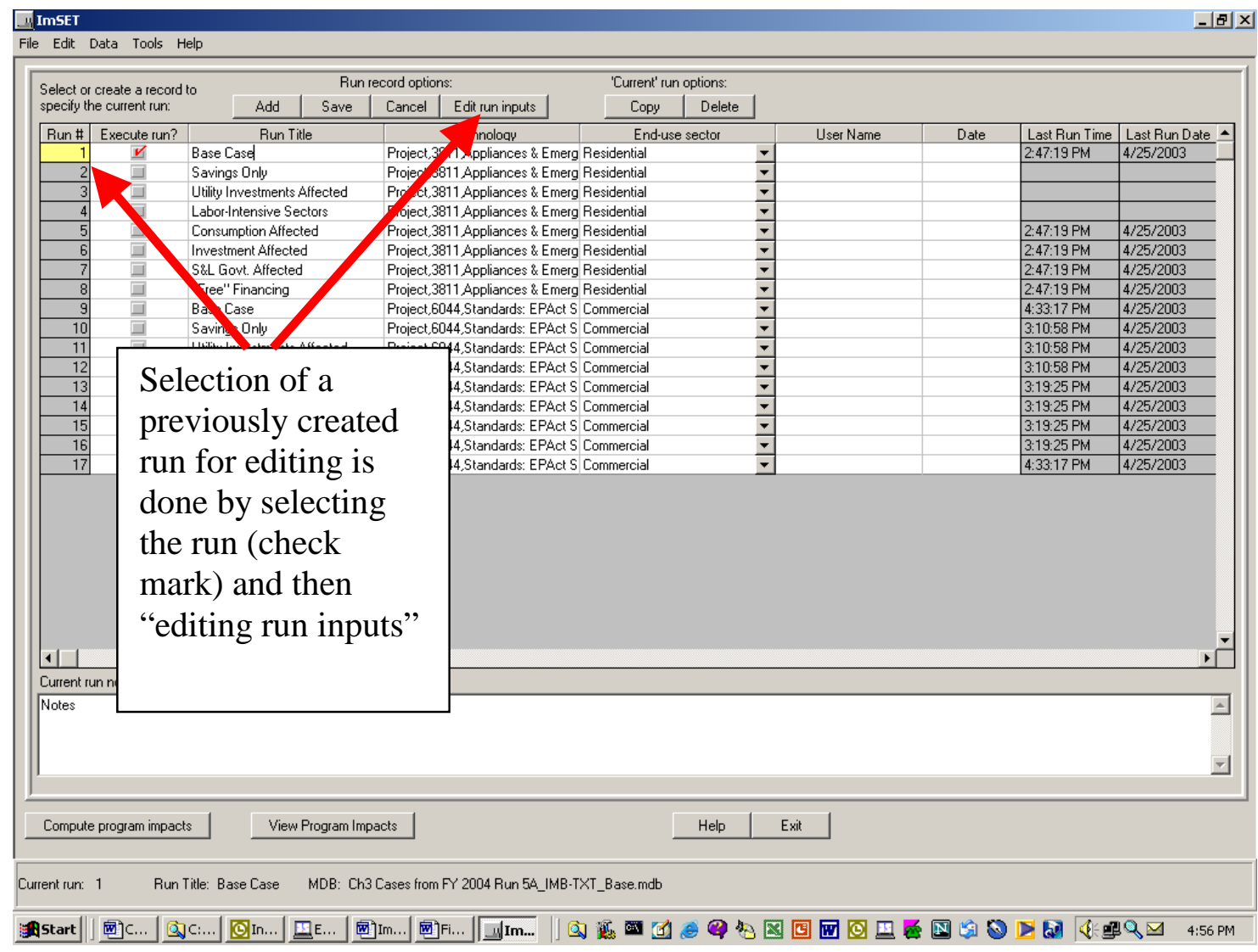

Figure 5-3. Run Specification Spreadsheet

\section{“Run specification” spreadsheet columns -}

Run \# - A unique identifier for a "run specification" record. This is a non-editable column and is determined programmatically.

Run title - User provided description of the "run specification”. 
Technology - The technology/program that is assigned to the "run specification". When a "run specification" record is added the technology list will be displayed as a drop-down list containing all default technologies/programs. Select the appropriate choice.

Note: you cannot change your technology choice after you have saved the "run specification" record. However, after saving the record, you can edit the technology description and edit its underlying data and/or copy the edited technology to another "run specification" record.

End-use sector - Identifies the appropriate end-use sector for the "run specification" record. The selection determines what set of economic sector distribution factors you will have access to in the "run inputs" screen.

User name - User provided name for reference purposes only.

Date - User provided date for reference purposes only.

Last run time - Indicates the time the record impacts were last evaluated.

Last run date - Indicates the date the record impacts were last evaluated.

If a new "run database" has been newly created, it will appear without any "run specification" records. Click the "Add" button to add a new record then fill in the cells. All cells except user name and date must be specified. Select "Save" to save any new records or changes to existing "run specification" records.

To access the underlying economic and technical data of the "run specification" record, select the "Edit run inputs" button and review/edit the data as needed.

When all data have been specified the user should select "Compute program impacts" to do the actual calculations and display the results. Note that only those "run specification" records that have "Execute run" checked will be included in the calculation process and displayed in the results screen. If there are no changes since the last calculations were run and the user simply wants to review the results then select the "View program impacts" button.

\subsection{Technology Data}

The technology data spreadsheet is used to specify the incremental programmatic impacts on capital cost, installation cost, energy or resource cost, O\&M cost, and energy or resource savings. The appropriate units for each are displayed in the row headings. Note that all data are specific to the "run specification" described in the drop-down list at the top of the screen. Furthermore, the rows that are displayed in the spreadsheet are dependent on the "end-use sector" that is selected for the "run specification". To see other technology data select a different "run specification" record at the top of the screen.

Add technology to list of default technologies - Enables the user to add a technology to the "default " technology list. This feature allows the user to establish customized versions of a technology that can then be used repeatedly when adding new "run specification” records. More specifically, the user may have a particular set of technology data and years that are not currently represented in the "default" technology list. To create a new "default” technology simply select an existing "default” technology, modify its data accordingly, save any changes, then select the "Add technology to list of default technologies" pop-up choice. You would then see a new "Add technology" screen appear in which you enter a unique technology name where requested then select "Add" and "Close". At this point you can return to the "run specification" screen and if you add new "run specification" records the newly created technology will appear in the drop-down list of "default" technologies. 


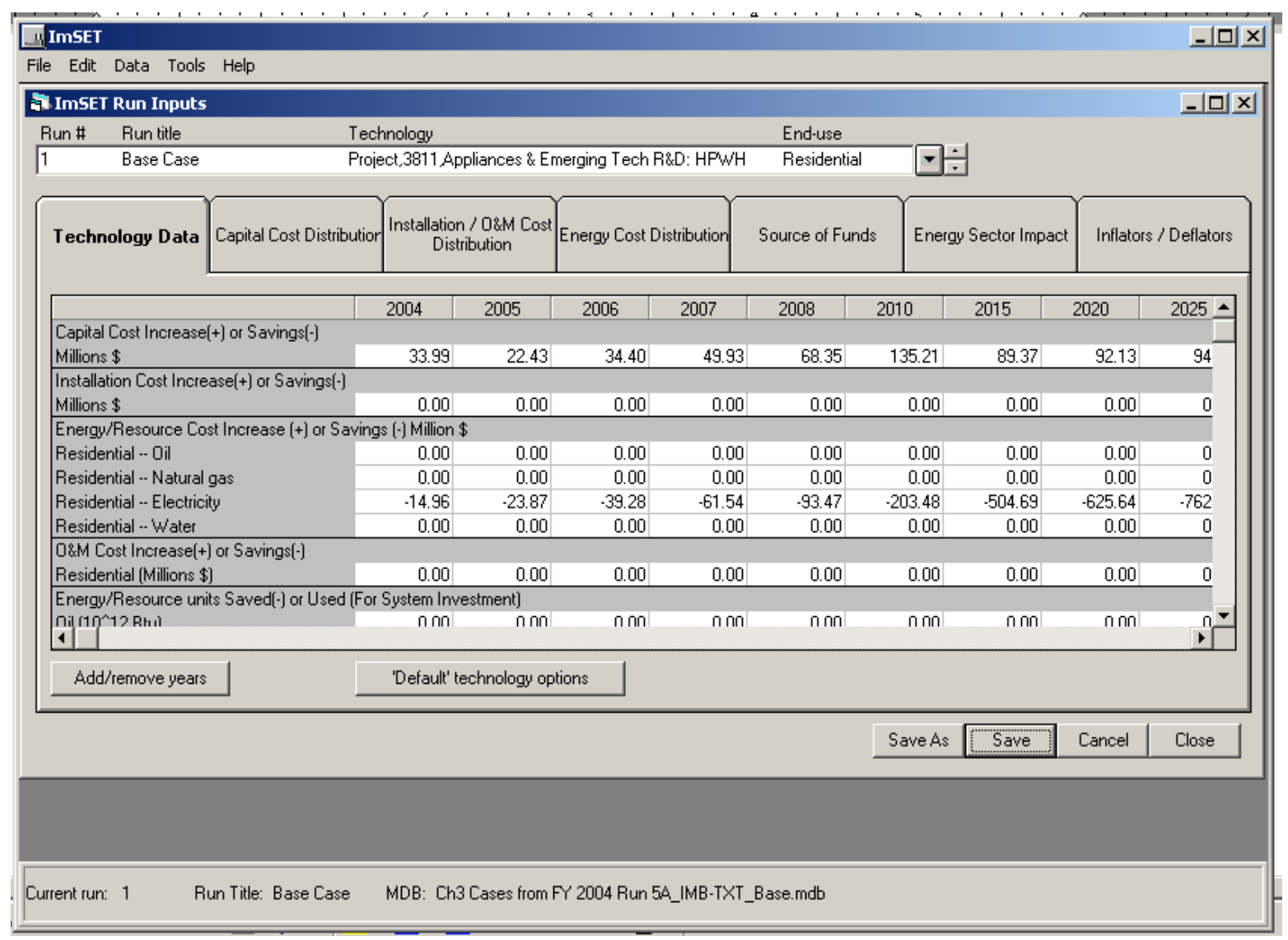

Figure 5-4. Technology Spreadsheet

\subsubsection{Technology Data}

The technology data spreadsheet is used to specify the incremental programmatic impacts on capital cost, installation cost, energy or resource cost, O\&M cost, and energy or resource savings. The appropriate units for each are displayed in the row headings. Note that all data are specific to the "run specification" described in the drop-down list at the top of the screen. Furthermore, the rows that are displayed in the spreadsheet are dependent on the "end-use sector" that is selected for the "run specification." To see other technology data select a different "run specification" record at the top of the screen.

The data on the technology data screen can be input or edited by hand. The years covered by the scenario also can be adjusted. Note that all costs or savings are considered to relate to differences from the conventional competing technology. For example, in example shown in Figure 5.4, the technology costs the economy an additional \$33.99 million in investment during the year 2004. The annual level energy and water impact in the same year is \$14.96 million saved in electricity, and no change to oil, natural gas, or water use, no change to non-energy operating costs. The energy, water, and operating cost savings are annual levels in the year shown that depend on cumulative investments. The capital costs are the cash investments in the year shown. This accounting is required by the input-output model's requirements for annual cash flow.

The following are some key functions: 
Advanced technology options - Enables the user to add a technology to the "default" technology list and/or delete technologies from the "default" technology list. This feature allows the user to establish customized versions of a technology that can then be used repeatedly when adding new "run specification” records.

Add/remove years - Enables the user to add and/or remove years from the currently displayed "run specification".

Note: The choices only affect the currently displayed "run specification”. Before "runs” can be processed all "run specifications" must have the same set of years.

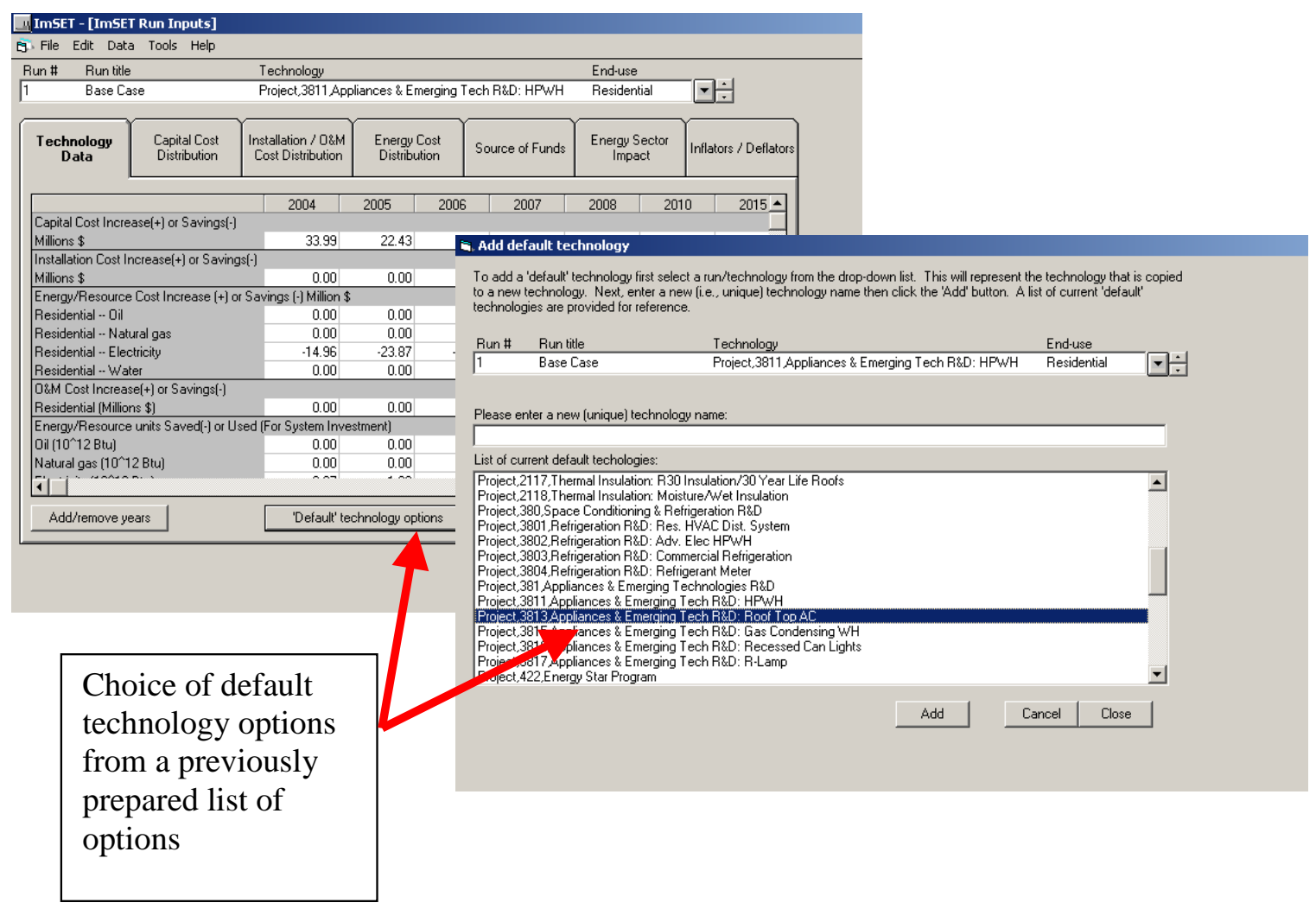

Figure 5-5. Adding to the Technology Options

\section{Changing the default technology options}

Add technology to list of default technologies - Enables the user to add a technology to the "default" technology list. This feature allows the user to establish customized versions of a technology that can then be used repeatedly when adding new "run specification” records. More specifically, the user may have a particular set of technology data and years that are not currently represented in the "default" technology list. To create a new "default" technology simply select an existing "default” technology, modify its data accordingly, save any changes, then select the "Add technology to list of default technologies" pop-up choice. The user would then see a new "Add technology" screen appear in which he enters a unique technology name where requested, then select s "Add" and "Close". At this point return to the "run specification" screen. If the user adds new "run specification” records, the newly created technology will appear in the drop-down list of "default" technologies. 
Delete technology from list of default technologies - Enables the user to delete technologies from the "default" technology list. Note: the deletion of a technology only affects the "default" technology list and in no way deletes records from the user database file.

\subsubsection{Capital cost distribution}

Enter the percentage values (enter $50 \%$ as 50 ) that represent the distribution of capital cost premiums for the applicable sectors. The total of all values must equal 100. In the example shown in Figure 5.6, $100 \%$ of the capital cost premium is spent on household appliances, not elsewhere classified (Sector 61).

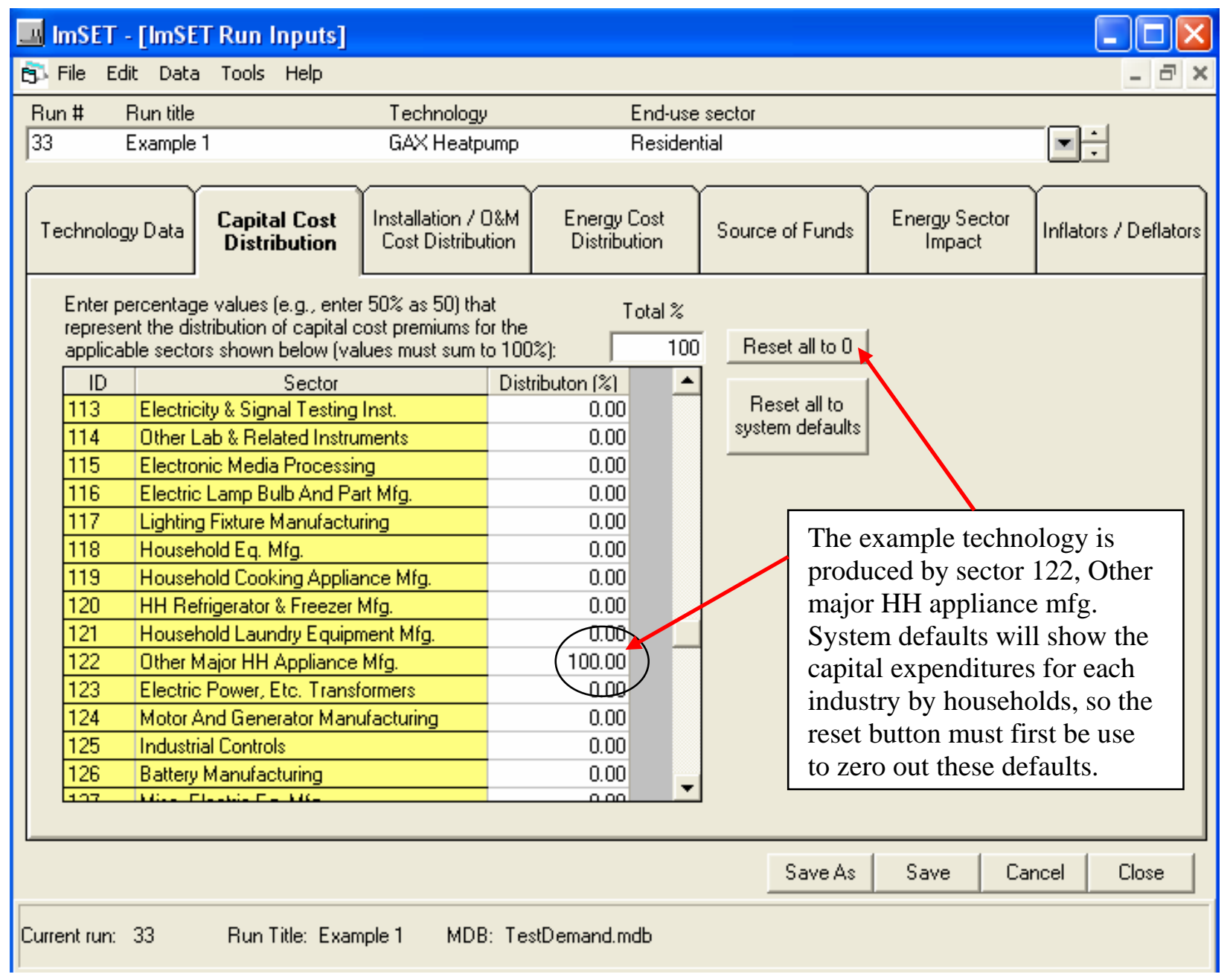

Figure 5-6. Allocation of Capital Cost

\subsubsection{Energy and Water Cost Savings Distribution}

Enter the percentage values (enter $50 \%$ as 50 ) that represent the distribution of energy and water cost savings for the applicable sectors. The total of all values must equal 100. Note that the sectors shown will be dependent on the end-use sector targeted by the technology/program. For example, commercial enduse sectors will be the sectors numbered 82 through 95, industrial end-use sectors will be sectors 1 through 72, transportation will be sectors 73 through 77. Residential end-use technology/program cost savings will all impact final demand; thus, there will be no industry sectors to specify. 
Energy savings in commercial buildings can be allocated to sectors 82-95 in proportion to each sector's likely purchase of each fuel; e.g., if Sector 82, Wholesale and Retail Trade, purchased 30.00 percent of baseline electricity purchased in sectors 82-95, Sector 82 likely would have seen 30.00 percent of the savings as well. The user is free to change these proportions. The model also includes water cost savings. This is important for some water-using equipment such as laundry equipment.

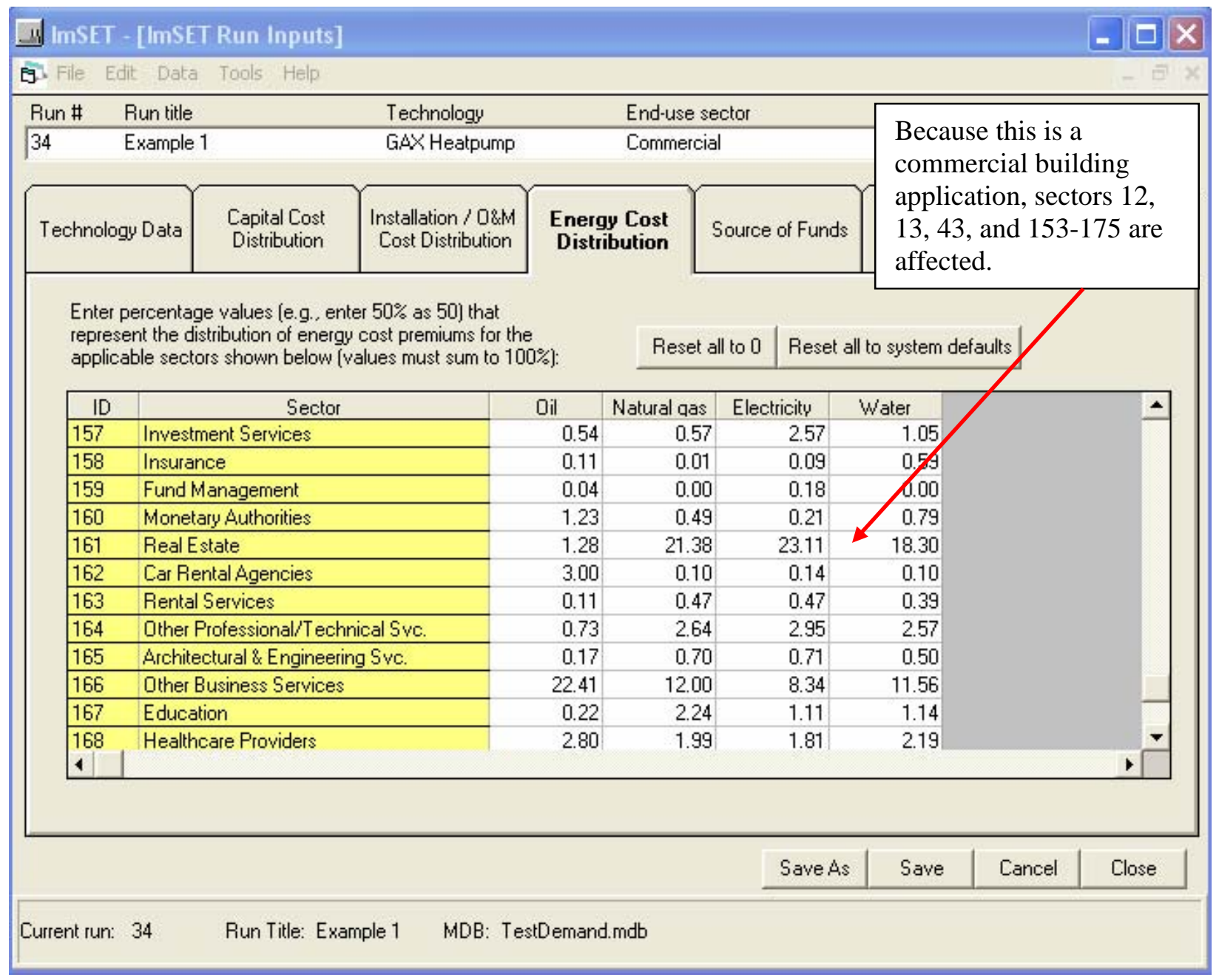

Figure 5-7. Energy/Water Cost Savings Distribution Across Sectors

\subsubsection{Allocation of O\&M Costs}

Default allocations for each of the end-use sectors currently are shown on the page, but these can be modified to suit the user. Operating and maintenance activities, if they are purchased from one of the sectors shown, would probably all be spent on personal services. Distributions for the other end-use sectors were calculated by summing the purchases from these four sectors then dividing each sector's sales by the total. The modest activities that transportation services sell to the commercial sector were deemed to be activities other than O\&M, so this cell is specified as zero in default.

In the previous version of the model, these costs/savings were embedded in the use table as interindustry transactions. With 188 sectors, this would generate many changes to the model, and would likely eventually cause an excess of changes to the FORTRAN program (the current limit is 350). Accordingly, 
rather than construct a distribution of O\&M expenditures for each of the end-use sectors, we treat these changes as applying to final demands. Thus at most, there will be four changes for O\&M costs or savings that are input to the calculator.

Sensitivity tests were run to see if this would make a substantial difference in the output of the model and we found the changes to be modest, in the extreme-in the thousandths of a percentage point for reasonable estimates of $\mathrm{O} \& \mathrm{M}$ costs/savings.

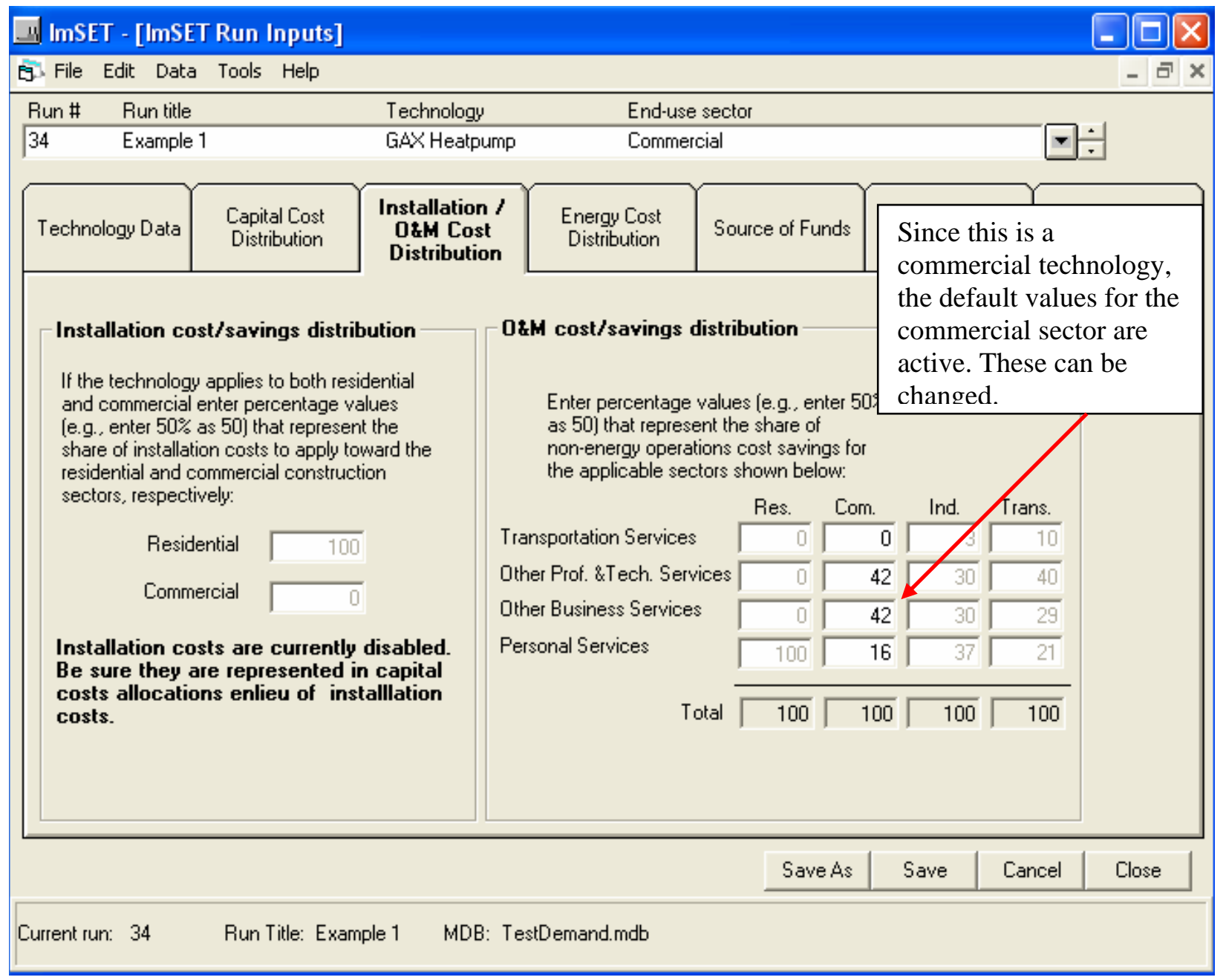

Figure 5-8. O\&M Cost Savings Distribution for Commercial Sector

\subsubsection{Source of Investment Funds}

Investment funds spent on energy-efficient equipment have an opportunity cost; that is, they would have been spent somewhere else in the domestic economy or overseas if they were not spent on energyefficient equipment. The source of funds sheet allows the user to specify the source of the funds used for investment. Enter the percentage values (e.g., enter 50\% as 50) that represent the share of investment funding provided by each applicable. The sum of the sector allocations does not need to equal $100 \%$, but if it does not, the model will allocate the remaining percentage to sum to $100 \%$ unless it is overridden, 
and will allocate spending reductions within the remainder using the average proportions in all final demand. However, even if all of the explicit shares are set to zero, each sector will have its spending reduced by the proportion it represents of all final demand unless the override box is checked. The override check box allows some or all of the opportunity cost of invested funds to not be counted against domestic final demand.

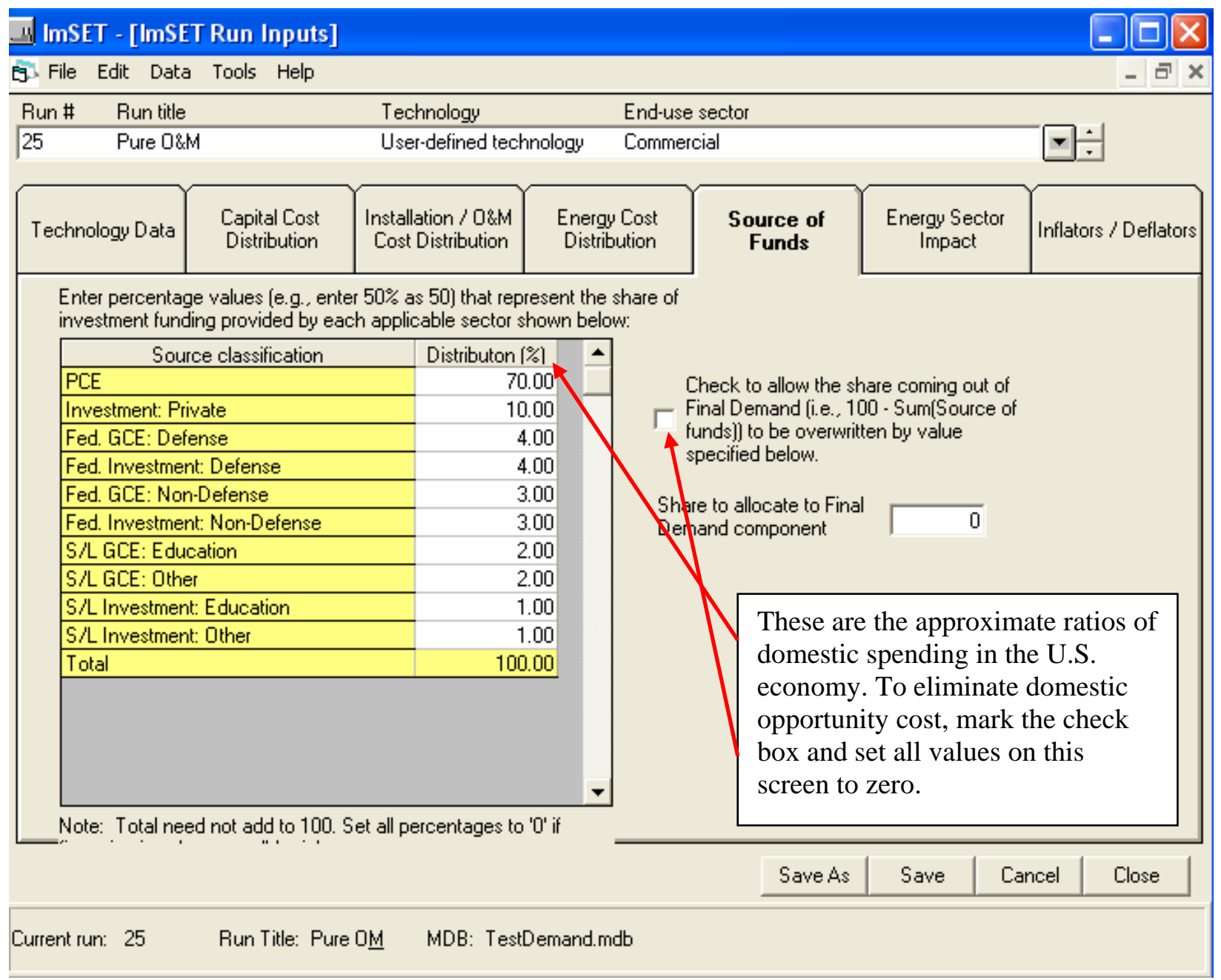

Figure 5-9. Opportunity Cost of Invested Funds

There are occasions when the user may not want to consider the opportunity cost of the funds used for investment. If, for example, only the impacts on a local region were being considered and the funds came from the national financial markets, then the local area might see the positive impact of the investment as well as any energy savings, but would not experience the costs to the national economy. These costs would be "somewhere else." Another reason might be if the displaced spending were somewhere else in the world and only the domestic impact was important. If opportunity cost of the investment funds is irrelevant to the analysis or the source of funds is "magic," then all values can be set to 0 . To do this, set all of the sectors to zero, check the check box, and then set the remainder box to zero as well. The most common assumption is that investment funds will come proportionately from all domestic spending. 


\subsubsection{Energy Sector Impact}

This screen allows the user to specify how the technology/program impacts will affect the investment in the energy sector, in particular the electricity and industries. Significant energy savings might allow electricity and natural gas production, transmission, and distribution companies to reduce the amount of investment that they undertake, which frees up investment capital for the general economy (this is the mirror image of the "source of funds" allocation). If reductions in investment occur due to the technology/program then enter "Yes" for the applicable question and enter any changes to load/capacity factors and costs as necessary. If either "Yes" is selected then enter where (percentage shares) investment dollars would be going to (what sectors would benefit) in the right hand box. In the example in Figure 5.9, the investment is proportionately distributed to the economy as a whole. Note that in this case the sum of those shares is handled the same way as the as the opportunity cost of invested funds. The "benefit" of investment savings need not remain in the region of interest.

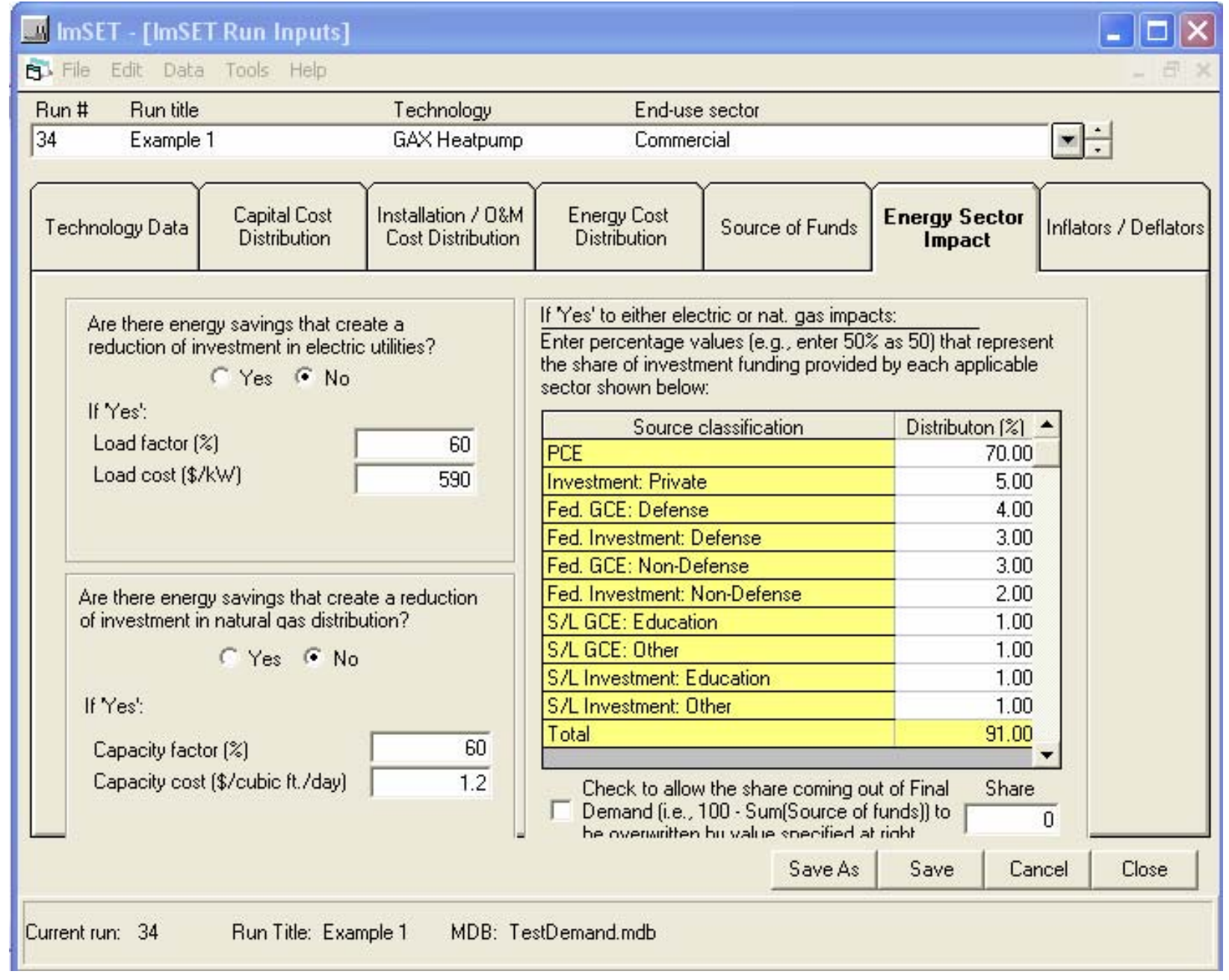

Figure 5-10. Impact of Energy Savings on Energy Sector Investments

\subsubsection{Inflators / Deflators}

The inflators/deflators page is designed to allow easy conversion of costs and savings to the appropriate year's dollars. The input-output table at the core of ImSET is in 1997 dollars, so inputs to the model need to be converted to a 1997 basis. In the example in Figure 5.10, capital costs and savings 
originally available to the analysts were expressed in 2000 dollars, which needed to be converted to 1997 dollars. This is the purpose of the deflators. On the other hand, for reporting purposes many users would like to see earnings numbers in some later year's constant dollars, not 1997. For example, in recent use of the model, results have been reported in constant 2002 dollars. This is the purpose of the inflators. Enter the appropriate inflators /deflators to use in the model. Note that capital cost deflators are used to adjust capital cost, installation costs, and utility impact costs to the base input-output year (1997). Operations cost deflators are used to adjust energy costs and O\&M costs to the base input-output year and to adjust the base input-output results for 'output' dollars back to the year assumed in the technology data. Both of these are based on Gross Domestic Product deflators. The inflator input is based on the appropriate year's Consumer Price Index and is used to adjust base input-output results for earnings to the technology data base year, or to some other year for reporting purposes.

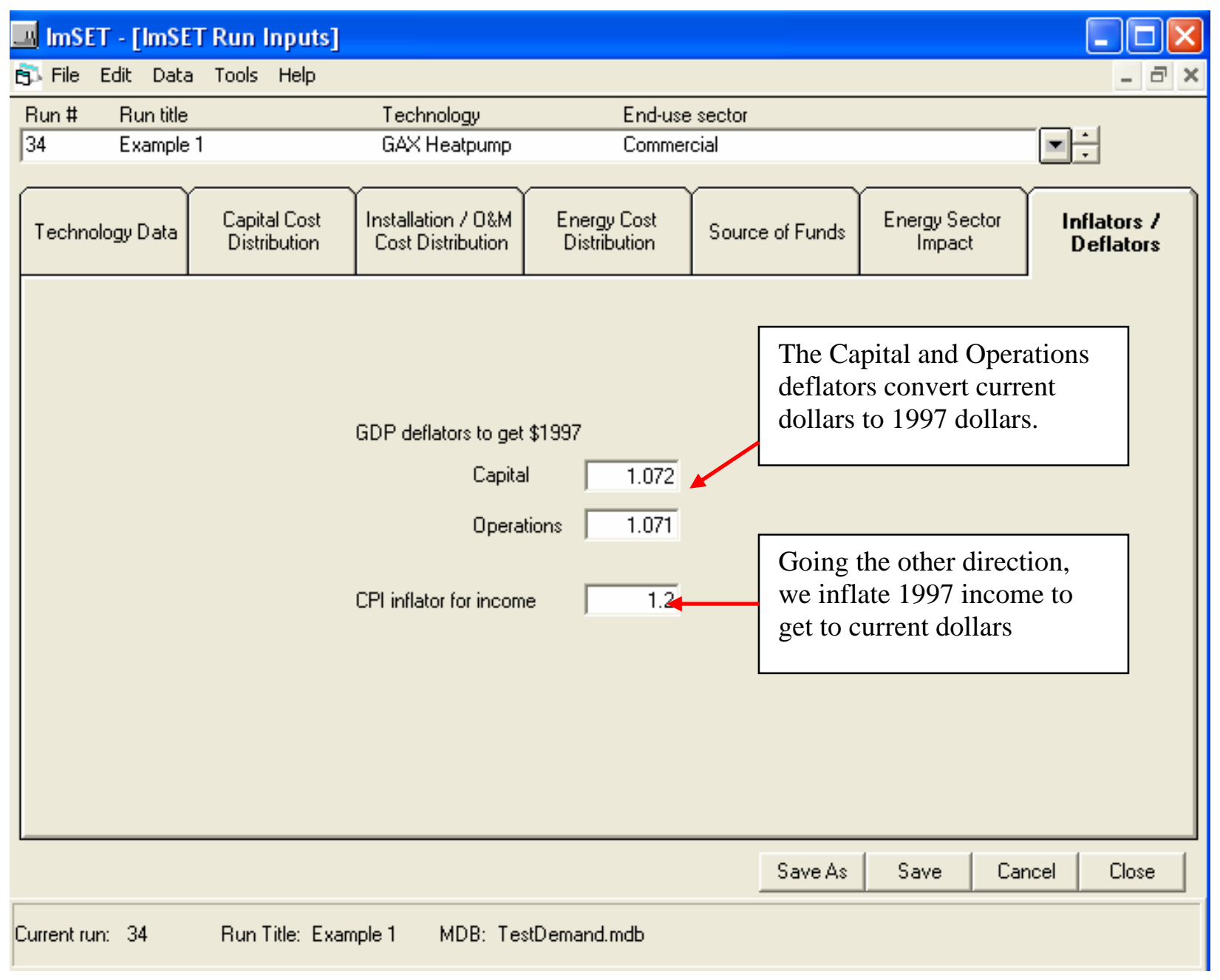

Figure 5-11. Assigning Inflators and Deflators

\subsection{Computing Program Impacts}

Selecting the "Compute program impacts" will run the computations for determining the impacts of the "run specifications". Only those records marked with "Execute run" will be processed. Before running 
computations the program checks for a common set of years between all technologies/programs. It will also test for conditions where there are no years represented.

With data integrity checks complete, the process loops through each "run scenario" and, in turn, creates an associated ASCII file of data that will be read by the ImSET model. The processing code (QMIO.EXE) is then called and when finished, the process retrieves the ASCII output file created by the model and parses and stores the results to the user database file. With that process complete, the ImSET tool opens the results screen and presents the calculated impacts in spreadsheet and graphical form.

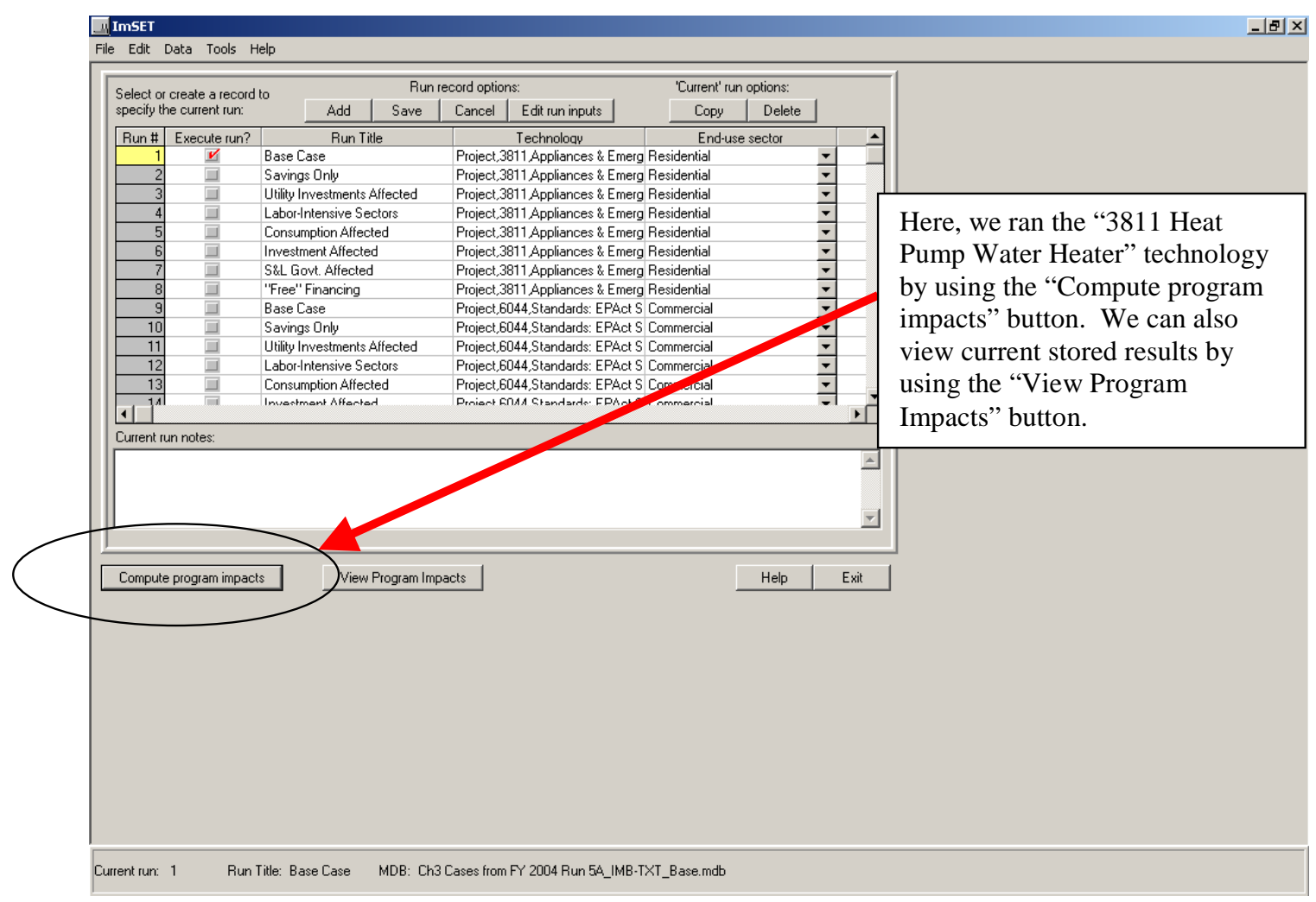

Figure 5-12. Running the ImSET Mode

\subsection{Viewing Program Impacts}

If the user wishes to view the last computed impacts without rerunning the calculations then he/she should select the "View program impacts" button. The results can be viewed in two display formats. The first will be in a spreadsheet form and second will be a graphical form. In either form the displayed data will be dependent on the "Impacts data type" choice that is available at the top of the screen. Additional options in this screen include printing the spreadsheet and all the data types and exporting all impact data types to an Excel spreadsheet file. The name assigned to the Excel file will be the same as the user database file. The graphical portion of the "Results" screen offers the user a rich set of options for changing the graph displayed. The user should feel free to "play" with the different option available including printing the graph to file or printer.

\section{Results presentation}


There are two styles of results presentation. The first style shows the results in tabular form and in graphical form presented in individual "tab" frames. Use the "Results type" drop-down list at the top of the screen to select the individual results data that are available. Select the "Print" button to print these as they appear on the screen. In this presentation style the user has liberty to access the graph properties pages to customize and print the graph in a customized fashion. The user also has the option of selecting which results to graph by selecting the appropriate button. The second results presentation is made available by clicking the "Reports manager" button in the "Results" screen. The "Report Manager" screen will present a spreadsheet contained all available reports. Each of these types of reports will display both a graph (Figure 5.13) and cross-tabbed table (Figure 5.14) of the selected results. This presentation of the results enables the user to export the results to a host of file formats. Data also may be exported and stored in Excel spreadsheet format for additional manipulation.

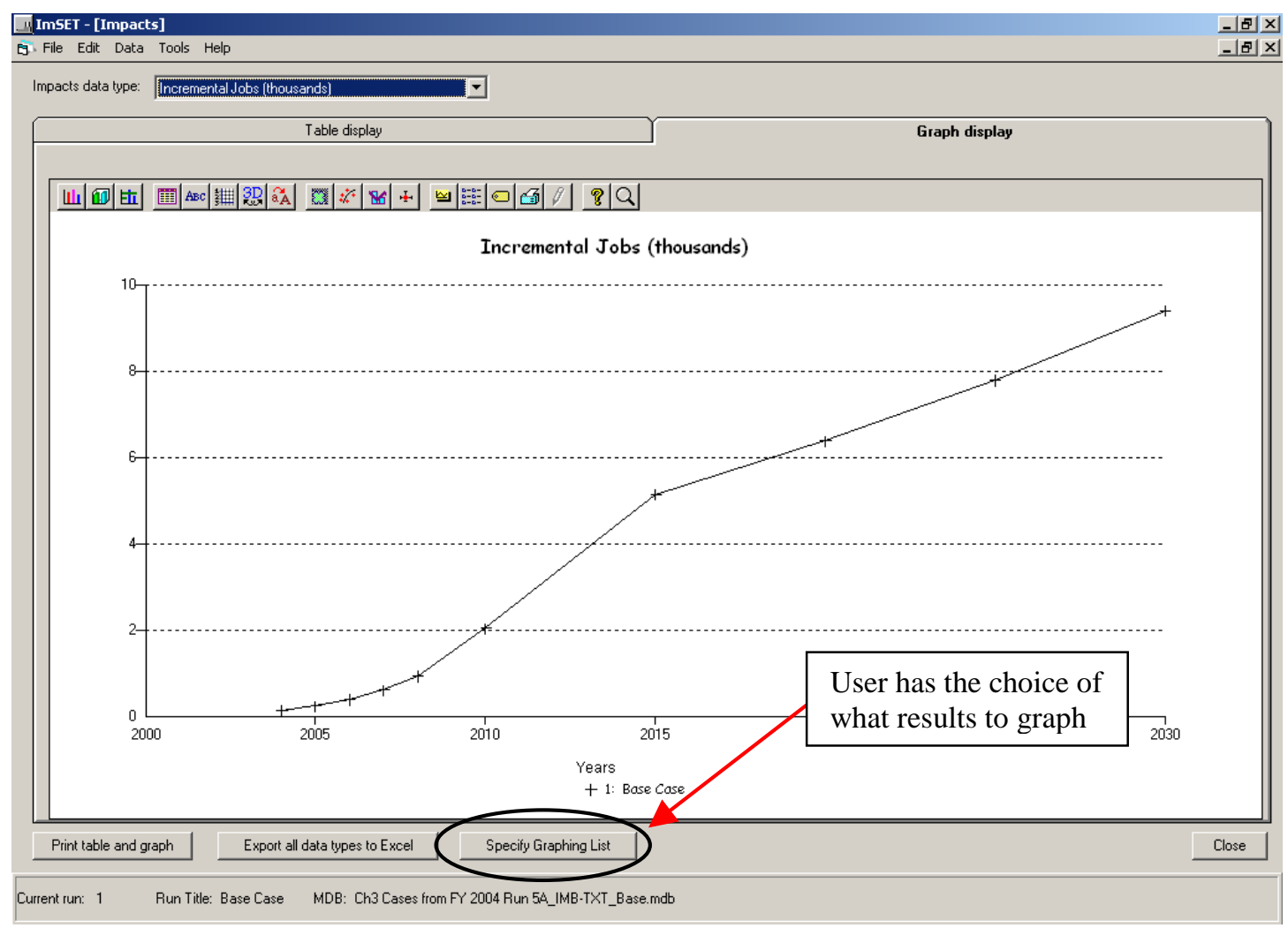

Figure 5-13. Report Manager Screens for Output (Graphical Display) 


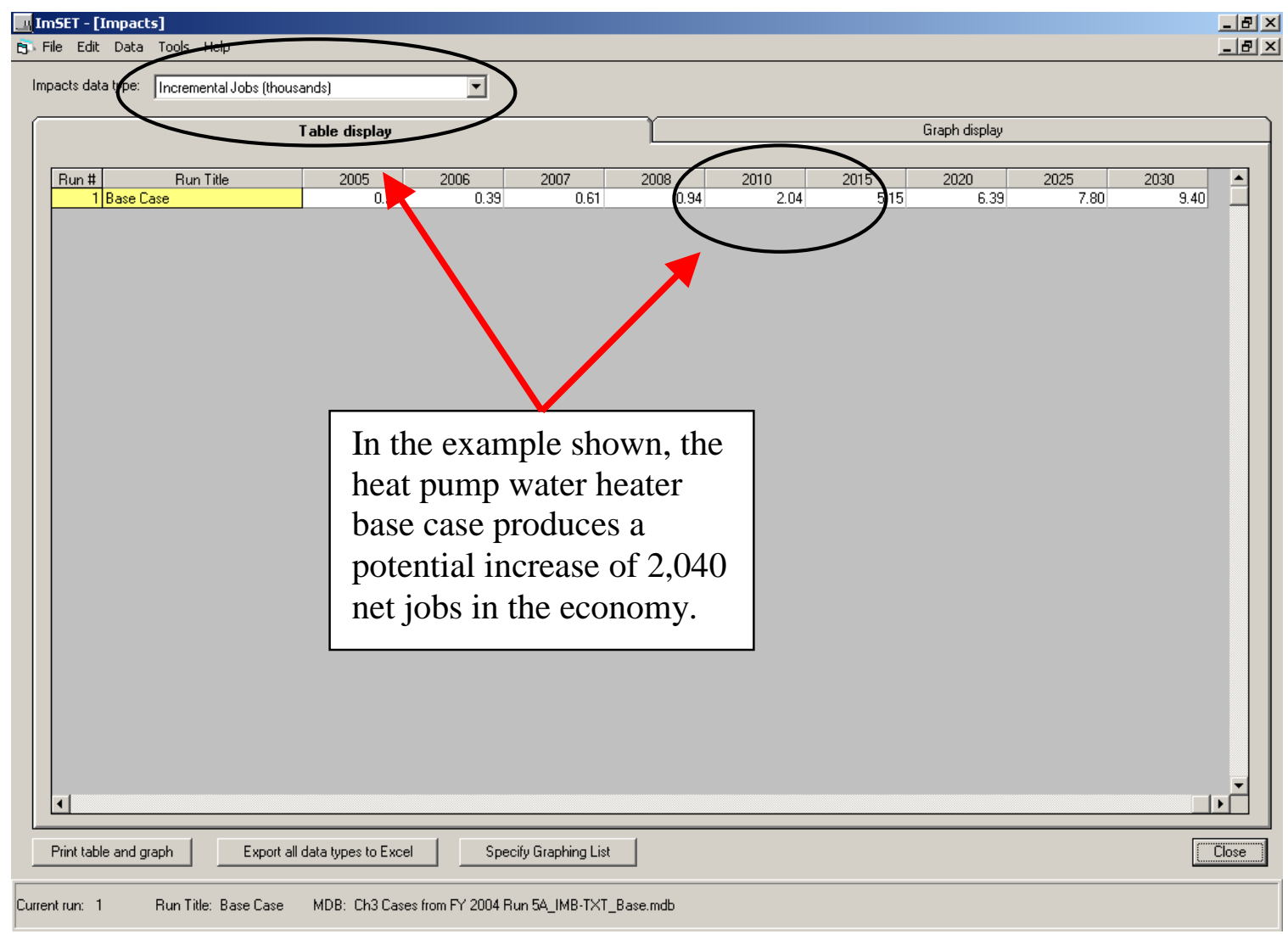

Figure 5-14 Report Manager Screens for Output (Table Display) 


\subsection{References}

Anderson, D.M., D.B. Belzer, K.A. Cort, J.A. Dirks, D.B. Elliott, D.J. Hostick, and M.J. Scott. 2003. Methodological Framework for Analysis GPRA Metrics: Application to FY04 Projects in BT and WIP. PNNL-14231. Pacific Northwest National Laboratory, Richland, Washington.

Berck, Peter and Sandra Hoffmann. 2002. "Assessing the Employment Impacts of Environmental and Natural Resource Policy,” Environmental and Resource Economics. 22: 133-156.

Economic Research Associates. 2005. Modeling the Economic Impacts of National and State Energy Policy Scenarios. A Working Paper for the U.S. PIRG Education Fund.

Elliott, D.B., Anderson, D.M., Belzer, D.B., Cort, K.A., Dirks, J.A., and Hostick D.J.: 2004, Methodological Framework for Analysis of Buildings-Related Programs: GPRA Metrics Effort, PNNL-14697, Richland, WA, Pacific Northwest National Laboratory.

Energy Information Administration (EIA). 1996. Natural Gas 1996: Issues and Trends. DOE/EIA0560(96). Energy Information Administration, U.S. Department of Energy, Washington, D.C.

Energy Information Administration (EIA). 1997. Annual Energy Outlook 1998. DOE/EIA-0383(98). Energy Information Administration, U.S. Department of Energy, Washington, D.C.

Geller, H., J. DeCicco, and S. Laitner. 1992. Energy Efficiency and Job Creation: The Employment and Income Benefits from Investing in Energy Conserving Technologies. Washington, D.C.: The American Council for an Energy-Efficient Economy.

Kaiser, M. J. and A. G. Pulsipher. 2003. "A generalized modeling framework for public benefit program valuation,” Energy: The International Journal. 28 (6): 519-538.

Kaiser, M. J., A. G. Pulsipher, and R. H. Baumann. 2004. “The potential economic and Environmental impact of a Public Benefit Fund in Louisiana,” Energy Policy. 32 (2): 191-206.

Kaiser, M. J., W. O. Olatubi, and A. G. Pulsipher. 2005. "Economic, energy, and environmental impact of the Louisiana Energy Fund,” Energy Policy. 33 (7): 873-883.

Laitner, S. 1992. "Missouri’s Two-Percent Solution: Energy Efficiency for Economic Development and the Environment.” Summary Report. Eugene, Oregon: Economic Research Associates.

Lawson, Ann M., Kurt S. Bersani, Mahnaz Fahim-Nader, and Jiemin Guo. 2002. "Benchmark InputOutput Accounts of the U. S. Economy, 1997,” Survey of Current Business, December, pp. 19117.

Moscovitch, E. 1994. "DSM in the Broader Economy: The Economic Impacts of Utility Efficiency Programs,” The Electricity Journal, 7(4): 14-28. 
Nayak, Navin. 2005. Redirecting America's Energy: The Economic and Consumer Benefits of Clean Energy Policies. U. S. PIRG Education Fund, Washington, D. C. Available at: http://www.uspirg.org, accessed 5 May 2005.

Scott, M. J., D. J. Hostick, and D. B. Belzer. 1998. ImBuild: Impact of Building Energy Efficiency Programs. PNNL-11884. Pacific Northwest National Laboratory, Richland, Washington.

Scott M. J., Roop J. M., and Schultz R. W. 2002. "ImBuild II: Impact of Technologies on Energy Efficiency Programs". PNNL-13926. Pacific Northwest National Laboratory, Richland, Washington.

Solow, R. M. 1994. “DSM: Not for Jobs, but on its Merits.” The Electricity Journal, 7(4):80-81.

Xie, Jian. 2000. “An Environmentally Extended Social Accounting Matrix: Conceptual

Framework and Application to Environmental Policy Analysis in China." Environmental and Resource Economics, 16: 391-406. 


\section{Appendix A. Base Cases for Energy Efficiency Technologies}

\section{Heat Pump Water Heater Base Case}

\begin{tabular}{|c|c|c|c|c|c|c|c|c|c|c|}
\hline \multirow[t]{2}{*}{ Base Case } & \multicolumn{10}{|c|}{ Heat Pump Water Heater } \\
\hline & 2005 & 2006 & 2007 & 2008 & 2009 & 2010 & 2015 & 2020 & 2025 & 2030 \\
\hline \multicolumn{11}{|c|}{ Capital and Installation Cost Increase (+) or Savings(-) Million \$ } \\
\hline & 141.66 & 143.83 & 89.37 & 89.87 & 90.70 & 91.84 & 0.01 & 0.01 & 0.01 & 0.01 \\
\hline \multicolumn{11}{|c|}{ Energy/Resource Cost Increase (+) or Savings (-) Million \$ } \\
\hline Residential -- Oil & 0 & 0 & 0 & 0 & 0 & 0 & 0 & 0 & 0 & 0 \\
\hline $\begin{array}{l}\text { Residential -- Natural } \\
\text { gas }\end{array}$ & 0 & 0 & 0 & 0 & 0 & 0 & 0 & 0 & 0 & 0 \\
\hline \multicolumn{11}{|l|}{ Residential -- } \\
\hline Electricity & -23.87 & -39.28 & -61.54 & -93.47 & -133.97 & -203.48 & -504.69 & -625.64 & -762.9 & -919.02 \\
\hline Residential -- Water & 0 & 0 & 0 & 0 & 0 & 0 & 0 & 0 & 0 & 0 \\
\hline Commercial -- Oil & 0 & 0 & 0 & 0 & 0 & 0 & 0 & 0 & 0 & 0 \\
\hline $\begin{array}{l}\text { Commercial -- Natural } \\
\text { gas }\end{array}$ & 0 & 0 & 0 & 0 & 0 & 0 & 0 & 0 & 0 & 0 \\
\hline $\begin{array}{l}\text { Commercial -- } \\
\text { Electricity }\end{array}$ & 0 & 0 & 0 & 0 & 0 & 0 & 0 & 0 & 0 & 0 \\
\hline ercial -- Water & 0 & 0 & 0 & 0 & 0 & 0 & 0 & 0 & 0 & 0 \\
\hline Industrial -- Oil & 0 & 0 & 0 & 0 & 0 & 0 & 0 & 0 & 0 & 0 \\
\hline $\begin{array}{l}\text { Industrial -- Natural } \\
\text { gas }\end{array}$ & 0 & 0 & 0 & 0 & 0 & 0 & 0 & 0 & 0 & 0 \\
\hline Industrial -- Electricity & 0 & 0 & 0 & 0 & 0 & 0 & 0 & 0 & 0 & 0 \\
\hline Industrial -- Water & 0 & 0 & 0 & 0 & 0 & 0 & 0 & 0 & 0 & 0 \\
\hline Transportation -- Oil & 0 & 0 & 0 & 0 & 0 & 0 & 0 & 0 & 0 & 0 \\
\hline $\begin{array}{l}\text { Transportation -- } \\
\text { Natural gas }\end{array}$ & 0 & 0 & 0 & 0 & 0 & 0 & 0 & 0 & 0 & 0 \\
\hline $\begin{array}{l}\text { Transportation -- } \\
\text { Electricity }\end{array}$ & 0 & 0 & 0 & 0 & 0 & 0 & 0 & 0 & 0 & 0 \\
\hline $\begin{array}{l}\text { Transportation -- } \\
\text { Water }\end{array}$ & 0 & 0 & 0 & 0 & 0 & 0 & 0 & 0 & 0 & 0 \\
\hline \multicolumn{11}{|c|}{ or Savings (-) (Million \$) } \\
\hline Residential & 0 & 0 & 0 & 0 & 0 & 0 & 0 & 0 & 0 & 0 \\
\hline Comı & 0 & 0 & 0 & 0 & 0 & 0 & 0 & 0 & 0 & 0 \\
\hline Indus & 0 & 0 & 0 & 0 & 0 & 0 & 0 & 0 & 0 & 0 \\
\hline Transportation & 0 & 0 & 0 & 0 & 0 & 0 & 0 & 0 & 0 & 0 \\
\hline \multicolumn{11}{|c|}{ Energy/Resource Units Saved (-) or Used (For System Investment) } \\
\hline Oil $\left(10^{12} \mathrm{Btu}\right)$ & 0 & 0 & 0 & 0 & 0 & 0 & 0 & 0 & 0 & 0 \\
\hline Natural gas $\left(10^{12}\right.$ Btu) & 0 & 0 & 0 & 0 & 0 & 0 & 0 & 0 & 0 & 0 \\
\hline Electricity $\left(10^{12} \mathrm{Btu}\right)$ & -1.09 & -1.78 & -2.81 & -4.27 & -6.12 & -9.3 & -22.93 & -28.22 & -34.18 & -40.9 \\
\hline Water (109 Gallons) & 0 & 0 & 0 & 0 & 0 & 0 & 0 & 0 & 0 & 0 \\
\hline
\end{tabular}




\section{EPACT Standards Base Case}

\begin{tabular}{|c|c|c|c|c|c|c|c|c|c|c|}
\hline \multirow[t]{2}{*}{ Base Case } & \multicolumn{10}{|c|}{ EPACT Standards } \\
\hline & 2005 & 2006 & 2007 & 2008 & 2009 & 2010 & 2015 & 2020 & 2025 & 2030 \\
\hline \multicolumn{11}{|c|}{ Capital and Installation Cost Increase (+) or Savings (-) Million \$ } \\
\hline & & & & & $\$ 1,066$. & $\$ 1,036$. & & & & \\
\hline & $\$ 198.2$ & $\$ 205.4$ & $\$ 189.0$ & $\$ 971.2$ & 6 & 1 & $\$ 1,331.9$ & $\$ 1,424.3$ & $\$ 574.7$ & $\$ 606.7$ \\
\hline \multicolumn{11}{|c|}{ Energy/Resource Cost Increase (+) or Savings (-) Million \$ } \\
\hline Residential -- Oil & 0 & 0 & 0 & 0 & 0 & 0 & 0 & 0 & 0 & 0 \\
\hline $\begin{array}{l}\text { Residential -- } \\
\text { Natural gas }\end{array}$ & 0 & 0 & 0 & 0 & 0 & 0 & 0 & 0 & 0 & 0 \\
\hline $\begin{array}{l}\text { Residential -- } \\
\text { Electricity }\end{array}$ & 0 & 0 & 0 & 0 & 0 & 0 & 0 & 0 & 0 & 0 \\
\hline Residential -- Water & 0 & 0 & 0 & 0 & 0 & 0 & 0 & 0 & 0 & 0 \\
\hline Commercial -- Oil & 0 & 0 & 0 & 0 & 0 & 0 & 0 & 0 & 0 & 0 \\
\hline Commercial -- & & & & & & & & & & \\
\hline $\begin{array}{l}\text { Natural gas } \\
\text { Commercial -- }\end{array}$ & $\$ 0.0$ & $\$ 0.0$ & $\$ 0.0$ & $-\$ 4.9$ & $-\$ 10.4$ & $-\$ 16.0$ & $-\$ 43.5$ & $-\$ 74.2$ & $-\$ 100.5$ & $-\$ 127.9$ \\
\hline Electricity & $-\$ 21.5$ & $-\$ 43.9$ & $-\$ 64.4$ & $-\$ 165.1$ & $-\$ 275.5$ & $-\$ 382.6$ & $-\$ 1,068.5$ & $-\$ 1,792.1$ & $-\$ 2,072.8$ & $-\$ 2,364.7$ \\
\hline $\begin{array}{l}\text { Commercial -- } \\
\text { Water }\end{array}$ & 0 & 0 & 0 & 0 & 0 & 0 & 0 & 0 & 0 & 0 \\
\hline Industrial -- Oil & 0 & 0 & 0 & 0 & 0 & 0 & 0 & 0 & 0 & 0 \\
\hline $\begin{array}{l}\text { Industrial -- Natural } \\
\text { gas }\end{array}$ & 0 & 0 & 0 & 0 & 0 & 0 & 0 & 0 & 0 & 0 \\
\hline $\begin{array}{l}\text { Industrial -- } \\
\text { Electricity }\end{array}$ & 0 & 0 & 0 & 0 & 0 & 0 & 0 & 0 & 0 & 0 \\
\hline Industrial -- Water & 0 & 0 & 0 & 0 & 0 & 0 & 0 & 0 & 0 & 0 \\
\hline tation -- Oil & 0 & 0 & 0 & 0 & 0 & 0 & 0 & 0 & 0 & 0 \\
\hline $\begin{array}{l}\text { Transportation -- } \\
\text { Natural gas }\end{array}$ & 0 & 0 & 0 & 0 & 0 & 0 & 0 & 0 & 0 & 0 \\
\hline $\begin{array}{l}\text { Transportation -- } \\
\text { Electricity }\end{array}$ & 0 & 0 & 0 & 0 & 0 & 0 & 0 & 0 & 0 & 0 \\
\hline $\begin{array}{l}\text { Transportation -- } \\
\text { Water }\end{array}$ & 0 & 0 & 0 & 0 & 0 & 0 & 0 & 0 & 0 & 0 \\
\hline O\&M Cost Increa & +) or Sa & vings $(-$ & ) (Mill & ion \$) & & & & & & \\
\hline Residenti & 0 & 0 & 0 & 0 & 0 & 0 & 0 & 0 & 0 & 0 \\
\hline Commercial & 0 & 0 & 0 & 0 & 0 & 0 & 0 & 0 & 0 & 0 \\
\hline Industrial & -2.38 & -2.55 & -2.78 & -3 & -3.12 & -3.18 & -3.87 & -6.01 & -5.88 & -6.25 \\
\hline Transportation & 0 & 0 & 0 & 0 & 0 & 0 & 0 & 0 & 0 & 0 \\
\hline Energy/Resource Un & s Saved & (-) or I & Jsed (F & or Sys & tem Inv & estment & & & & \\
\hline Oil (10 $12 \mathrm{Btu})$ & 0 & 0 & 0 & 0 & 0 & 0 & 0 & 0 & 0 & 0 \\
\hline Natural gas $\left(10^{12}\right.$ & & & & & & & & & & \\
\hline Btu) & 0 & 0 & 0 & -0.9 & -1.9 & -2.9 & -7.9 & -13 & -17.3 & -21.6 \\
\hline Electricity $\left(10^{12} \mathrm{Btu}\right)$ & -1.1 & -2.3 & -3.5 & -9.1 & -15.4 & -21.7 & -60.3 & -98.9 & -112.9 & -127 \\
\hline Water (10 ${ }^{9}$ Gallons) & 0 & 0 & 0 & 0 & 0 & 0 & 0 & 0 & 0 & 0 \\
\hline
\end{tabular}




\section{Glass Manufacturing Base Case}

\begin{tabular}{|c|c|c|c|c|c|c|c|c|c|c|}
\hline \multirow[t]{2}{*}{ Base Case } & \multicolumn{10}{|c|}{ Residential Technology Research and Development } \\
\hline & 2003 & 2004 & 2005 & 2006 & 2007 & 2010 & 2015 & 2020 & 2025 & 2030 \\
\hline \multicolumn{11}{|c|}{ Capital and Installation Cost Increase (+) or Savings(-) Million \$ } \\
\hline & 22.53 & 21.1 & 22.6 & 22.6 & 22.6 & 21.1 & 17.11 & 11.12 & 6 & 6 \\
\hline \multicolumn{11}{|c|}{ Energy/Resource Cost Increase (+) or Savings (-) Million \$ } \\
\hline Residential -- Oil & 0 & 0 & 0 & 0 & 0 & 0 & 0 & 0 & 0 & 0 \\
\hline esidential -- Natural ga & 0 & 0 & 0 & 0 & 0 & 0 & 0 & 0 & 0 & 0 \\
\hline esic & 0 & 0 & 0 & 0 & 0 & 0 & 0 & 0 & 0 & 0 \\
\hline esidential -- Water & 0 & 0 & 0 & 0 & 0 & 0 & 0 & 0 & 0 & 0 \\
\hline Lomr & 0 & 0 & 0 & 0 & 0 & 0 & 0 & 0 & 0 & 0 \\
\hline $\begin{array}{l}\text { Commercial -- Natural } \\
\text { gas }\end{array}$ & 0 & 0 & 0 & 0 & 0 & 0 & 0 & 0 & 0 & 0 \\
\hline ommerci & 0 & 0 & 0 & 0 & 0 & 0 & 0 & 0 & 0 & 0 \\
\hline Som & 0 & 0 & 0 & 0 & 0 & 0 & 0 & 0 & 0 & 0 \\
\hline ndu & -0.98 & -1 & -1.01 & -1.03 & -1.04 & -1.04 & -0.9 & -0.46 & -0.14 & 0 \\
\hline Industrial -- Natural gas & -67.98 & -71.32 & -75.22 & -79.21 & -80.98 & -82.77 & -86.87 & -72.64 & -65.67 & -72.72 \\
\hline Industrial -- Electricity & -152.58 & -154.14 & -151.91 & -153.43 & -153.73 & -154.94 & 132.91 & -44.84 & -9.94 & 0 \\
\hline ndustrial -- Water & 0 & 0 & 0 & 0 & 0 & 0 & 0 & 0 & 0 & 0 \\
\hline Tran & 0 & 0 & 0 & 0 & 0 & 0 & 0 & 0 & 0 & 0 \\
\hline $\begin{array}{l}\text { Transportation -- Natural } \\
\text { gas }\end{array}$ & 0 & 0 & 0 & 0 & 0 & 0 & 0 & 0 & 0 & 0 \\
\hline $\begin{array}{l}\text { Transportation -- } \\
\text { Electricity }\end{array}$ & 0 & 0 & 0 & 0 & 0 & 0 & 0 & 0 & 0 & 0 \\
\hline Transportation -- Water & 0 & 0 & 0 & 0 & 0 & 0 & 0 & 0 & 0 & 0 \\
\hline \multicolumn{11}{|c|}{ O\&M Cost Increase (+) or Savings(-) (Million \$) } \\
\hline Residential & 0 & 0 & 0 & 0 & 0 & 0 & 0 & 0 & 0 & 0 \\
\hline Con & 0 & 0 & 0 & 0 & 0 & 0 & 0 & 0 & 0 & 0 \\
\hline & 0 & 0 & 0 & 0 & 0 & 0 & 0 & 0 & 0 & 0 \\
\hline Transportation & 0 & 0 & 0 & 0 & 0 & 0 & 0 & 0 & 0 & 0 \\
\hline \multicolumn{11}{|c|}{ Energy/Resource units Saved (-) or Used (For System Investment) } \\
\hline Oil (10^12 Btu) & -0.18 & -0.18 & -0.18 & -0.18 & -0.18 & -0.18 & -0.16 & -0.08 & -0.02 & 0 \\
\hline Natural ga & -22.04 & -22.75 & -23.61 & -24.47 & -24.82 & -25.17 & -25.66 & -20.74 & -17.58 & -18.25 \\
\hline Elect & -12.7 & -12.83 & -12.96 & -13.09 & -13.11 & -13.22 & -11.63 & -4.03 & -0.92 & 0 \\
\hline Water (10^9 Gallons) & 0 & 0 & 0 & 0 & 0 & 0 & 0 & 0 & 0 & 0 \\
\hline
\end{tabular}




\section{Appendix B. Sectoral Detail}

\section{Table B.1 Cross Reference Between ImSET Sectors and 1997 U.S. Input-Output Table Sectors}

$\begin{array}{rll}\text { IO_IND } & \text { IOcode } & \text { Industry (1997 Benchmark IO) } \\ 1 & 1111 \mathrm{~A} 0 & \text { Oilseed farming } \\ 2 & 1111 \mathrm{~B} 0 & \text { Grain farming } \\ 3 & 111200 & \text { Vegetable and melon farming } \\ 4 & 111335 & \text { Tree nut farming } \\ 5 & 1113 \mathrm{~A} 0 & \text { Fruit farming } \\ 6 & 111400 & \text { Greenhouse and nursery production } \\ 7 & 111910 & \text { Tobacco farming } \\ 8 & 111920 & \text { Cotton farming } \\ 9 & 1119 \mathrm{~A} 0 & \text { Sugarcane and sugar beet farming } \\ 10 & 1119 \mathrm{~B} 0 & \text { All other crop farming } \\ 11 & 112100 & \text { Cattle ranching and farming } \\ 12 & 112300 & \text { Poultry and egg production } \\ 13 & 112 \mathrm{~A} 00 & \text { Animal production, except cattle and poultry and eggs } \\ 14 & 113300 & \text { Logging } \\ 15 & 113 \mathrm{~A} 00 & \text { Forest nurseries, forest products, and timber tracts } \\ 16 & 114100 & \text { Fishing } \\ 17 & 114200 & \text { Hunting and trapping } \\ 18 & 115000 & \text { Agriculture and forestry support activities } \\ 19 & 211000 & \text { Oil and gas extraction } \\ 20 & 212100 & \text { Coal mining } \\ 21 & 212210 & \text { Iron ore mining } \\ 22 & 212230 & \text { Copper, nickel, lead, and zinc mining }\end{array}$

$\begin{aligned} \text { ImSET } & \text { ImSET Name } \\ 1 & \text { Crop Farming } \\ 1 & \text { Crop Farming } \\ 1 & \text { Crop Farming } \\ 1 & \text { Crop Farming } \\ 1 & \text { Crop Farming } \\ 1 & \text { Crop Farming } \\ 1 & \text { Crop Farming } \\ 1 & \text { Crop Farming } \\ 1 & \text { Crop Farming } \\ 1 & \text { Crop Farming } \\ 2 & \text { Animal Farming } \\ 2 & \text { Animal Farming } \\ 2 & \text { Animal Farming } \\ 3 & \text { Forest Products } \\ 3 & \text { Forest Products } \\ 4 & \text { Fish/Hunt/Ag Support } \\ 4 & \text { Fish/Hunt/Ag Support } \\ 4 & \text { Fish/Hunt/Ag Support } \\ 5 & \text { Oil and Gas Extraction } \\ 6 & \text { Coal Mining } \\ 7 & \text { Metal Mining } \\ 7 & \text { Metal Mining } \\ & \end{aligned}$




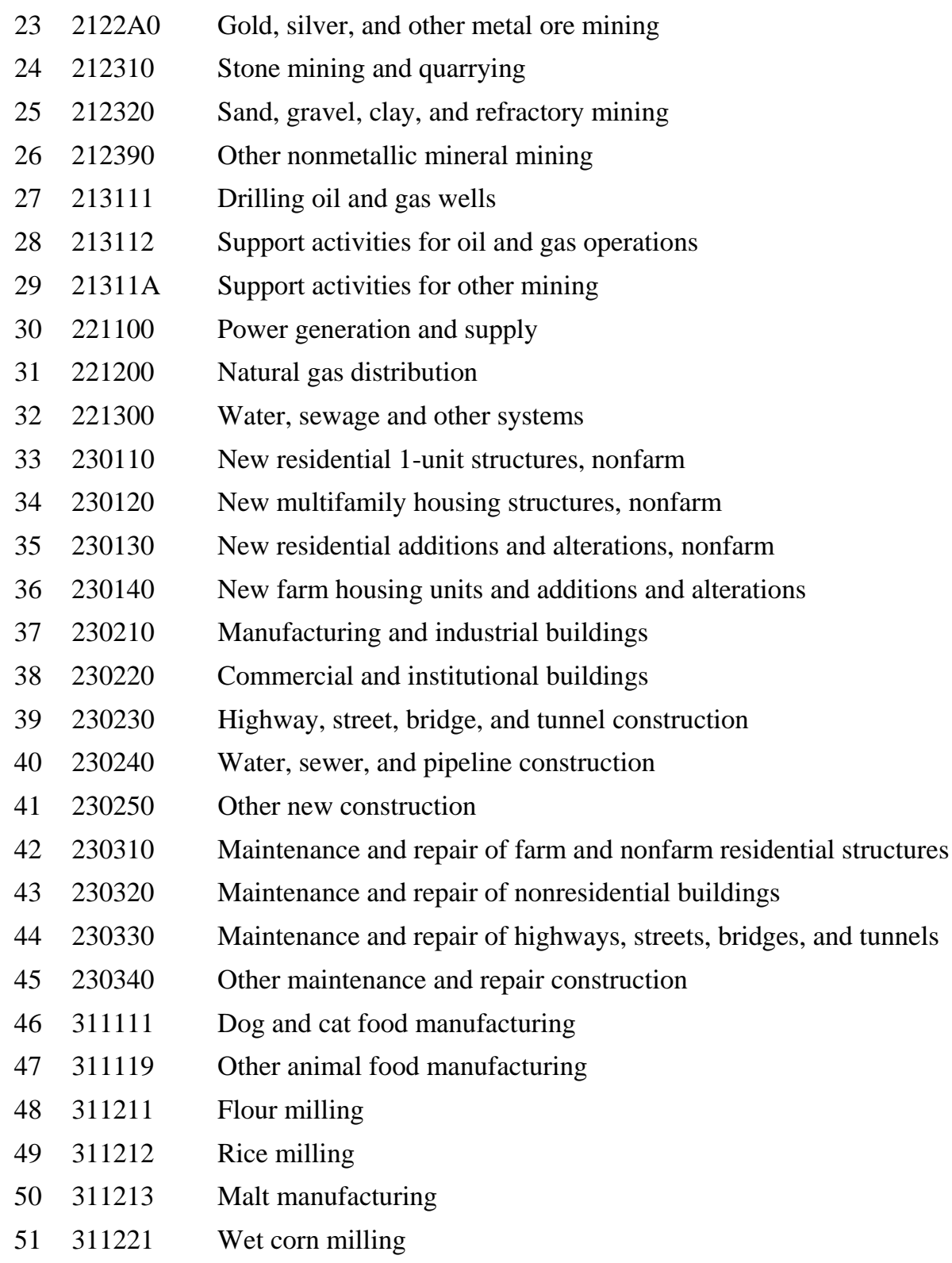

7 Metal Mining

8 Nonmetalic Mineral Mining

8 Nonmetalic Mineral Mining

8 Nonmetalic Mineral Mining

9 Oil and Gas Drilling

10 Oil and Gas Support

11 Other Mining Support

12 Electricity Gen. and Trans.

13 Natural Gas Distribution

14 Water/Sewer, Other Systems

15 New Single-Family Const.

16 New Multifamily Const.

17 New Residential Remodeling Const.

18 New Farm Housing

19 Industrial Building Construction

20 Commercial Building Construction

21 Road Construction

21 Pipeline Construction

22 Other New Construction

23 Res. Maintenance \& Repair

23 Non-Res. Maintenance \& Repair

23 Road Maintenance \& Repair

23 Other Maintenance \& Repair

24 Food Processing

24 Food Processing

24 Food Processing

24 Food Processing

24 Food Processing

24 Food Processing 


\begin{tabular}{lll}
52 & 311222 & Soybean processing \\
53 & 311223 & Other oilseed processing \\
54 & 311225 & Fats and oils refining and blending \\
55 & 311230 & Breakfast cereal manufacturing \\
56 & 311310 & Sugar manufacturing \\
57 & 311320 & Confectionery manufacturing from cacao beans \\
58 & 311330 & Confectionery manufacturing from purchased chocolate \\
59 & 311340 & Nonchocolate confectionery manufacturing \\
60 & 311410 & Frozen food manufacturing \\
61 & 311420 & Fruit and vegetable canning and drying \\
62 & 311511 & Fluid milk manufacturing \\
63 & 311512 & Creamery butter manufacturing \\
64 & 311513 & Cheese manufacturing \\
65 & 311514 & Dry, condensed, and evaporated dairy products \\
66 & 311520 & Ice cream and frozen dessert manufacturing \\
67 & 311611 & Animal, except poultry, slaughtering \\
68 & 311612 & Meat processed from carcasses \\
69 & 311613 & Rendering and meat byproduct processing \\
70 & 311615 & Poultry processing \\
71 & 311700 & Seafood product preparation and packaging \\
72 & 311813 & Frozen cakes and other pastries manufacturing \\
73 & 31181 A & Bread and bakery product, except frozen, manufacturing \\
74 & 311821 & Cookie and cracker manufacturing \\
75 & 311822 & Mixes and dough made from purchased flour \\
76 & 311823 & Dry pasta manufacturing \\
77 & 311830 & Tortilla manufacturing \\
78 & 311911 & Roasted nuts and peanut butter manufacturing \\
79 & 311919 & Other snack food manufacturing \\
80 & 311920 & Coffee and tea manufacturing \\
\hline
\end{tabular}

24 Food Processing

24 Food Processing

24 Food Processing

24 Food Processing

24 Food Processing

24 Food Processing

24 Food Processing

24 Food Processing

24 Food Processing

24 Food Processing

24 Food Processing

24 Food Processing

24 Food Processing

24 Food Processing

24 Food Processing

24 Food Processing

24 Food Processing

24 Food Processing

24 Food Processing

24 Food Processing

24 Food Processing

24 Food Processing

24 Food Processing

24 Food Processing

24 Food Processing

24 Food Processing

24 Food Processing

24 Food Processing

24 Food Processing 


$\begin{array}{rll}81 & 311930 & \text { Flavoring syrup and concentrate manufacturing } \\ 82 & 311941 & \text { Mayonnaise, dressing, and sauce manufacturing } \\ 83 & 311942 & \text { Spice and extract manufacturing } \\ 84 & 311990 & \text { All other food manufacturing } \\ 85 & 312110 & \text { Soft drink and ice manufacturing } \\ 86 & 312120 & \text { Breweries } \\ 87 & 312130 & \text { Wineries } \\ 88 & 312140 & \text { Distilleries } \\ 89 & 312210 & \text { Tobacco stemming and redrying } \\ 90 & 312221 & \text { Cigarette manufacturing } \\ 91 & 312229 & \text { Other tobacco product manufacturing } \\ 92 & 313100 & \text { Fiber, yarn, and thread mills } \\ 93 & 313210 & \text { Broadwoven fabric mills } \\ 94 & 313220 & \text { Narrow fabric mills and schiffli embroidery } \\ 95 & 313230 & \text { Nonwoven fabric mills } \\ 96 & 313240 & \text { Knit fabric mills } \\ 97 & 313310 & \text { Textile and fabric finishing mills } \\ 98 & 313320 & \text { Fabric coating mills } \\ 99 & 314110 & \text { Carpet and rug mills } \\ 100 & 314120 & \text { Curtain and linen mills } \\ 101 & 314910 & \text { Textile bag and canvas mills } \\ 102 & 314992 & \text { Tire cord and tire fabric mills } \\ 103 & 31499 \text { A } & \text { Other miscellaneous textile product mills } \\ 104 & 315111 & \text { Sheer hosiery mills } \\ 105 & 315119 & \text { Other hosiery and sock mills } \\ 106 & 315190 & \text { Other apparel knitting mills } \\ 107 & 315200 & \text { Cut and sew apparel manufacturing } \\ 108 & 315900 & \text { Accessories and other apparel manufacturing } \\ 109 & 316100 & \text { Leather and hide tanning and finishing } \\ & & \end{array}$

24 Food Processing

24 Food Processing

24 Food Processing

24 Food Processing

24 Food Processing

25 Alcoholic Beverage Processing

25 Alcoholic Beverage Processing

25 Alcoholic Beverage Processing

26 Tobacco Processing

26 Tobacco Processing

26 Tobacco Processing

27 Textile Mills

27 Textile Mills

27 Textile Mills

27 Textile Mills

27 Textile Mills

27 Textile Mills

27 Textile Mills

28 Textile Product Mills

28 Textile Product Mills

28 Textile Product Mills

28 Textile Product Mills

28 Textile Product Mills

29 Apparel Manufacturing

29 Apparel Manufacturing

29 Apparel Manufacturing

29 Apparel Manufacturing

29 Apparel Manufacturing

30 Leather Products Mfg. 


$\begin{array}{lll}110 & 316200 & \text { Footwear manufacturing } \\ 111 & 316900 & \text { Other leather product manufacturing } \\ 112 & 321113 & \text { Sawmills } \\ 113 & 321114 & \text { Wood preservation } \\ 114 & 321219 & \text { Reconstituted wood product manufacturing } \\ 115 & 32121 \text { A } & \text { Veneer and plywood manufacturing } \\ 116 & 32121 \text { B } & \text { Engineered wood member and truss manufacturing } \\ 117 & 321911 & \text { Wood windows and door manufacturing } \\ 118 & 321912 & \text { Cut stock, resawing lumber, and planing } \\ 119 & 321918 & \text { Other millwork, including flooring } \\ 120 & 321920 & \text { Wood container and pallet manufacturing } \\ 123 & 321999 & \text { Miscellaneous wood product manufacturing } \\ 121 & 321991 & \text { Manufactured home, mobile home, manufacturing } \\ 122 & 321992 & \text { Prefabricated wood building manufacturing } \\ 124 & 322110 & \text { Pulp mills } \\ 125 & 3221 \text { A0 } & \text { Paper and paperboard mills } \\ 126 & 322210 & \text { Paperboard container manufacturing } \\ 127 & 322225 & \text { Flexible packaging foil manufacturing } \\ 128 & 322226 & \text { Surface-coated paperboard manufactuing } \\ 129 & 32222 \mathrm{~A} & \text { Coated and laminated paper and packaging materials } \\ 130 & 32222 \mathrm{~B} & \text { Coated and uncoated paper bag manufacturing } \\ 131 & 322231 & \text { Die-cut paper office supplies manufacturing } \\ 132 & 322232 & \text { Envelope manufacturing } \\ 133 & 322233 & \text { Stationery and related product manufacturing } \\ 134 & 322291 & \text { Sanitary paper product manufacturing } \\ 135 & 322299 & \text { All other converted paper product manufacturing } \\ 136 & 323116 & \text { Manifold business forms printing } \\ 137 & 323117 & \text { Books printing } \\ 138 & 323118 & \text { Blankbook and looseleaf binder manufacturing } \\ & & \end{array}$

30 Leather Products Mfg.

30 Leather Products Mfg.

31 Lumber Mills

31 Lumber Mills

31 Lumber Mills

31 Lumber Mills

31 Lumber Mills

32 Specialized Wood Product Mfg.

32 Specialized Wood Product Mfg.

32 Specialized Wood Product Mfg.

33 Misc. Wood Product Mfg.

33 Misc. Wood Product Mfg.

34 Manufactured Buildings

34 Manufactured Buildings

35 Pulp Mills

36 Paper And Paperboard Mills

37 Paperboard Container Mfg.

38 Converted Paper Product Mfg.

38 Converted Paper Product Mfg.

38 Converted Paper Product Mfg.

38 Converted Paper Product Mfg.

38 Converted Paper Product Mfg.

38 Converted Paper Product Mfg.

38 Converted Paper Product Mfg.

38 Converted Paper Product Mfg.

38 Converted Paper Product Mfg.

39 Commercial Printing

39 Commercial Printing

39 Commercial Printing 


\begin{tabular}{lll}
139 & 32311 A & Commercial printing \\
140 & 323121 & Tradebinding and related work \\
141 & 323122 & Prepress services \\
142 & 324110 & Petroleum refineries \\
143 & 324121 & Asphalt paving mixture and block manufacturing \\
144 & 324122 & Asphalt shingle and coating materials manufacturing \\
145 & 324191 & Petroleum lubricating oil and grease manufacturing \\
146 & 324199 & All other petroleum and coal products manufacturing \\
147 & 325110 & Petrochemical manufacturing \\
148 & 325120 & Industrial gas manufacturing \\
149 & 325130 & Synthetic dye and pigment manufacturing \\
150 & 325180 & Other basic inorganic chemical manufacturing \\
151 & 325190 & Other basic organic chemical manufacturing \\
152 & 325211 & Plastics material and resin manufacturing \\
153 & 325212 & Synthetic rubber manufacturing \\
154 & 325221 & Cellulosic organic fiber manufacturing \\
155 & 325222 & Noncellulosic organic fiber manufacturing \\
156 & 325311 & Nitrogenous fertilizer manufacturing \\
157 & 325312 & Phosphatic fertilizer manufacturing \\
158 & 325314 & Fertilizer, mixing only, manufacturing \\
159 & 325320 & Pesticide and other agricultural chemical manufacturing \\
160 & 325400 & Pharmaceutical and medicine manufacturing \\
161 & 325510 & Paint and coating manufacturing \\
162 & 325520 & Adhesive manufacturing \\
163 & 325611 & Soap and other detergent manufacturing \\
164 & 325612 & Polish and other sanitation good manufacturing \\
165 & 325613 & Surface active agent manufacturing \\
166 & 325620 & Toilet preparation manufacturing \\
167 & 325910 & Printing ink manufacturing \\
& & \\
\hline
\end{tabular}

39 Commercial Printing

39 Commercial Printing

39 Commercial Printing

40 Petroleum Refineries

41 Oth. Petroleum/Coal Prod. Mfg.

41 Oth. Petroleum/Coal Prod. Mfg.

41 Oth. Petroleum/Coal Prod. Mfg.

41 Oth. Petroleum/Coal Prod. Mfg.

42 Inorganic Chemical Mfg.

42 Inorganic Chemical Mfg.

42 Inorganic Chemical Mfg.

42 Inorganic Chemical Mfg.

43 Organic Chemical Mfg.

44 Plastics Material \& Resin Mfg.

45 Synthetic Rubber Mfg.

46 Organic Fiber Mfg.

46 Organic Fiber Mfg.

47 Fertilizer \& Pesticide Mfg.

47 Fertilizer \& Pesticide Mfg.

47 Fertilizer \& Pesticide Mfg.

47 Fertilizer \& Pesticide Mfg.

48 Pharmaceutical \& Medicine Mfg.

49 Misc. Chemical Prod. Mfg.

49 Misc. Chemical Prod. Mfg.

49 Misc. Chemical Prod. Mfg.

49 Misc. Chemical Prod. Mfg.

49 Misc. Chemical Prod. Mfg.

49 Misc. Chemical Prod. Mfg.

49 Misc. Chemical Prod. Mfg. 


$\begin{array}{lll}168 & 325920 & \text { Explosives manufacturing } \\ 169 & 325991 & \text { Custom compounding of purchased resins } \\ 170 & 325992 & \text { Photographic film and chemical manufacturing } \\ 171 & 325998 & \text { Other miscellaneous chemical product manufacturing } \\ 172 & 326110 & \text { Plastics packaging materials, film and sheet } \\ 173 & 326120 & \text { Plastics pipe, fittings, and profile shapes } \\ 174 & 326130 & \text { Laminated plastics plate, sheet, and shapes } \\ 175 & 326160 & \text { Plastics bottle manufacturing } \\ 176 & 326192 & \text { Resilient floor covering manufacturing } \\ 177 & 32619 \text { A } & \text { Plastics plumbing fixtures and all other plastics products } \\ 178 & 3261 \text { A0 } & \text { Foam product manufacturing } \\ 179 & 326210 & \text { Tire manufacturing } \\ 180 & 326220 & \text { Rubber and plastics hose and belting manufacturing } \\ 181 & 326290 & \text { Other rubber product manufacturing } \\ 182 & 327111 & \text { Vitreous china plumbing fixture manufacturing } \\ 183 & 327112 & \text { Vitreous china and earthenware articles manufacturing } \\ 184 & 327113 & \text { Porcelain electrical supply manufacturing } \\ 185 & 327121 & \text { Brick and structural clay tile manufacturing } \\ 186 & 327122 & \text { Ceramic wall and floor tile manufacturing } \\ 187 & 327125 & \text { Nonclay refractory manufacturing } \\ 188 & 32712 \text { A } & \text { Clay refractory and other structural clay products } \\ 189 & 327213 & \text { Glass container manufacturing } \\ 190 & 32721 \text { A } & \text { Glass and glass products, except glass containers } \\ 191 & 327310 & \text { Cement manufacturing } \\ 192 & 327320 & \text { Ready-mix concrete manufacturing } \\ 193 & 327331 & \text { Concrete block and brick manufacturing } \\ 194 & 327332 & \text { Concrete pipe manufacturing } \\ 195 & 327390 & \text { Other concrete product manufacturing } \\ 196 & 327410 & \text { Lime manufacturing } \\ & & \end{array}$

49 Misc. Chemical Prod. Mfg.

49 Misc. Chemical Prod. Mfg.

49 Misc. Chemical Prod. Mfg.

49 Misc. Chemical Prod. Mfg.

50 Plastics \& Related Prod. Mfg.

50 Plastics \& Related Prod. Mfg.

50 Plastics \& Related Prod. Mfg.

50 Plastics \& Related Prod. Mfg.

50 Plastics \& Related Prod. Mfg.

50 Plastics \& Related Prod. Mfg.

50 Plastics \& Related Prod. Mfg.

51 Rubber Porducts Mfg.

51 Rubber Porducts Mfg.

51 Rubber Porducts Mfg.

52 China \& Porcelain Prod. Mfg.

52 China \& Porcelain Prod. Mfg.

52 China \& Porcelain Prod. Mfg.

53 Clay Products Mfg.

53 Clay Products Mfg.

53 Clay Products Mfg.

53 Clay Products Mfg.

54 Glass Container Mfg.

55 Glass and Glass Products Mfg.

56 Cement Manufacturing

57 Concrete Products Mfg.

57 Concrete Products Mfg.

57 Concrete Products Mfg.

57 Concrete Products Mfg.

58 Lime Manufacturing 


$\begin{array}{lll}197 & 327420 & \text { Gypsum product manufacturing } \\ 198 & 327910 & \text { Abrasive product manufacturing } \\ 199 & 327991 & \text { Cut stone and stone product manufacturing } \\ 200 & 327992 & \text { Ground or treated minerals and earths manufacturing } \\ 202 & 327999 & \text { Miscellaneous nonmetallic mineral products } \\ 201 & 327993 & \text { Mineral wool manufacturing } \\ 203 & 331111 & \text { Iron and steel mills } \\ 204 & 331112 & \text { Ferroalloy and related product manufacturing } \\ 205 & 331210 & \text { Iron, steel pipe and tube from purchased steel } \\ 206 & 331221 & \text { Rolled steel shape manufacturing } \\ 207 & 331222 & \text { Steel wire drawing } \\ 208 & 331311 & \text { Alumina refining } \\ 209 & 331312 & \text { Primary aluminum production } \\ 210 & 331314 & \text { Secondary smelting and alloying of aluminum } \\ 211 & 331315 & \text { Aluminum sheet, plate, and foil manufacturing } \\ 212 & 331316 & \text { Aluminum extruded product manufacturing } \\ 213 & 331319 & \text { Other aluminum rolling and drawing } \\ 214 & 331411 & \text { Primary smelting and refining of copper } \\ 215 & 331419 & \text { Primary nonferrous metal, except copper and aluminum } \\ 216 & 331421 & \text { Copper rolling, drawing, and extruding } \\ 217 & 331422 & \text { Copper wire, except mechanical, drawing } \\ 218 & 331423 & \text { Secondary processing of copper } \\ 219 & 331491 & \text { Nonferrous metal, except copper and aluminum, shaping } \\ 220 & 331492 & \text { Secondary processing of other nonferrous } \\ 221 & 331510 & \text { Ferrous metal foundaries } \\ 222 & 33152 \text { A } & \text { Aluminum foundries } \\ 223 & 33152 B & \text { Nonferrous foundries, except aluminum } \\ 224 & 332111 & \text { Iron and steel forging } \\ 225 & 332112 & \text { Nonferrous forging } \\ & & \end{array}$

59 Gypsum Product Manufacturing

60 Oth. Nonmetalic Mineral Prod.

60 Oth. Nonmetalic Mineral Prod.

60 Oth. Nonmetalic Mineral Prod.

60 Oth. Nonmetalic Mineral Prod.

61 Mineral Wool Manufacturing

62 Iron And Steel Mills

63 Ferroalloy Product Mfg.

64 Steel Shape Mfg.

64 Steel Shape Mfg.

64 Steel Shape Mfg.

65 Aluminium Mills

65 Aluminium Mills

65 Aluminium Mills

66 Aluminum Product Mfg.

66 Aluminum Product Mfg.

66 Aluminum Product Mfg.

67 Nonferrous Metals Mfg.

67 Nonferrous Metals Mfg.

67 Nonferrous Metals Mfg.

67 Nonferrous Metals Mfg.

67 Nonferrous Metals Mfg.

67 Nonferrous Metals Mfg.

67 Nonferrous Metals Mfg.

68 Ferrous Metal Foundaries

69 Aluminum Foundries

70 Other Nonferrous Foundaries

71 Iron And Steel Forging

72 Other Forging and Stamping 


\section{Custom roll forming}

All other forging and stamping

Cutlery and flatware, except precious, manufacturing

Hand and edge tool manufacturing

Saw blade and handsaw manufacturing

Kitchen utensil, pot, and pan manufacturing

Prefabricated metal buildings and components

Fabricated structural metal manufacturing

Plate work manufacturing

Metal window and door manufacturing

Sheet metal work manufacturing

Ornamental and architectural metal work manufacturing

Power boiler and heat exchanger manufacturing

Metal tank, heavy gauge, manufacturing

Metal can, box, and other container manufacturing

Hardware manufacturing

Spring and wire product manufacturing

Machine shops

Turned product and screw, nut, and bolt manufacturing

Metal heat treating

Metal coating and nonprecious engraving

Electroplating, anodizing, and coloring metal

Metal valve manufacturing

Ball and roller bearing manufacturing

Fabricated pipe and pipe fitting manufacturing

Industrial pattern manufacturing

Enameled iron and metal sanitary ware manufacturing

Miscellaneous fabricated metal product manufacturing

Small arms manufacturing
80 Other Fabricated Metal Mfg.

80 Other Fabricated Metal Mfg.

80 Other Fabricated Metal Mfg.

80 Other Fabricated Metal Mfg.

81 Ordinance and Ammunition Mfg. 
Other ordnance and accessories manufacturing

Ammunition manufacturing

Farm machinery and equipment manufacturing

Construction machinery manufacturing

Mining machinery and equipment manufacturing

Oil and gas field machinery and equipment

Lawn and garden equipment manufacturing

Sawmill and woodworking machinery

Plastics and rubber industry machinery

Paper industry machinery manufacturing

Textile machinery manufacturing

Printing machinery and equipment manufacturing

Food product machinery manufacturing

Semiconductor machinery manufacturing

All other industrial machinery manufacturing

Office machinery manufacturing

Optical instrument and lens manufacturing

Photographic and photocopying equipment manufacturing

Other commercial and service industry machinery manufacturing

Automatic vending, commercial laundry and drycleaning machinery

Air purification equipment manufacturing

Industrial and commercial fan and blower manufacturing

Heating equipment, except warm air furnaces

AC, refrigeration, and forced air heating

Industrial mold manufacturing

Metal cutting machine tool manufacturing

Metal forming machine tool manufacturing

Special tool, die, jig, and fixture manufacturing

Cutting tool and machine tool accessory manufacturing
81 Ordinance and Ammunition Mfg.

81 Ordinance and Ammunition Mfg.

82 Heavy Machinery Mfg.

82 Heavy Machinery Mfg.

82 Heavy Machinery Mfg.

82 Heavy Machinery Mfg.

83 Lawn \& Garden Eq. Mfg.

84 Wood Processing Machinery Mfg.

85 Plastics \& Rubber Machinery Mfg.

86 Paper Industry Machinery Mfg.

87 Textile Machinery Mfg.

88 Printing Industry Machinery Mfg.

89 Food Product Machinery Mfg.

89 Misc. Industrial Machinery Mfg.

89 Misc. Industrial Machinery Mfg.

90 Commercial Service Macinery Mfg.

90 Commercial Service Macinery Mfg.

90 Commercial Service Macinery Mfg.

90 Commercial Service Macinery Mfg.

90 Commercial Service Macinery Mfg.

91 Air Purification Eq. Mfg.

92 Com/Ind Fan \& Blower Mfg.

93 Nonfurnace Heating Eq. Mfg.

94 AC, Ref. \& Forced Air Heating

95 Industrial Mold Manufacturing

95 Machine Tool Manufacturing

95 Machine Tool Manufacturing

95 Machine Tool Manufacturing

95 Machine Tool Manufacturing 
284 33351A

285333611

286333618
Rolling mill and other metalworking machinery

Turbine and turbine generator set units manufacturing

Other engine equipment manufacturing

Speed changers and mechanical power transmission equipment

Pump and pumping equipment manufacturing

Air and gas compressor manufacturing

Measuring and dispensing pump manufacturing

Elevator and moving stairway manufacturing

Conveyor and conveying equipment manufacturing

Overhead cranes, hoists, and monorail systems

Industrial truck, trailer, and stacker manufacturing

Power-driven handtool manufacturing

Welding and soldering equipment manufacturing

Packaging machinery manufacturing

Industrial process furnace and oven manufacturing

Fluid power cylinder and actuator manufacturing

Fluid power pump and motor manufacturing

Scales, balances, and miscellaneous general purpose machinery

Electronic computer manufacturing

Computer storage device manufacturing

Computer terminal manufacturing

Other computer peripheral equipment manufacturing

Telephone apparatus manufacturing

Broadcast and wireless communications equipment

Other communications equipment manufacturing

Audio and video equipment manufacturing

Electron tube manufacturing

Semiconductors and related device manufacturing
Metalworking Machinery Mfg.

Turbines and Related Mfg.

Other Engine Eq. Manufacturing Power Transmission Equipment Mfg.

Pumps and Related Eq. Mfg.

Air And Gas Compressor Mfg. Measuring And Dispensing Pump

Mfg.

Other Electric Machinery Mfg.

Other Electric Machinery Mfg.

Other Electric Machinery Mfg.

Other Electric Machinery Mfg.

Other Electric Machinery Mfg.

Other Electric Machinery Mfg.

Other Electric Machinery Mfg.

Ind. Process Furnace \& Oven Mfg.

Misc. Machinery Mfg.

Misc. Machinery Mfg.

Misc. Machinery Mfg.

Computer Products Mfg.

Computer Products Mfg.

Computer Products Mfg.

Computer Products Mfg.

Communications Eq. Mfg.

Communications Eq. Mfg.

Communications Eq. Mfg.

Electronic Components Mfg.

Electronic Components Mfg.

Electronic Components Mfg. 
312 33441A

$313 \quad 334510$

314334511

315334512

316334513

$317 \quad 334514$

318334515

319334516

$320 \quad 334517$

$321 \quad 33451 \mathrm{~A}$

322334611

$323 \quad 334612$

$324 \quad 334613$

325335110

$326 \quad 335120$

$327 \quad 335211$

$328 \quad 335212$

$329 \quad 335221$

$330 \quad 335222$

331335224

$332 \quad 335228$

33333531

334335312

335335313

$336 \quad 335314$

$337 \quad 335911$

$338 \quad 335912$

339335921

$340 \quad 335929$
All other electronic component manufacturing

Electromedical apparatus manufacturing

Search, detection, and navigation instruments

Automatic environmental control manufacturing

Industrial process variable instruments

Totalizing fluid meters and counting devices

Electricity and signal testing instruments

Analytical laboratory instrument manufacturing

Irradiation apparatus manufacturing

Watch, clock, and other measuring and controlling device mfg

Software reproducing

Audio and video media reproduction

Magnetic and optical recording media manufacturing

Electric lamp bulb and part manufacturing

Lighting fixture manufacturing

Electric housewares and household fan manufacturing

Household vacuum cleaner manufacturing

Household cooking appliance manufacturing

Household refrigerator and home freezer manufacturing

Household laundry equipment manufacturing

Other major household appliance manufacturing

Electric power and specialty transformer manufacturing

Motor and generator manufacturing

Switchgear and switchboard apparatus manufacturing

Relay and industrial control manufacturing

Storage battery manufacturing

Primary battery manufacturing

Fiber optic cable manufacturing

Other communication and energy wire manufacturing
108 Electronic Components Mfg.

109 Instruments Manufacturing

109 Instruments Manufacturing

110 Automatic Environmental Controls

111 Ind. Process Variable Instruments

112 Fluid Meters \& Counting Devices

113 Electricity \& Signal Testing Inst.

114 Other Lab \& Related Instruments

114 Other Lab \& Related Instruments

114 Other Lab \& Related Instruments

115 Electronic Media Processing

115 Electronic Media Processing

115 Electronic Media Processing

116 Electric Lamp Bulb And Part Mfg.

117 Lighting Fixture Manufacturing

118 Household Eq. Mfg.

118 Household Eq. Mfg.

119 Household Cooking Appliance Mfg.

120 HH Refrigerator \& Freezer Mfg.

121 Household Laundry Equipment Mfg.

122 Other Major HH Appliance Mfg.

123 Electric Power, Etc. Transformers

124 Motor And Generator Mfg.

125 Industrial Controls

125 Industrial Controls

126 Battery Manufacturing

126 Battery Manufacturing

127 Misc. Electric Eq. Mfg.

127 Misc. Electric Eq. Mfg. 


$\begin{array}{lll}341 & 335930 & \text { Wiring device manufacturing } \\ 342 & 335991 & \text { Carbon and graphite product manufacturing } \\ 343 & 335999 & \text { Miscellaneous electrical equipment manufacturing } \\ 344 & 336110 & \text { Automobile and light truck manufacturing } \\ 346 & 336211 & \text { Motor vehicle body manufacturing } \\ 345 & 336120 & \text { Heavy duty truck manufacturing } \\ 347 & 336212 & \text { Truck trailer manufacturing } \\ 348 & 336213 & \text { Motor home manufacturing } \\ 349 & 336214 & \text { Travel trailer and camper manufacturing } \\ 350 & 336300 & \text { Motor vehicle parts manufacturing } \\ 351 & 336411 & \text { Aircraft manufacturing } \\ 352 & 336412 & \text { Aircraft engine and engine parts manufacturing } \\ 353 & 336413 & \text { Other aircraft parts and equipment } \\ 354 & 336414 & \text { Guided missile and space vehicle manufacturing } \\ 355 & 33641 \text { A } & \text { Propulsion units and parts for space vehicles and guided missiles } \\ 356 & 336500 & \text { Railroad rolling stock manufacturing } \\ 357 & 336611 & \text { Ship building and repairing } \\ 358 & 336612 & \text { Boat building } \\ 359 & 336991 & \text { Motorcycle, bicycle, and parts manufacturing } \\ 360 & 336992 & \text { Military armored vehicles and tank parts manufacturing } \\ 361 & 336999 & \text { All other transportation equipment manufacturing } \\ 362 & 337110 & \text { Wood kitchen cabinet and countertop manufacturing } \\ 363 & 337121 & \text { Upholstered household furniture manufacturing } \\ 364 & 337122 & \text { Nonupholstered wood household furniture manufacturing } \\ 366 & 337127 & \text { Institutional furniture manufacturing } \\ 367 & 33712 \text { A } & \text { Other household and institutional furniture } \\ 365 & 337124 & \text { Metal household furniture manufacturing } \\ 368 & 337211 & \text { Wood office furniture manufacturing } \\ 370 & 337214 & \text { Office furniture, except wood, manufacturing } \\ & & \end{array}$

127 Misc. Electric Eq. Mfg.

127 Misc. Electric Eq. Mfg.

127 Misc. Electric Eq. Mfg.

128 Car and Light Truck Mfg.

128 Car and Light Truck Mfg.

129 Truck Manufacturing

129 Truck Manufacturing

130 RV Manufacturing

130 RV Manufacturing

131 Motor Vehicle Parts Manufacturing

132 Aerospace Product Manufacturing

132 Aerospace Product Manufacturing

132 Aerospace Product Manufacturing

132 Aerospace Product Manufacturing

132 Aerospace Product Manufacturing

133 Railroad Rolling Stock Mfg.

134 Ship Building And Repairing

135 Boat/Cycle \& Parts Mfg.

135 Boat/Cycle \& Parts Mfg.

136 Other Transportation Eq.

136 Other Transportation Eq.

137 HH \& Institutional Furniture

137 HH \& Institutional Furniture

137 HH \& Institutional Furniture

137 HH \& Institutional Furniture

137 HH \& Institutional Furniture

138 Office Furniture Mfg.

138 Office Furniture Mfg.

138 Office Furniture Mfg. 
Showcases, partitions, shelving, and lockers

Custom architectural woodwork and millwork

Mattress manufacturing

Blind and shade manufacturing

Laboratory apparatus and furniture manufacturing

Surgical and medical instrument manufacturing

Surgical appliance and supplies manufacturing

Dental equipment and supplies manufacturing

Ophthalmic goods manufacturing

Dental laboratories

Jewelry and silverware manufacturing

Sporting and athletic goods manufacturing

Doll, toy, and game manufacturing

Office supplies, except paper, manufacturing

Sign manufacturing

Gasket, packing, and sealing device manufacturing

Musical instrument manufacturing

Broom, brush, and mop manufacturing

Burial casket manufacturing

Buttons, pins, and all other miscellaneous manufacturing

Wholesale trade

Air transportation

Rail transportation

Water transportation

Truck transportation

Transit and ground passenger transportation

Pipeline transportation

Scenic and sightseeing transport \& support activities for transport

Postal service
138 Office Furniture Mfg.

139 Custom Woodwork And Millwork

140 Misc. Furniture Mfg.

140 Misc. Furniture Mfg.

141 Laboratory Instruments \& Eq.

141 Laboratory Instruments \& Eq.

141 Laboratory Instruments \& Eq.

141 Laboratory Instruments \& Eq.

141 Laboratory Instruments \& Eq.

141 Laboratory Instruments \& Eq.

141 Laboratory Instruments \& Eq.

142 Misc. Manufacturing

142 Misc. Manufacturing

142 Misc. Manufacturing

142 Misc. Manufacturing

142 Misc. Manufacturing

142 Misc. Manufacturing

142 Misc. Manufacturing

142 Misc. Manufacturing

142 Misc. Manufacturing

143 Wholesale Trade

144 Air Transportation

145 Rail Transportation

146 Water Transportation

147 Truck Transportation

148 Transit \& Related Services

149 Pipeline Transportation

150 Sightseeing Transportation

151 Postal and Courier Services 
Couriers and messengers

Warehousing and storage

Retail trade

Newpaper publishers

Periodical publishers

Book publishers

Database, directory, and other publishers

Software publishers

Motion picture and video industries

Sound recording industries

Radio and television broadcasting

Cable networks and program distribution

Telecommunications

Information services

Data processing services

Nondepository credit intermediation and related activities

Securities, commodity contracts, investments

Insurance carriers

Insurance agencies, brokerages, and related

Funds, trusts, and other financial vehicles

Monetary authorities and depository credit intermediation

Real estate

Automotive equipment rental and leasing

Video tape and disc rental

Machinery and equipment rental and leasing

General and consumer goods rental except video tapes and discs

Lessors of nonfinancial intangible assets

Legal services

Accounting and bookkeeping services
151 Postal and Courier Services

152 Warehousing And Storage

153 Retail Trade

154 Publishers

154 Publishers

154 Publishers

154 Publishers

154 Publishers

155 Telecom \& Entertainment

155 Telecom \& Entertainment

155 Telecom \& Entertainment

155 Telecom \& Entertainment

155 Telecom \& Entertainment

155 Telecom \& Entertainment

155 Telecom \& Entertainment

156 Credit Counseling

157 Investment Services

158 Insurance

158 Insurance

159 Fund Management

160 Monetary Authorities

161 Real Estate

162 Car Rental Agencies

163 Rental Services

163 Rental Services

163 Rental Services

163 Rental Services

164 Other Professional/Technical Svc.

164 Other Professional/Technical Svc. 
$428 \quad 541300$

$429 \quad 54140$

430541511

431541512

432 54151A

433541610

434 5416A0

$435 \quad 541700$

$436 \quad 541800$

$437 \quad 541920$

438541940

439 5419A0

440550000

441561100

442561200

443561300

444561400

$445 \quad 561500$

446561600

$447 \quad 561700$

$448 \quad 561900$

449562000

$450 \quad 611100$

451 611A00

452 611B00

453621600

454 621A00

455 621B00

$456 \quad 622000$
Architectural and engineering services

Specialized design services

Custom computer programming services

Computer systems design services

Other computer related services, including facilities management

Management consulting services

Environmental and other technical consulting services

Scientific research and development services

Advertising and related services

Photographic services

Veterinary services

All other miscellaneous professional and technical services

Management of companies and enterprises

Office administrative services

Facilities support services

Employment services

Business support services

Travel arrangement and reservation services

Investigation and security services

Services to buildings and dwellings

Other support services

Waste management and remediation services

Elementary and secondary schools

Colleges, universities, and junior colleges

Other educational services

Home health care services

Offices of physicians, dentists, and other health practioners

Other ambulatory health care services

Hospitals
165 Architectural \& Engineering Svc.

164 Other Professional/Technical Svc.

164 Other Professional/Technical Svc.

164 Other Professional/Technical Svc.

164 Other Professional/Technical Svc.

164 Other Professional/Technical Svc.

164 Other Professional/Technical Svc.

164 Other Professional/Technical Svc.

164 Other Professional/Technical Svc.

164 Other Professional/Technical Svc.

164 Other Professional/Technical Svc.

164 Other Professional/Technical Svc.

166 Other Business Services

166 Other Business Services

166 Other Business Services

166 Other Business Services

166 Other Business Services

166 Other Business Services

166 Other Business Services

166 Other Business Services

166 Other Business Services

166 Other Business Services

167 Education

167 Education

167 Education

168 Healthcare Providers

168 Healthcare Providers

168 Healthcare Providers

169 Hospitals and Residential Care 


$\begin{array}{lll}457 & 623000 & \text { Nursing and residential care facilities } \\ 458 & 624400 & \text { Child day care services } \\ 459 & 624 \mathrm{~A} 00 & \text { Social assistance, except child day care services } \\ 460 & 711100 & \text { Performing arts companies } \\ 461 & 711200 & \text { Spectator sports } \\ 462 & 711500 & \text { Independent artists, writers, and performers } \\ 463 & 711 \text { A00 } & \text { Promoters of performing arts \& sports \& agents for public figures } \\ 464 & 712000 & \text { Museums, historical sites, zoos, and parks } \\ 465 & 713940 & \text { Fitness and recreational sports centers } \\ 466 & 713950 & \text { Bowling centers } \\ 467 & 713 \text { A00 } & \text { Other amusement, gambling, and recreation industries } \\ 468 & 7211 \text { A0 } & \text { Hotels and motels, including casino hotels } \\ 469 & 721 \text { A00 } & \text { Other accommodations } \\ 470 & 722000 & \text { Food services and drinking places } \\ 471 & 811192 & \text { Car washes } \\ 472 & 8111 \text { A0 } & \text { Automotive repair and maintenance, except car washes } \\ 473 & 811200 & \text { Electronic equipment repair and maintenance } \\ 474 & 811300 & \text { Commercial machinery repair and maintenance } \\ 475 & 811400 & \text { Household goods repair and maintenance } \\ 476 & 812100 & \text { Personal care services } \\ 477 & 812200 & \text { Death care services } \\ 478 & 812300 & \text { Drycleaning and laundry services } \\ 479 & 812900 & \text { Other personal services } \\ 480 & 813100 & \text { Religious organizations } \\ 481 & 813 \mathrm{~A} 00 & \text { Grantmaking and giving and social advocacy organizations } \\ 482 & 813 \mathrm{~B} 00 & \text { Civic, social, professional and similar organizations } \\ 483 & 814000 & \text { Private households } \\ 484 & \text { S00101 } & \text { Federal electric utilities } \\ 485 & \text { S00102 } & \text { Other Federal Government enterprises } \\ & & \end{array}$

169 Hospitals and Residential Care

170 Day Care and Social Assistance

170 Day Care and Social Assistance

171 Amusement \& Recreation

171 Amusement \& Recreation

171 Amusement \& Recreation

171 Amusement \& Recreation

171 Amusement \& Recreation

171 Amusement \& Recreation

171 Amusement \& Recreation

171 Amusement \& Recreation

172 Lodging

172 Lodging

173 Food \& Beverage Services

174 Personal Services

174 Personal Services

174 Personal Services

174 Personal Services

174 Personal Services

174 Personal Services

174 Personal Services

174 Personal Services

174 Personal Services

175 Other Services

175 Other Services

175 Other Services

176 Households

177 Federal Electric Utilities

178 Other Fed. Gov. Enterprises 
486 S00201 State and local government passenger transit

487 S00202 State and local government electric utilities

488 S00203 Other State and local government enterprises

489 S00300 Noncomparable imports

$490 \quad$ S00401 Scrap

491 S00402 Used and secondhand goods

$492 \quad 500500$

$493 \quad 500600$

$494 \quad 500700$

$495 \quad 500800$

V00100

V0010

V00200

V00300

F01000

F02000

F04000

F05000

F06C00

F06I00

F07C00

F07I00

F08C00

F08I00

F09C00

F09I00
General government industry

Rest of the world adjustment to final uses

Inventory valuation adjustment

Owner-occupied dwellings

Compensation of employees

Indirect business tax and nontax liability

Other value added

Personal consumption expenditures

Private fixed investment + Change in private inventories

Exports of goods and services

Imports of goods and services

National defense: Consumption expenditures

National defense: Gross investment

Nondefense: Consumption expenditures

Nondefense: Gross investment

State and local government consumption expenditures, education

State and local government gross investment, education

State and local consumption expenditures, other

State and local government gross investment, other
S/L Government Passenger Transit S/L Government Electric Utilities Other S/L Government Enterprises Noncomparable Imports

Scrap

Used And Secondhand Goods

General Government Industry

RTW Adjustment

Inventory Valuation Adjustment

Owner-Occupied Dwellings 


\section{Appendix C. FORTRAN Calculator}

This appendix describes the input file generated by the Visual Basic program ImSET 2.0, three FORTRAN routines used to do the calculations, and the output file that returns the calculations to ImSET 2.0.

\section{C.1 The Input File}

The FORTRAN calculator is designed to process a data stream generated by the program ImSET 2.0. Such a file, labeled "qminput.txt," is shown below in the box.

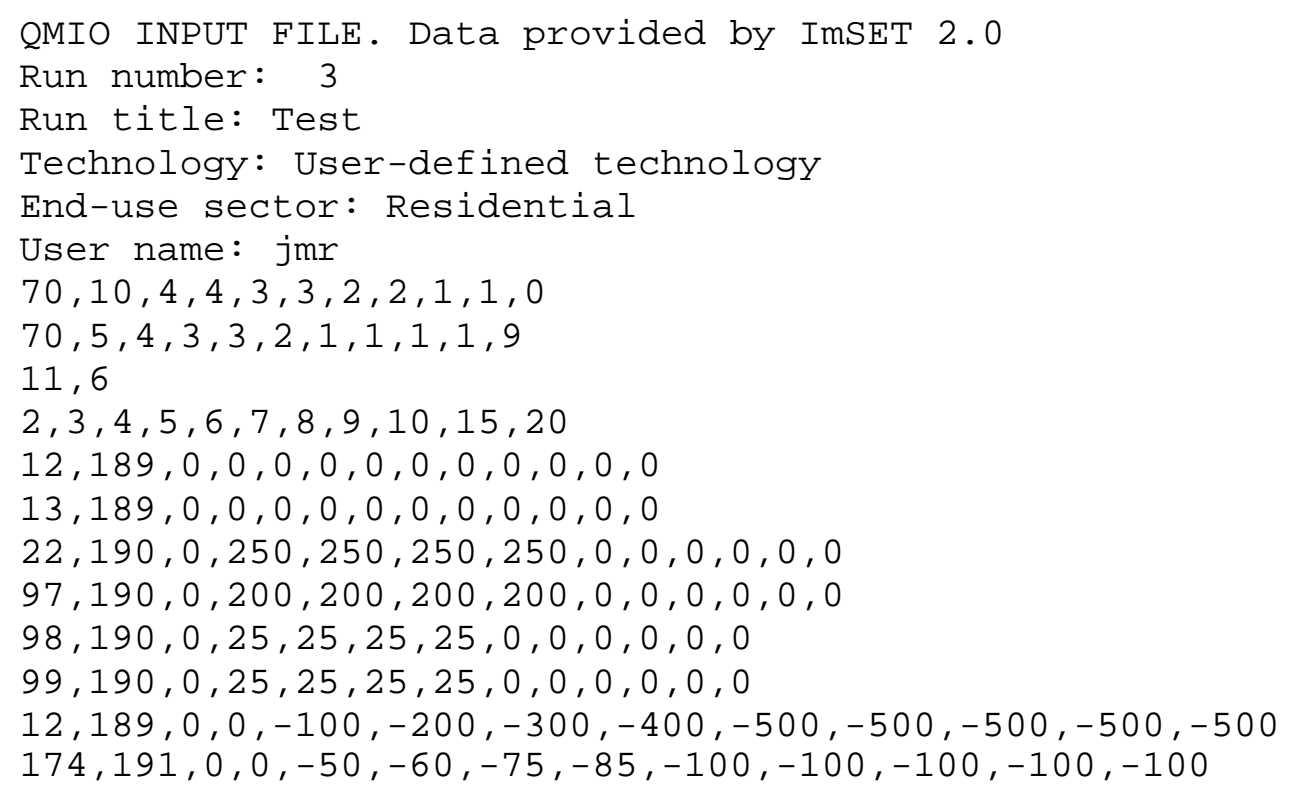

The file contains six lines of text ending with the user name. The text is followed by two sets of seven weights (the two lines beginning with 70,10 , etc.), a line that tells the calculator how many years of data are included (10) and the number of changes to read (6), and the year numbers (2,3, etc.). These year numbers are added to 2000 so the results are reported as 2002, 2003, etc. Following the year numbers, there are two lines that report the capacity adjustments as a result of energy savings, one for electricity (12) and one for gas utilities (13). In this case, there are no changes to capacity, so all ten of the numbers are zero. Following these capacity changes are six sets of changes to the data, one for each of the sectors 22, 97, 98, 99, 12, and 174. Cross referencing these sectors (see Appendix B) reveals that the capital changes are for other construction (22), turbines and related manufacturing (97), other engine equipment manufacturing (98), and power transmission equipment manufacturing (99). These capital equipment changes give rise to electricity (sector 12) savings by the residential sector and a series of O\&M savings (that for residential buildings go to sector 174, personal services) beginning in 2005 and peaking in 2009 at $\$ 500 \mathrm{M}$ and $\$ 100 \mathrm{M}$ respectively.

The second index number, for capital expenditures 190, indicates that these changes are to be made to the final demand vector, specifically to investment. If commercial equipment was considered rather than residential equipment, there would be changes to other industry sectors which would be represented by 
the second index number and would be one of the 188 industries identified in Appendix B. For fuel savings, the second index number is 189, indicating that the savings, for the residential sector, occur in the consumption vector. The operations and maintenance expenditures have a second index that is 191 . While these are treated much like capital expenses, these are separately identified so that the final demand vector can be adjusted without concerns about financing.

\section{C.2 The FORTRAN Programs}

There is a FORTRAN main program, IMSET, which calls a FORTRAN subroutine, QM3, which then calls subroutine DEMAND. The main program reads in the data file described above and transfers the data to the calculating subroutine QM3, which returns the results to the main program and writes the data file that is then read by the Visual Basic (VB) program. The subroutine QM3 first reads the core data from a binary file that holds the 1997 Benchmark I-O data, then calculates the base period employment, earnings, and output. It then loops through each of the years to be processed, changing the Use matrix data or the final demand data, then recalculating the employment, earnings and output. When all years are processed, the routine transfers the results back to the main program. In the course of this processing, QM3 calls the DEMAND subroutine to make adjustments to final demands and assure that the final demand vector is appropriately rescaled. In addition, there are five other routines that multiply, add, and invert matrices, which are briefly described but not shown here.

\section{C.2.1 The Main Program, ImSET}

The main program, ImSET, is shown in the text boxes on the next two pages. While comments in the code explain most of the operations, this explanation will be cued to the input file, shown above. After a number of parameter and variable definitions, the program opens two files, the input file above, and the file to which the results will be printed, QM-CHG.DAT. The program then skips over the six lines of text that are not used by the calculator. The next read statements put the first set of eleven weights into the variable iwgt, and the second set of weights into the variable jwgt. Since these are read in as integer percentages, they are converted to floating point decimal numbers in the loop that begins, DO 14. Since the final demand vectors include both exports and imports, two additional weights (both zero) are added to be consistent with the structure of final demand. The next two read statements (in the continuation text box) assign the number of years processed to JYR and the number of changes to be made to N. The next two read statements read the capacity changes into the variable y. The read that completes the input file reads the two variables, inx and indx, that hold the set of industry or final demand indexes, along with all the I-O changes into $\mathrm{X}$.

At this point the program has input the data stream and turns over processing to QM3. When the results are returned from QM3, they are contained in six variables: SUMJ, SUMH, and SUMQ contain the base period jobs, earnings and total output. The vectors SJ, SH, and SQ contain the calculated model results, one for each year, of which there are JYR $(=10)$ years. The program next prints the base period values to the output file, then calculates and prints out the difference between subsequent years calculated values and the base period values to this same file.

The program is then completed, so control is transferred back to the VB program. 


\begin{tabular}{|c|c|}
\hline $\mathrm{C}$ & PROGRAM ImSET \\
\hline C & This program will read in data, make a few calculations, then \\
\hline C & transfer operation to QM3, which does the work: Changes the \\
\hline C & Use matrix, then calculate output then multiply the outputs by \\
\hline C & the employment intensities, after adjusting final demands by \\
\hline C & iwgt. JYR is the number of years. JWGT is used for capital \\
\hline C & distribution. The years for analysis are then read in as 2,3 , \\
\hline C & etc., then these are added to 2000 to construct the vector of \\
\hline C & years reported. There are twelve categories of final demand: $\mathrm{C}$, \\
\hline C & I, X, M, FI, for both Defense and Nondefense $(D, N)$, FC for both \\
\hline C & D\&N, SLI for Education and Other $(E \& 0)$ and SLC $(E \& 0)$, \\
\hline C & but just ten are read in - no $X$ or $M$ (weights for these are \\
\hline C & set to zero. The thirteenth column is total final demand. \\
\hline C & If iwgt $(11)=100$ changes are just made to the total vector. \\
\hline C & This version allows up to 350 changes and 50 years of data. \\
\hline $\mathrm{C}$ & INTEGER MP NY \\
\hline & PARAMETER $(M P=350, N Y=50)$ \\
\hline & INTEGER iyr(NY), JYR, inx $(2,2)$ \\
\hline & INTEGER $i, j, m, \operatorname{ind} x(M P, 2), 11,12, n$, iwgt(11), jwgt(11) \\
\hline & $\mathrm{REAL}^{\star} 8 \mathrm{X}(\mathrm{MP}, \mathrm{NY}), \mathrm{SUMH}, \mathrm{SUMJ}, \mathrm{SUMQ}, \mathrm{SH}(\mathrm{NY}), \mathrm{SJ}(\mathrm{NY}), \mathrm{SQ}(\mathrm{NY}), \operatorname{wgt}(13)$ \\
\hline & $R E A L * 8$ wgt2 $(13), Y(2, N Y)$ \\
\hline & CHARACTER ${ }^{1} 1 \mathrm{~A}(1)$ \\
\hline & OPEN (10, FILE= 'QM-CHG.DAT' ) \\
\hline & $\begin{array}{l}\operatorname{OPEN}(11, \text { FILE= ' QMINPUT . TXT' }) \\
i=0\end{array}$ \\
\hline C & \\
\hline C & This section reads in the input file, for one technology \\
\hline C & First skip the first 6 lines, then read in two sets of 7 weights \\
\hline C & one for final demand (wgt), one for capacity savings (wgt2) \\
\hline C & These integer values are divided by 100 as floating point \#s \\
\hline C & $D F A D(11 *)$ \\
\hline & $\operatorname{READ}\left(11,{ }^{*}\right) \mathrm{A}$ \\
\hline & $\operatorname{READ}\left(11,{ }^{*}\right) \mathrm{A}$ \\
\hline & $\operatorname{READ}\left(11,{ }^{*}\right) \mathrm{A}$ \\
\hline & $\operatorname{READ}\left(11,{ }^{*}\right) \mathrm{A}$ \\
\hline & $\operatorname{READ}\left(11,{ }^{*}\right) \mathrm{A}$ \\
\hline & $\operatorname{READ}\left(11,{ }^{*}\right) \mathrm{A}$ \\
\hline & $\operatorname{READ}\left(11,{ }^{*}\right)(\operatorname{iwgt}(I), I=1,11)$ \\
\hline & $\operatorname{READ}(11, *) \quad(\mathrm{JWGT}(\mathrm{I}), \mathrm{I}=1,11)$ \\
\hline C & WRITE $\left(*,{ }^{*}\right)$ iwgt \\
\hline C & WRITE $\left(*,{ }^{*}\right)$ jwgt \\
\hline C & \\
\hline C & NOTE! 11 weights are read in but 13 are passed to the calculator \\
\hline C & The difference is, we construct zero weights for $M, x$. \\
\hline$\tau^{2}$ & Do $14, j=1,11$ \\
\hline & $\mathrm{k}=\mathrm{j}$ \\
\hline & $\operatorname{If}(j . g t .2) \quad k=j+2$ \\
\hline & $\operatorname{wgt}(k)=i w g t(j)$ \\
\hline & $\operatorname{wgt2}(k)=j w g t(j)$ \\
\hline 14 & wgt2 $(k)=$ wgt2 $(k) / 100$ \\
\hline 14 & $\operatorname{Wg} \tau(K)=W g \tau(K) / 100$ \\
\hline C & Now read the $\#$ of years and number of changes to read in \\
\hline
\end{tabular}




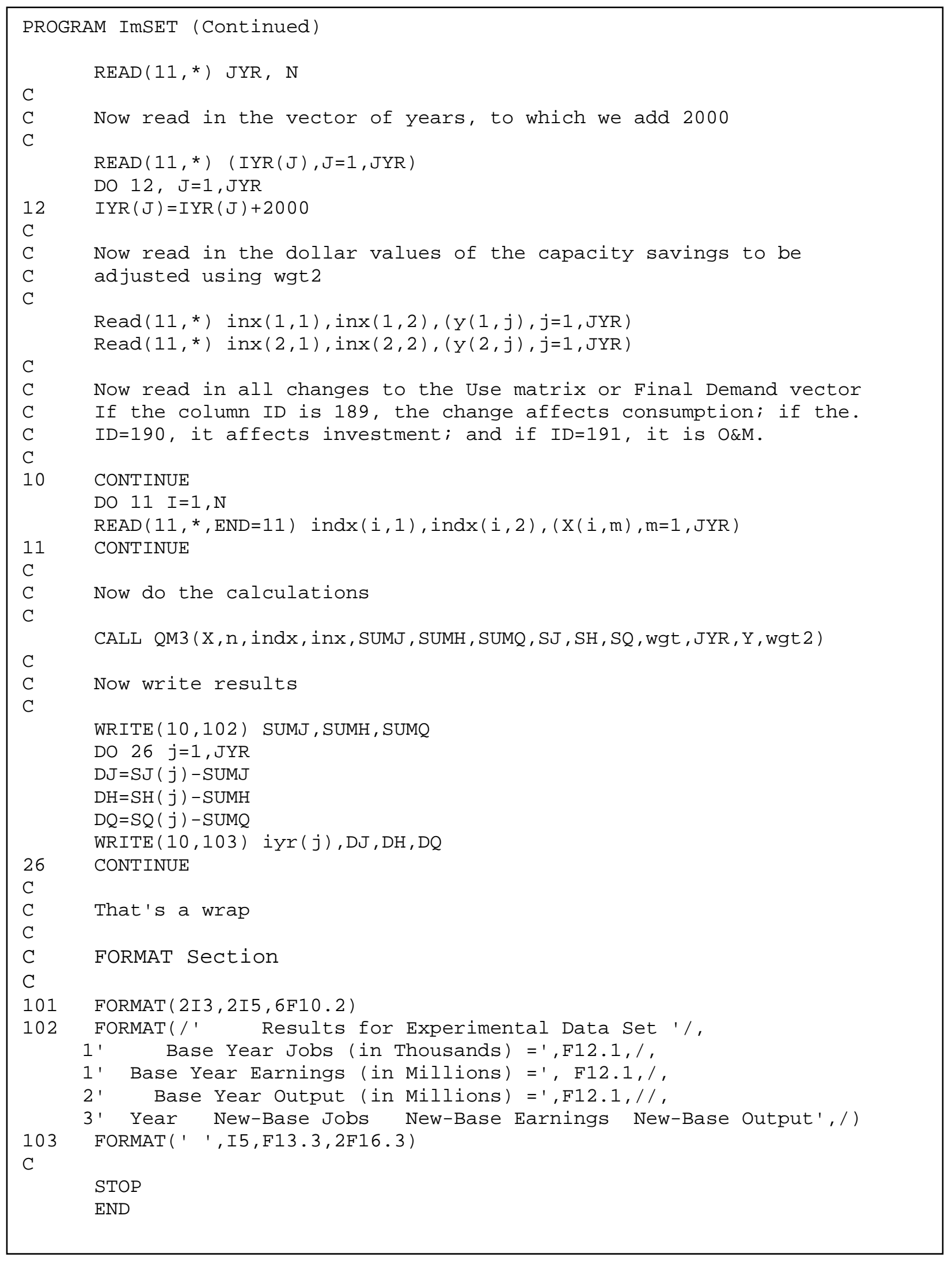




\section{C.2.2 The Calculator - QM3}

The lengthy text box on pages C-6 through C-8 is a listing of the calculation routine, QM3. The first set of comments explains how the naming convention changes from the main program within this routine. Parameters and variables are than defined and the binary file that contains the 1997 Benchmark I-O data is opened. The variables read from this file are $\mathrm{D}$, the market share matrix (derived from the make matrix), U, the use matrix, Q, the vector of industry outputs, DF, the final demand matrix, EI, the matrix of employment and earnings intensity by industry and $\mathrm{P}$, the fraction of scrap produced by each industry. The dimensionality of each of these variables can be determined from the variable definitions at the beginning of the program.

Once the I-O data is returned, the data are used to construct the base period employment, earnings and output. Base period results are constructed by multiplying industry output, the first column of Q, by two sets of industry intensities. These intensities are found in the variable EI, with the first column job intensities and the second earnings intensities. Multiplying each industry's output by these intensities yields jobs and earning, which are cumulated over all industries. Total output is also cumulated and returned in the scalar variables SUJ, SUE, and SUQ, as indicated in the comments on page C-6 in the comments after statement numbered 63.

The loop beginning with DO 40, on the next page, processes each year's data. The processing of each year begins by rewinding and re-reading the binary file that contains the I-O data, to assure that any changes will be made to the original data, since the changes to this data will be different for each year. The next set of statements zero out the set of variables used to differentiate between changes to capital purchases, changes to fuel use, changes in water use, and changes in O\&M expenses. Then vectors are defined that allow the program to identify which changes fall into each of these categories. These are the vectors, FL, KL, WL, and OM, consisting of zeros and ones, where the units identify the change as falling into the specific categories, with F, K, W, and OM referencing fuel, capital water and O\&M changes, respectively.

After these assignments, QM3 begins processing each year's data. Then after zeroing out two variables to hold the sum of final demand and the sum of changes to value added, identified by fuel type, the total to capacity adjustment is calculated for this year. That is stored in the variable ADJK. Then the changes to final demand and the use matrix are made, identifying the capital and O\&M, fuel, and water final demand changes separately. The value-added changes to the use matrix are made to each of the appropriate columns, then cumulated into sva and O\&M changes are cumulated into OAM. While specific industries have their use of the fuels adjusted within the use matrix, the impact on the fuel supplying industry is applied to the final demand vector.

Once these changes are made and results for this year have been zeroed out, I-O data are processed to create a total requirements matrix. This is done by creating a matrix, $\mathrm{B}$, which is derived from the use matrix by dividing each element in the columns by that industry's output. This loop is also used to create the identity matrix ai. First $\mathrm{W}$ is constructed by premultiplying PH by D the market share matrix - this is derived from the make matrix. Then $\mathrm{W}$ is premultiplied by $\mathrm{B}$. These matrix multiplications rely on calls to a matrix multiply subroutine, MMULT, which multiplies a matrix of dimension ( $\mathrm{k} \mathrm{x} \mathrm{n}$ ) by a second (n $\mathrm{x} \mathrm{m})$ matrix and returns a $(\mathrm{k} \mathrm{x} \mathrm{m})$ matrix. A similar routine, MMULT1, multiplies a ( $\mathrm{k} \mathrm{n})$ matrix by an ( $\mathrm{x}$ 1) vector to create a ( $\mathrm{k} \times 1)$ vector. This $\mathrm{B}^{*} \mathrm{~W}$ matrix (called "a" in the program) is then subtracted from the identity matrix, ai, using the subroutine MADD (which adds or subtracts, depending on the value 
of $\mathrm{j},-1$ in this case for subtraction). The result, which replaces the Use matrix, is then inverted using two subroutine from Numerical Recipes ${ }^{21}$.

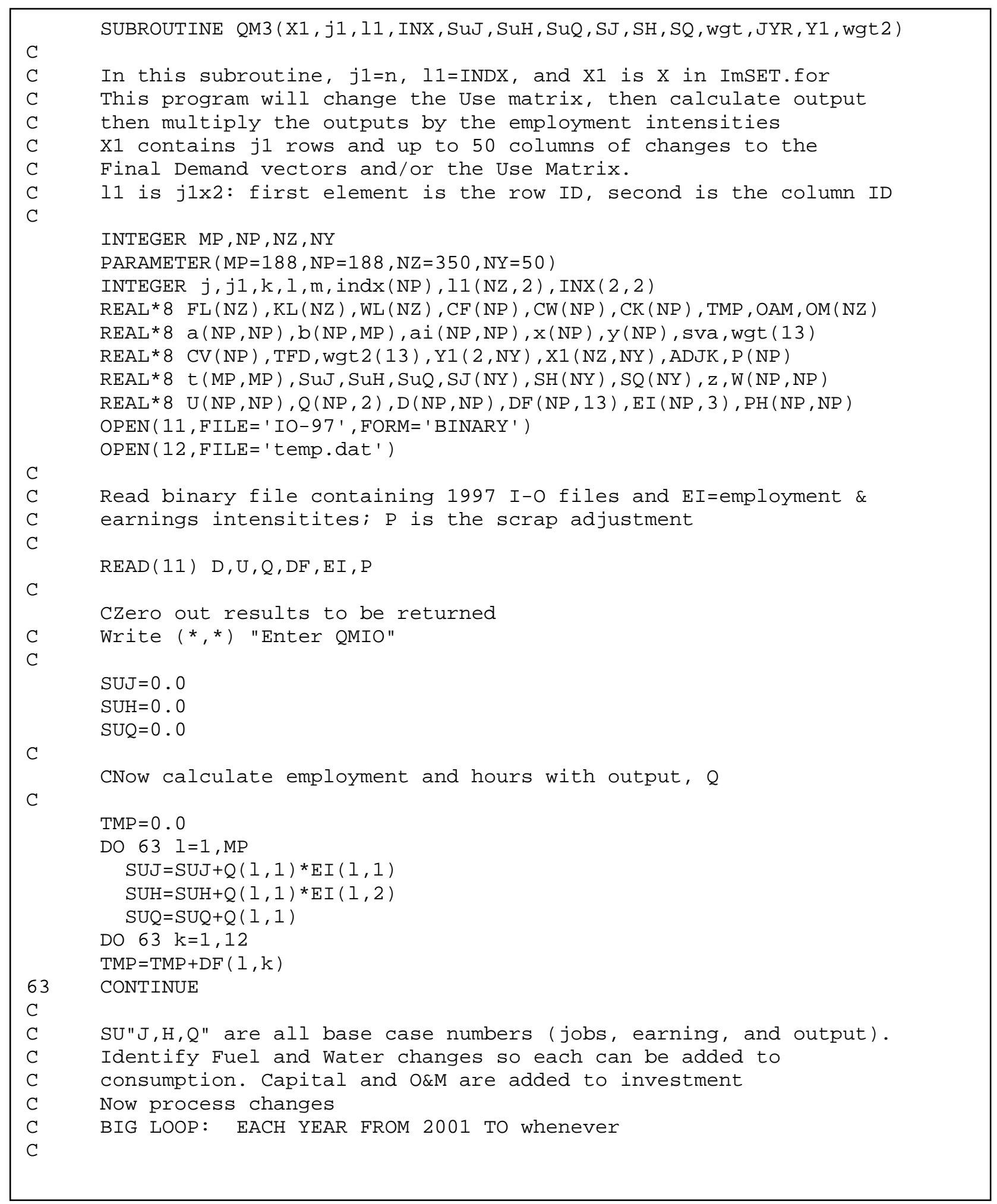

${ }^{21}$ Press, William H., et al. 1986. Numerical Recipes: The Art of Scientific Computing. New York: Cambridge University Press. For matrix inversion, see p. 38. 


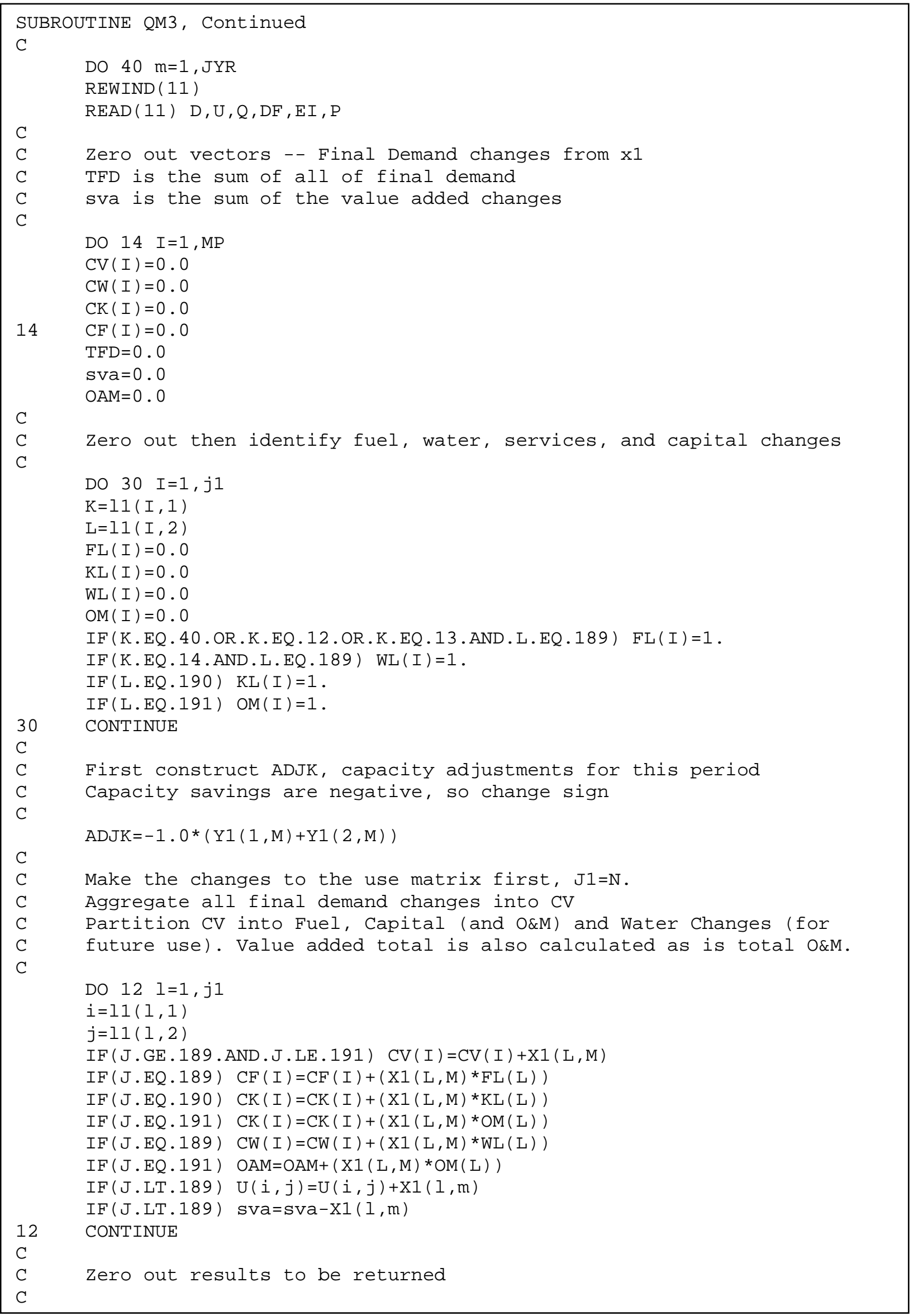




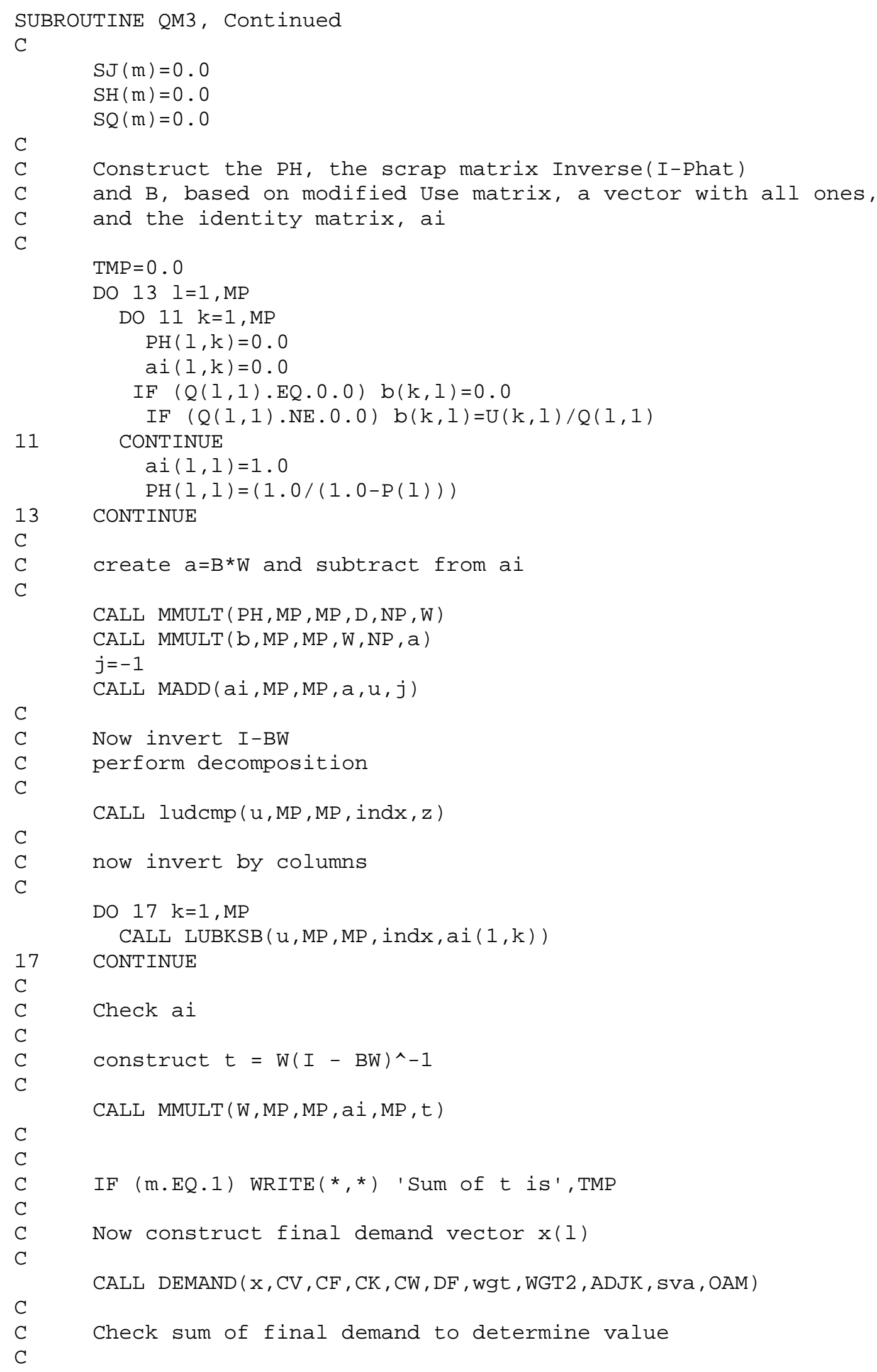




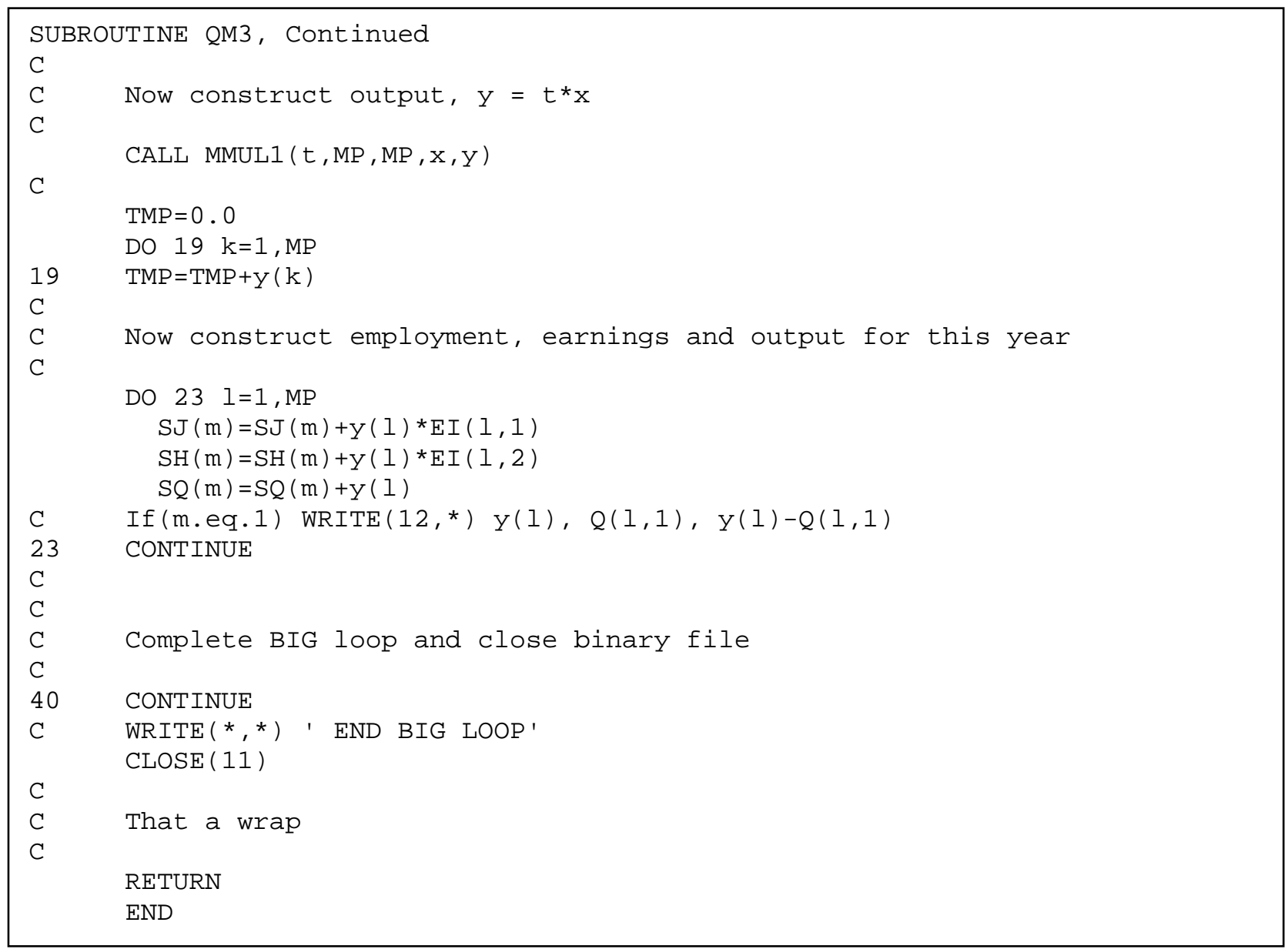

The resulting inverse (replacing ai) then is premultiplied by the modified market share matrix, $\mathrm{W}$, to yield the total requirements matrix, labeled $t$. At this point, we are ready to create the final demand vector, so a call is made to the subroutine DEMAND. This returns the final demand vector $\mathrm{x}$, which is then premultiplied by the total requirements matrix, $t$, to yield the output vector, $y$. Output then is multiplied by each column of the intensity matrix to yield this year's jobs, and earnings. This period's output is then just the sum of all of the industry outputs. When each of the JYRs of data have been processed, the big loop is complete and the results are returned to the main program.

\section{C.2.3 Changing Final Demands -- DEMAND}

The call to this subroutine transfers the changes to final demand read in by the main program, contained in the vectors CV, CF, CK, and CW, and the array of final demands, DF, read in from the binary file. In addition, the weights to distribute the financing charges and the weights to allocate the capacity changes are transferred in the wgt and WGT2, along with the value of the capacity changes, contained in ADJK. Finally, all the value-added variables, a total and a variable for each of the fuel changes, and the total value of O\&M changes contained in OAM are transferred. The first set of statements below the initial comments zero out accumulator variables, aggregate the finance and capacity weights, and sum each of the components of final demand. The $13^{\text {th }}$ column in this array is the total final demand vector, with the other columns corresponding to consumption, investment, exports, imports, various Federal government investment and consumption and various state and local investment and 
consumption. The next block of calculations zero out the vector of final demands to be returned and cumulates the changes to final demand partitioning these changes into capital and O\&M purchases, which affect investment, and fuel and water purchases, which affect consumption.

The capital and O\&M changes (all those changes to final demand expect for changes to the fuel vectors) are added to the investment vector, just as the fuel savings are subtracted from the consumption vector. These investments need to be financed by "taxing" some component of final demand, after adjusting for O\&M expenses, which are not "financed.". The strategy is this version of the model is to first determine how the different components of final demand are to be taxed; then adjust components of final demand for the tax, carrying along all changes to the twelve vectors that constitute the components of final demand. In the event that all the "tax" applies to the aggregated component, then these weights for the various components are zero and no adjustment occurs. From a computational point of view, this simply means that the components are not modified when adjustments are made. Once the aggregation occurs, if then a portion of the "tax" is applied to the aggregate component, then that is treated. A similar scheme is used if the "savings" achieved by a reduction in the building of energy capacity is distributed back to final demand or applies to the aggregate.

Accordingly, the first step is to adjust the consumption vector for the fuel savings and redistribute these savings back to other consumption; this is done in the loop beginning DO 20. Similarly, adjustments to the investment vector are made according to the distribution of capital expenditures after adjusting for O\&M changes (in our example on page C1, these capital expenses occur for sectors 22, 97, 98, and 99), then each of the vectors of final demand are "taxed" my multiplying the weight associated with this component of GDP (which in our example, is the first string of numbers beginning with $70,10, \ldots$ ) by the total capital expense and rescaling each component of GDP to reflect the cost of financing the investment. (Note, that if the investment costs are nil, then no scaling occurs, but the adjustment proceeds as if the weights were there.) Then if there are capacity adjustments to be made, these are subtracted from the "Other New Construction" activity that is in row 22 of the final demand vector. The scalars provided by the user to make these adjustments are used to expand (or contract) the vector of final demand so it is scaled appropriately. Note also that if the capital costs are not financed, then the total of final demand will expand by that capital expense just as if the capacity savings are not redistributed to other sectors, then these savings are "lost" and the total of final demand is reduced.

Capital costs and capacity adjustments might not be fully added back in, depending on sum of the weights provided in wgt and WGT2.

Before final adjustments are made, the 12 components of final demand are aggregated to a single vector. Then the program branches to the concluding section that makes adjustments if there is a non-zero weight in component 13 of the two weighting vectors (note that in the example, these numbers are zero). The next step adjusts this aggregate vector for the changes either to the financing of capital expenditures or for the distribution of capacity savings changes. As with each component of final demand, we construct a scalar that integrates the financing proportion or the capacity adjustment used to scale the total final demand vector. The $13^{\text {th }}$ weight in each case is used to construct a scalar, Z1, which is the total of final demand minus the $13^{\text {th }}$ weight times the capital change divided by the total of final demand. In symbols, as in the code, $\mathrm{z1}=(\mathrm{ztot}-\mathrm{WGT}(13) * \mathrm{SCK}) / \mathrm{ztot}$ (note that this is one if WGT(13) is zero). The remaining task is the adjustment for changes in value-added if changes were made to the use matrix. (The continuation statement 45 shows the entry point from the section where final demand is treated as a single vector; recall that the same variable, SCV, was used to sum total final demand.) A scaling multiplier, z1, is constructed by adding the sum of value added, SVA, to SCV, then dividing by SCV. Z1 is then used to multiply each element of the final demand vector $\mathrm{x}$, which is then returned to QM3. 


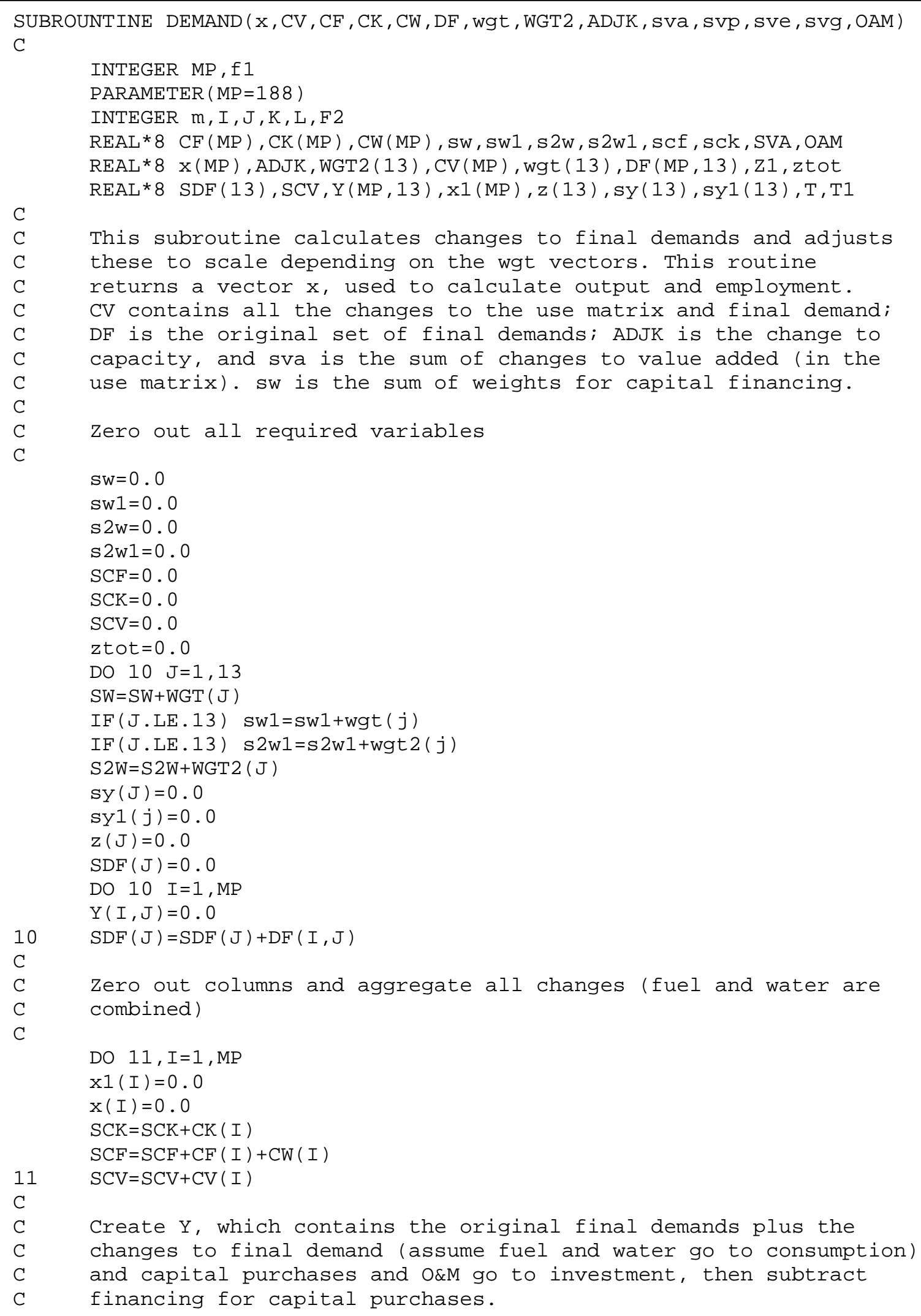




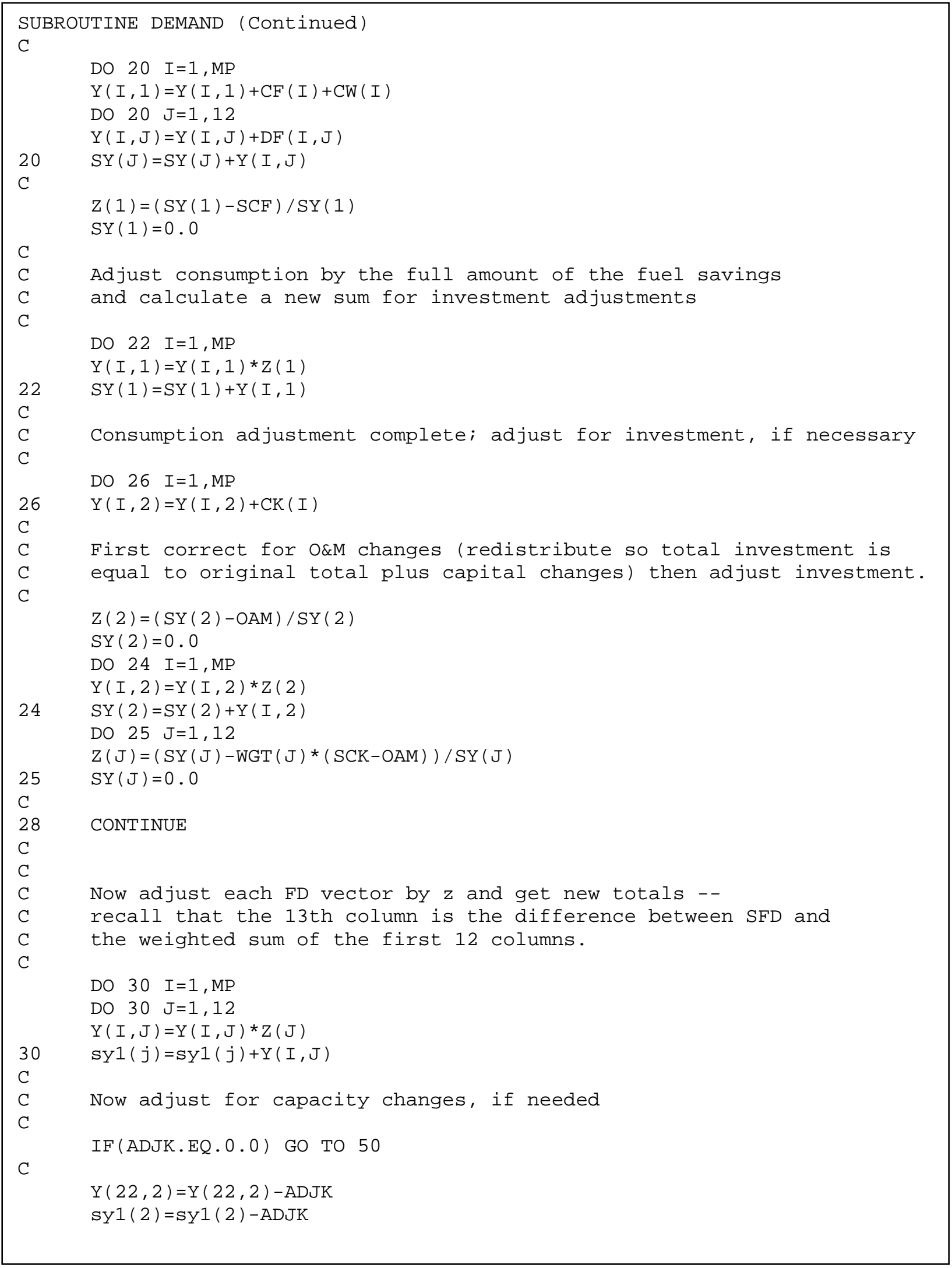




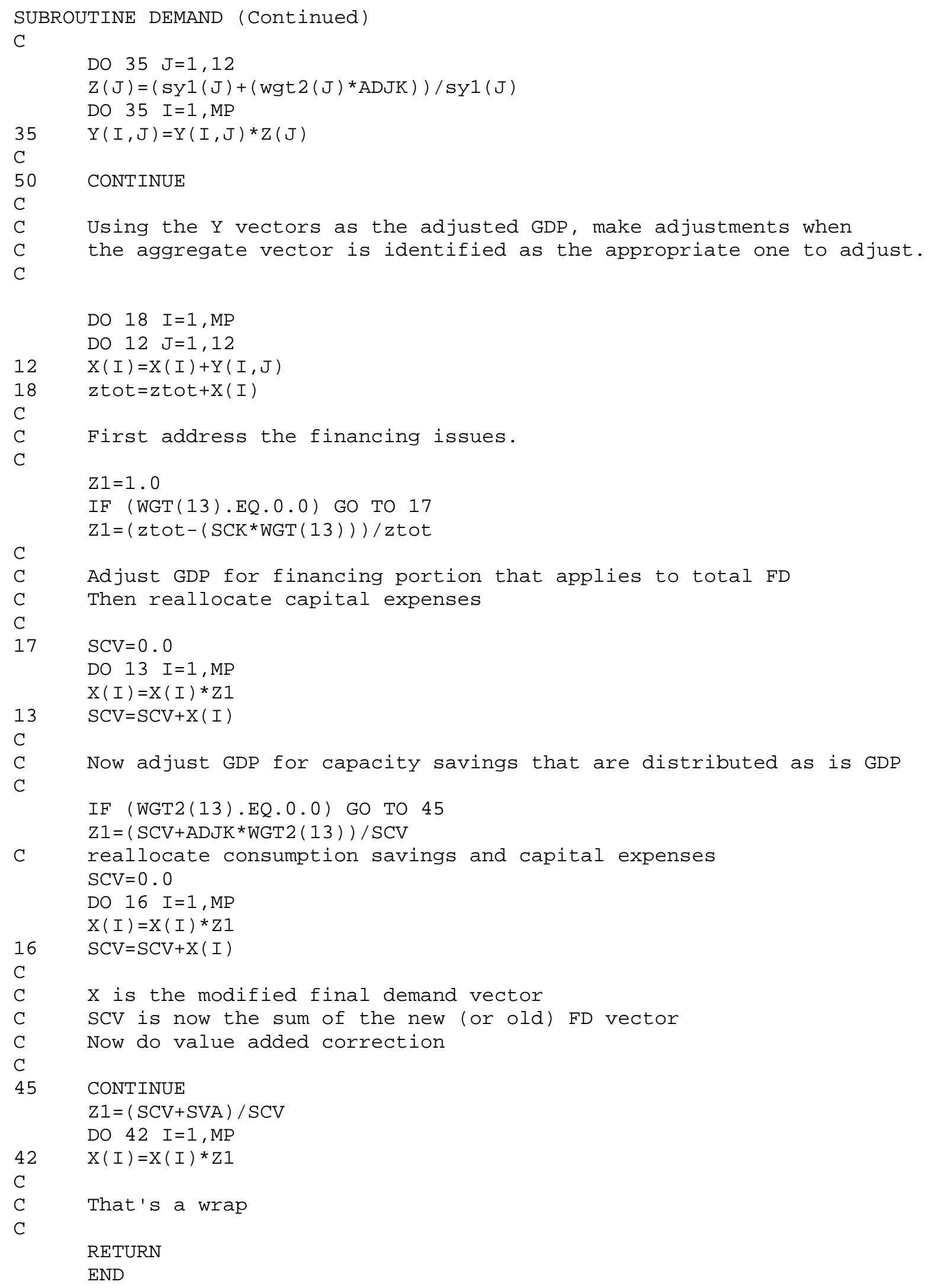




\section{C.3 The Output File}

The calculations from the ImSET FORTRAN Engine generate a file called QM-CHG.DAT, which contains the results of the calculation, and is shown in the text box below. This file is read back into ImSET 2.0 to provide the data and graphics shown below in Figure C.1. The numbers graphed are the same as the right-hand column of outputs shown in the text box.

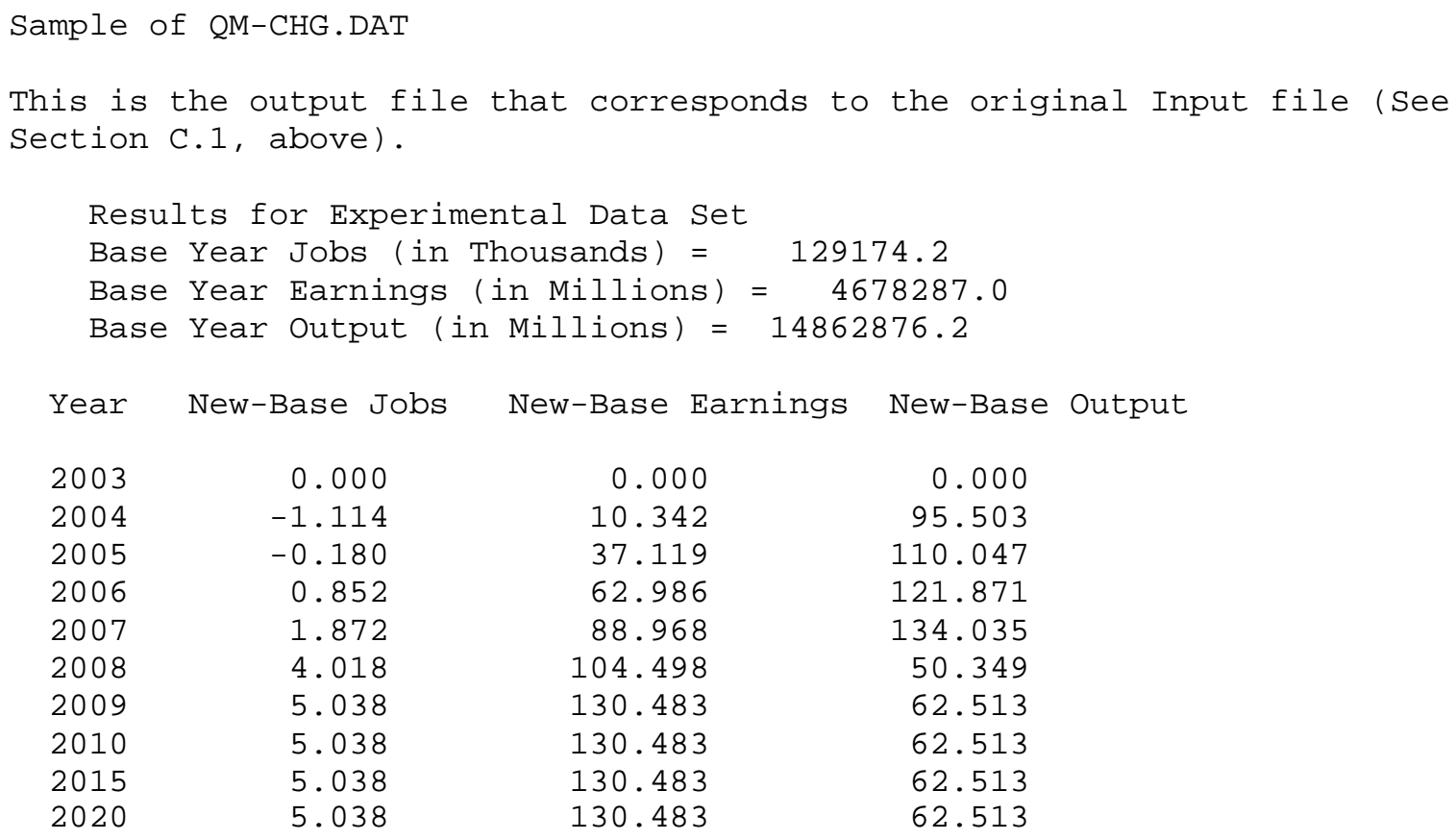




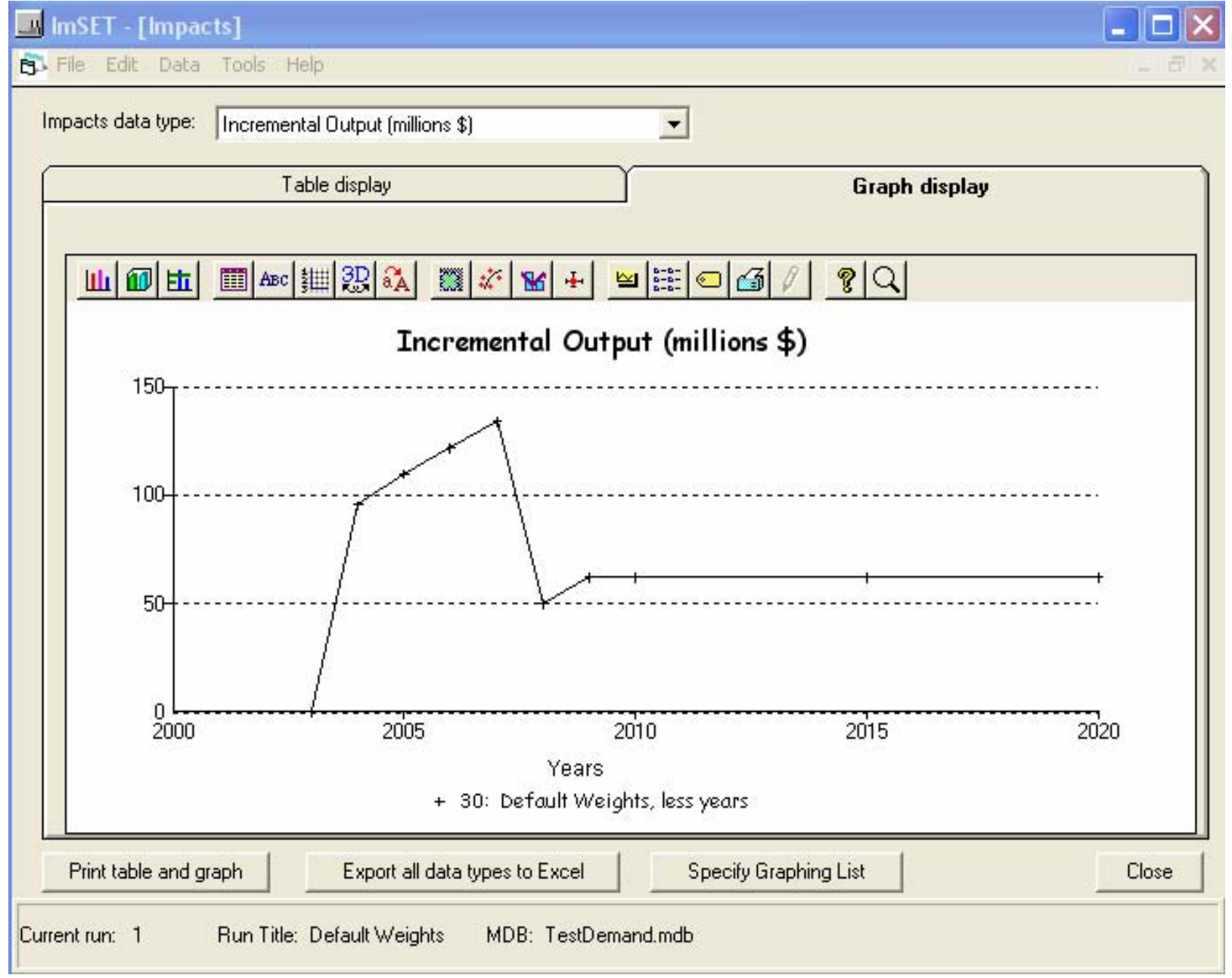

Figure C.1: Graph of Output Changes Shown in Previous Text Box 